$$
\text { قيبم العهل وأثرها على الالترزام التنظيسي }
$$

دراسة تطبيقية على همتشفى اللهاك عبد العزيز بمحافظة الطائف

\author{
د/ وجيه عبد الستار نافح \\ أستاذ إدارة الأعهال المساءد \\ كلية العلوم الإدارية والمالية ـ جامعة الطائف الطمائف
}



يتمثل الهذف العام اللبحث في دراسة قيم العطل Work Values و أثرها على الالتزام

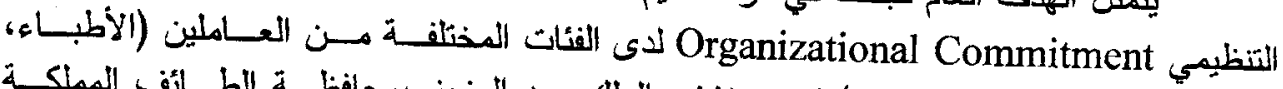

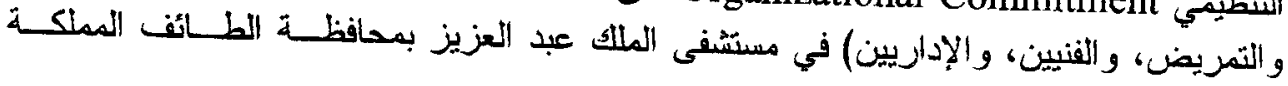
العريبة السعودية.

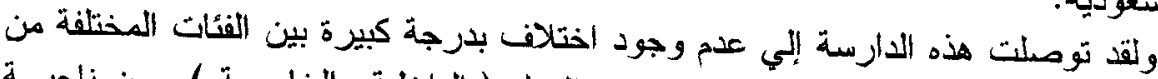

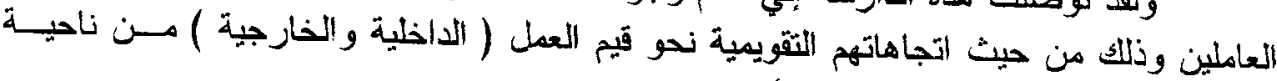
والالتز ام التنظيمي للعاملين من ناحية أخري.

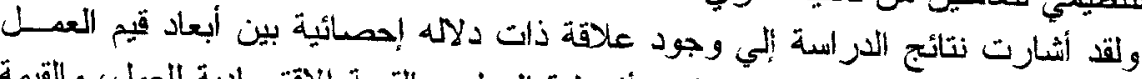

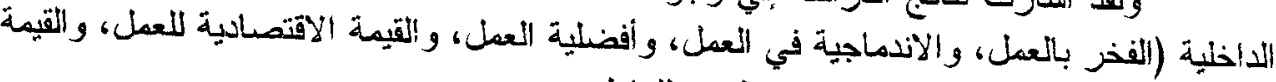

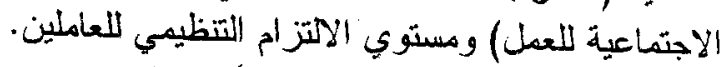

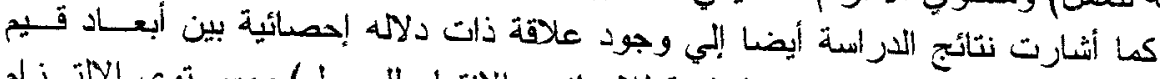

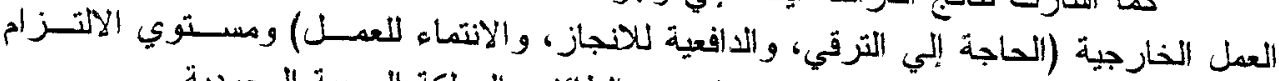
التتظيمي للعاملين في مستشفي الملك عبد العزيز بالطائف بالمملكة العربية العبعودية.

\section{The abstract}

The general aim of this research is to study the work values and its impact on organizational commitment in the various categories of personnel (doctors, nurses, technicians, and administrators) at King Abdul-Aziz Hospital, Al-Taif, Governorate, in Saudi Arabia.

The most important results of the study indicated that there was a lack of significant differences between the various categories of workers in terms of attitudes toward work values dimensions (internal and external) on the one hand, and organizational commitment to employees on the other.

The findings of the study indicated that there was a statistically significant relationship between the dimensions of work values of the internal work values (proud to work, fusion work, action is preferable, the economic value of the social value of work) and the level of organizational commitment of employees.

The results of the study also indicated that there was a statistically significant relationship between the dimensions of the values of external work values (the need for promotion, achievement motivation, sense of belonging to the work of) and the level of organizational commitment of employees in King Abdul Aziz Hospital, Taif Governorate in Saudi Arabia 


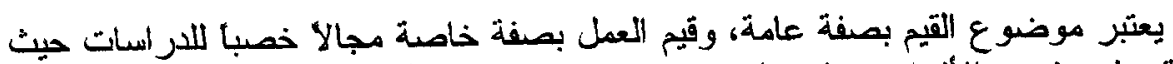

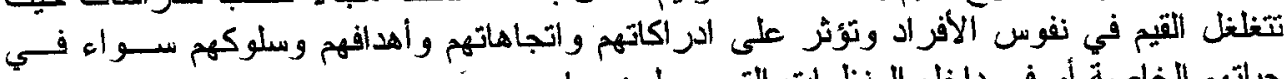

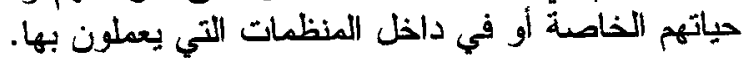

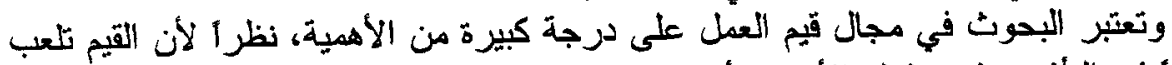

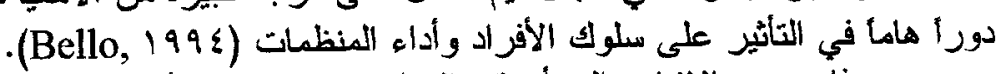

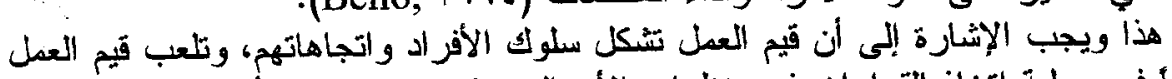

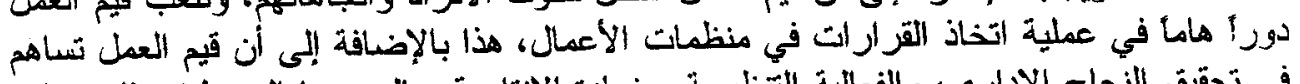

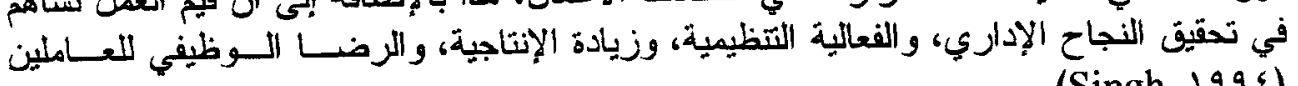

(Singh, 199६)

ومن الجدير بالذكر أن كل مدير يجب إلى أن يعرف قيم العمل الخاصة بالأفراد العاملين

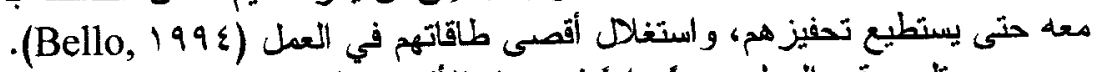

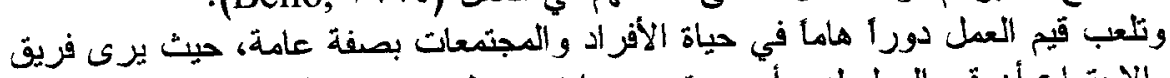

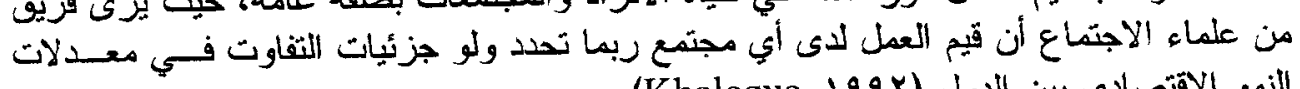
النمو الاقتصادي بين الدول (Khaleque, 199r).

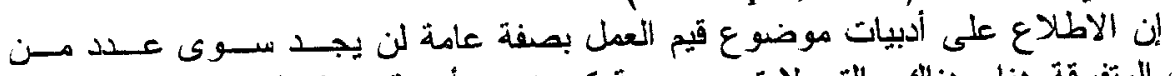

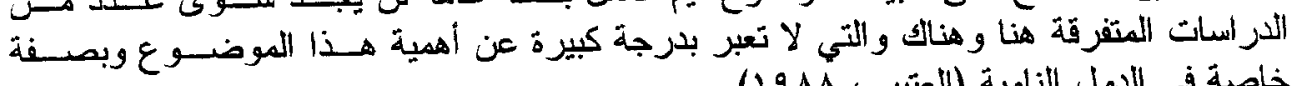

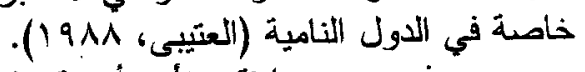

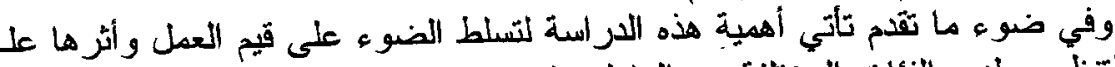

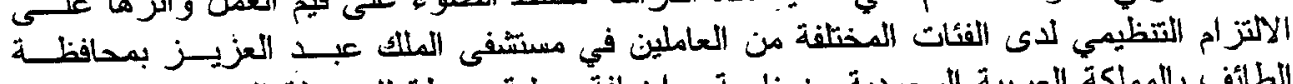

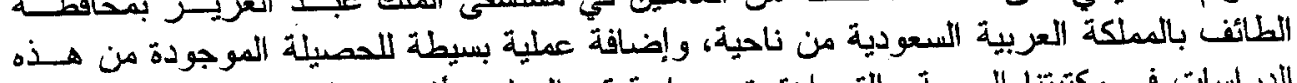

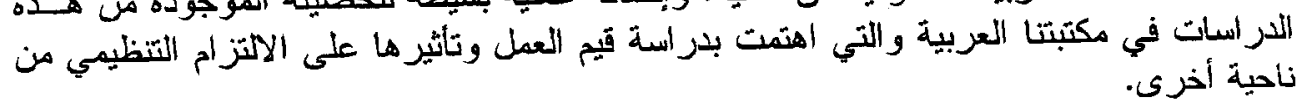

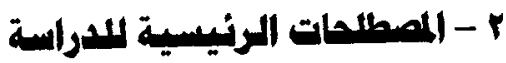

يتتاول الباحث في هذا الجزء المصطلحات الرئيسية المستخدمة في الدراسة وذلك على لئ

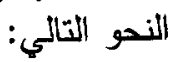

\section{Work Values 1/r}

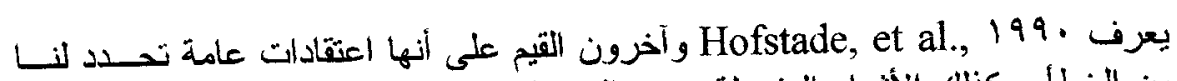
الصواب من الخطا، وكذلك الأشياء المفضلة وغير المغرو المفضلة.

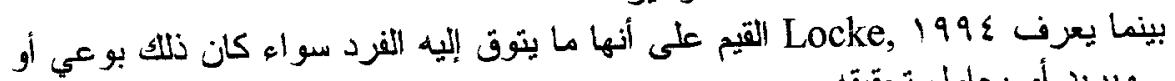

$$
\text { بدون وعي ويريد أو يحاول تحقيقه. }
$$

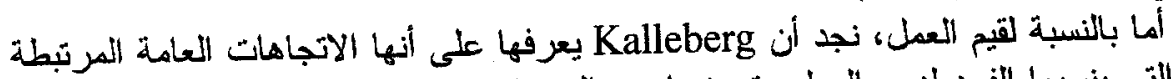

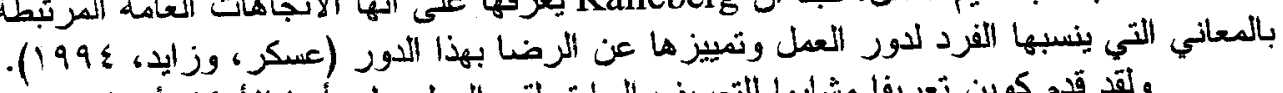

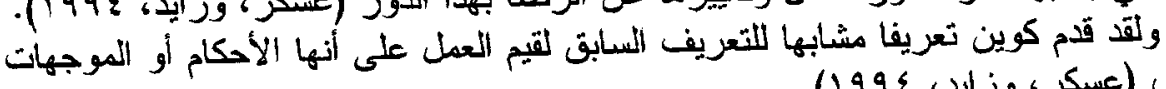

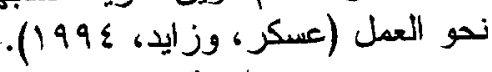
وبعد مراجعة مستفيضة للمفاهيم المختلفة لقيم العدل نجد أن مفهوم قيم العمل يشير إلى. 


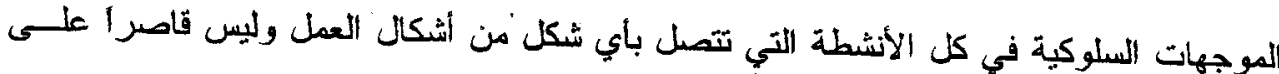

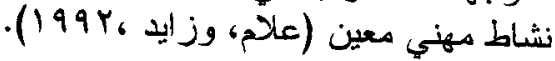

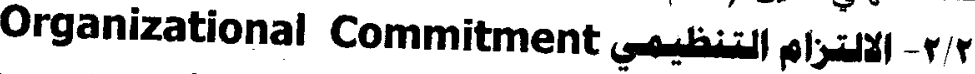

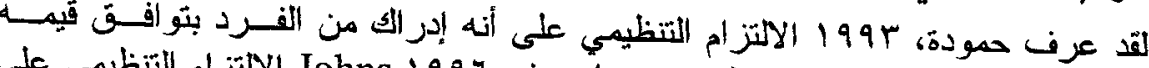

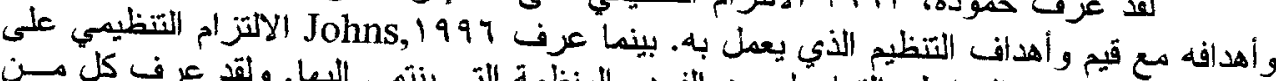

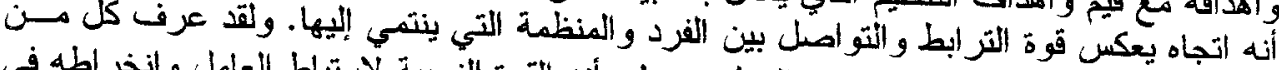

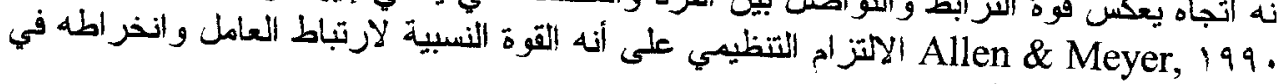

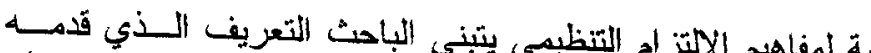

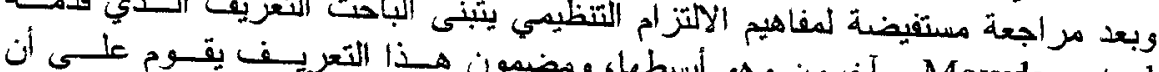

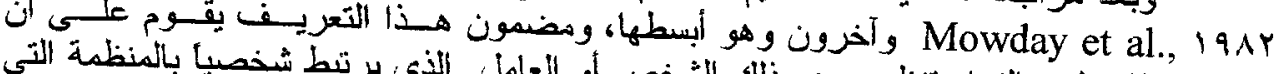

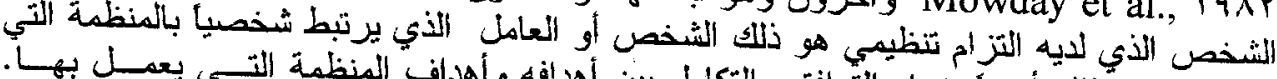

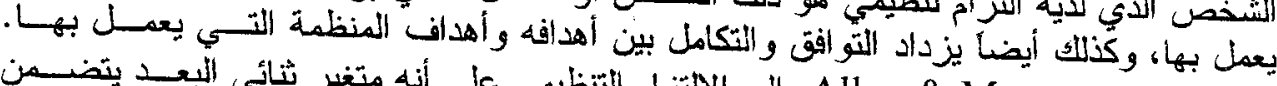

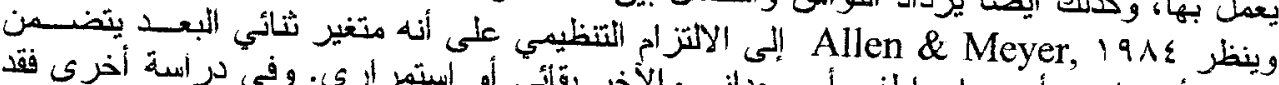

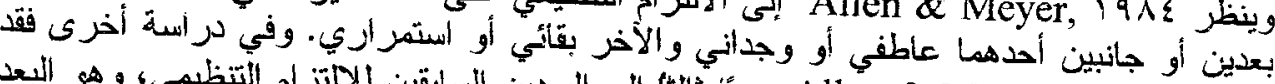

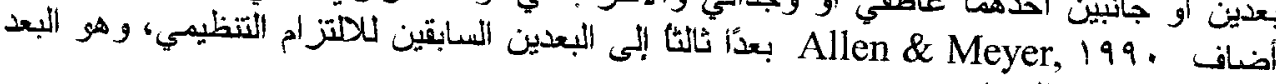
الخاص بالالنز ام المعياري. وفي هذه الدراسية سوف يستخدم الباحث مفهوم الالتز ام التتظيمسي ذو الأبعساد الثنلاثــة

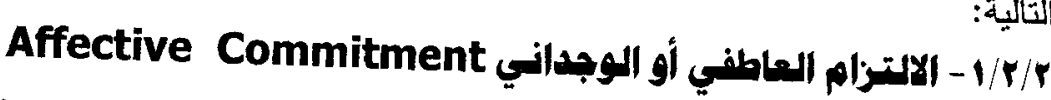

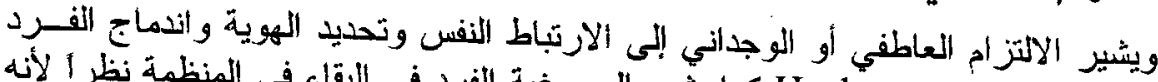

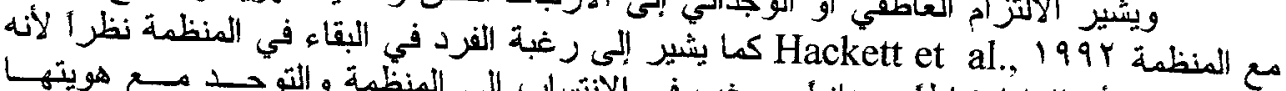

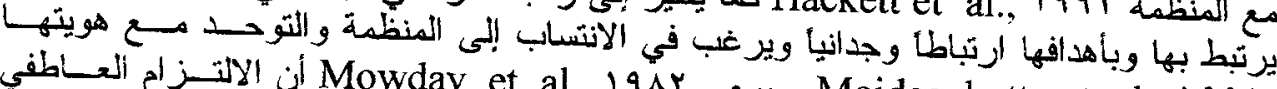

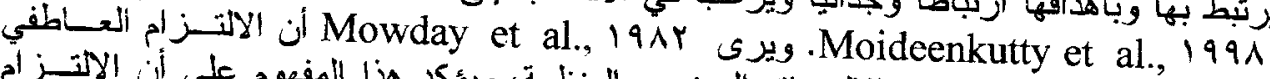

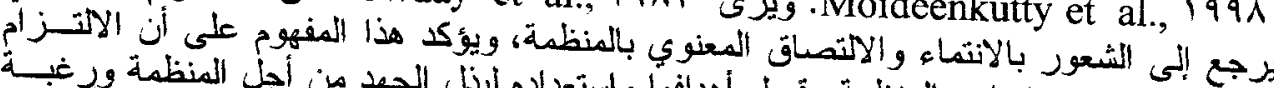

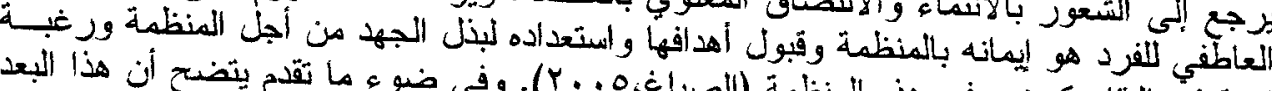

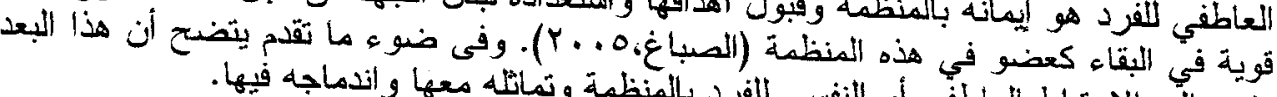

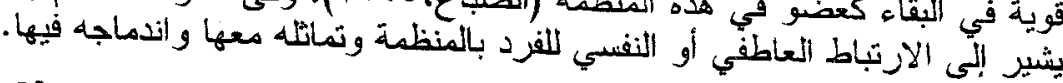

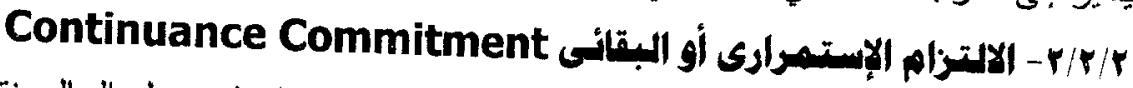

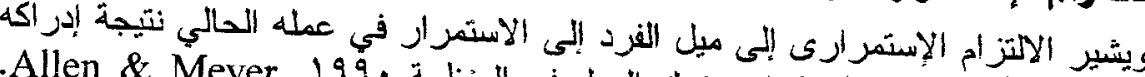

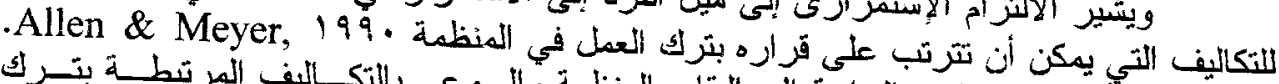

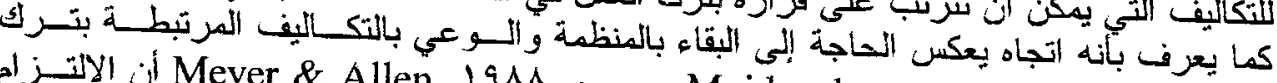

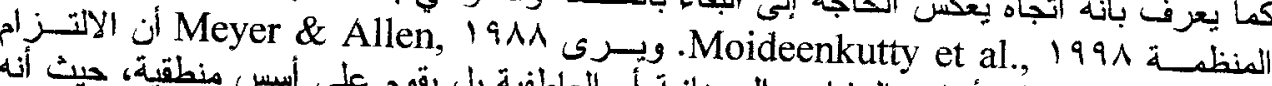

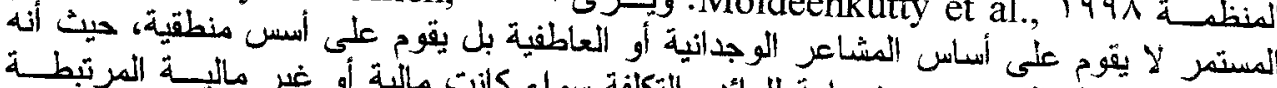

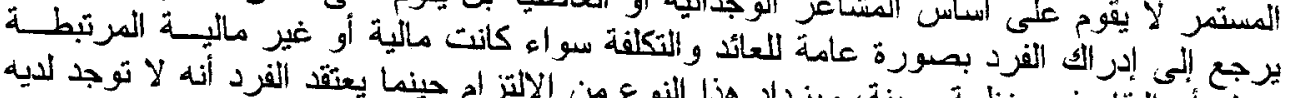

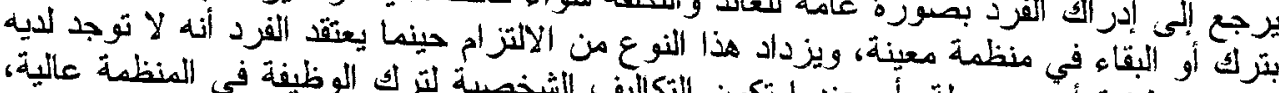

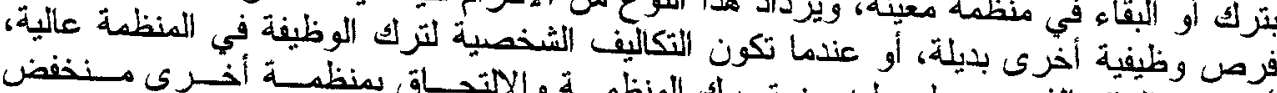

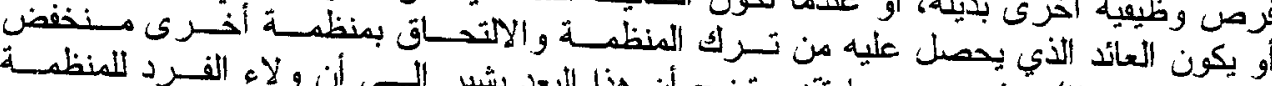

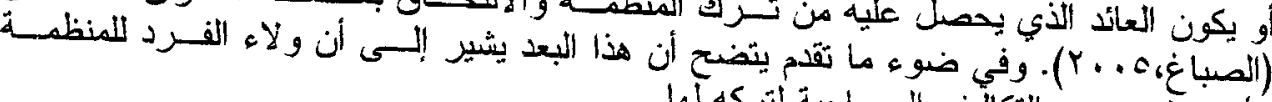
يتاسس في ضوء

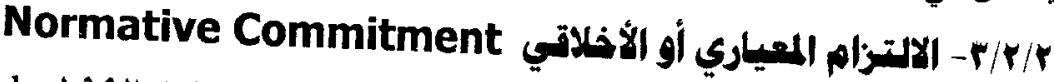

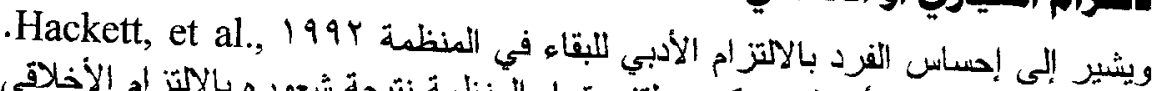

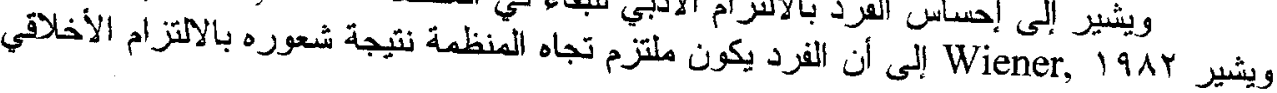




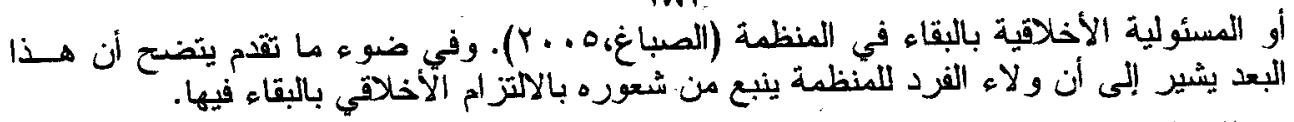

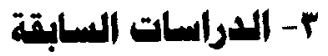

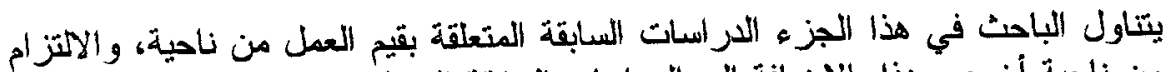

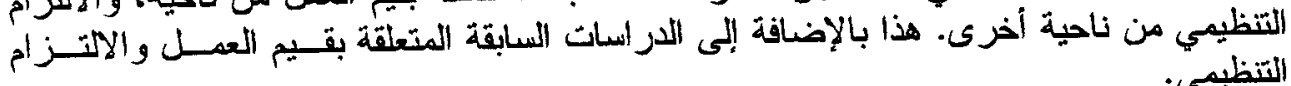

\section{"1/ - المدراسات السابقة المتعاقة بقيس الهمل}

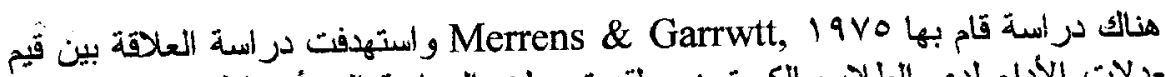

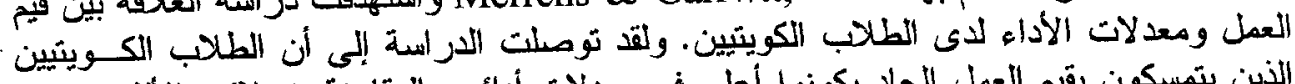

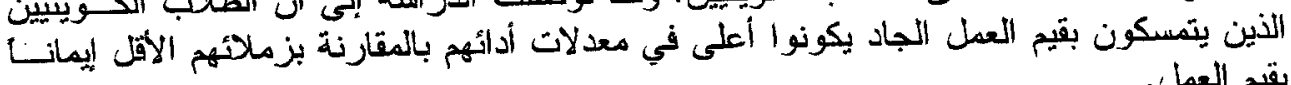

بقيم العمل.

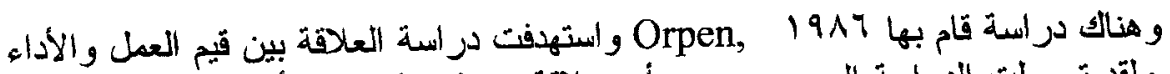

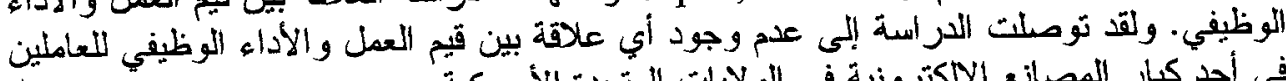

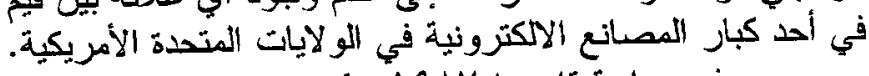

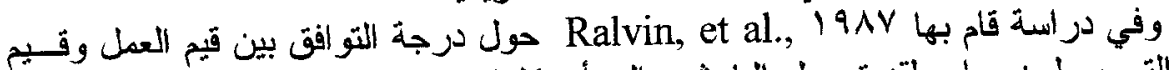

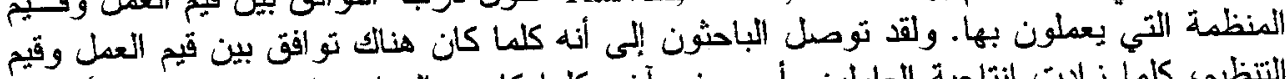

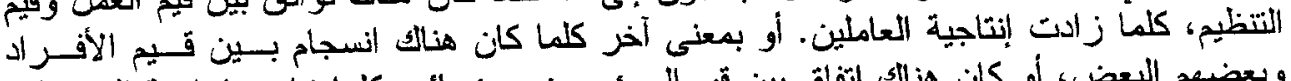

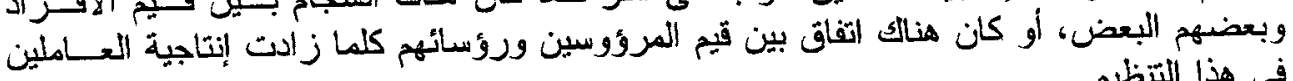
في هذا التظظيم.

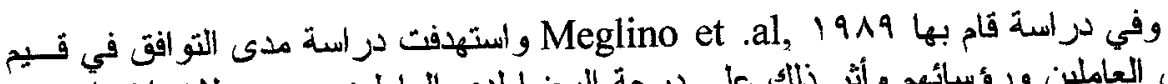

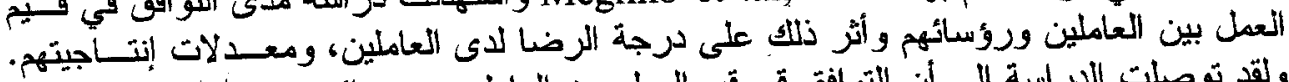

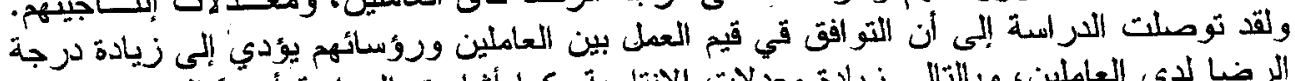

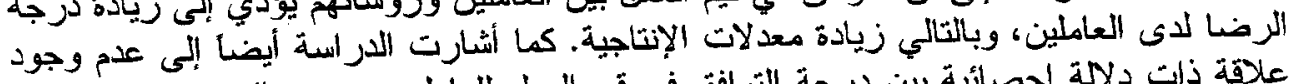

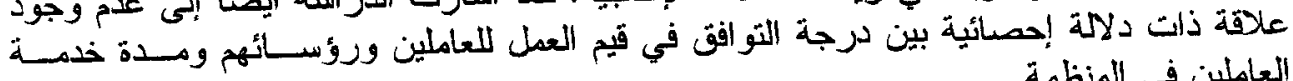
العاملين في المنظمة.

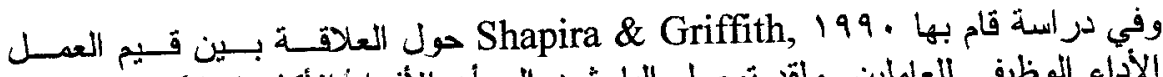

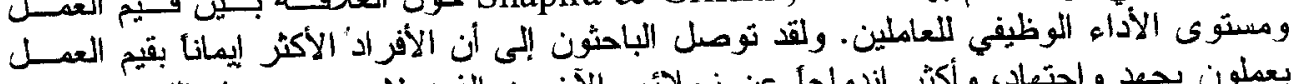

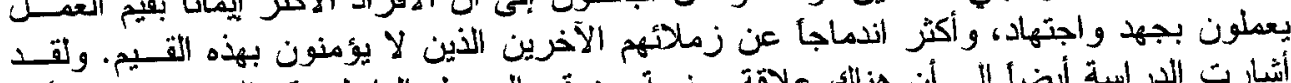

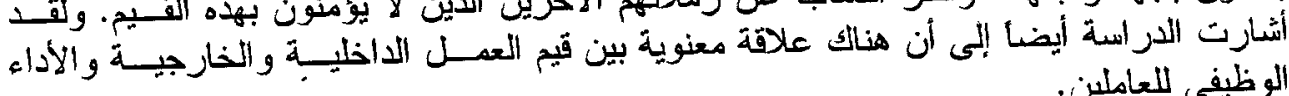

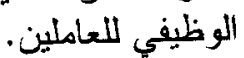

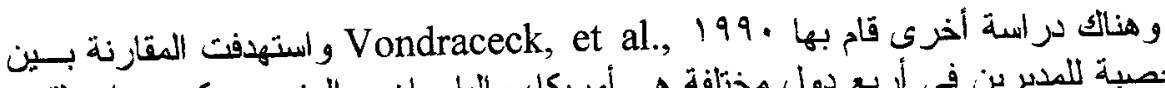

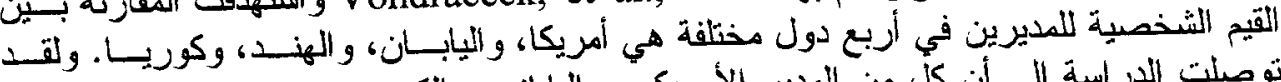

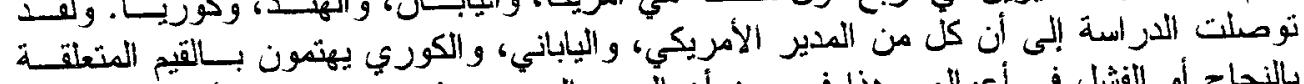

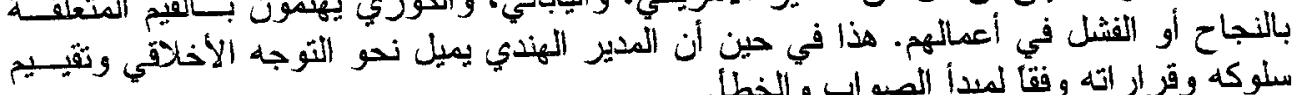

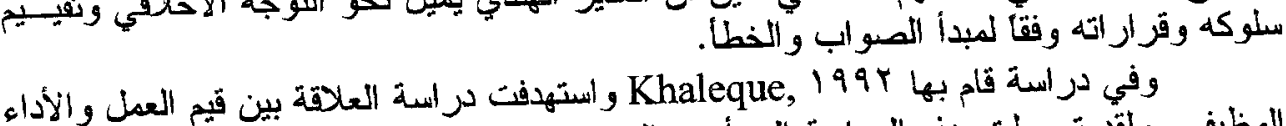

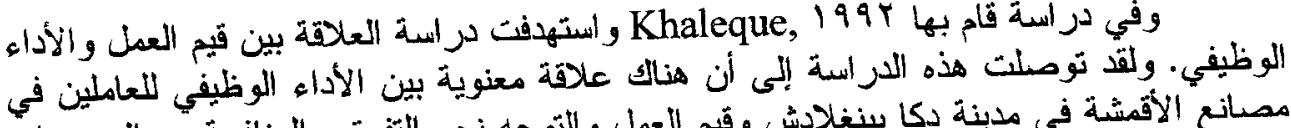

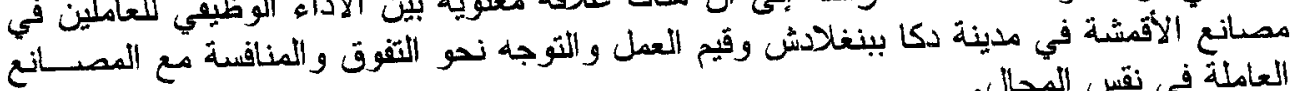

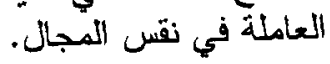

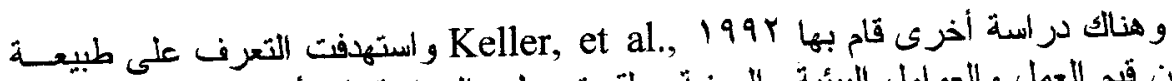

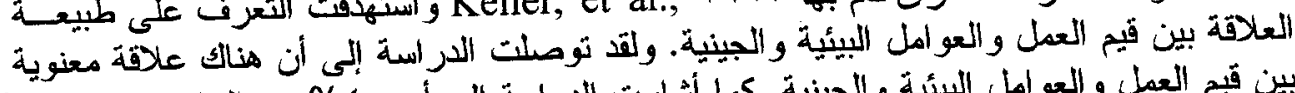

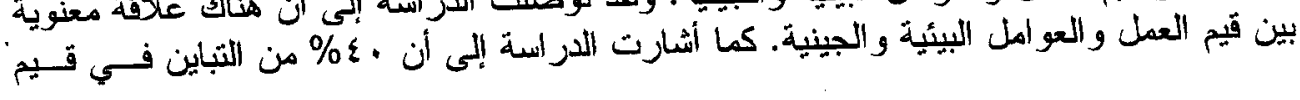




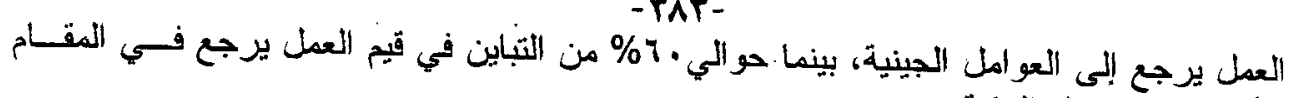

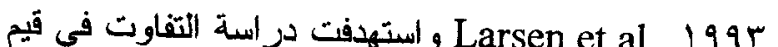

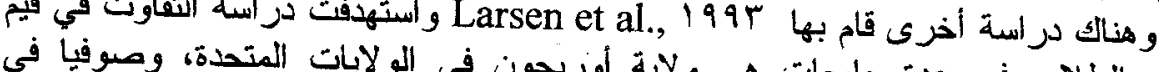

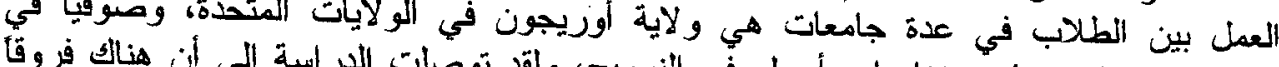

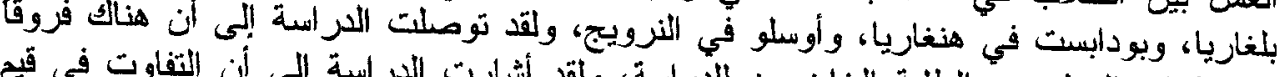

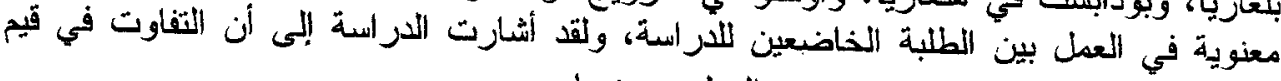

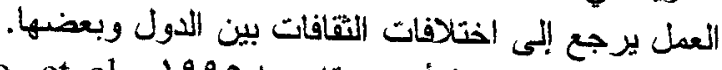

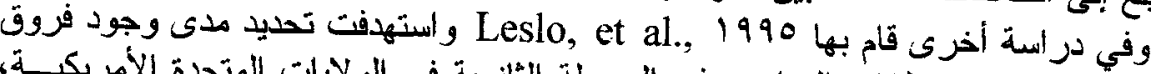

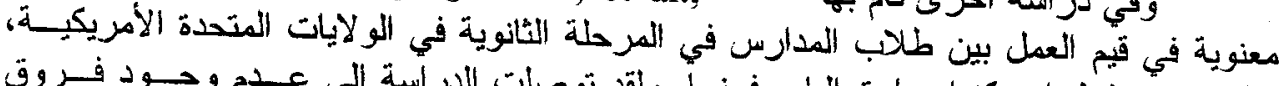

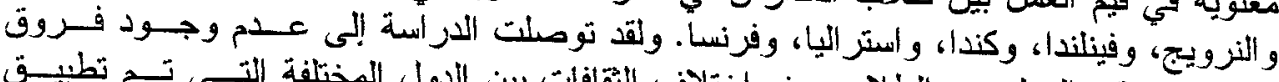

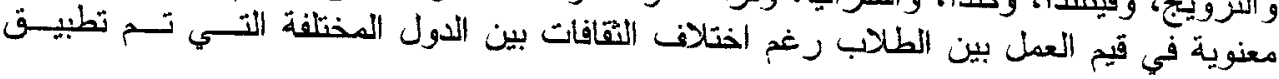
الندر اسية عليها.

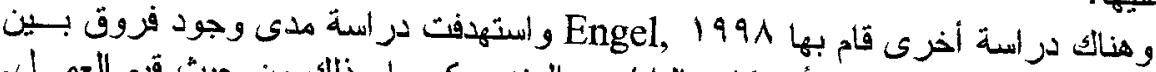

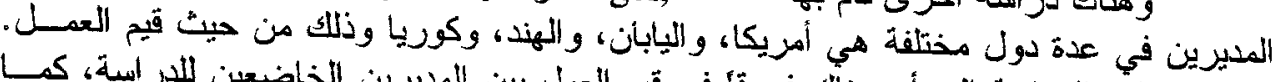

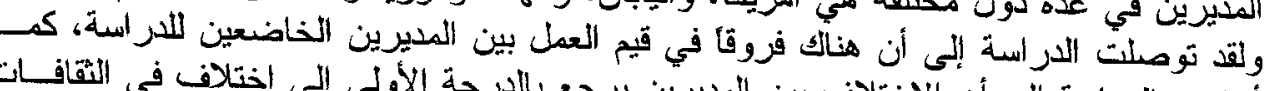

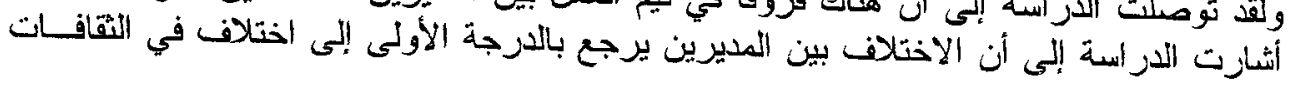

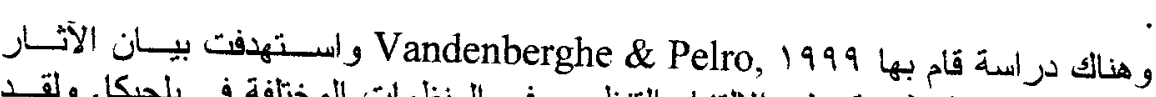

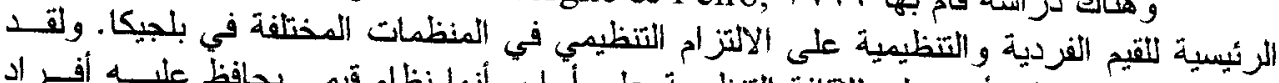

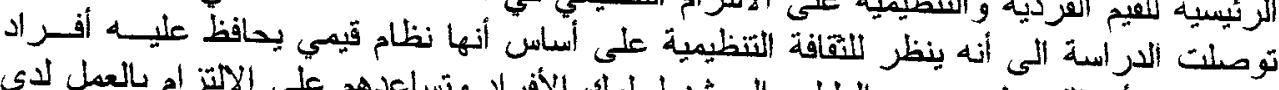

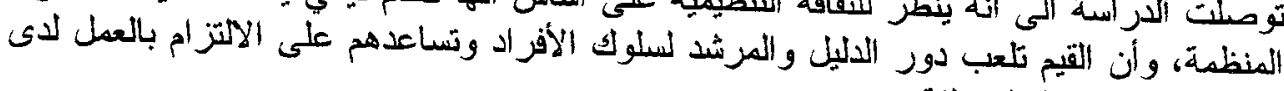
المنظمات البلجيكية المختلفة وانيم.

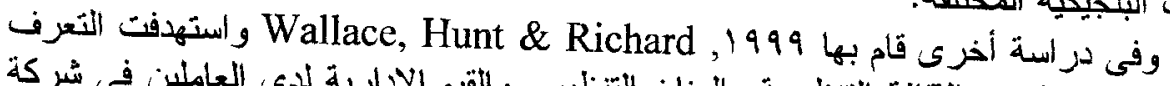

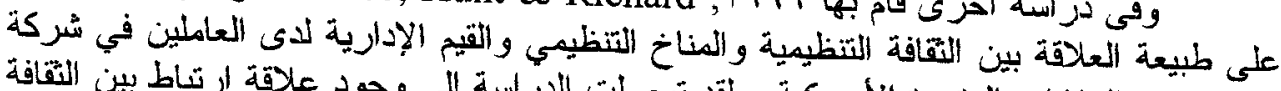

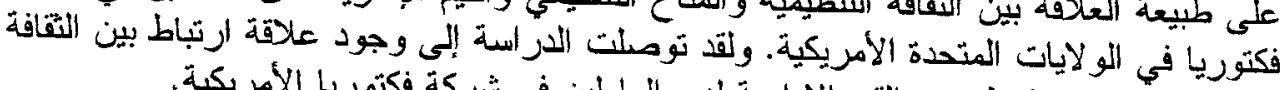

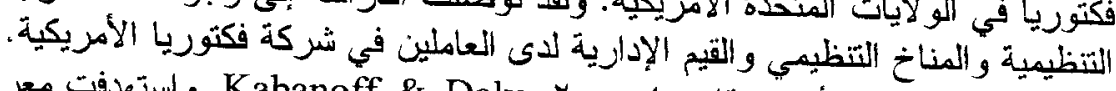

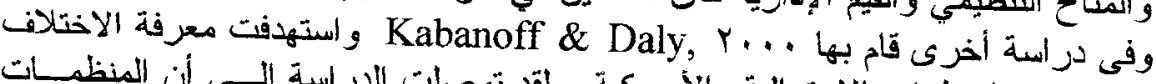

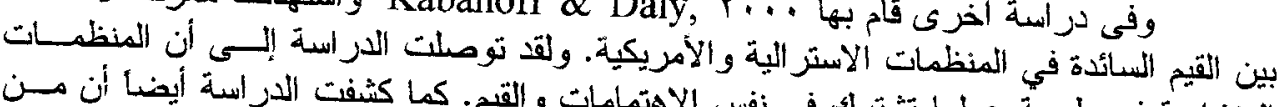

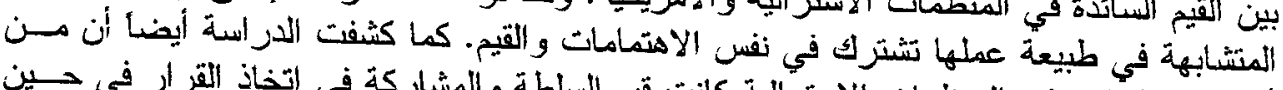

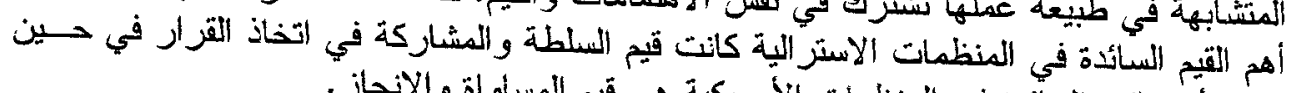

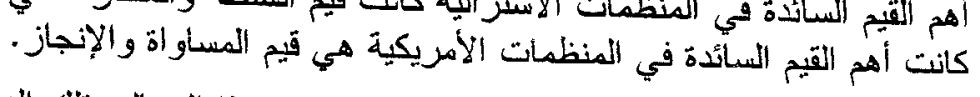

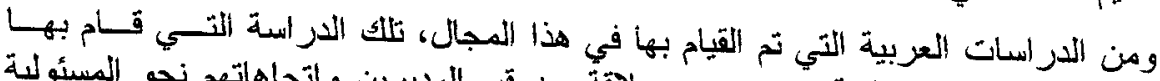

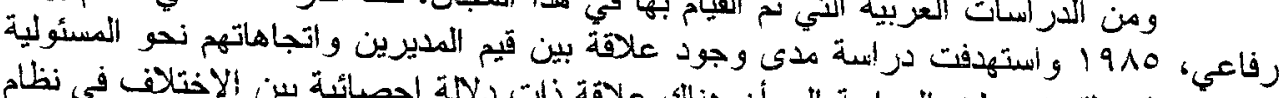

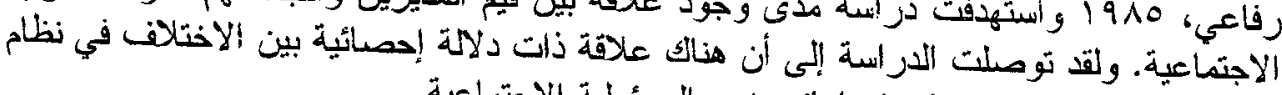

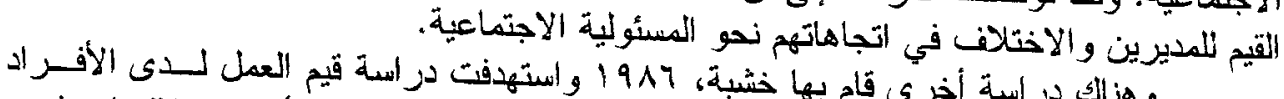

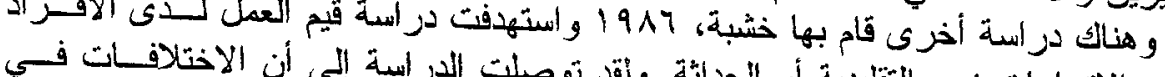

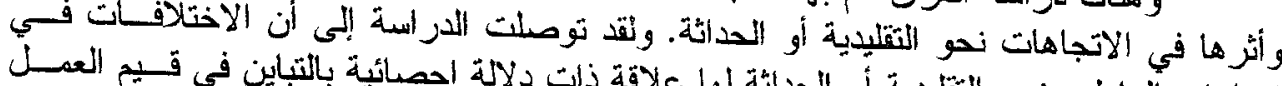

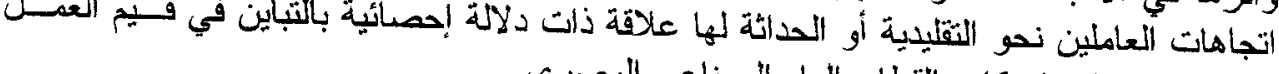

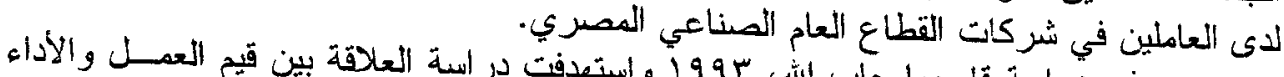

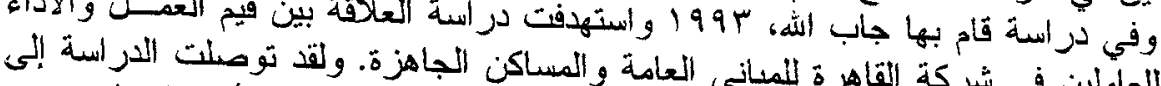

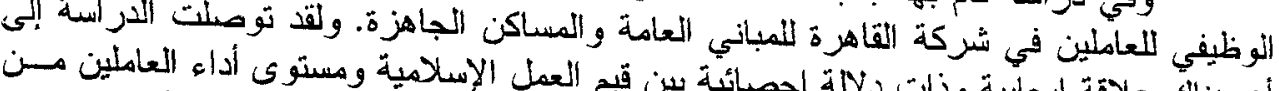

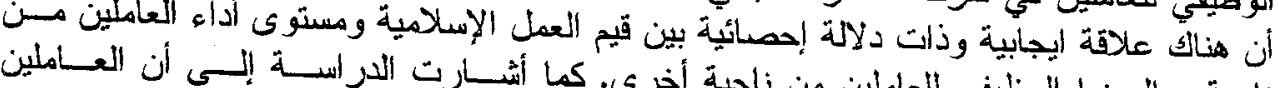


الملتزمون بقيم العمل الإسلامية يرتفع مستوى أدائهم الوظيفي، وبالتالي يكونون أكثر رضا عـن بـن زملائهم غير المتمسكين بهذه الإسلافيم.

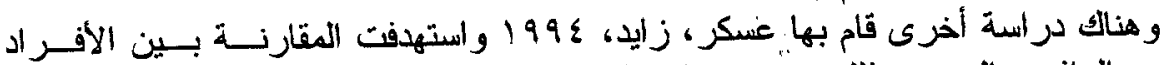

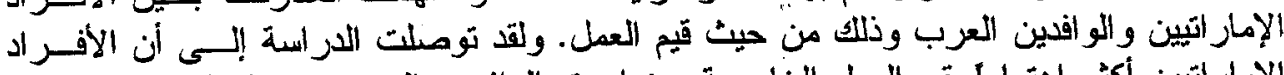

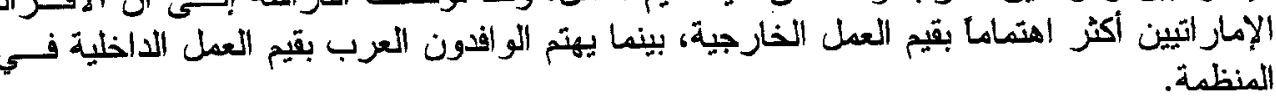

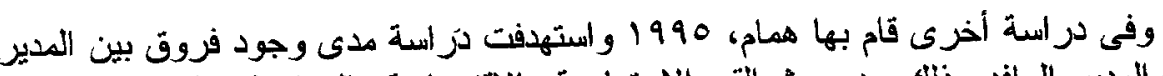

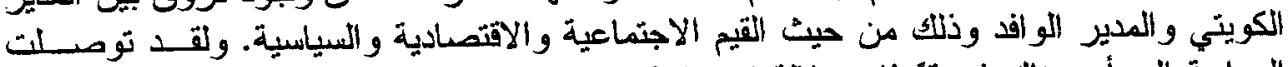

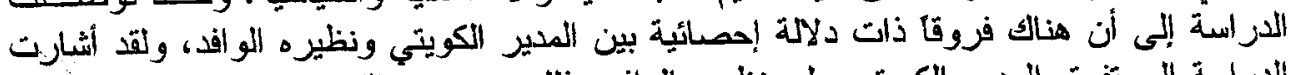

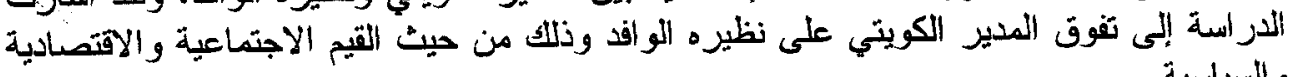
و السياسية

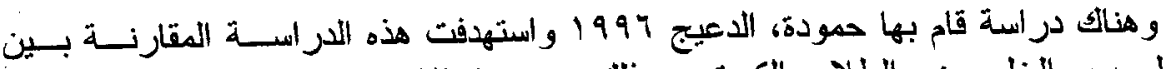

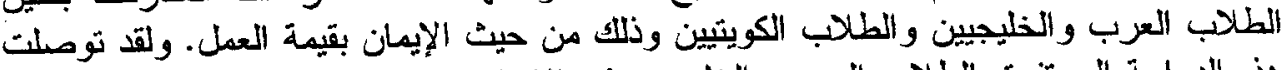

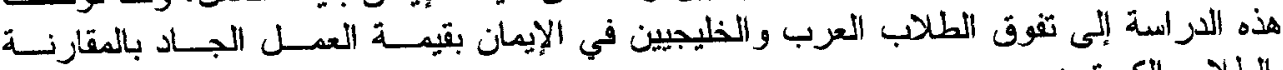
بالطلاب الكويتين.

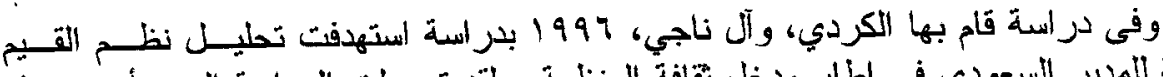

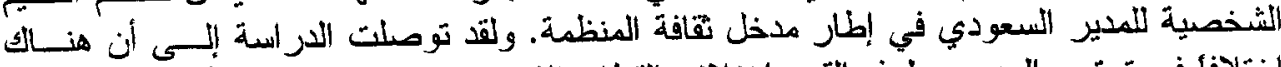

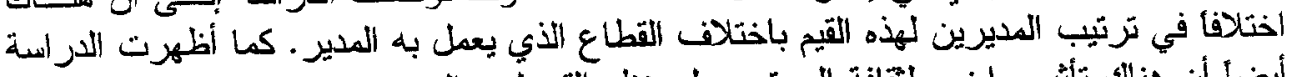

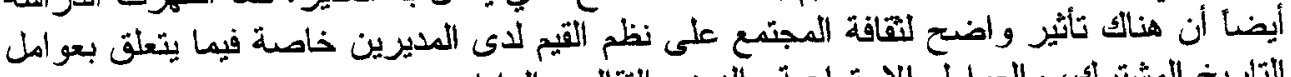

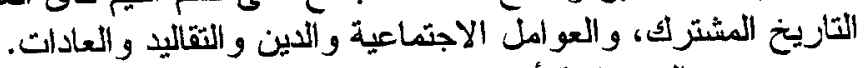

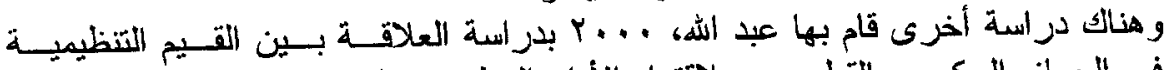

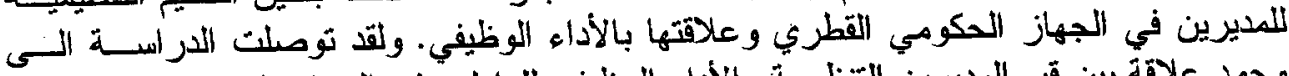

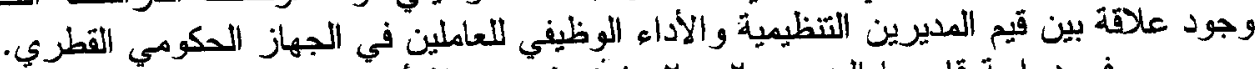

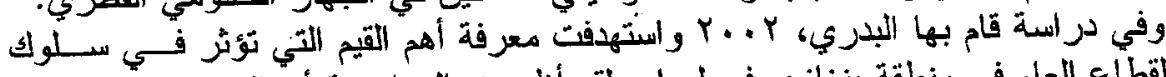

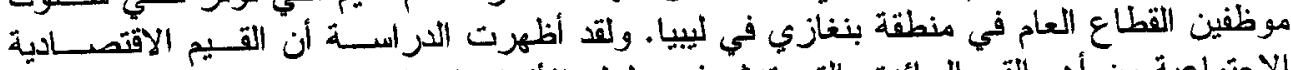

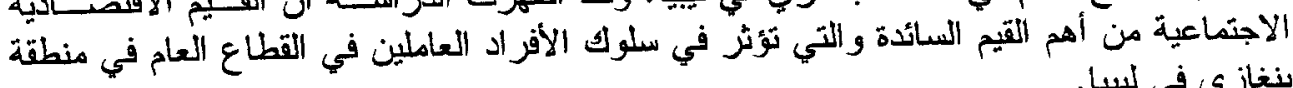

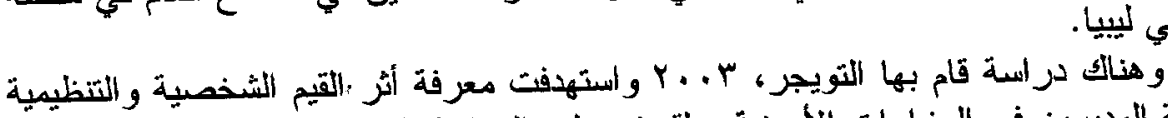

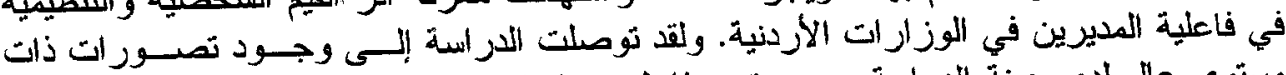

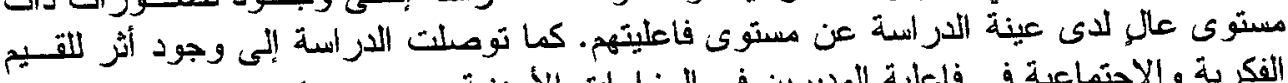

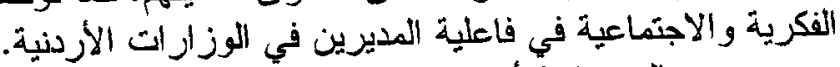

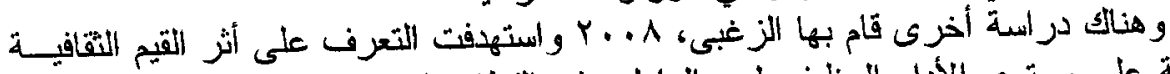

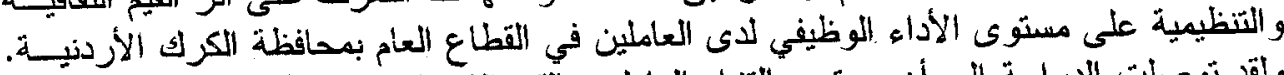

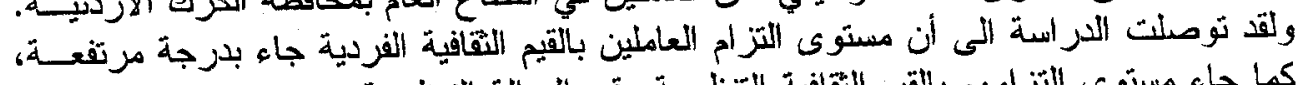

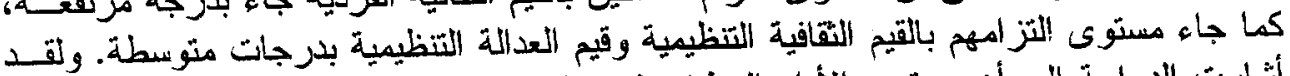

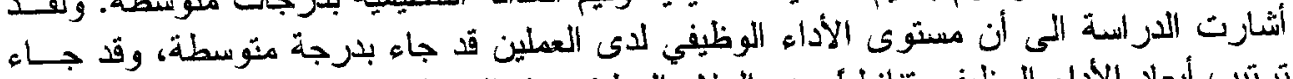

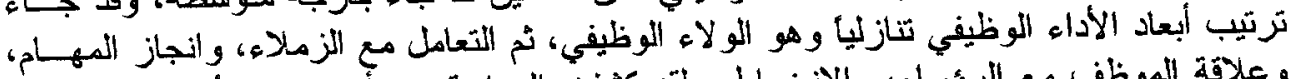

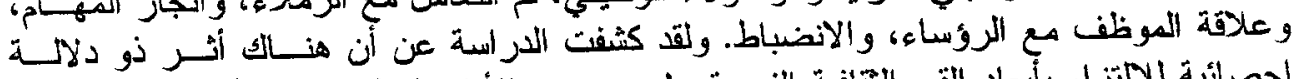

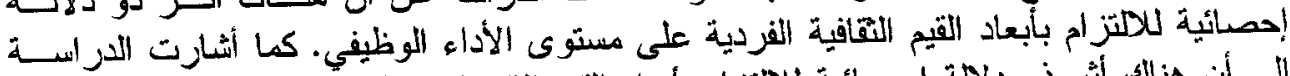

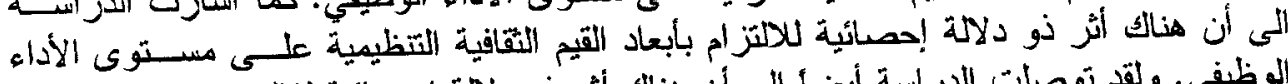

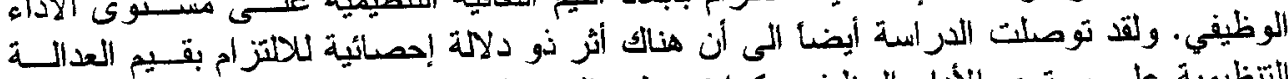

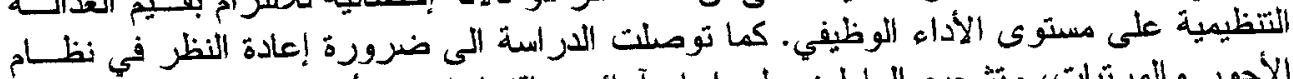

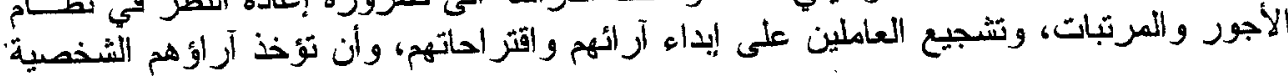


بعين الاعتبار، ثم تعزيز مبدأ الثقافة لدى العاملين في القطاع العام بمحافظة الكرك الأردنية.

\section{r/r r الدراسات السابقة المتعاقة بالالتزام التنظيمي}

هناك دراسة قام بها

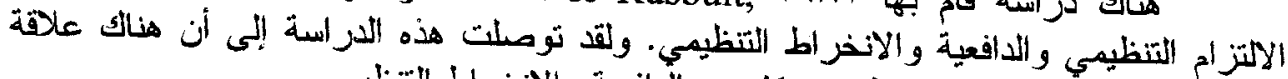

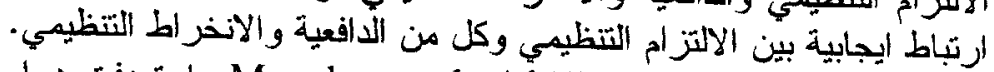

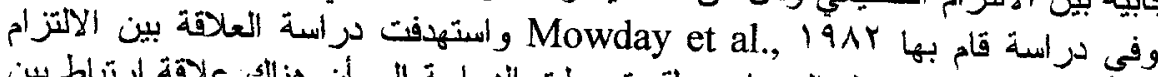

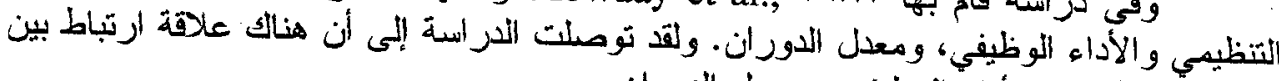

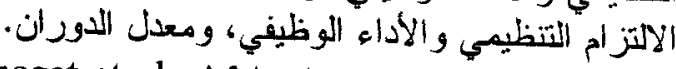
وفى يز اسة قام بها

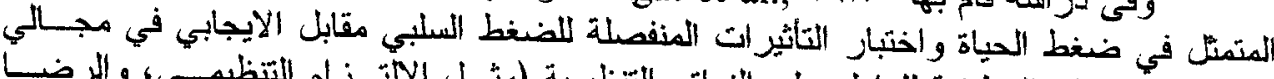

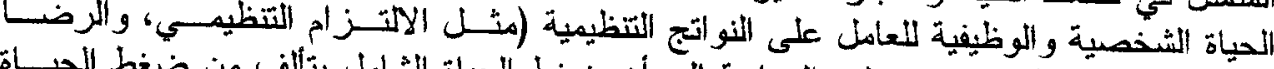

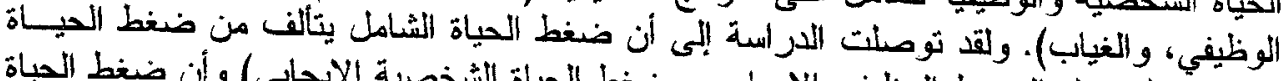

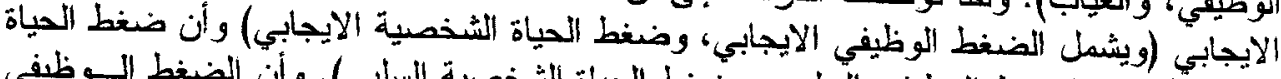

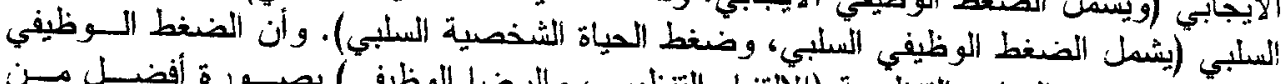

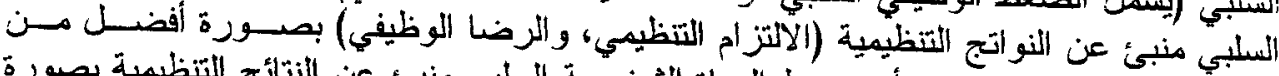

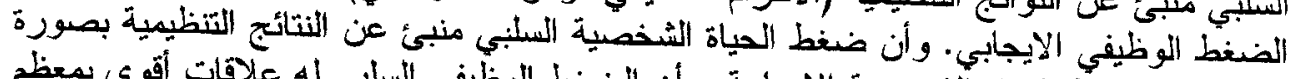

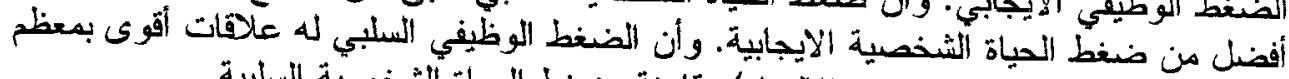

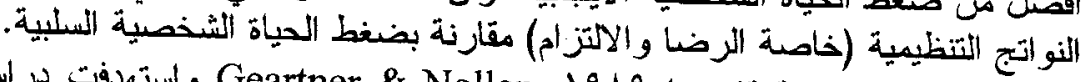

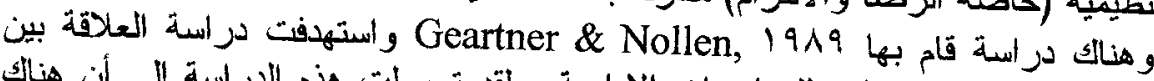

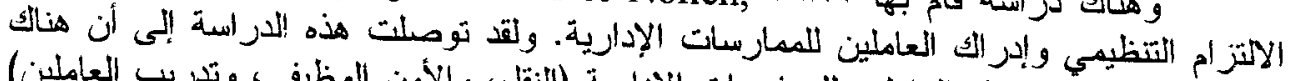

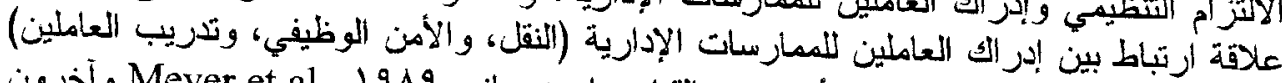

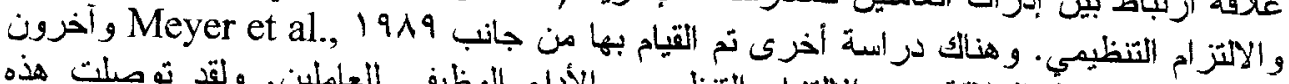

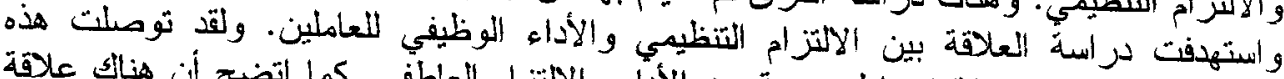

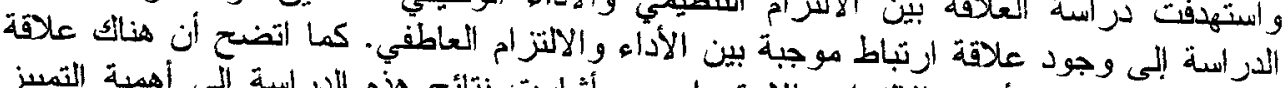

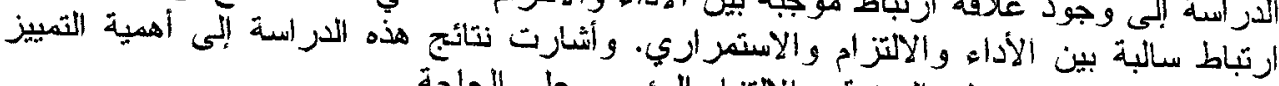

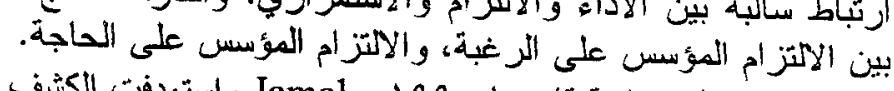

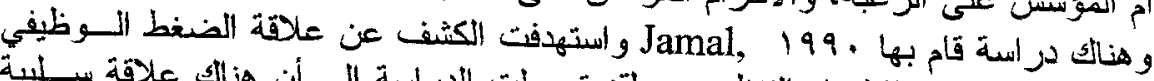

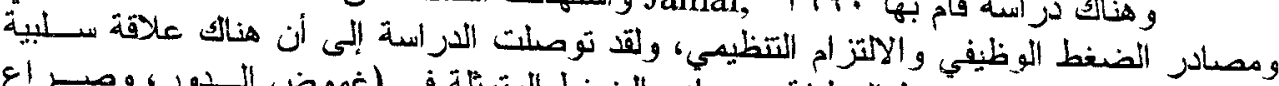

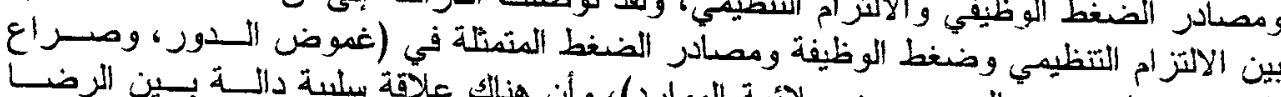

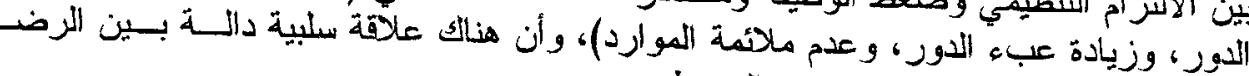

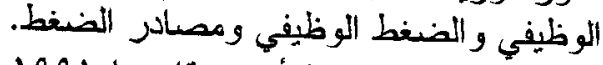

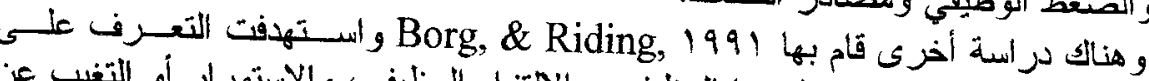

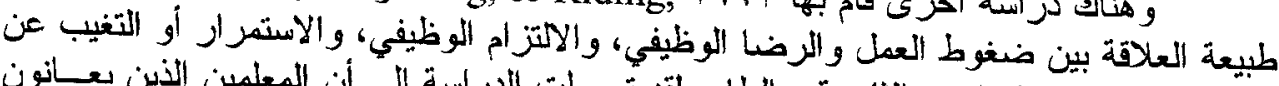

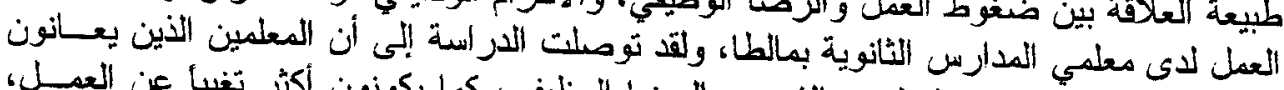

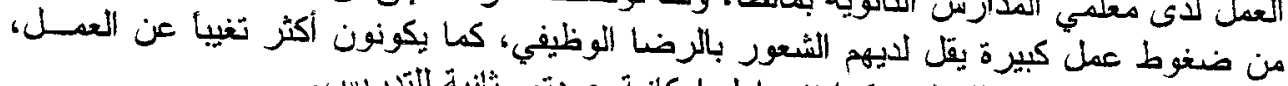

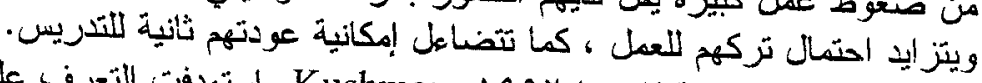

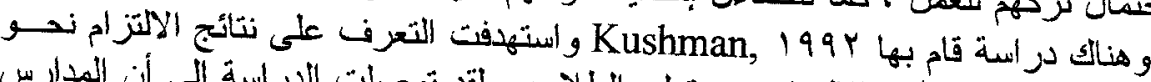

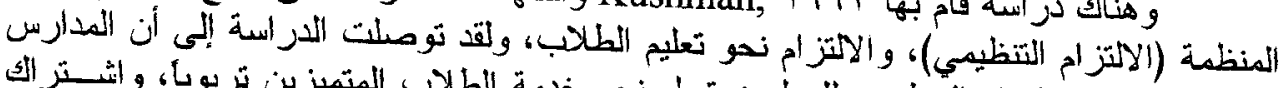

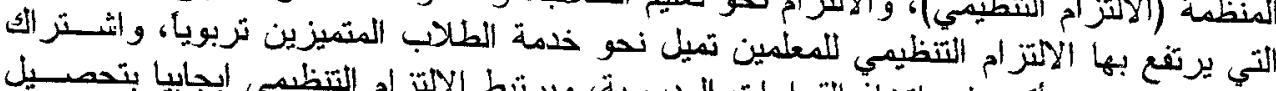

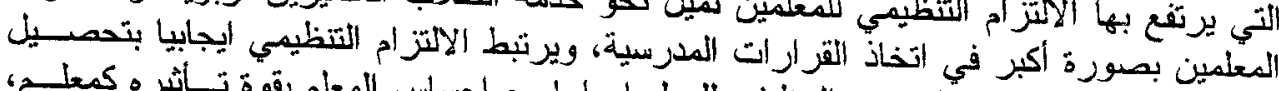

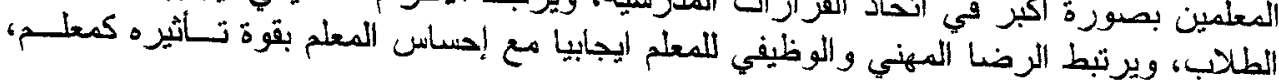




\section{- rAT-}

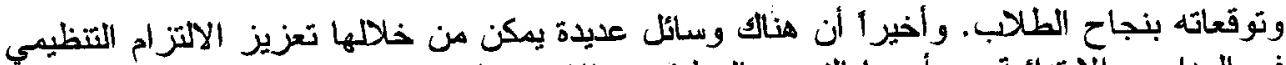

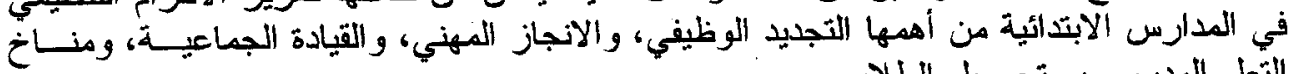

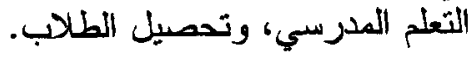

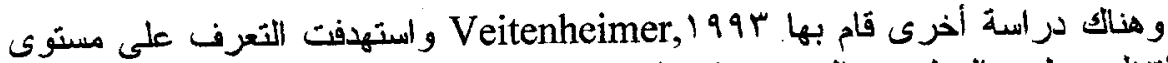

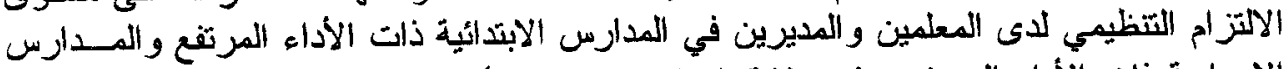

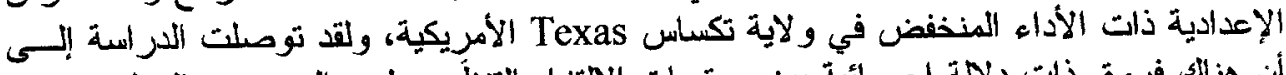

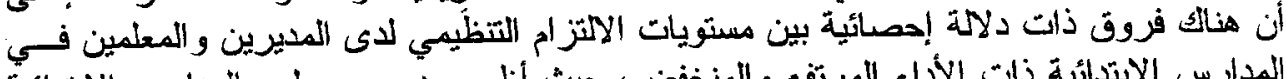

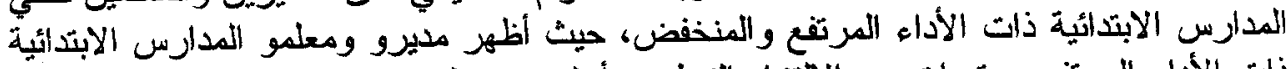

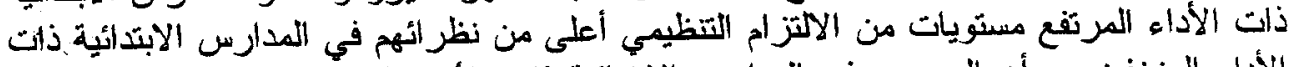

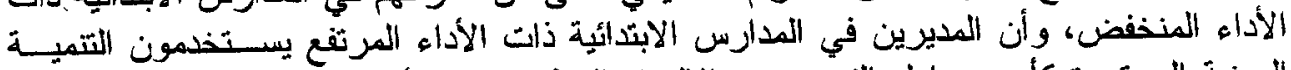

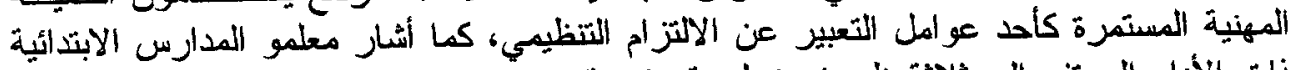

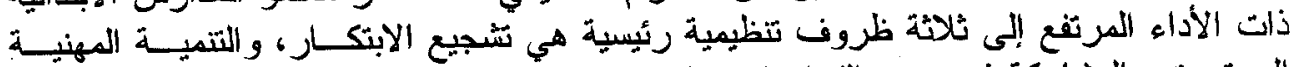

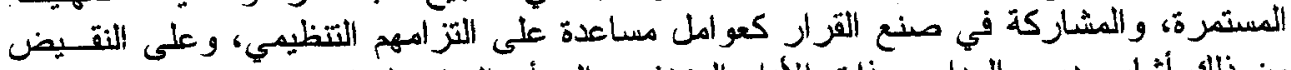

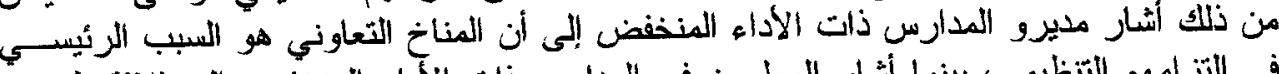

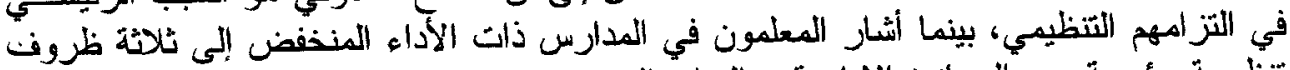

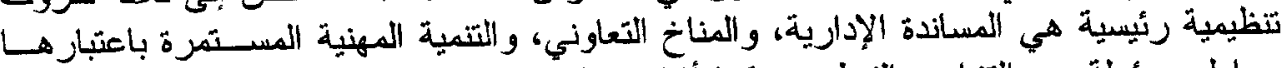

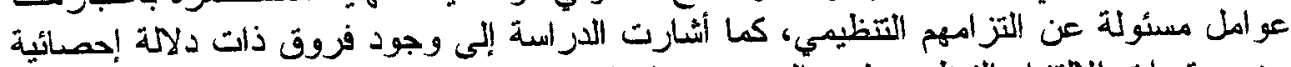

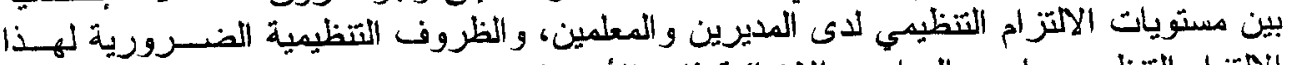

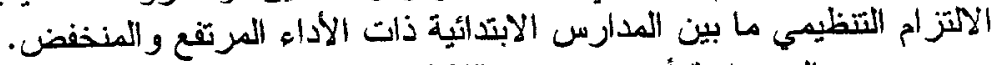

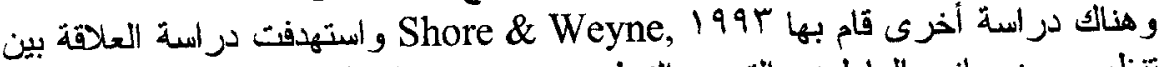

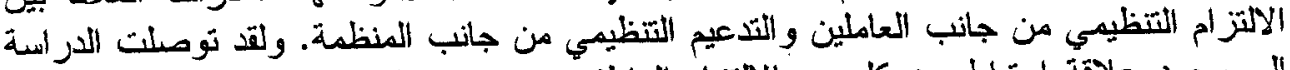

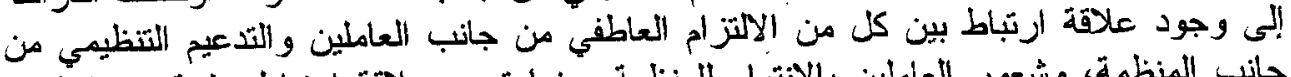

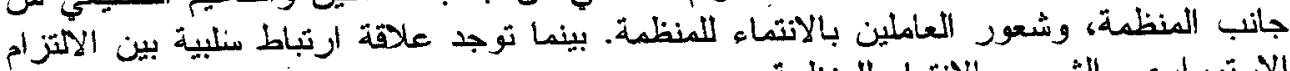
الاستمر اري و الشعور بالانتماء للمنظمة.

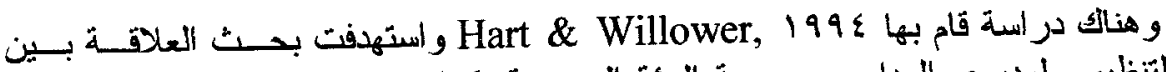

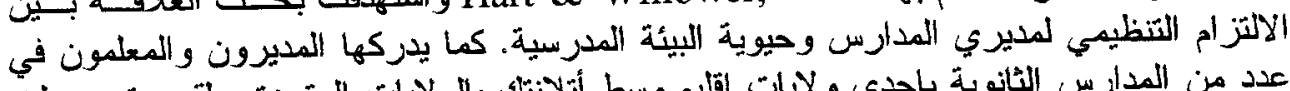

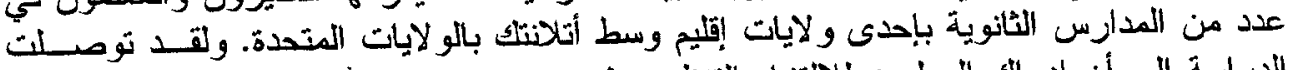

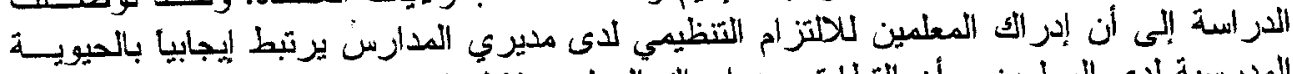

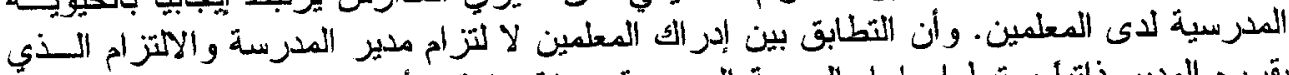

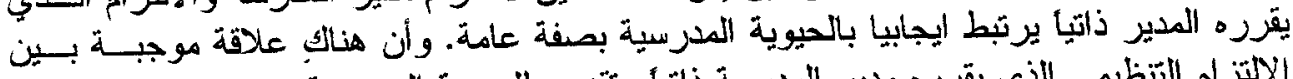

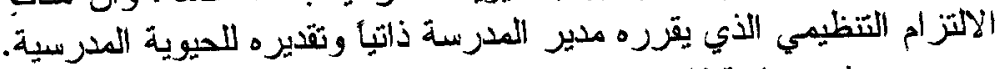

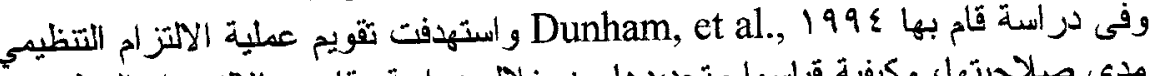

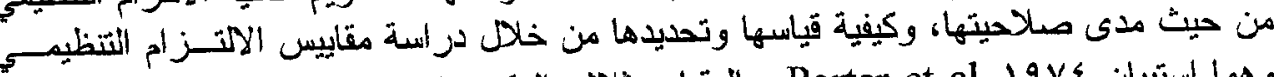

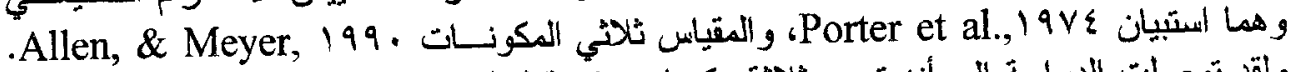

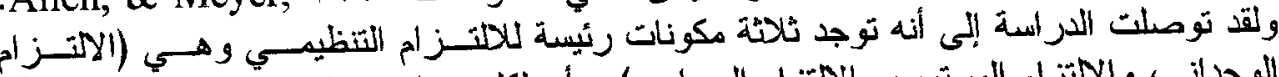

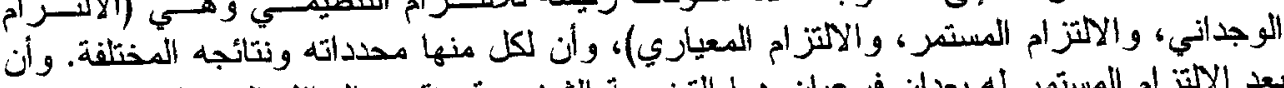

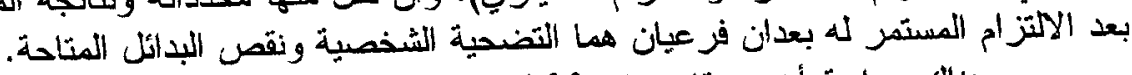

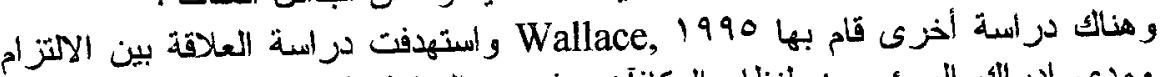

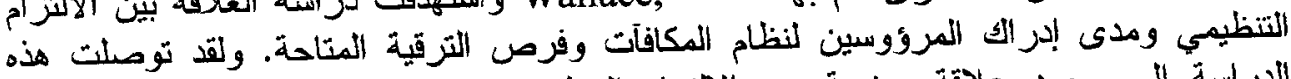

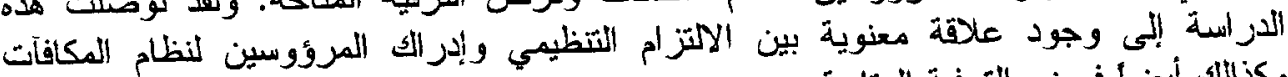
وكذاللك أيضا فرض وخرد الترفية المناحة. وفى دراسة قام بها Lious, 1990 


\section{- rAY -}

والثقة بالمشرفين. ولقد توصلت الدرأسة إلى وجود علاقةة معنوية وذات دلالة إحصائية بين مستوى الالتز ام التنظيمي و الثقة في المشرفين.

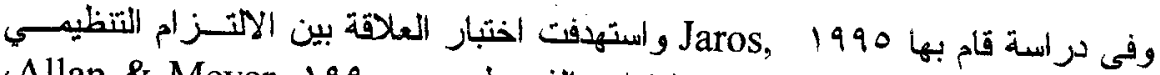

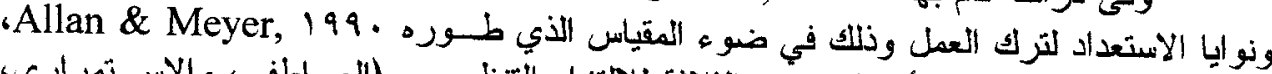

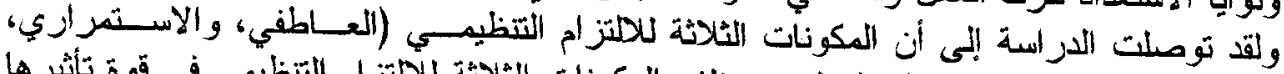

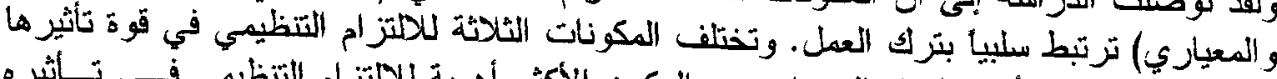

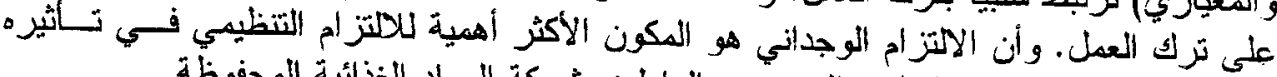

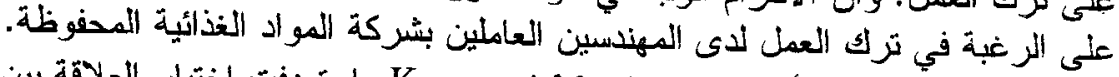

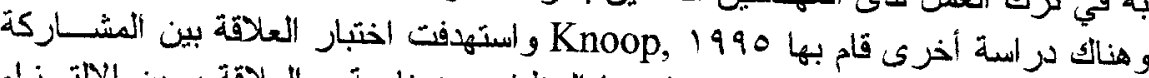

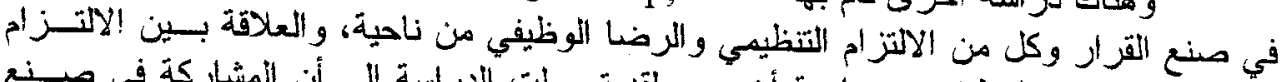

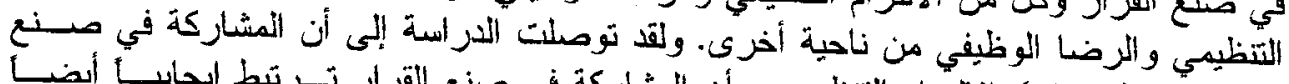

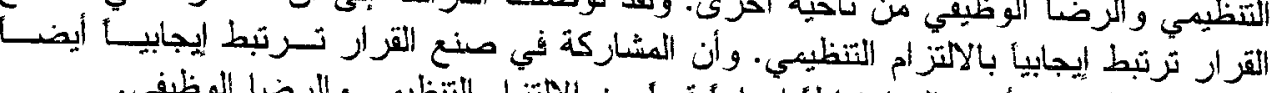

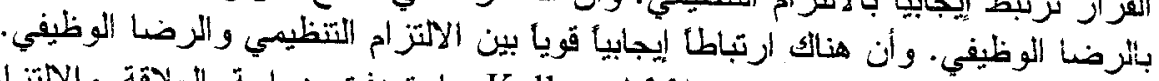

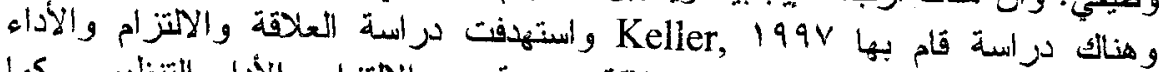

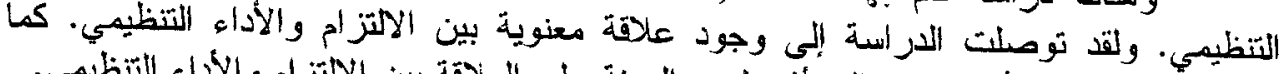

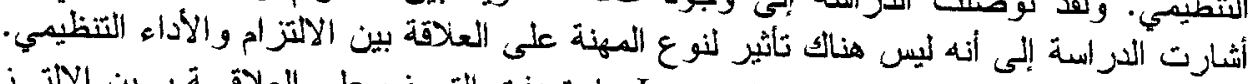

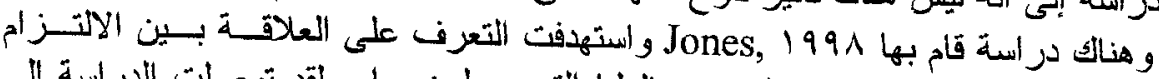

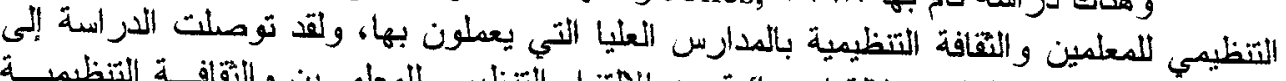

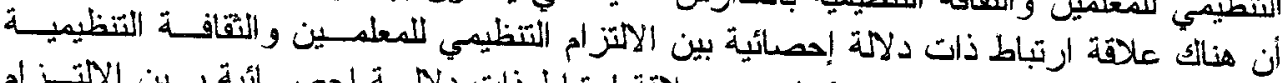

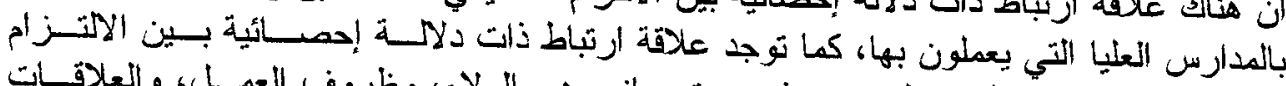

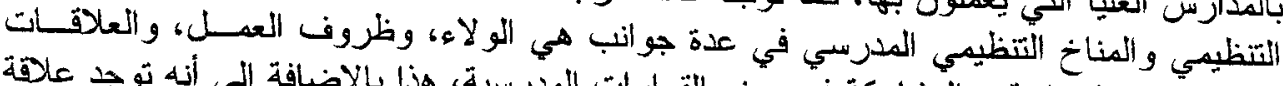

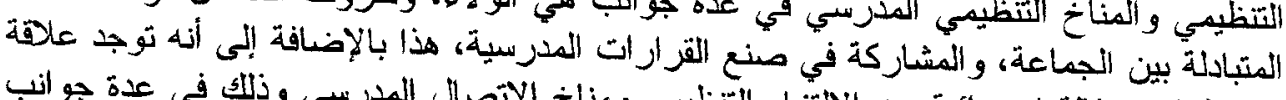

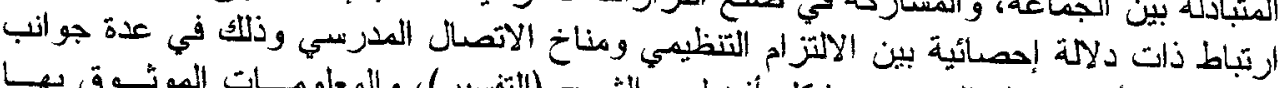

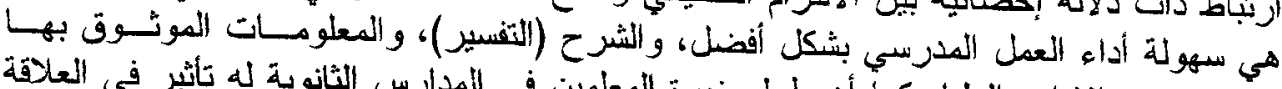

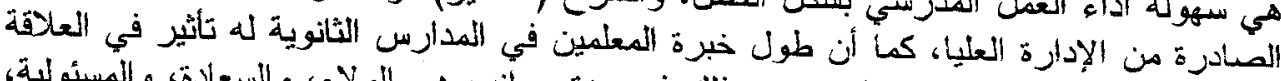

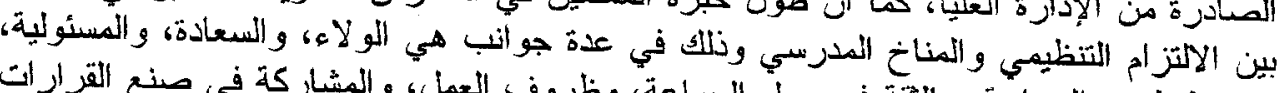

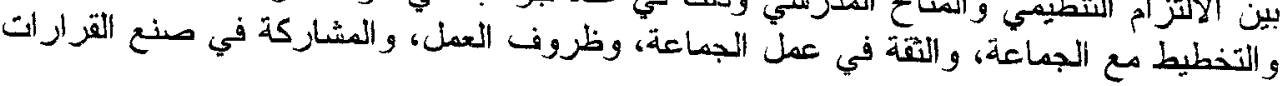

و واستهدفت تحديد أهم دعائم وعو ائق الالتزلمام

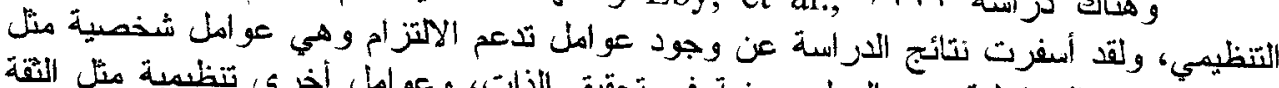

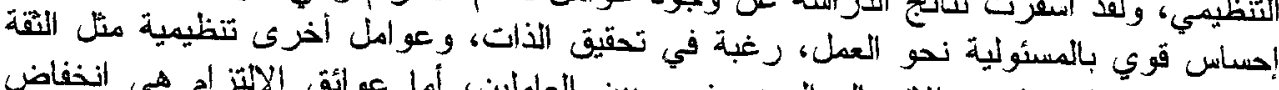

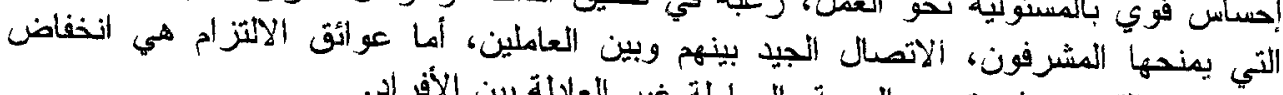

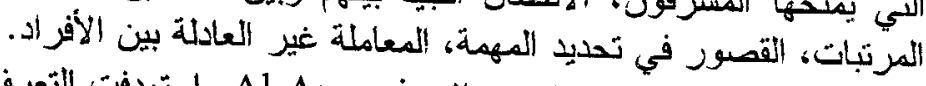

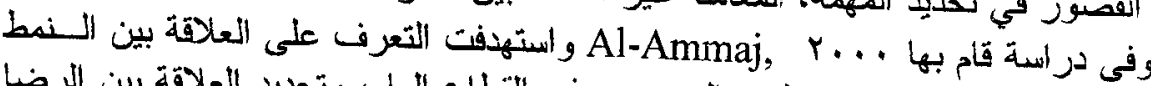

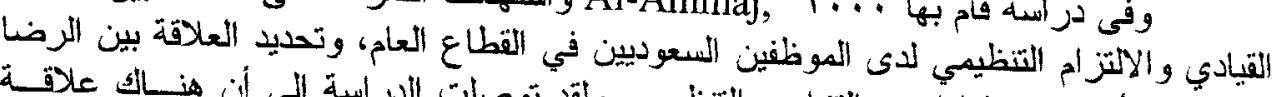

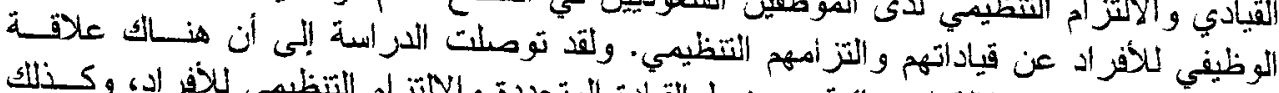

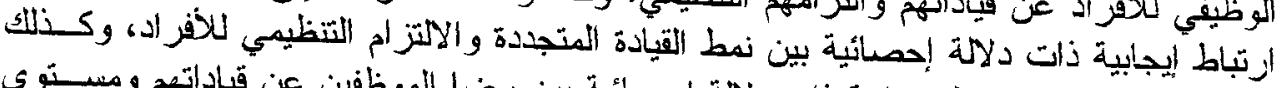

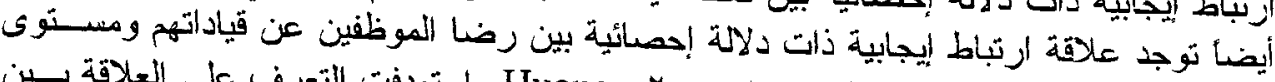

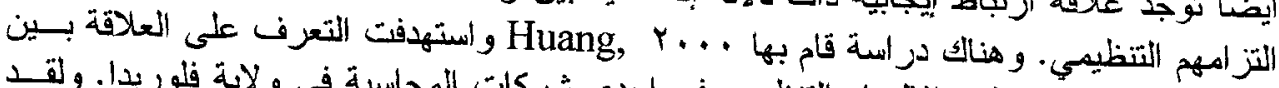

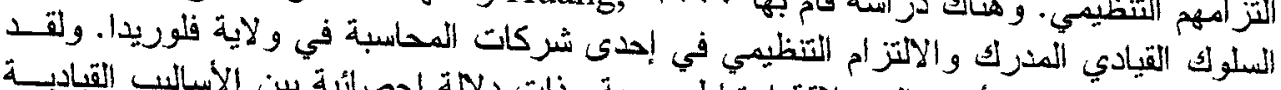

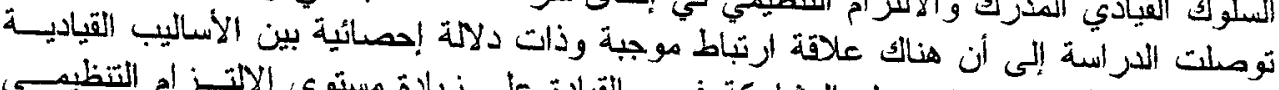

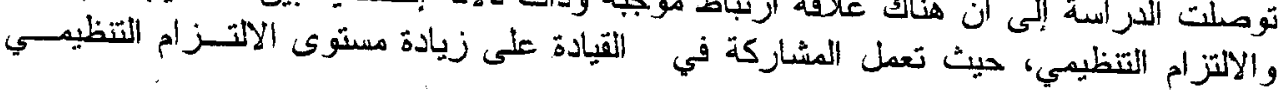




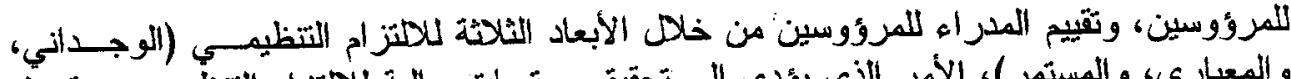

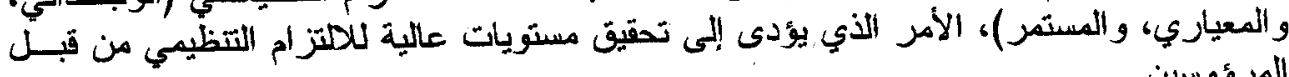

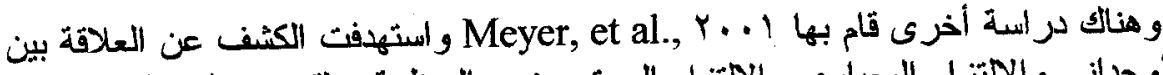

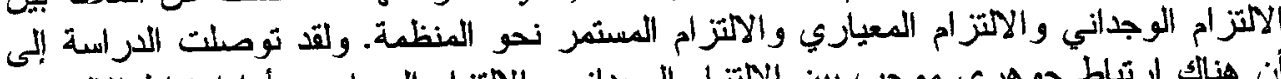

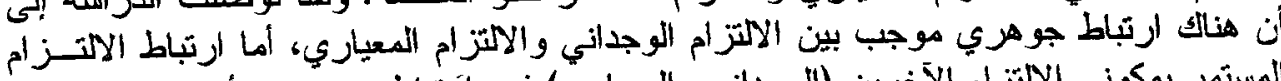

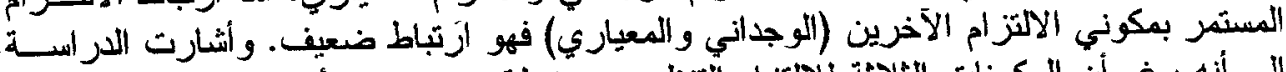

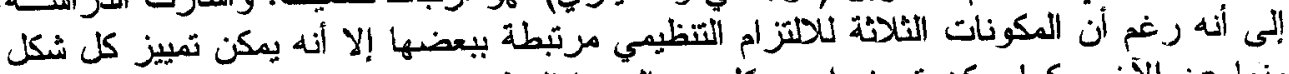

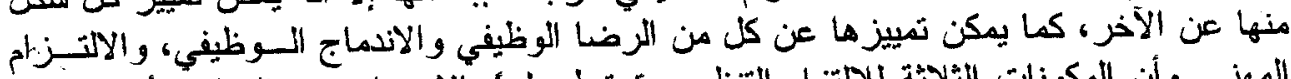

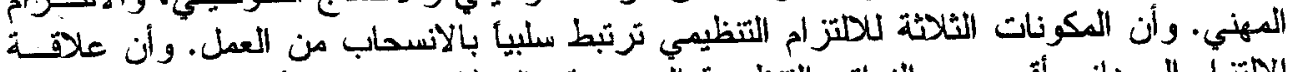

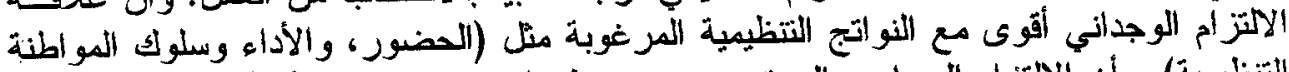

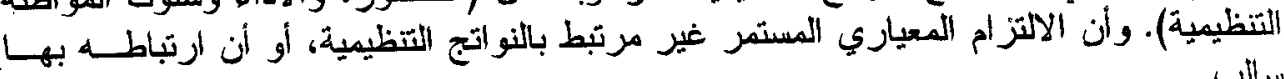

وفى دراسة أخرى قام بها ل مahim, et al., Y. و واستهدفت فحص العلاقة بين أبعاد

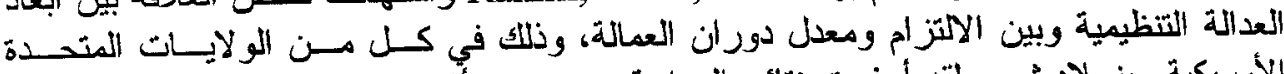

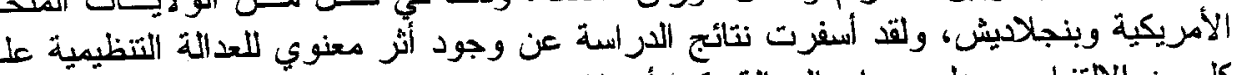

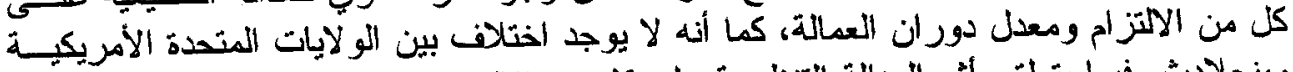

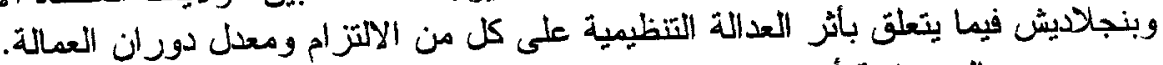

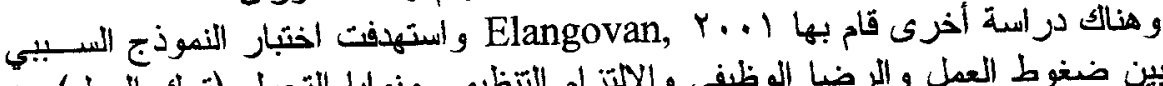

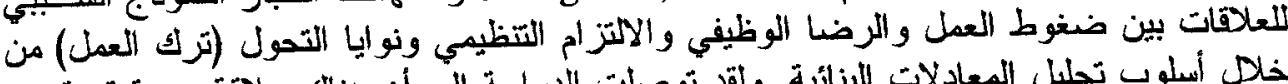

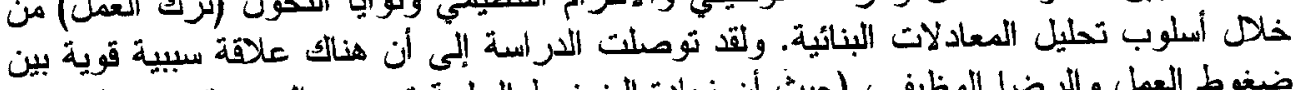

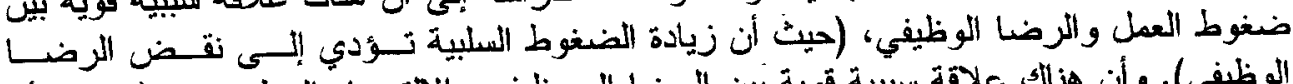

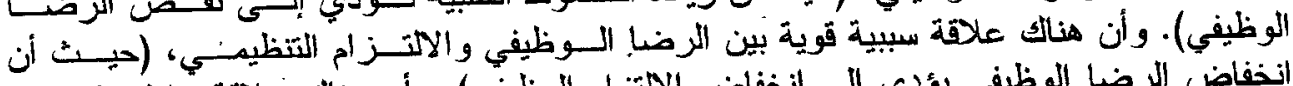

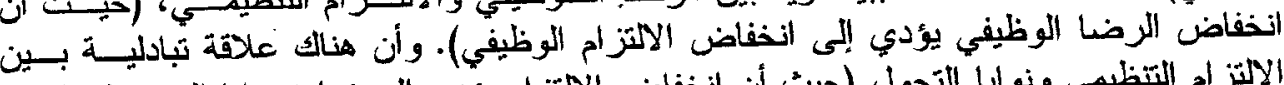

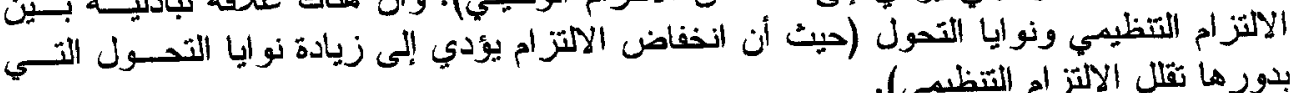
بدور ها نقلل الالتز ام التتظيمي).

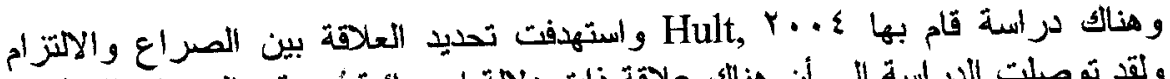

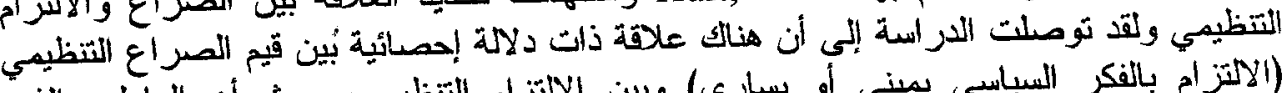

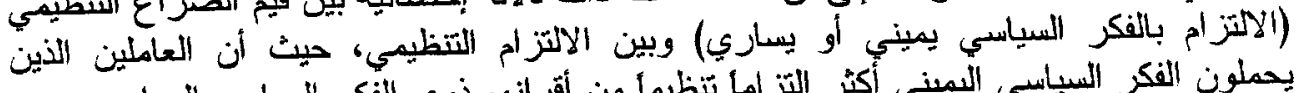

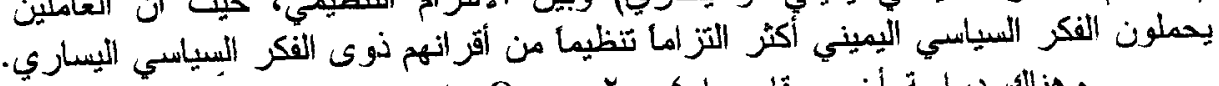

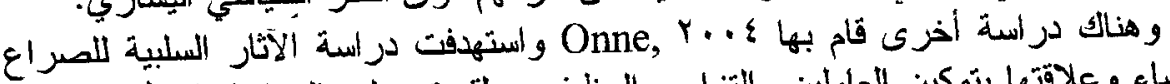

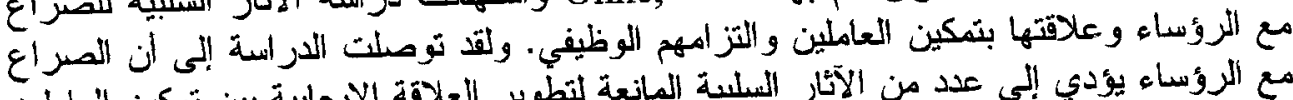

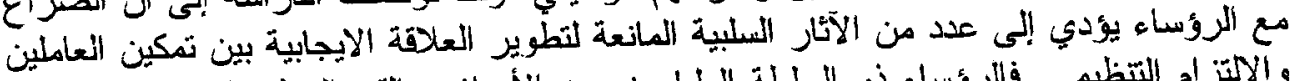

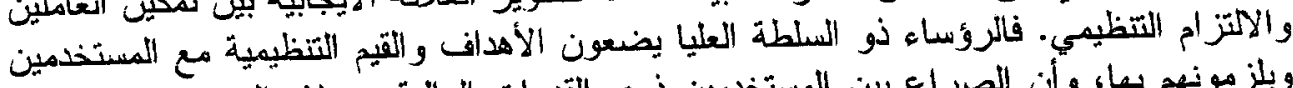

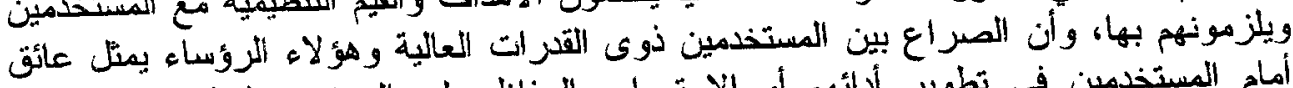

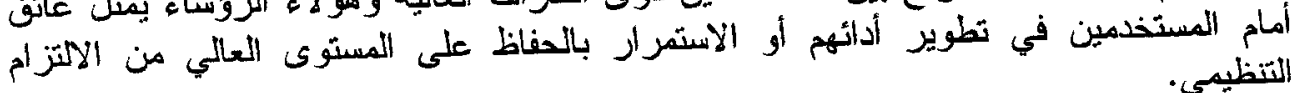

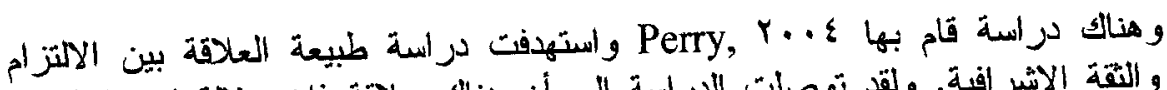

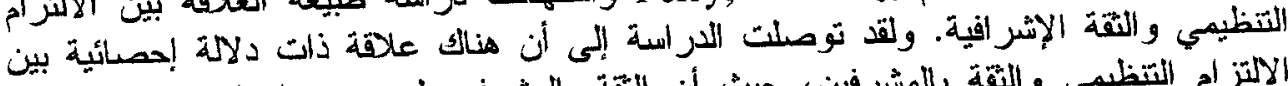

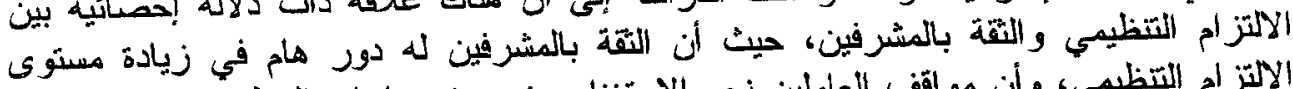

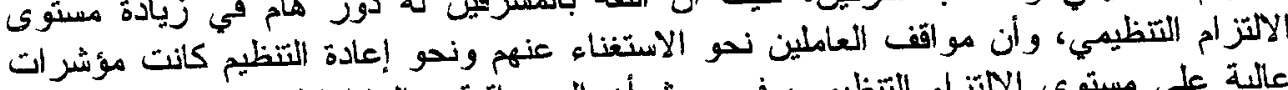

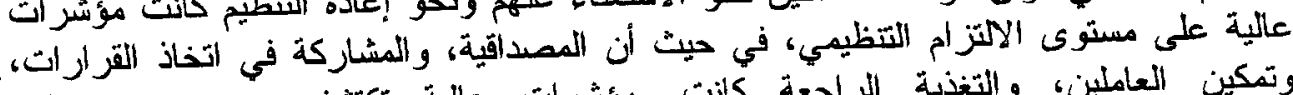

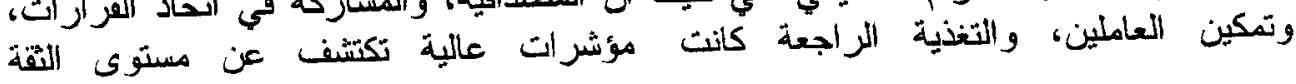




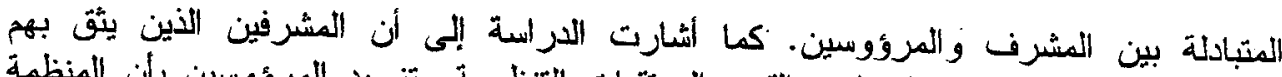

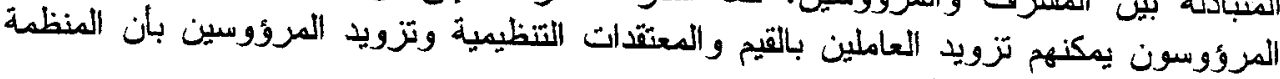
ثؤكد وتذعم القيم التي يحملونها. تئمان.

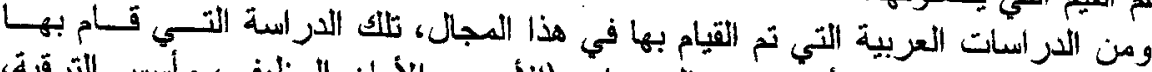

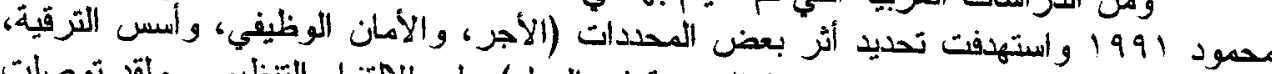

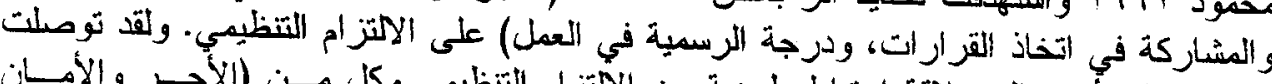

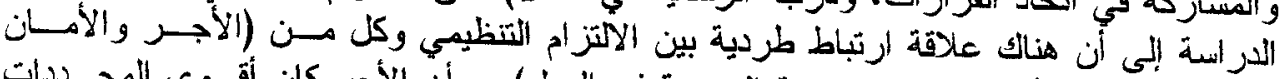

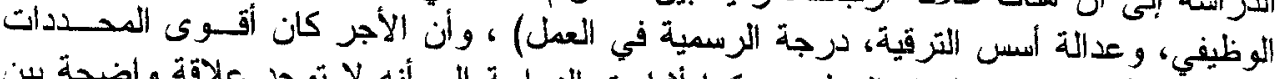

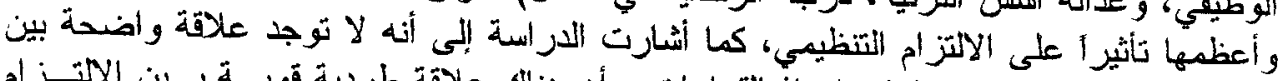

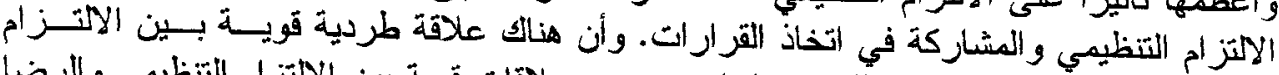

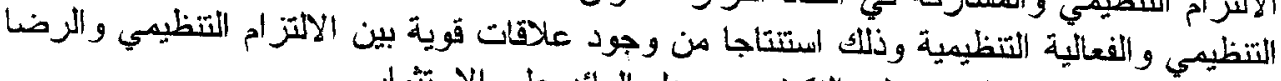

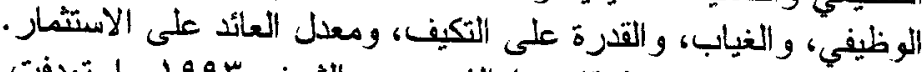

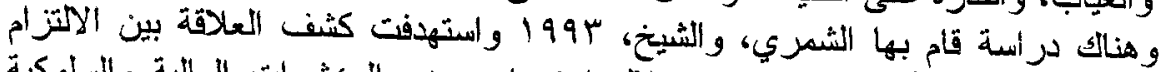

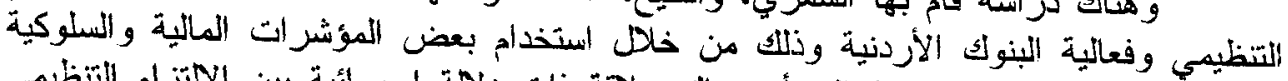

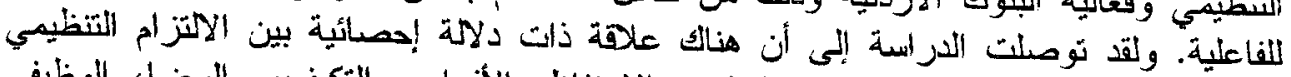

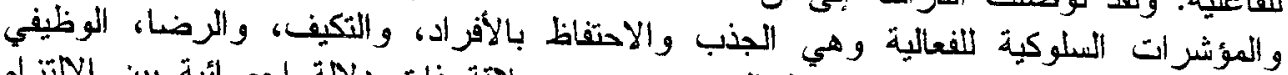

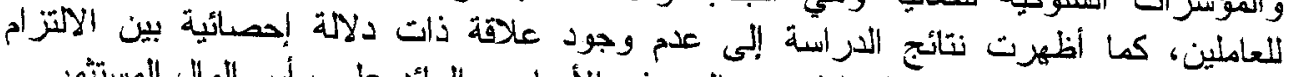

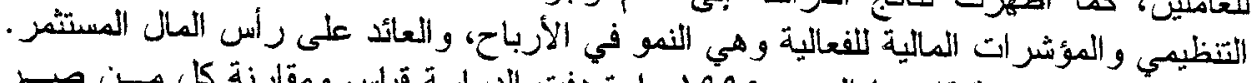

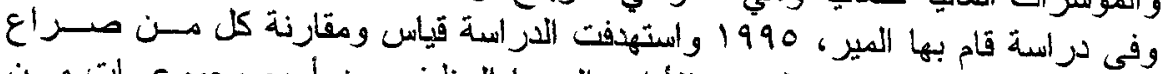

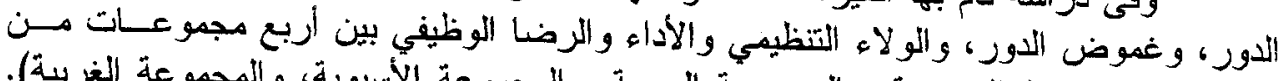

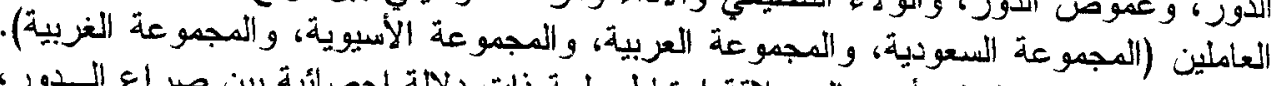

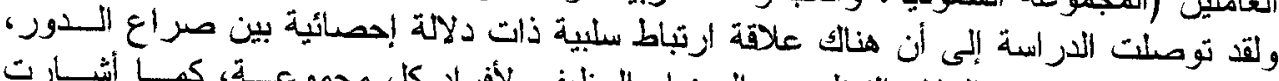

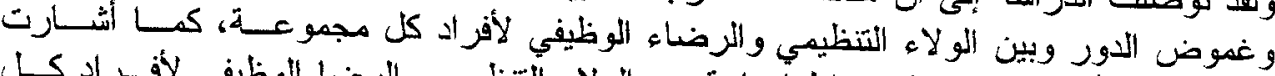

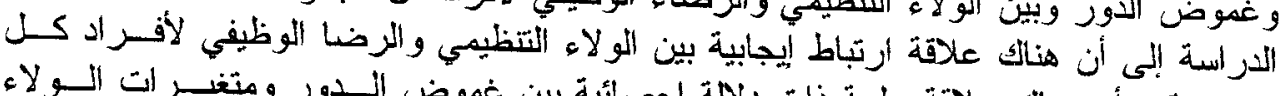

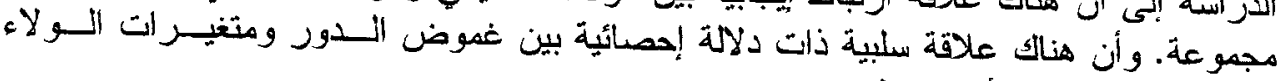

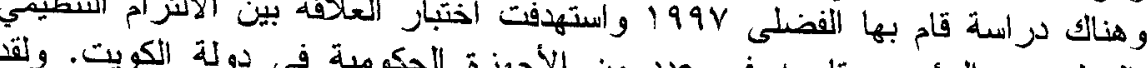

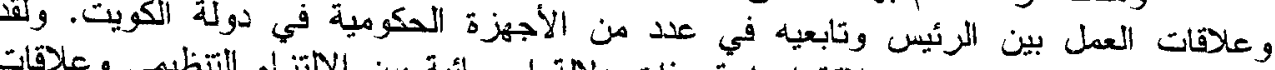

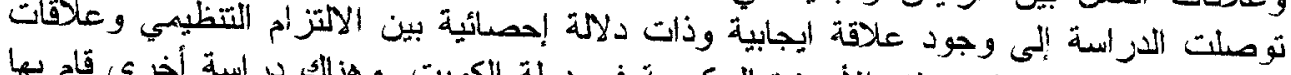

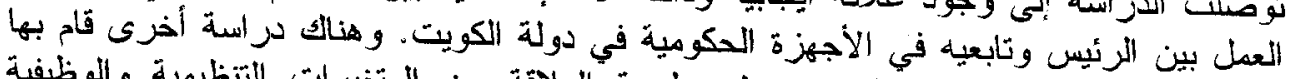

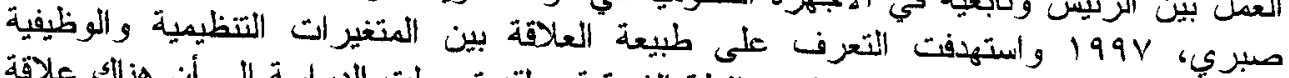

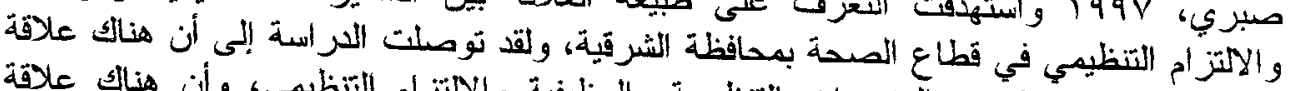

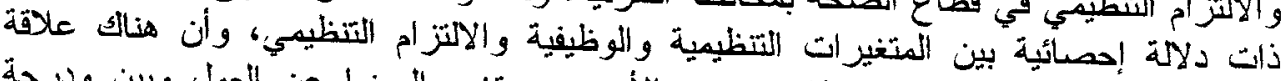

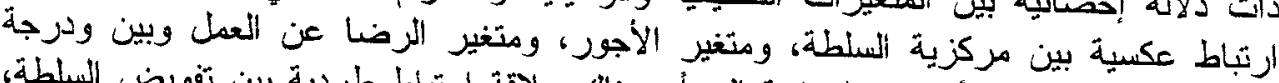

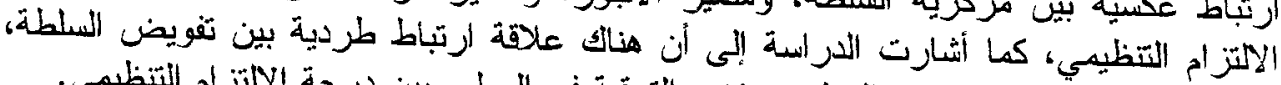

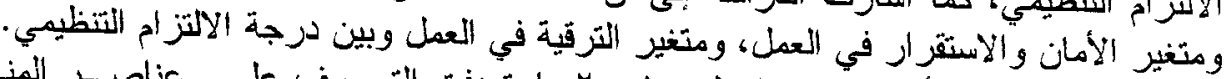

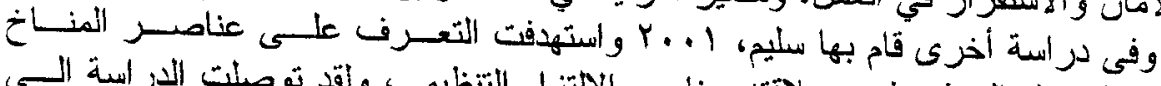

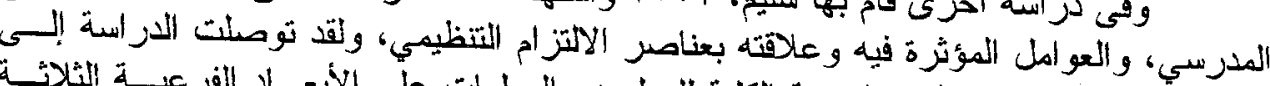

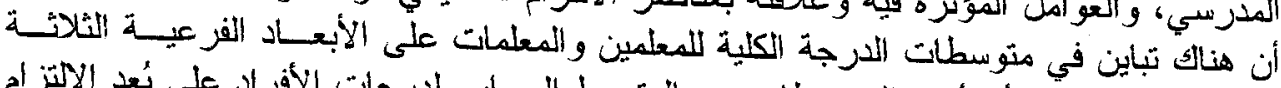

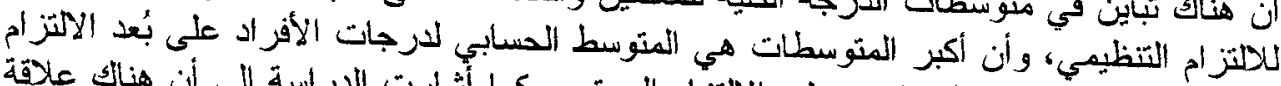

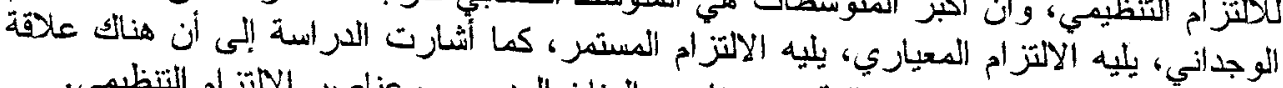

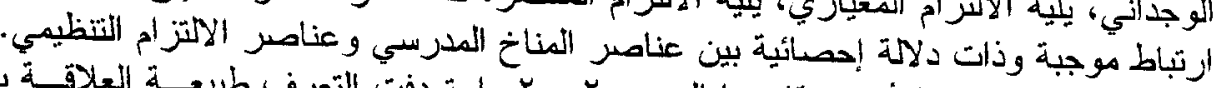

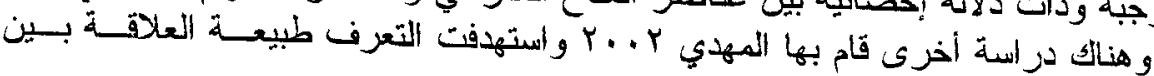




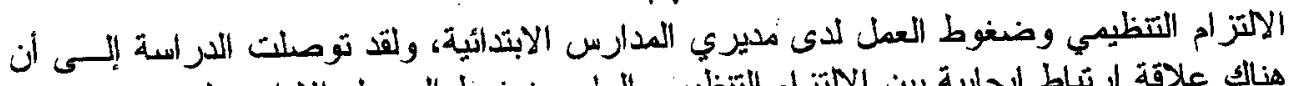

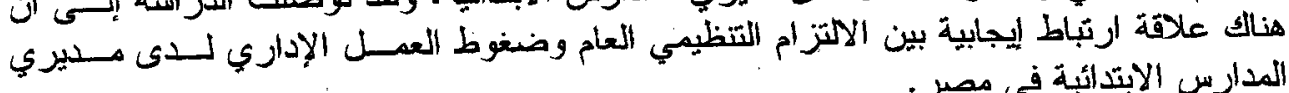

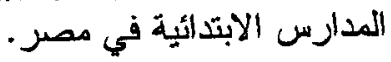

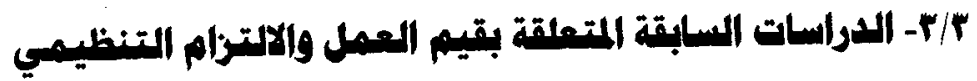

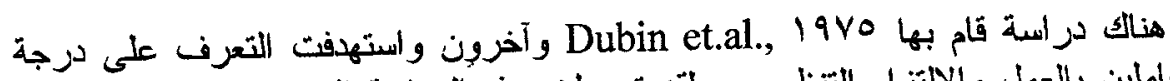

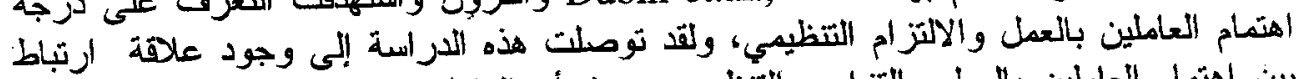

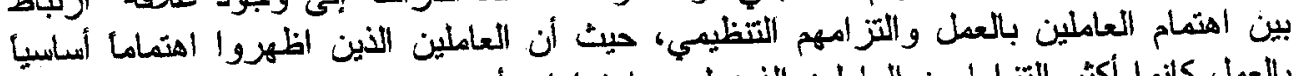

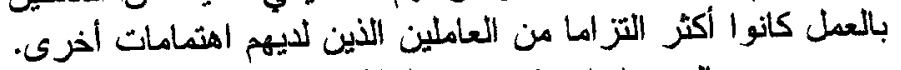

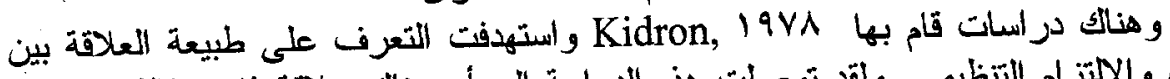

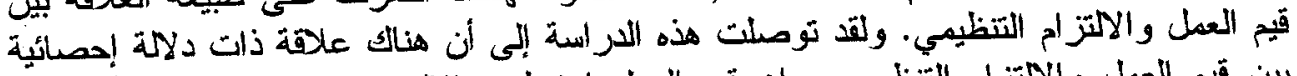

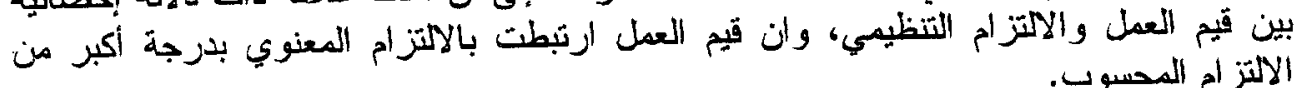

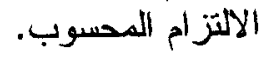

وفى در اسة أخرى قام بها Mottaz, 1911 و استهدفت تحديد الطريقة التي بها مكافآت

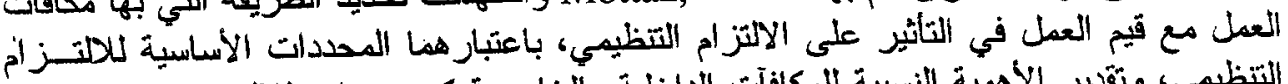

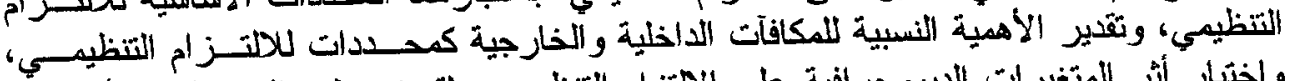

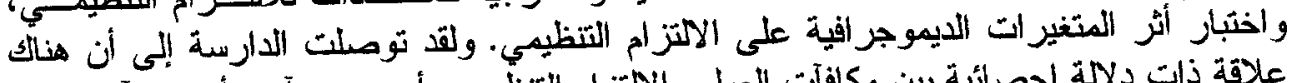

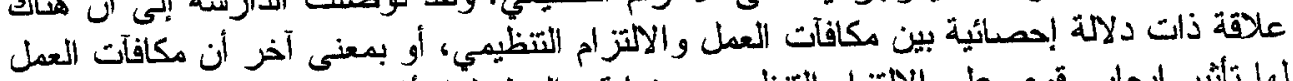

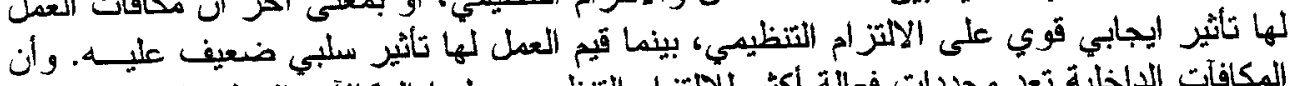

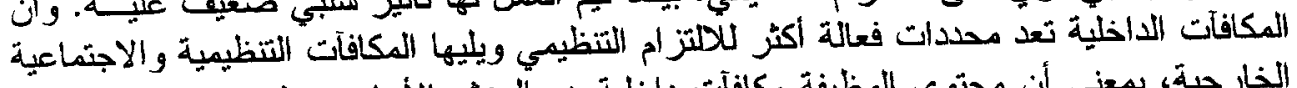

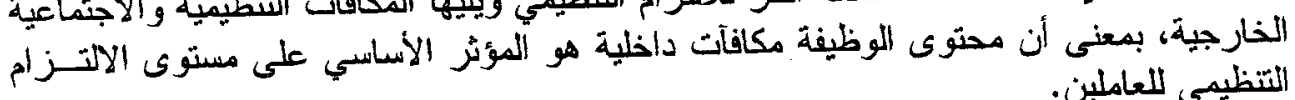
التنظيمي اللعاملين.

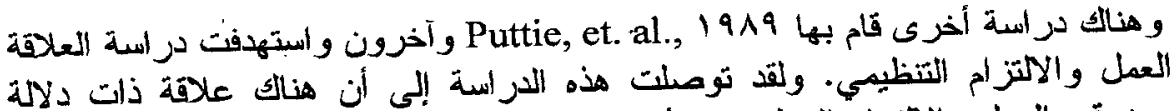

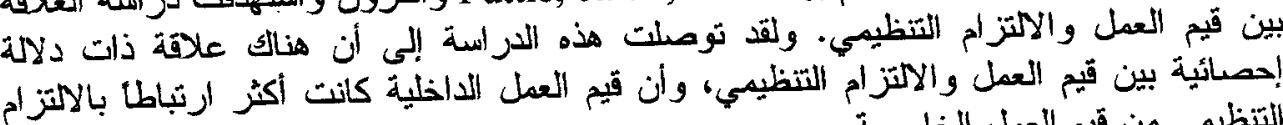

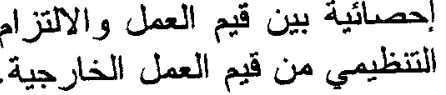

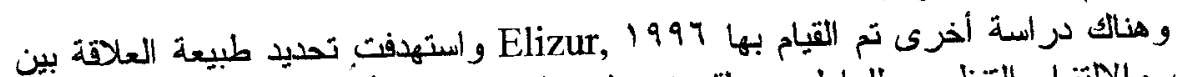

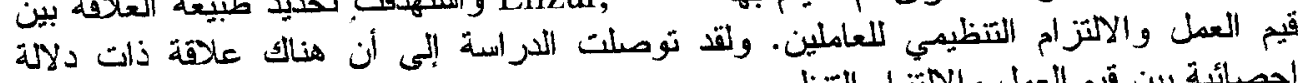

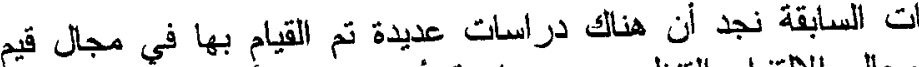

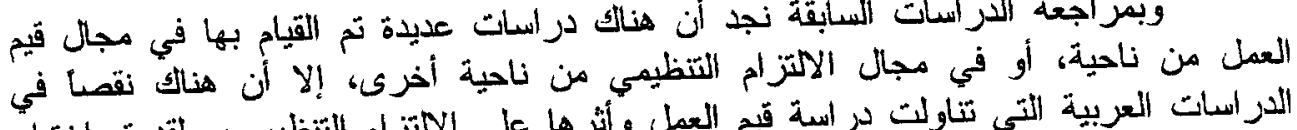

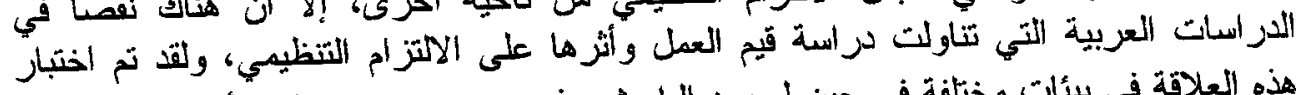

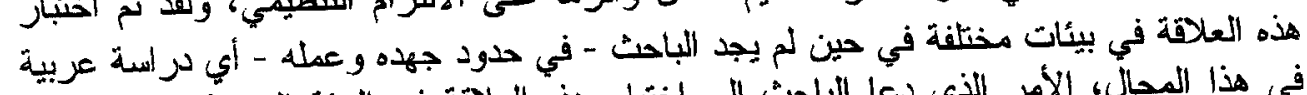

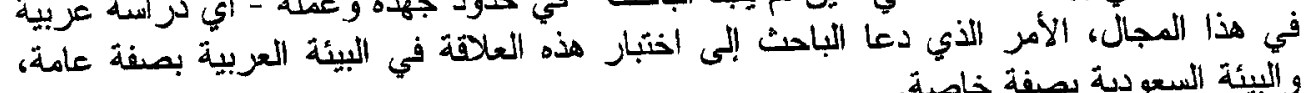
و ألبيئة السعودية بصفة المجرة خاصنة.

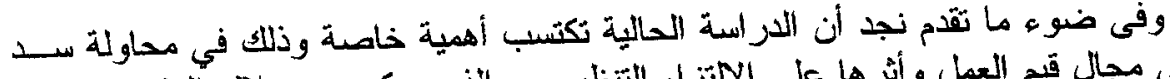

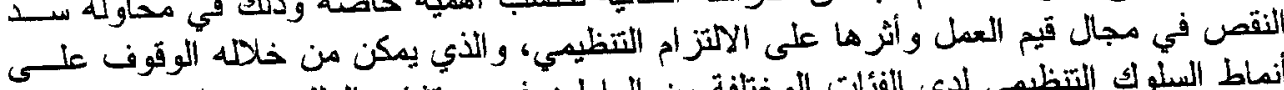

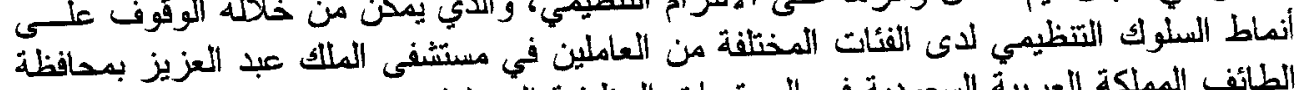

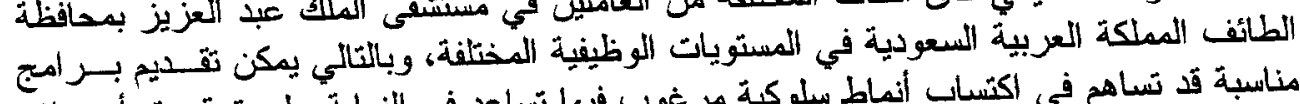

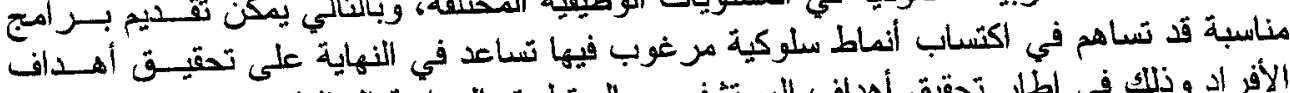

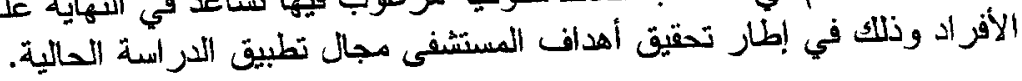




\section{؟- هشكة وأسئلة البحث}

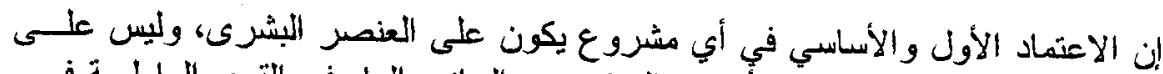

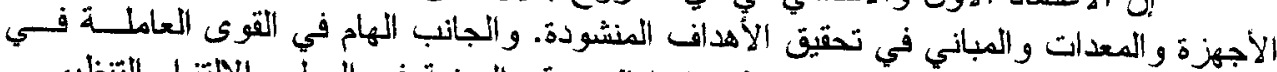

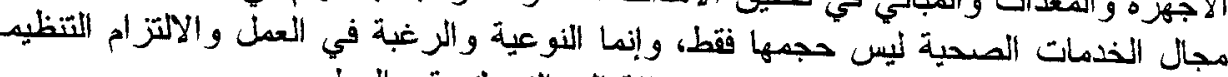

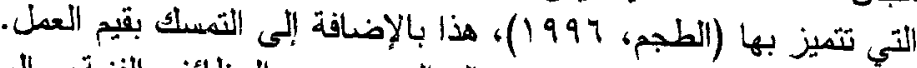

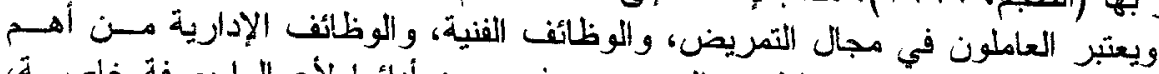

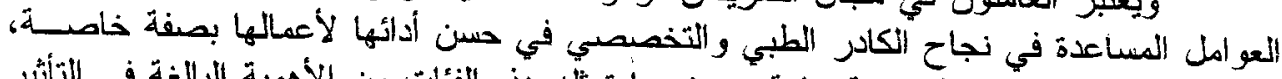

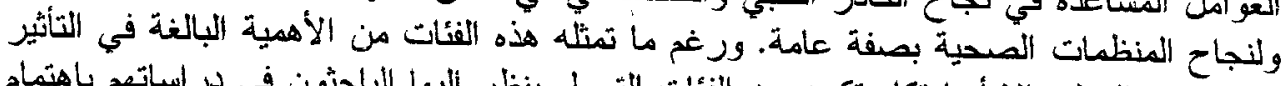

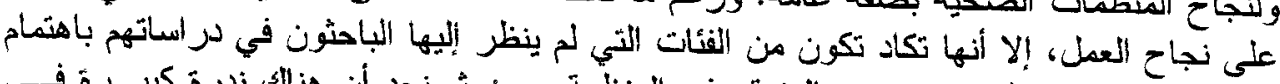

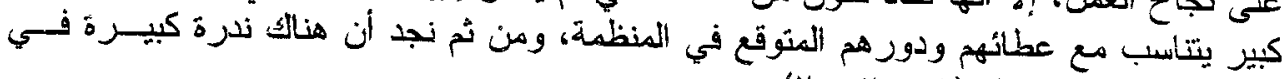

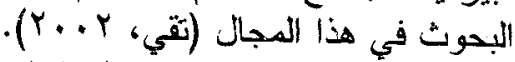

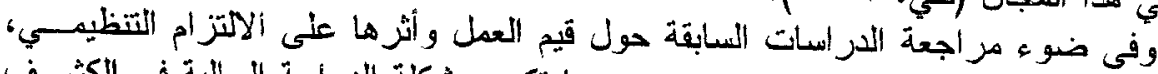

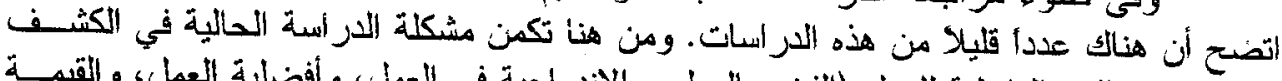

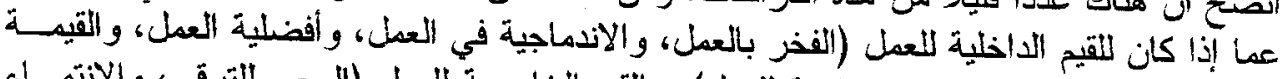

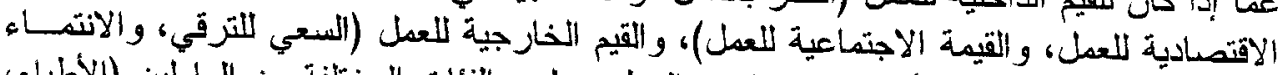

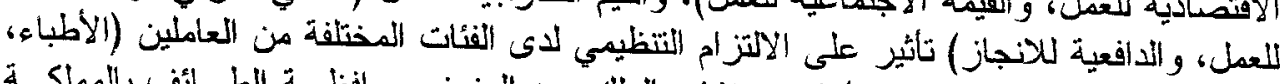

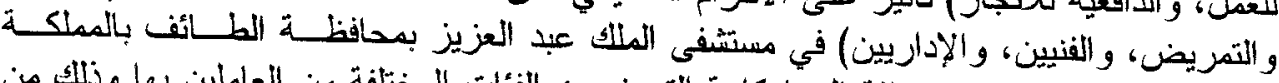

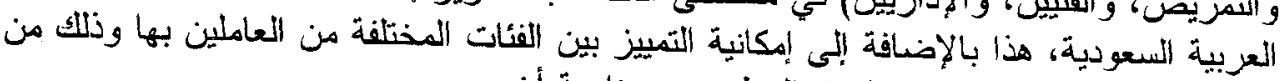

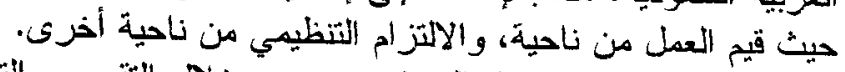

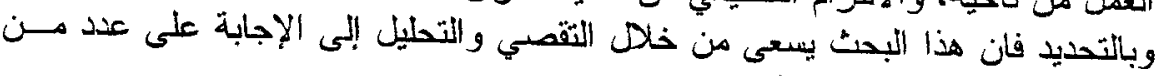

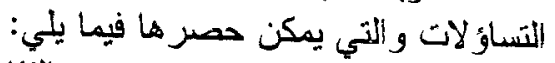

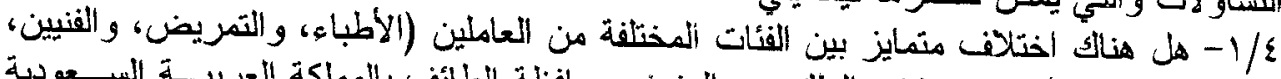

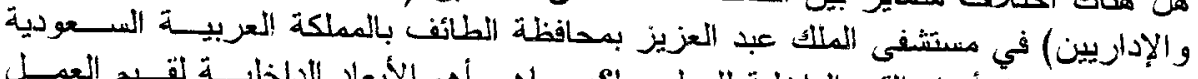

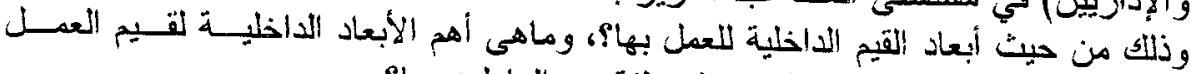

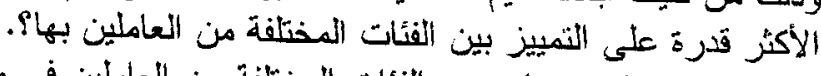

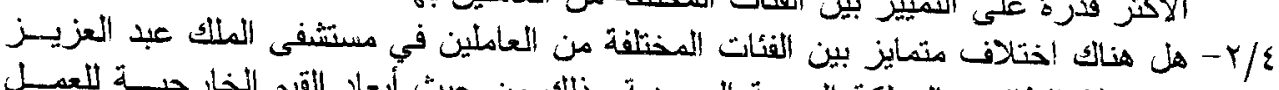

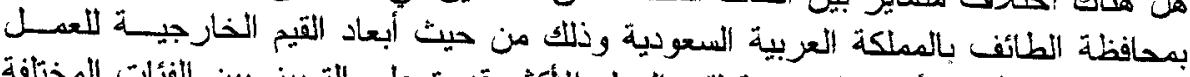

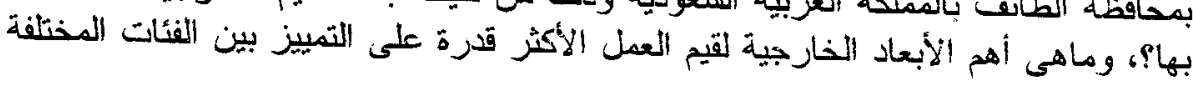

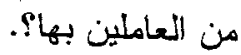
ع/r-r هن هناك اختلاف منمايز بين الفئات إلمختلفة من العاملين في مستشفى الملك عبد العزيـز

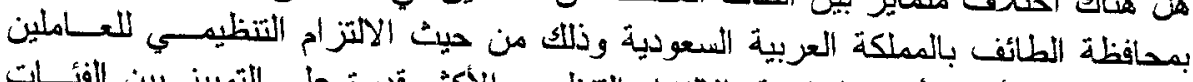

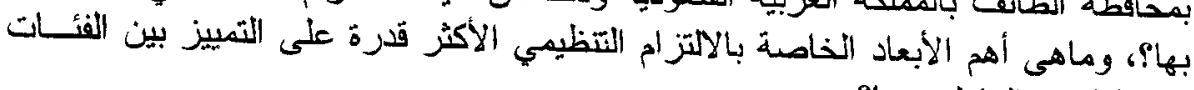

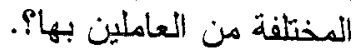

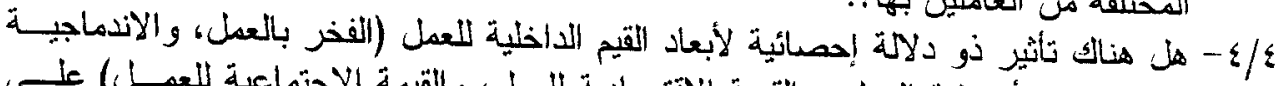

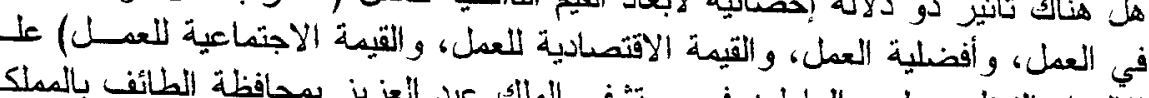

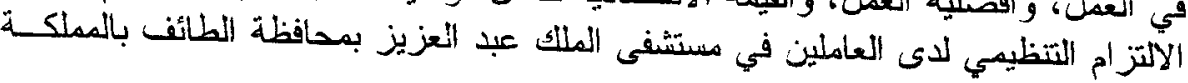

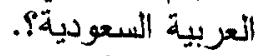

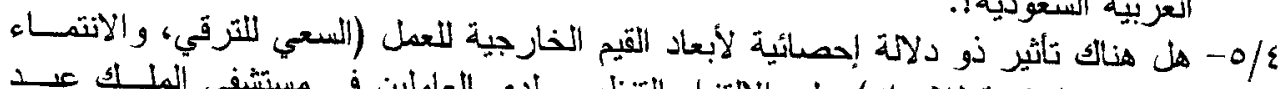

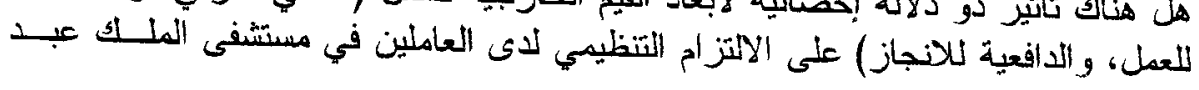




\section{ه- أهداف البمث}

يسعى هذا البحث إلى تحقيق مجموعة من الأهداف والتي بمكن صياغتها علـى النحسو

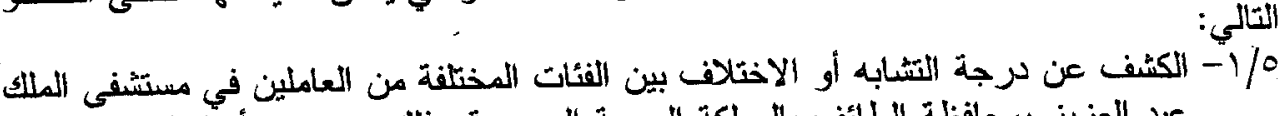

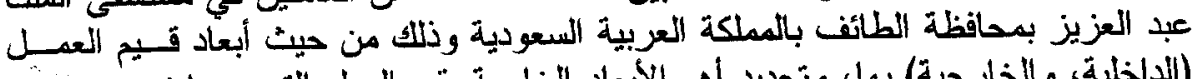

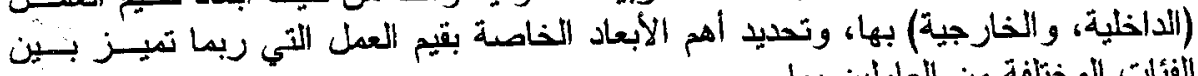

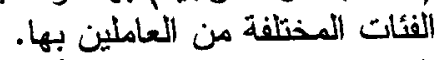

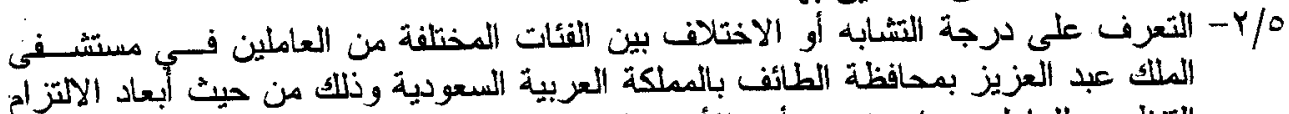

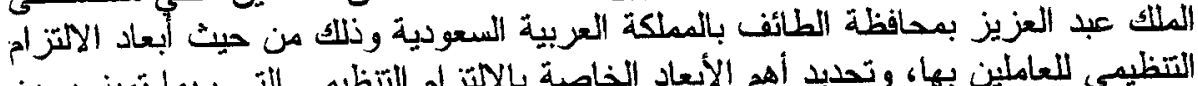

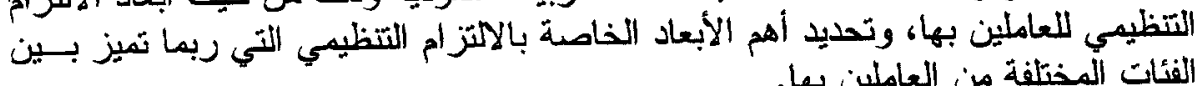

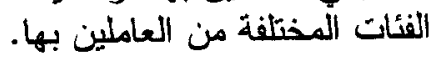

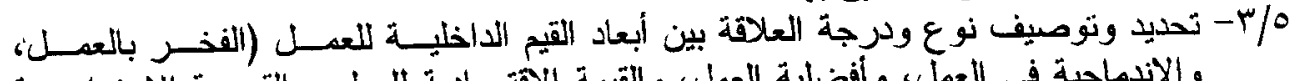

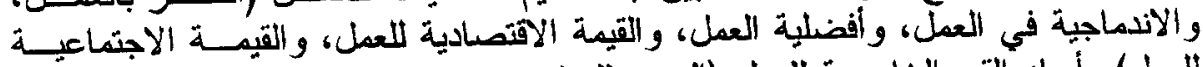

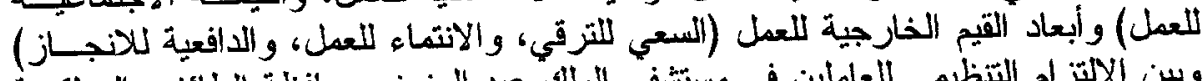

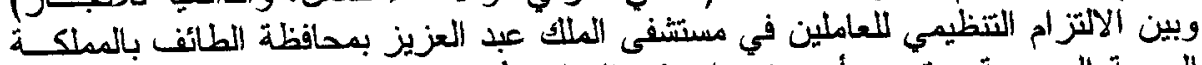

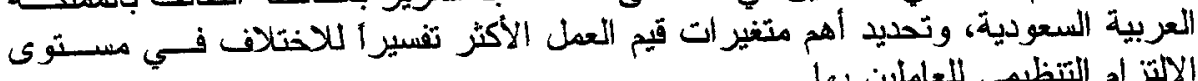
الالتز ام التنظيمي اللعاملين بها.

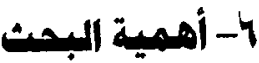

تنبع أهمية البحث في النقاط التالية:

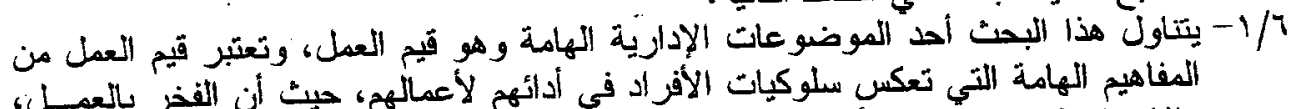

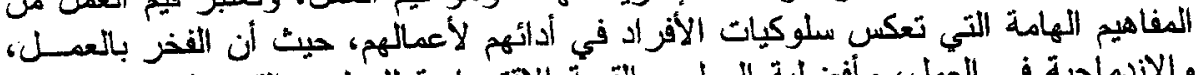

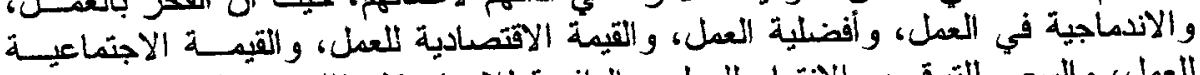

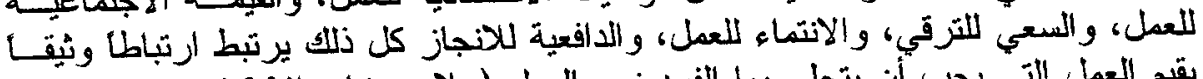

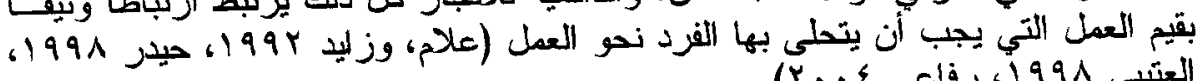

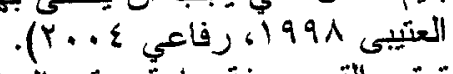

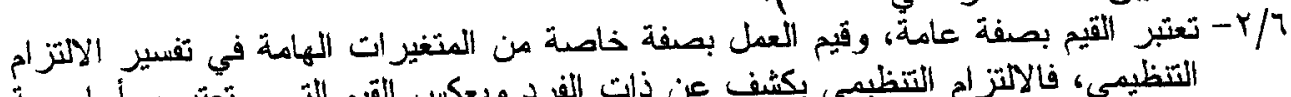

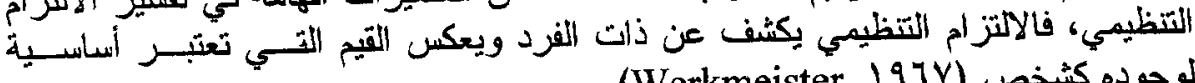
لوجوده كشخص (Werkmeister, 197V).

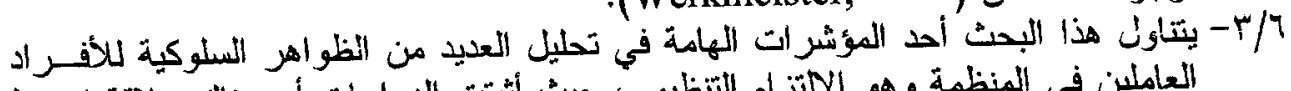

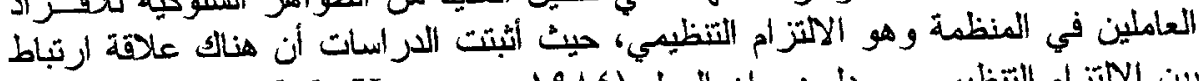

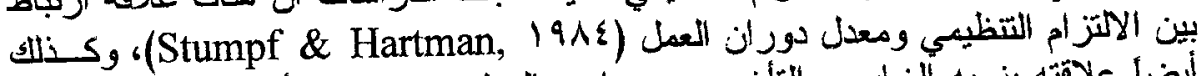

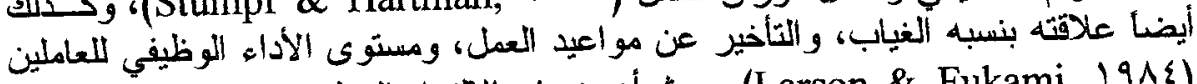

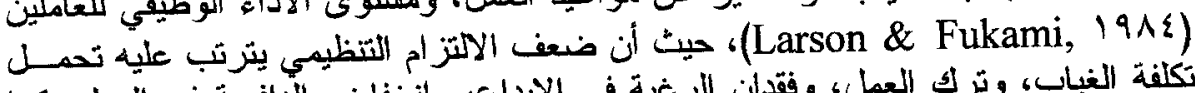

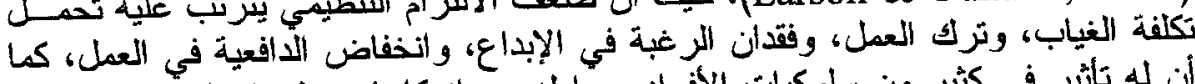

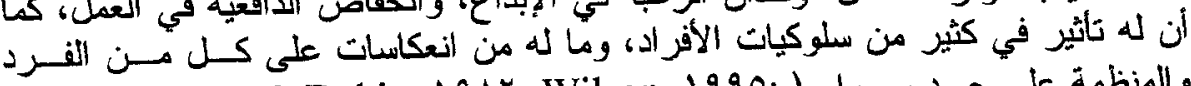

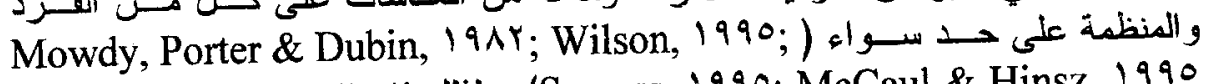
الع (Somers, 1990; McCaul \& Hinsz, 1990

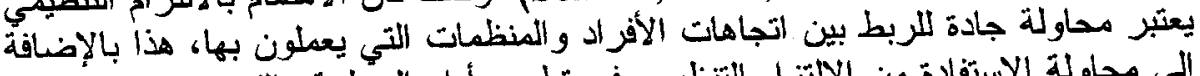

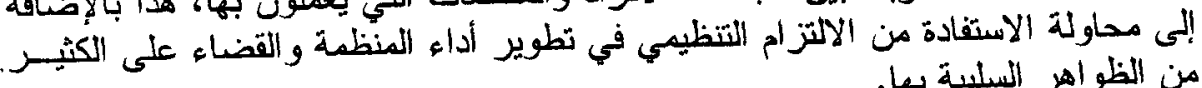
من الظواهر السلبية بها. 


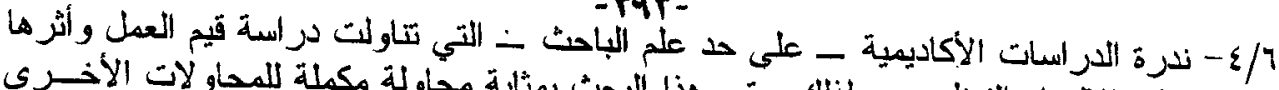

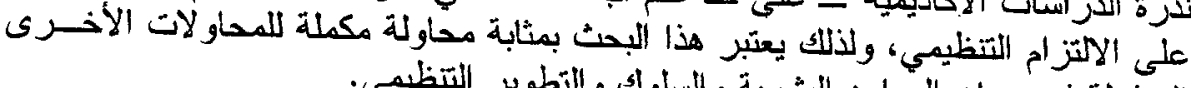

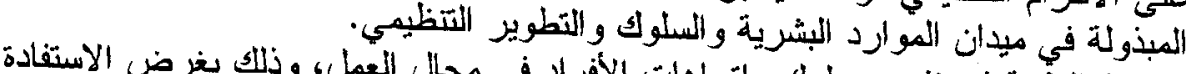

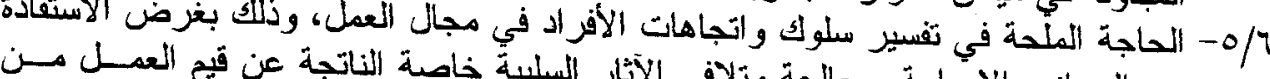

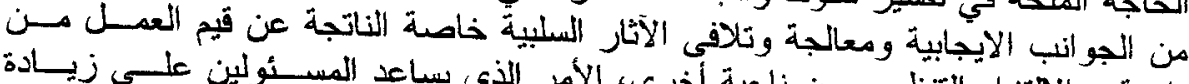

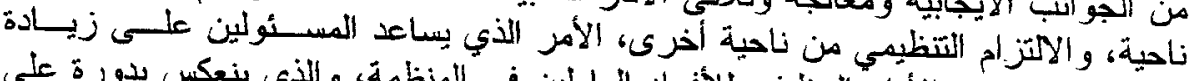

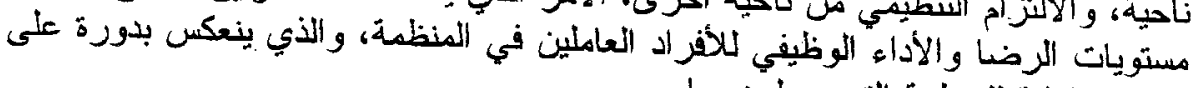

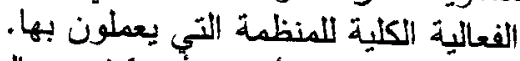

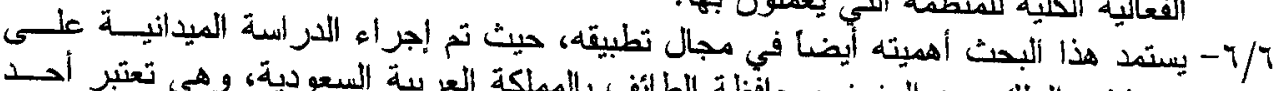

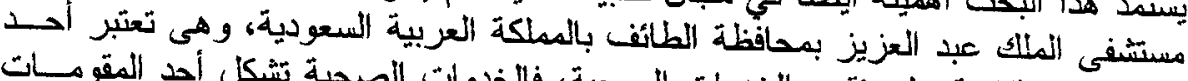

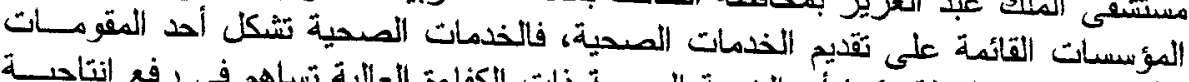

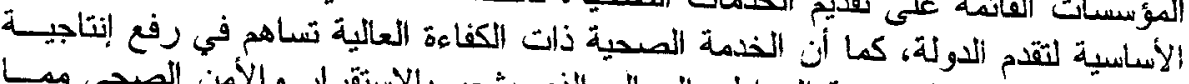

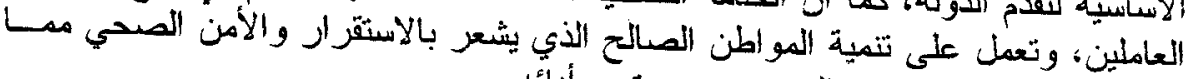

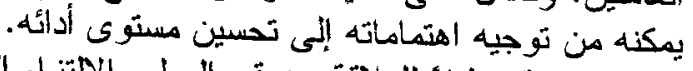

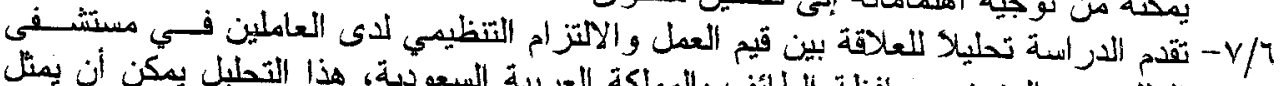

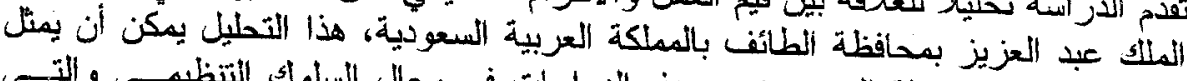

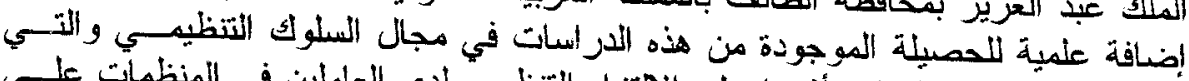

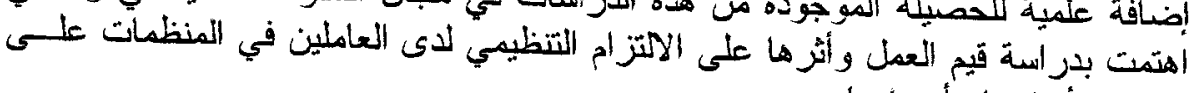
اختلاف أنو اعها و أحجامها.

- هنهـ البحث

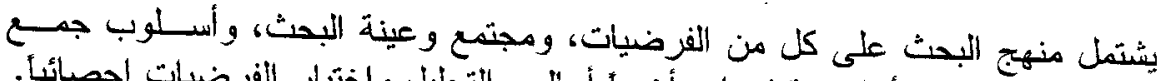

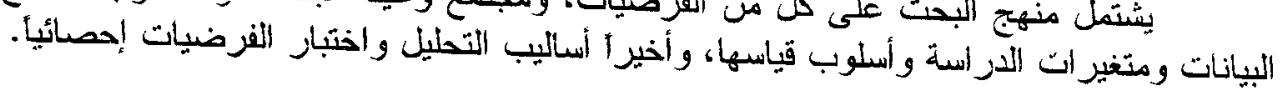

\section{1/ ا فرضيات البمثث}

تم تصميم هذا البحث ليكون موجها بخمسة فرضيات رئيسية تتعلق بكل من الاختلافات

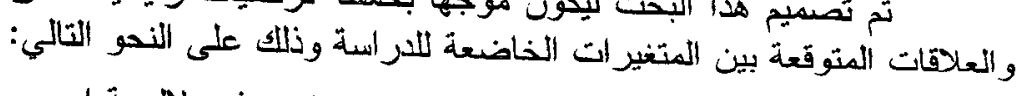

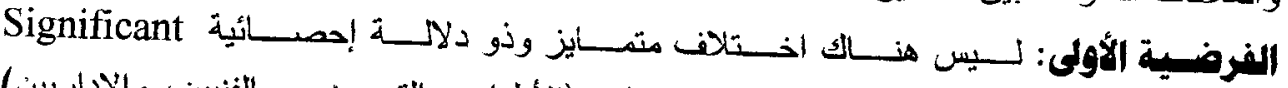
مiscrimination

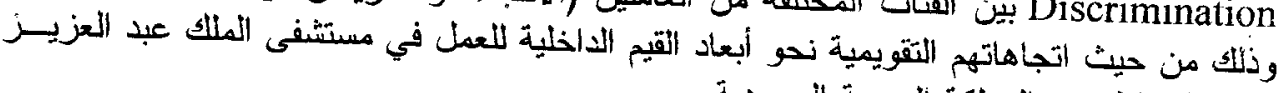
بمحافظة الطائف بالمملكة ألعربية النسعودية.

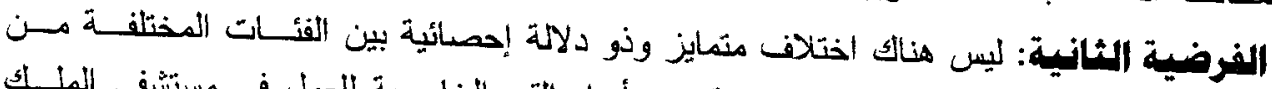

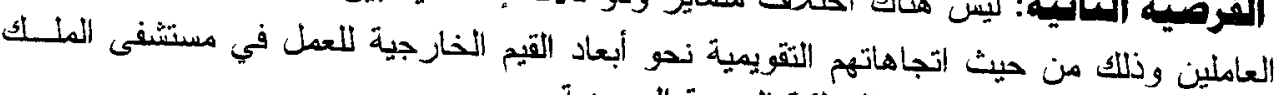

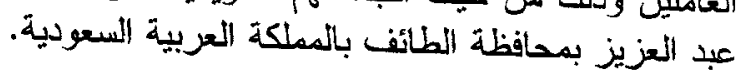

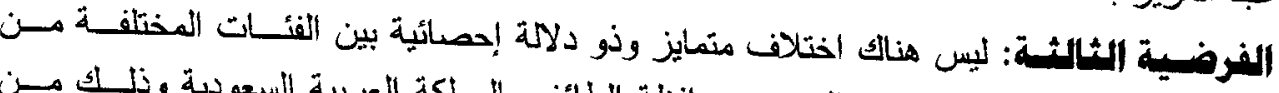

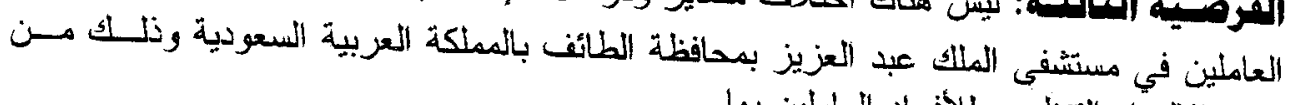
حيث الالتز ام التنظيمي للأفراد العاملين بها.

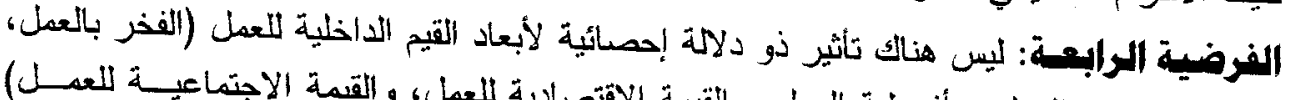

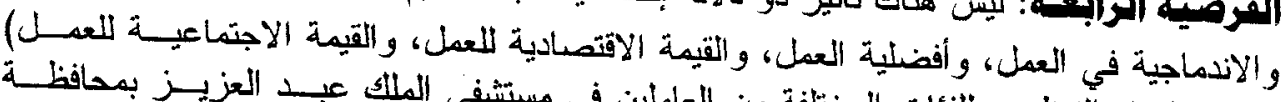

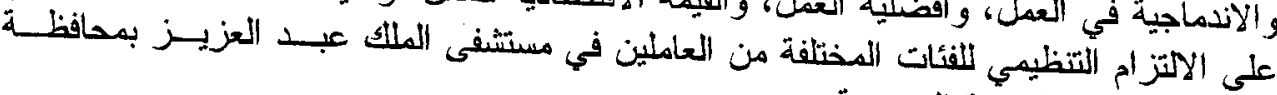
الطائف بالمملكة العربية السعودية. 


\section{- ra\&-}

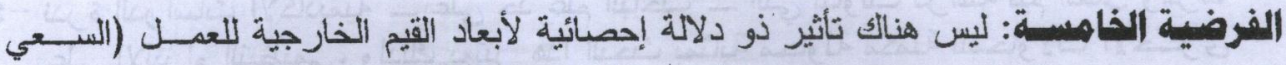

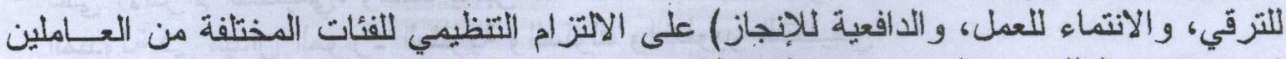
في مستشفى الملك عبد العزيز بمحافظة الطائف بالمملكة العربية اللسعودية.

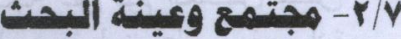

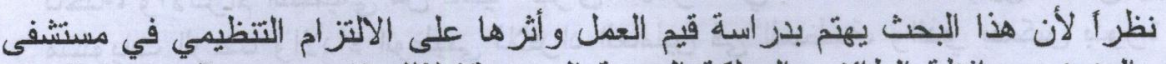

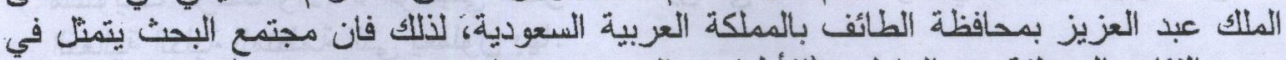

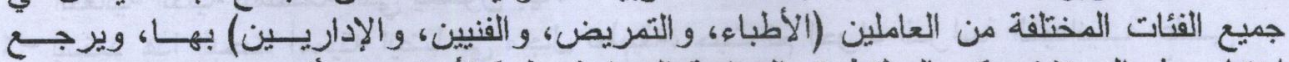

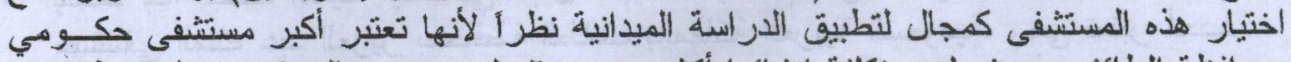

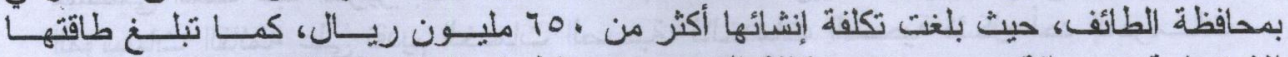

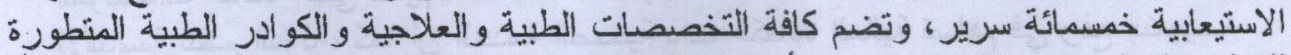

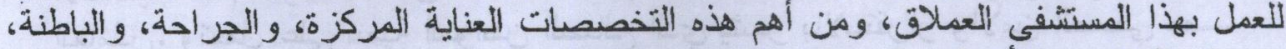

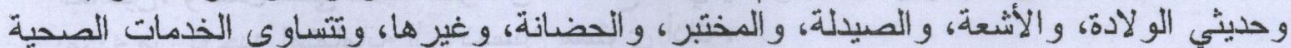

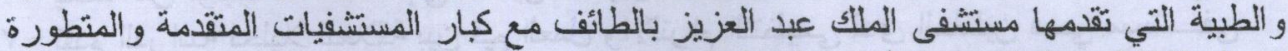

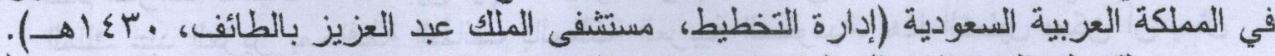

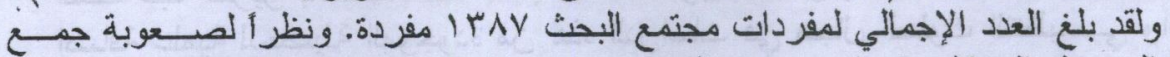

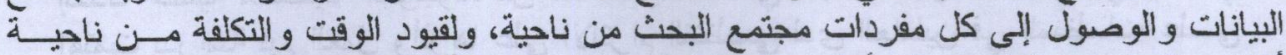

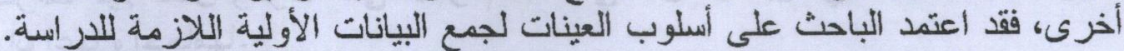

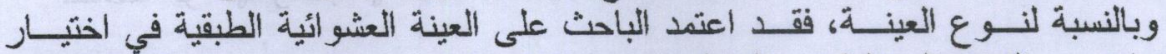

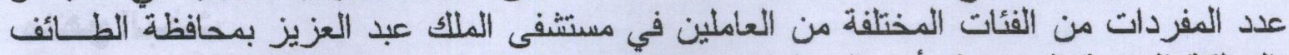

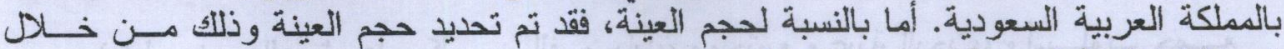
المعادلة التالية (على، وأخرون،

$$
\frac{(-1) \omega \times \dot{0} \times{ }^{r} ت}{(-1) \omega^{r} ت+\dot{u}^{r} \Delta}=\dot{0}
$$

وباستخدام المعادلة السابقة بيضنح أن حجم العينة:

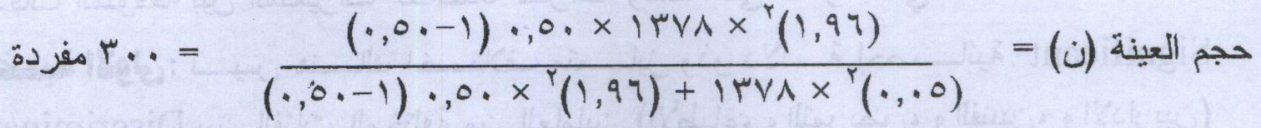

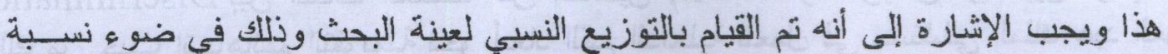

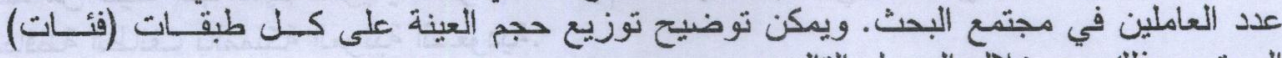
المجتمع وذللك من خلال الجدول التالي ويدي:

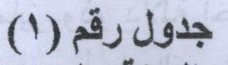

\begin{tabular}{|c|c|c|c|}
\hline 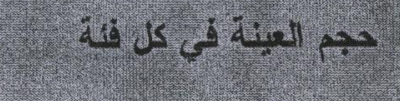 & Eg all & (") suall & Lids ol $\mathrm{a}$ (is) \\
\hline$\exists .=\% Y \cdot \times r+$. & $\%$ r. & rVq & الأطباء \\
\hline $1 r^{\prime}=\% \varepsilon r \times r \ldots$ & $\% \varepsilon r$ & OAY & التمريض \\
\hline$\uparrow+=\% r \cdot \times r \cdot$. & $\%$ \%. & rA. & الفنيين \\
\hline $0 \xi=\% \backslash \wedge \times \mu \ldots$ & $\% \backslash \wedge$ & $r \leqslant 7$ & الإداريين \\
\hline$r+\cdot=n / 01+\cdots \times r \cdot$. & $\% 1$. & Irva & ل \\
\hline
\end{tabular}

توزيع حجم العينة على مجتمع البحث 


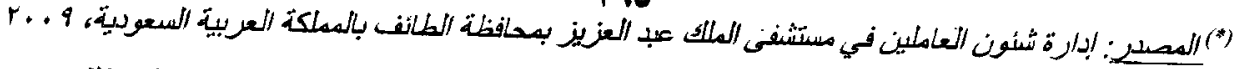

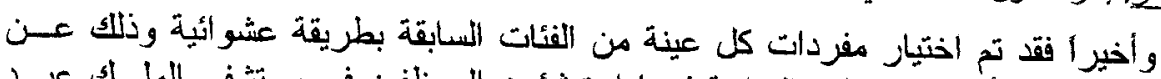

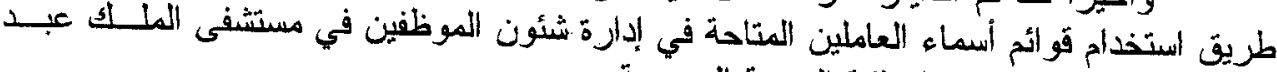
العزيز بمحافظة الطائف بالمملكة العربية السعودية.

r/ أسلوب جمع البيانات

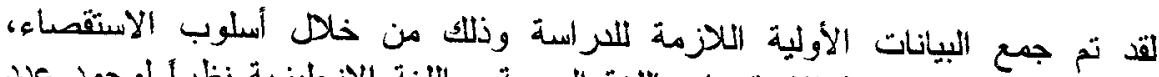

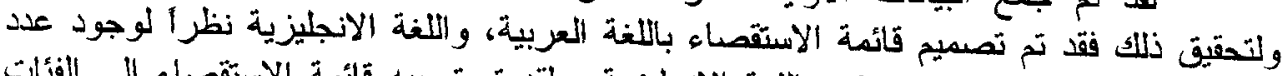

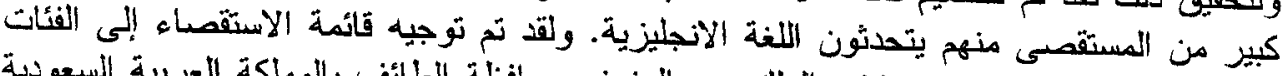

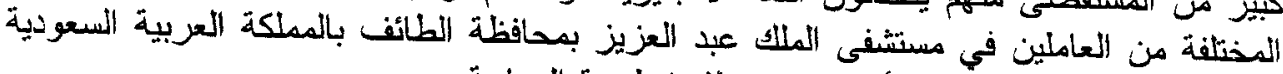

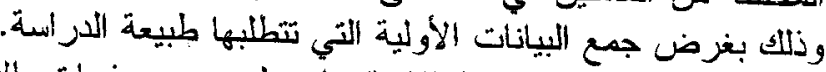

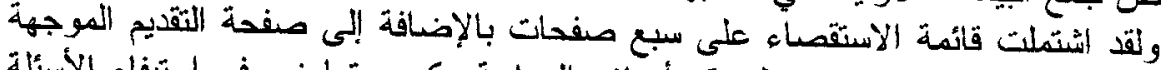

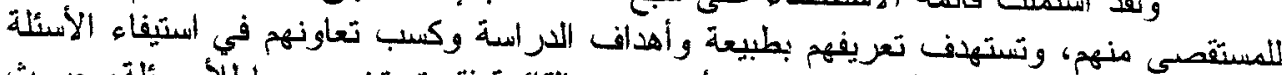

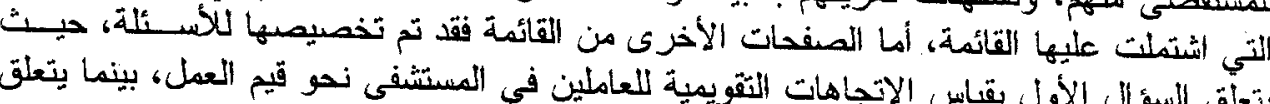

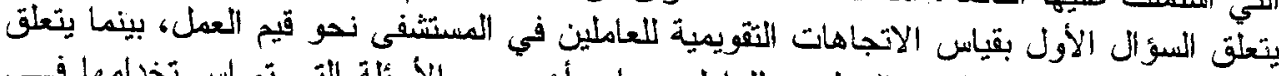

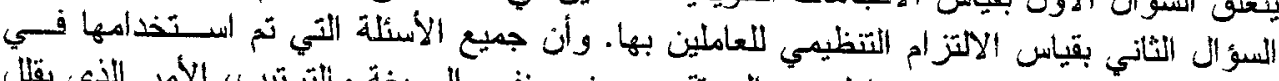

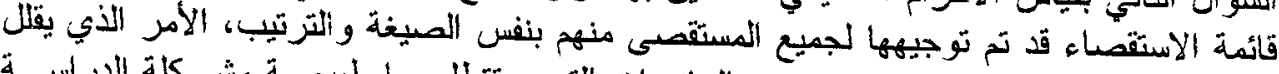

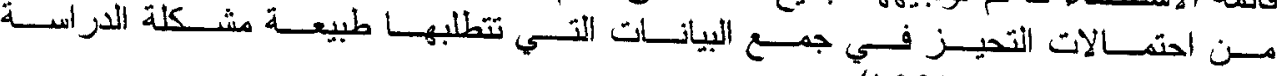

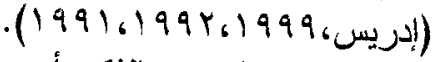

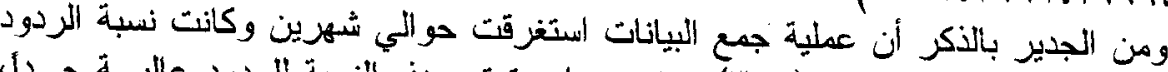

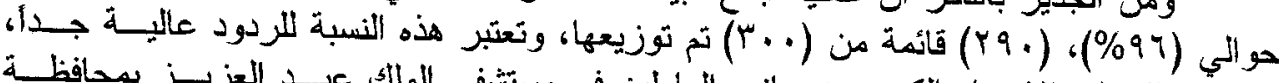

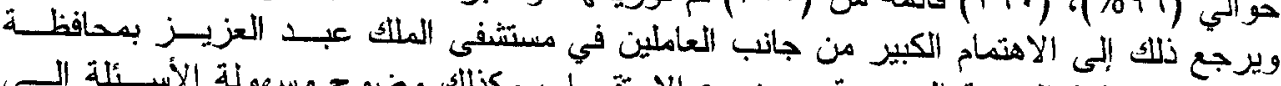

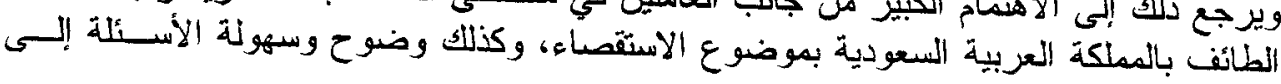
أتنتل عليها الاستقصاء.

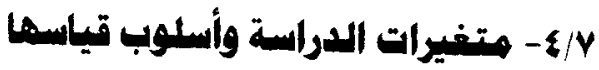

تمثلت متغير ات الدر اسة و المقاييس المستخدمة فيما يلي:

1/\%/V

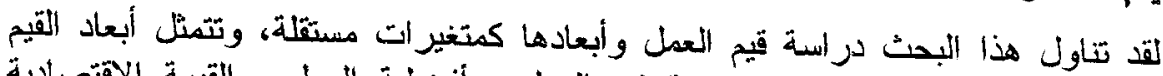

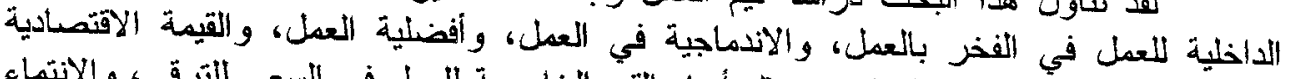

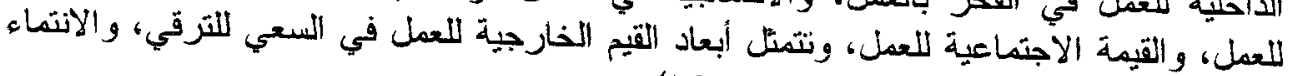

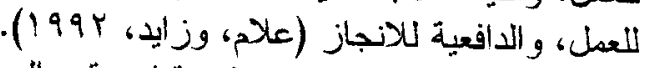

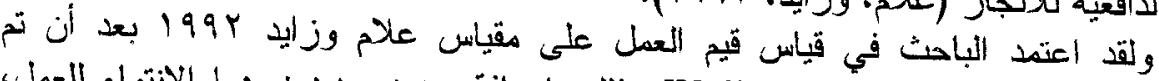

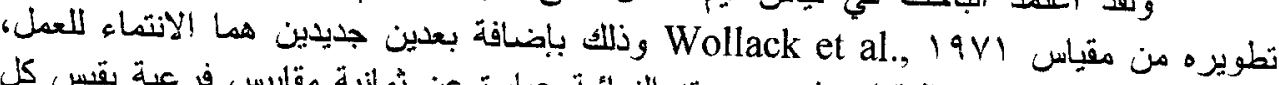

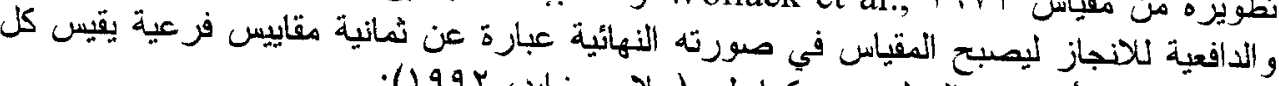

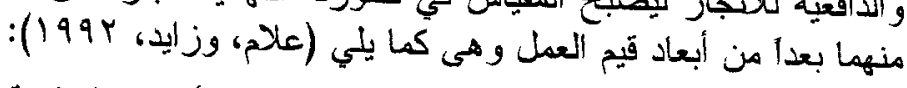

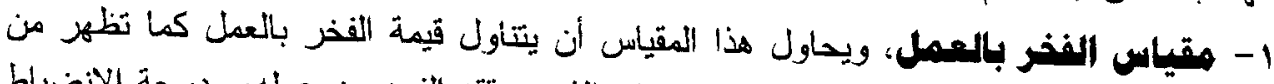

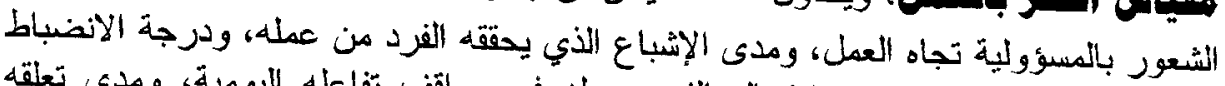

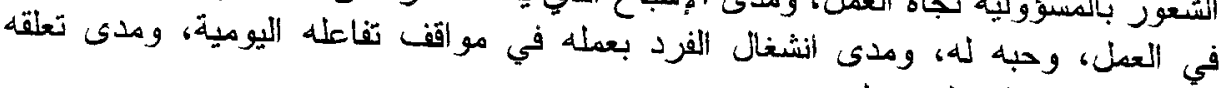
بالرموز التي تلد على على عله ومدي. r- مقياس الاندهاجية في العمل، ويتاول هذا المقياس قيمة الاندهاجية في العمل أو 


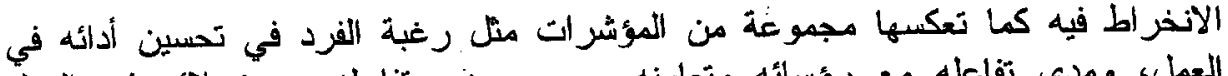

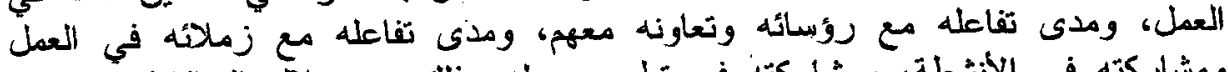

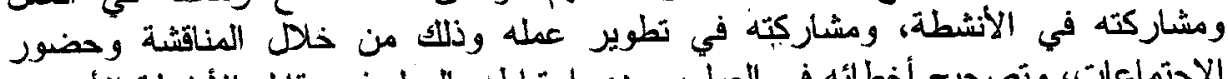

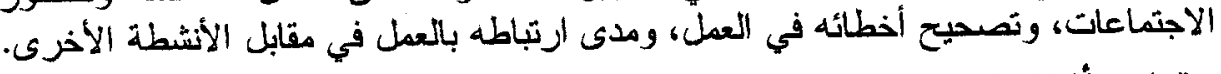

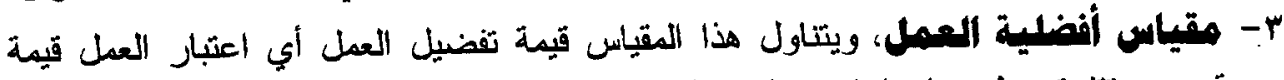

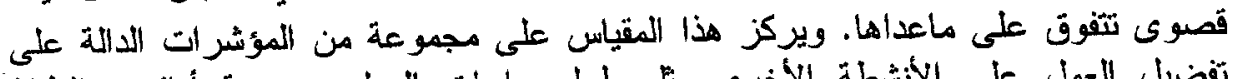

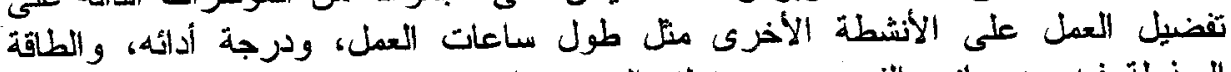

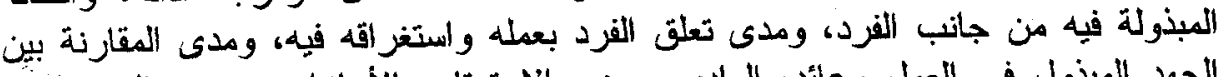

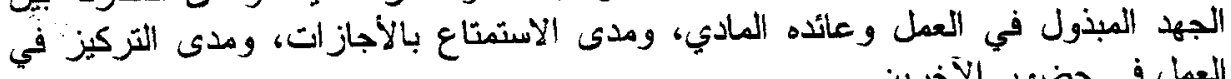
العمل في حضور الآخرين.

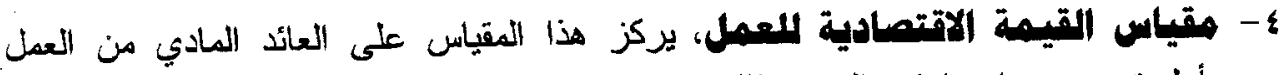

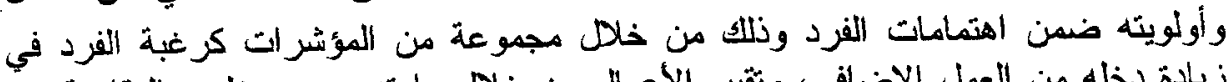

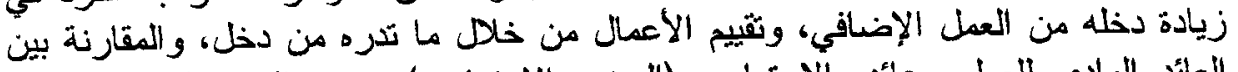

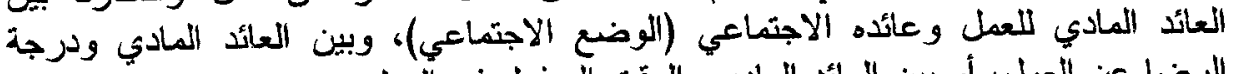

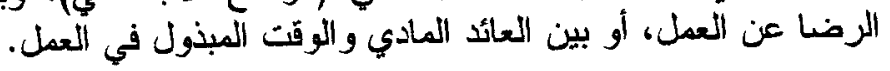

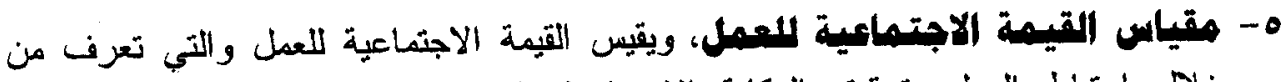

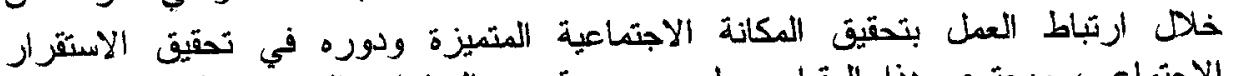

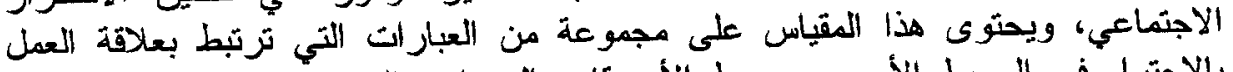

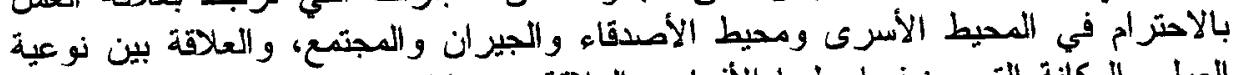

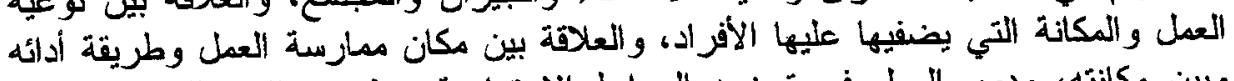

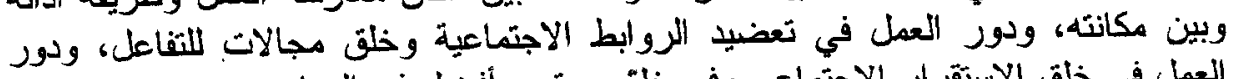

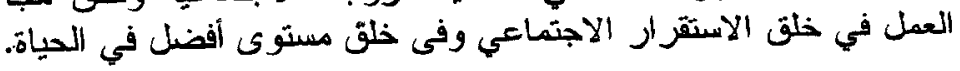

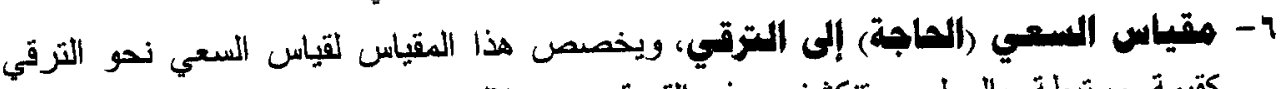

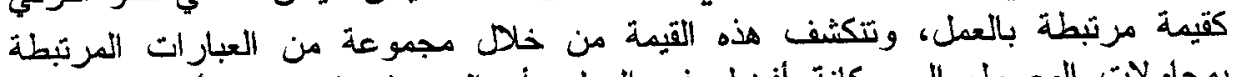

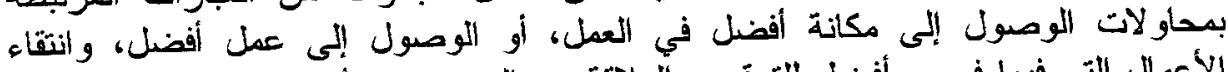

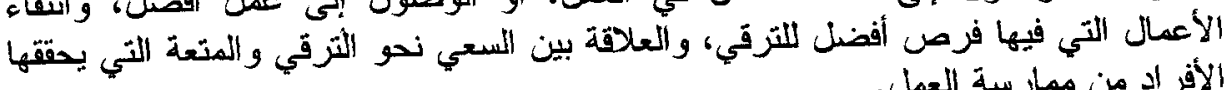

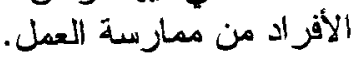

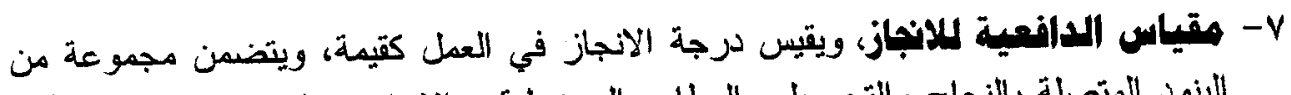

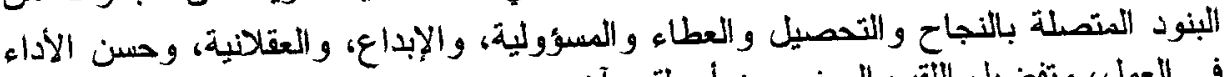

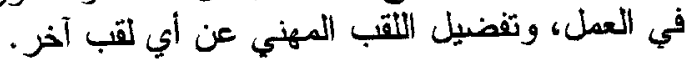

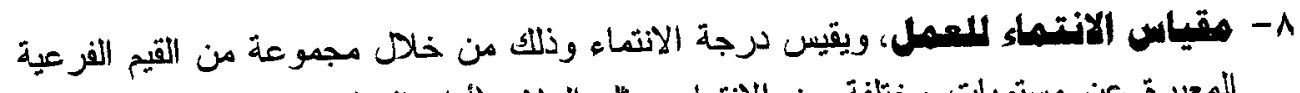

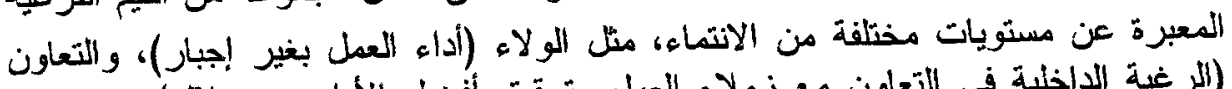

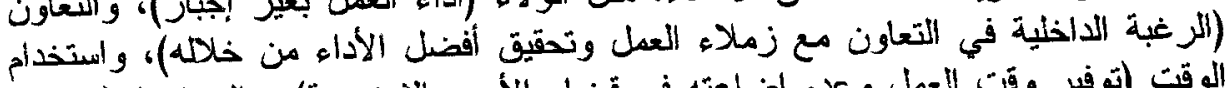

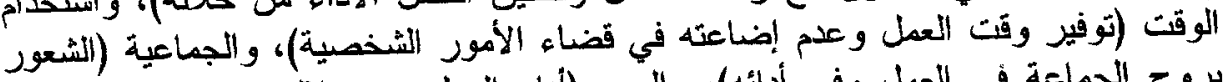

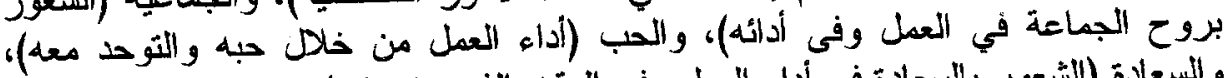

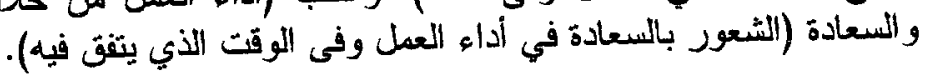

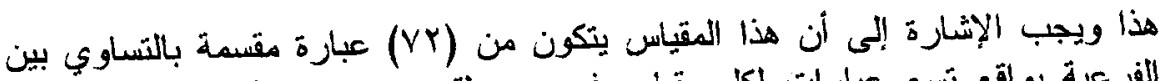

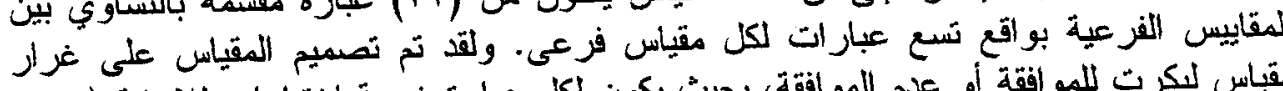

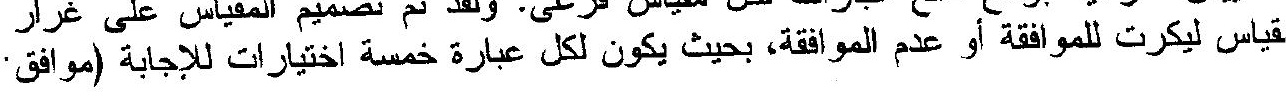




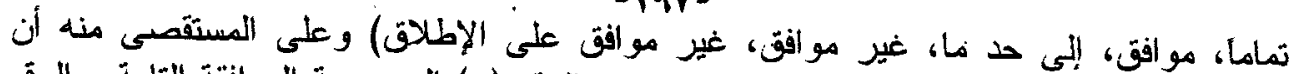

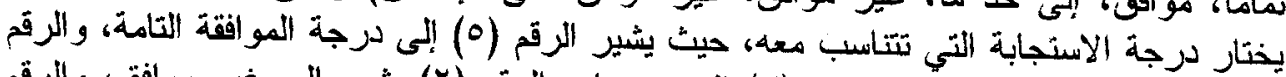

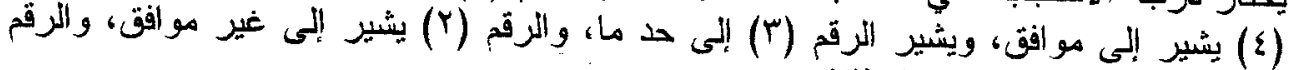
(1) يشير إلى عدم المو أفقة المطلقة.

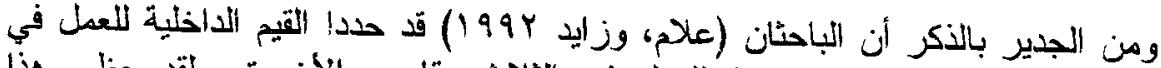

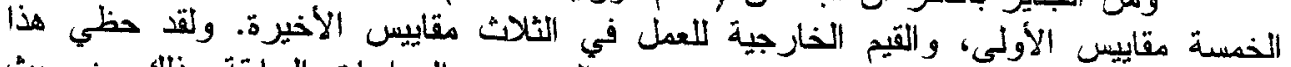

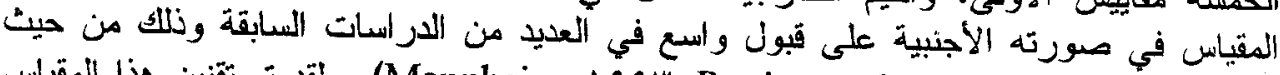

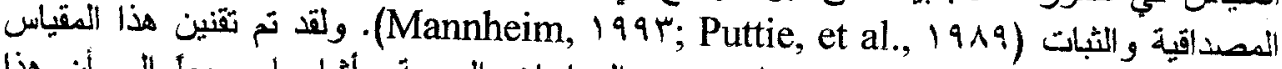

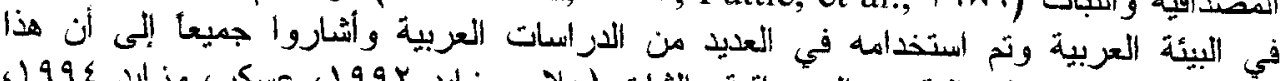

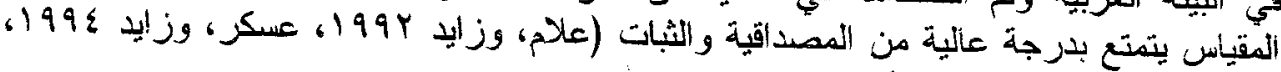

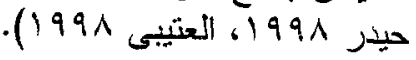

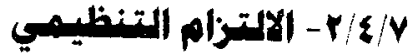

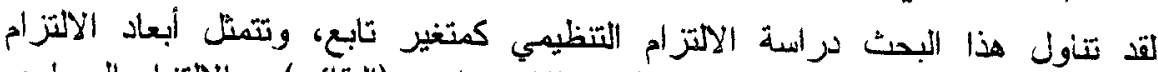

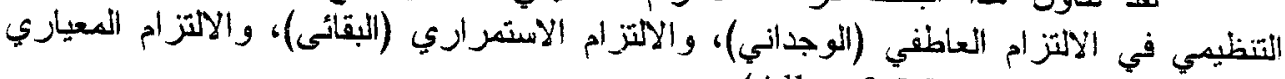
(الأخلاقي) (Allan \& Meyer, 199.)

والقد استخم الباحث المقياس الذي طوره ، Allan \& Meyer, 199 في قياس الالتز ام

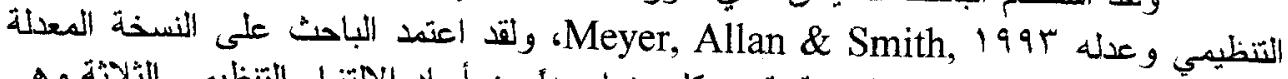

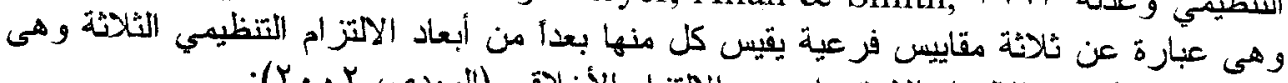

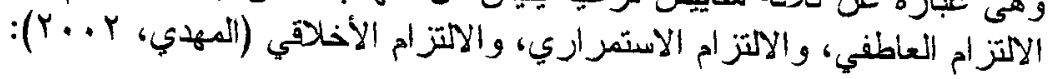

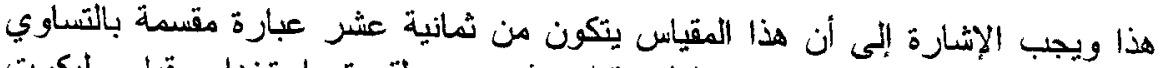

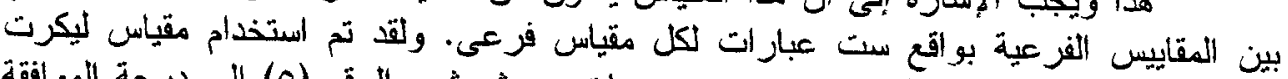

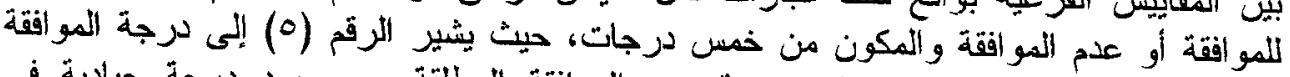

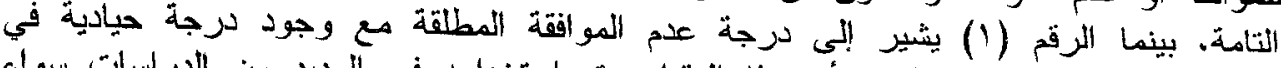

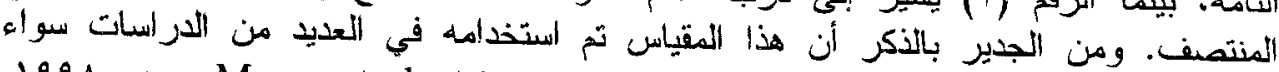

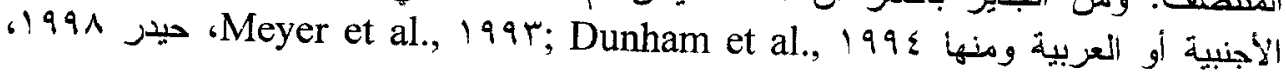

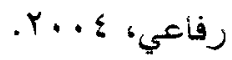

\section{ه/V أساليب تمليل البيانات واختبار الفرضيات}

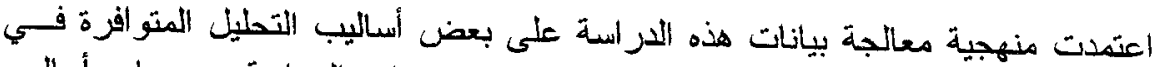

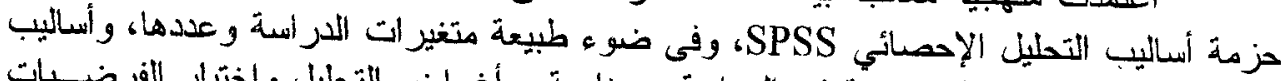

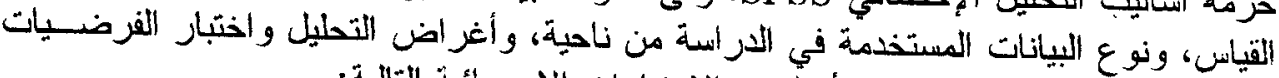

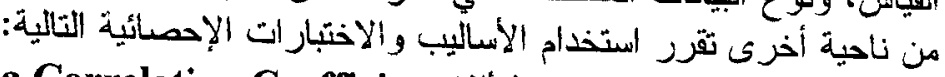

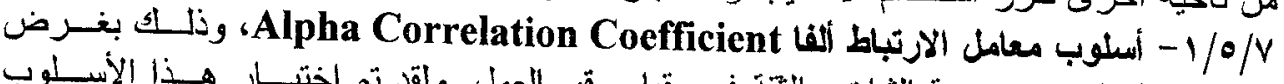

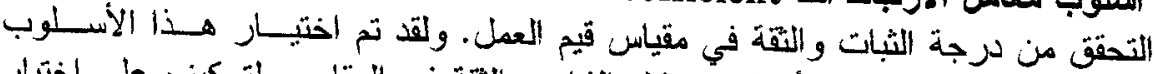

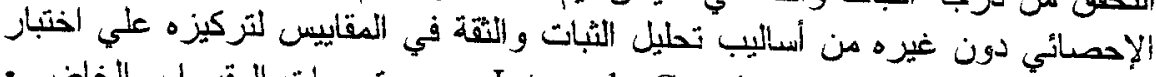

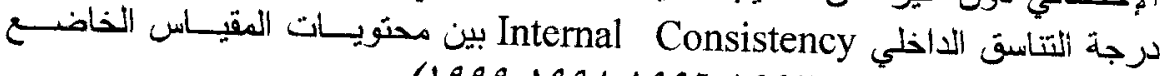

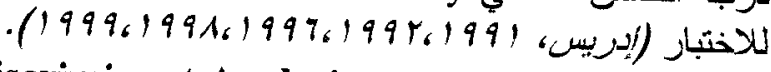

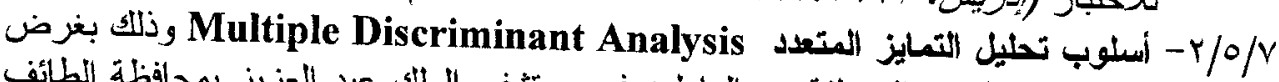
التمييز بين الفئات المختلفة من العاملين في مستشفى الملك عبد العزيز بمحافظة الطائف 
بالمملكة العربية السعودية وذللك من حيث قيم العمل من ناحية، والالتزام التتظيمي مـن ناحية أخرى.

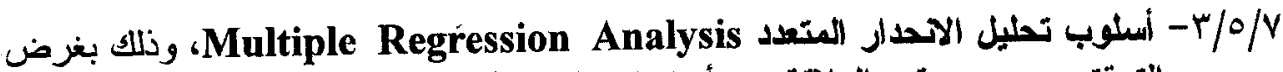

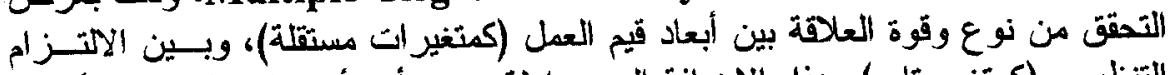

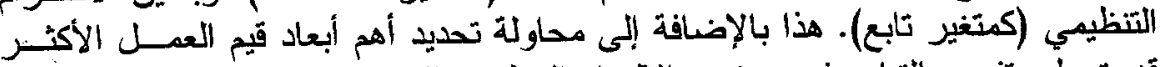

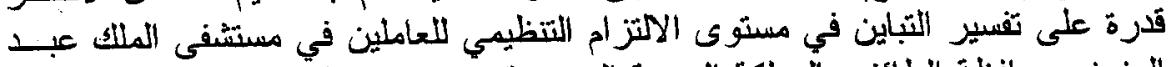
العزيز بمحافظة الطائف بالكملكة العربية السعودية.

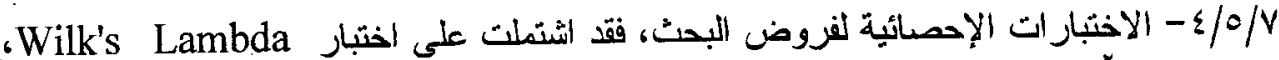

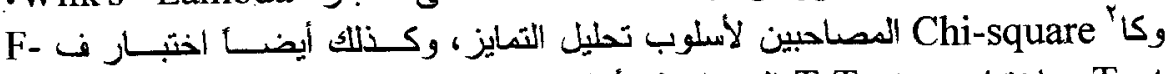

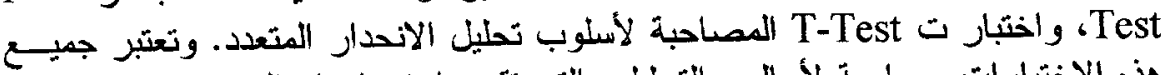

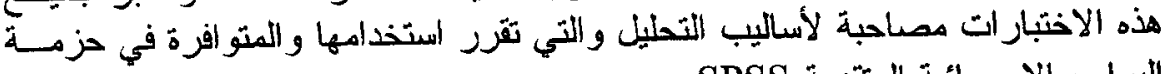

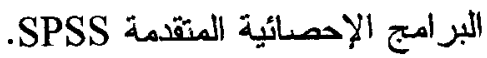

\section{1- ترهيز وتفريغ وتجهيز البيانات لأغراض التصليل}

بعد جمع ومر اجعة البيانات اللازمة و التي تتطلبها طبيعة مشكلة الدراسة وقبل البداء في

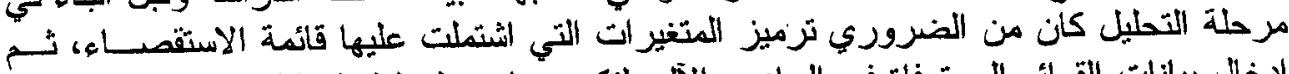

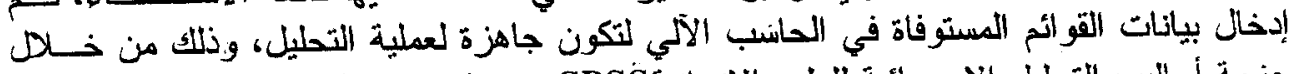

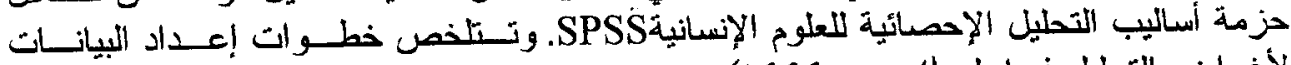

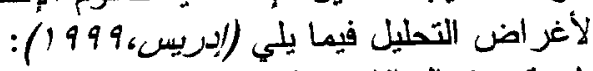

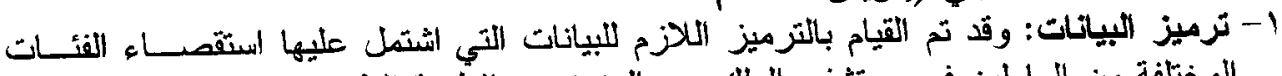

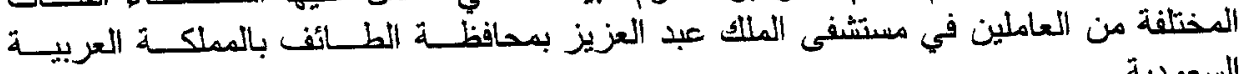

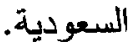

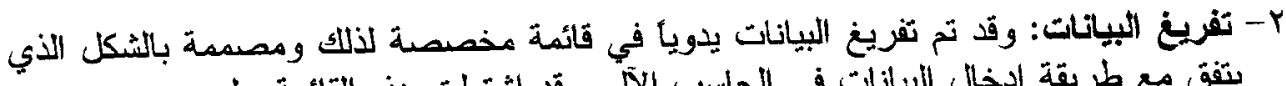

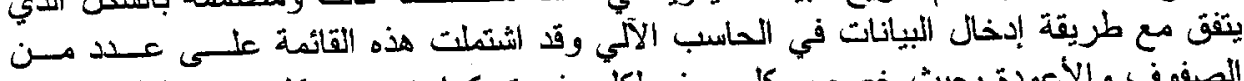

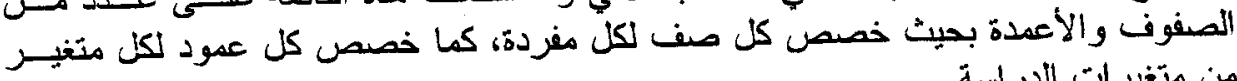

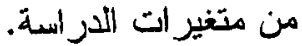

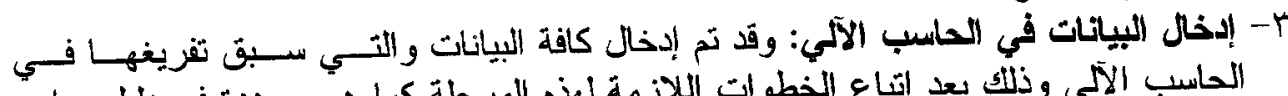

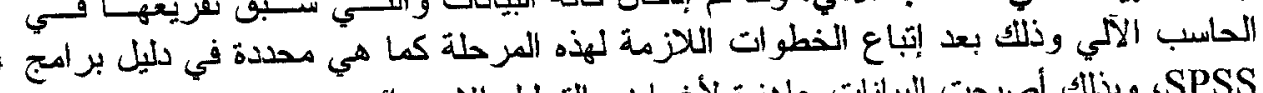

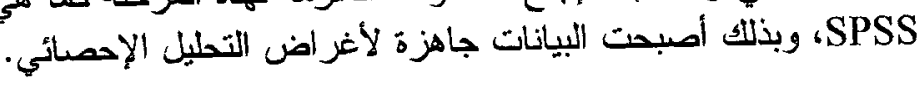




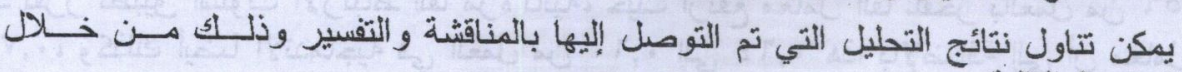

المحاور الرئيسية التالية: 1/9- تقييم الاعتمادية للمقاييس

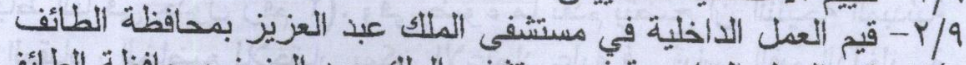

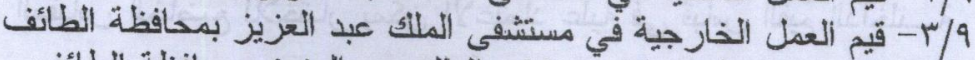

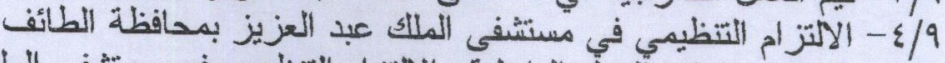

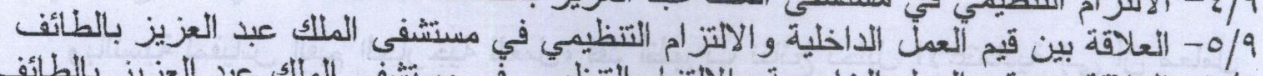

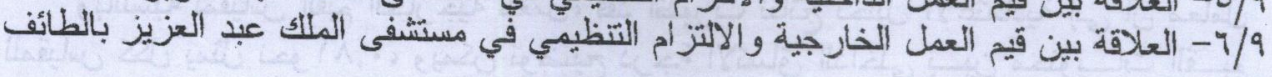

\section{1/9- تقييم الاعتهادية للمقايسيس}

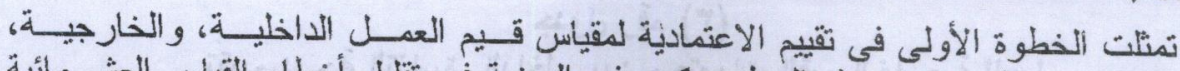

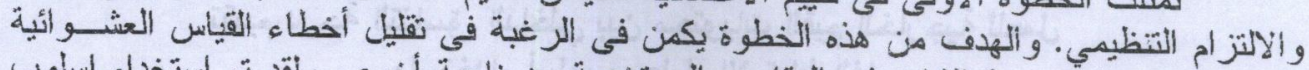

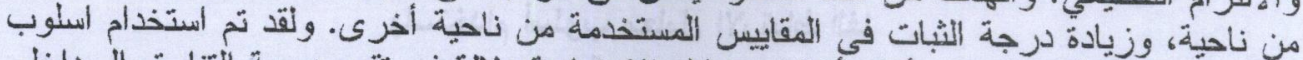

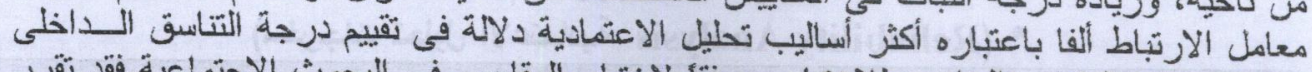

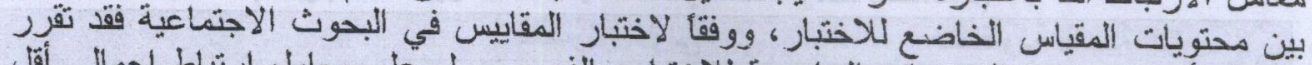

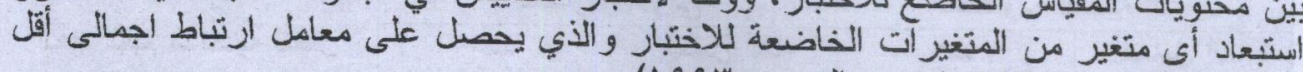

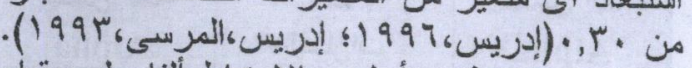

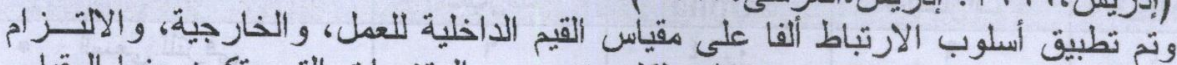

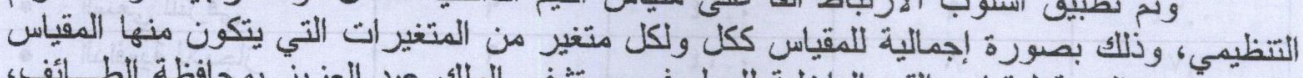

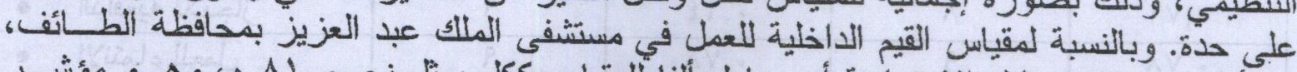

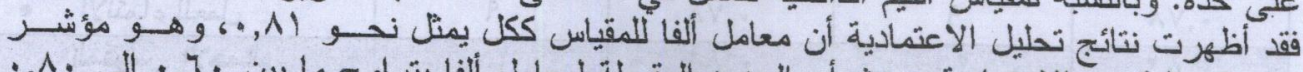

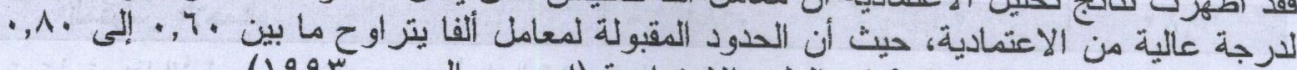

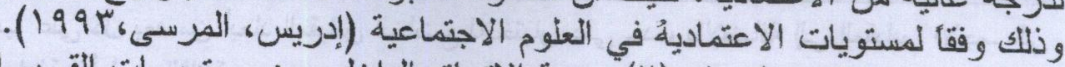

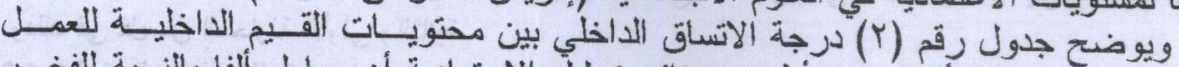

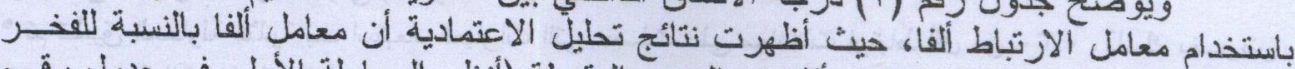

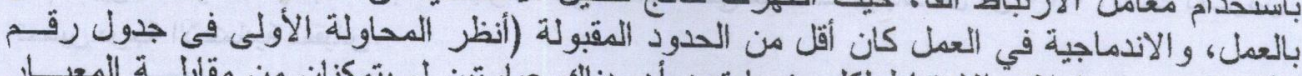

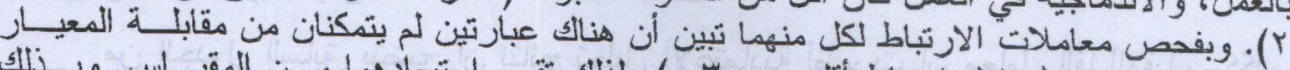

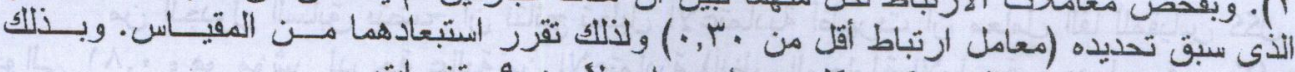

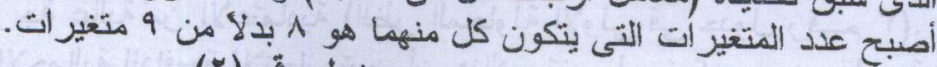

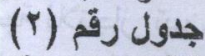

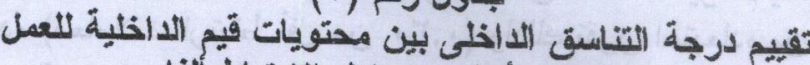

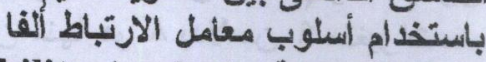

* (Reliability Analysis مخرجات تمليل الإتنمادية )

\begin{tabular}{|c|c|c|c|c|c|}
\hline \multicolumn{2}{|c|}{ 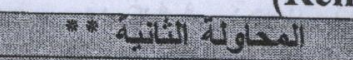 } & जी & (i & \multirow{2}{*}{\multicolumn{2}{|c|}{ 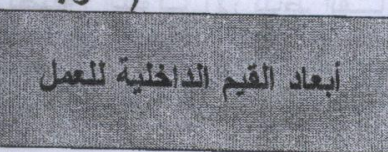 }} \\
\hline $\begin{array}{l}\text { Wi Joles } \\
\text { Alpha }\end{array}$ & 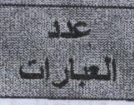 & $\begin{array}{l}\text { Lai Lales } \\
\text { Alpha }\end{array}$ & 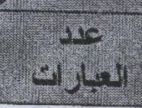 & & \\
\hline$\cdot, \times 1$ & $\Lambda$ &., 07 & 9 & الفخر بالعهل & - \\
\hline$\cdot, 7 \varepsilon$ & $\Lambda$ & $\cdot, 7$ & 9 & الاندماجية في العمل & - \\
\hline$\cdot, 7 \pi$ & 9 & $\cdot, 4 \pi$ & 9 & أفضلية العمل & $\bullet$ \\
\hline$\cdot, \mathrm{\vee} 9$ & 9 & $\cdot, 199$ & 9 & القيمة الاقتصادية للعمل & $\bullet$ \\
\hline$\cdot, 7 \pi$ & 9 & $\cdot, 7 T$ & 9 & القبمة الاجنماعية للعكل & $\bullet$ \\
\hline$\frac{, A r}{\square}$ & $\xi^{4}$ & $\therefore, \mathrm{AI}$ & 50 & 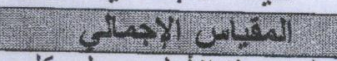 & \\
\hline
\end{tabular}




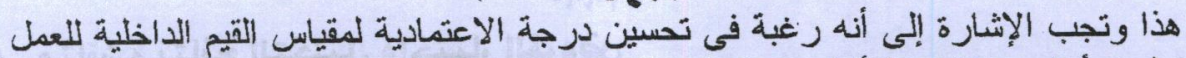

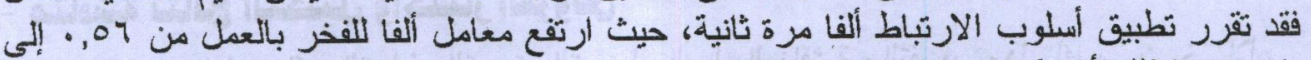

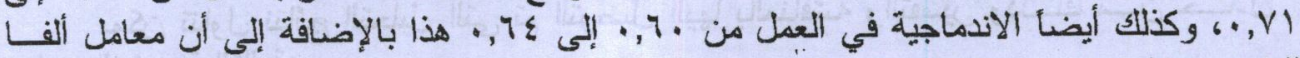

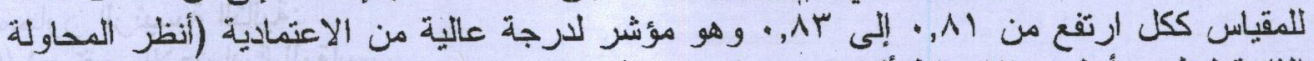

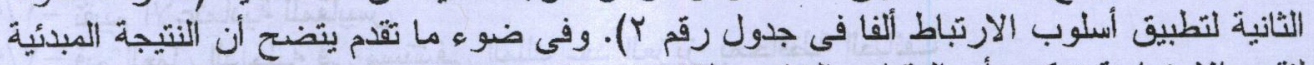

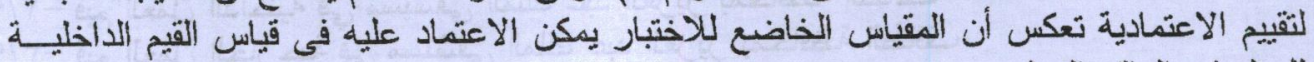
لالعمل في الو اقع العملي. وبالثنبة لمقياس القيم الخارجية للعمل، فقد أظهرت نتائج تحليل الاعتمادية إلى أن معامل

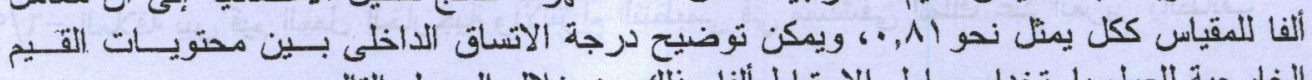

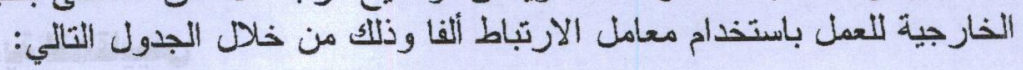

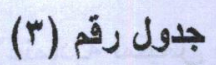

تقييم درجة التناسق الإخلي بين محتويات القيم الخارجية للعمل

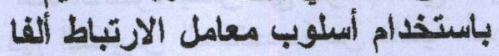

* (Reliability Analysis مخرجات تحليل الاعتمادية الاربية

\begin{tabular}{|c|c|c|c|c|c|}
\hline \multicolumn{2}{|c|}{ 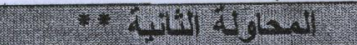 } & \multicolumn{2}{|c|}{ जुशा सुप्या } & & \\
\hline if dole & ise & Wil chen & 130 & 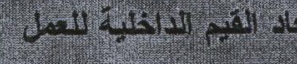 & \\
\hline Alpha & ألمبار ات & Alpha & 4 & & \\
\hline., $7 \varepsilon$ & 9 & $\cdot, 7 \varepsilon$ & 9 & السعي للترقي & $\cdot$ \\
\hline$\cdot, V_{1}$ & $\wedge$ & $\cdot, 7 \varepsilon$ & 9 & الدافعية للانجاز & - \\
\hline$\cdot, \mathrm{VA}$ & 9 & $\cdot, \mathrm{VA}$ & 9 & الانتماء للعمل & $\bullet$ \\
\hline.,$\lambda r$ & 18 & 0,11 & IV & Mall & \\
\hline
\end{tabular}

* تم تطبيق هذا الأسلوب على كل بعد من أبعاد المقياس الخاضع للاختبار على حده، بالإضافة إلى المقياس الاجمسالى

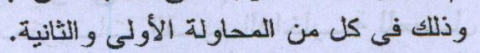

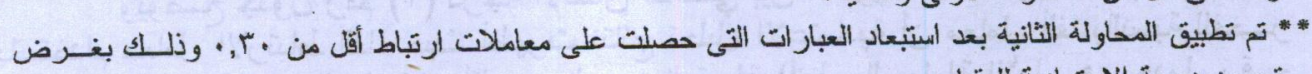
تحسين درجة الاعتمادية للمقياس.

من الجدول السابق يتضح أن نتائج تحليل الاعتمادية أظهرت أن الن معامل ألفا للإقياس ككل

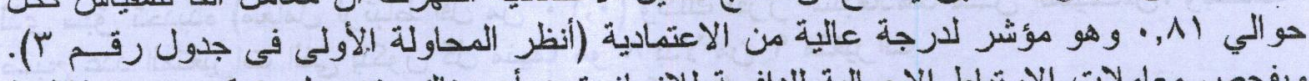

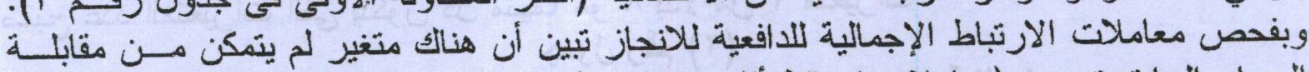

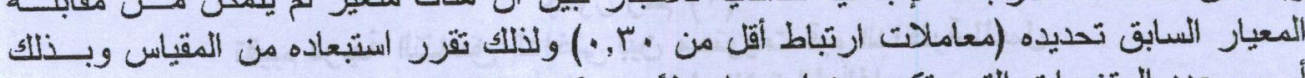

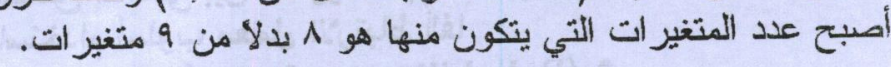

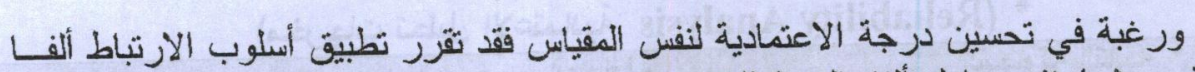

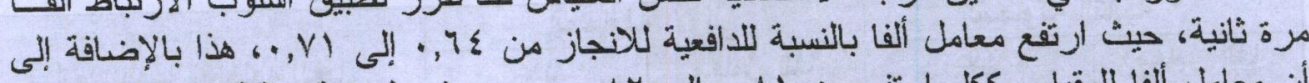

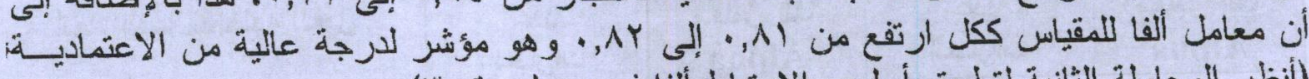

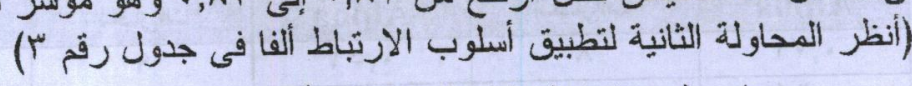

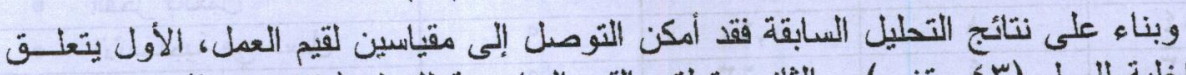

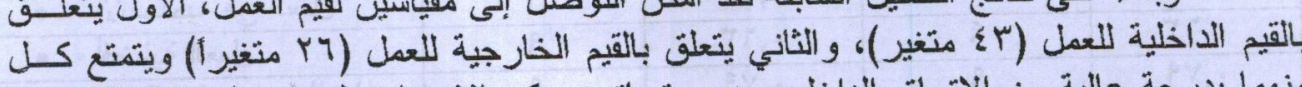

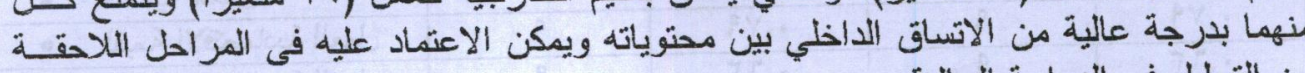

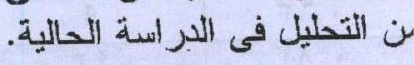


ولقد تم تطبيق أسلوب الارتباط ألفا على مقياس الالتز ام التنظيمي، وذلك بصورة إجمالية

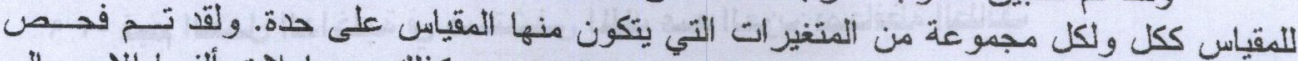

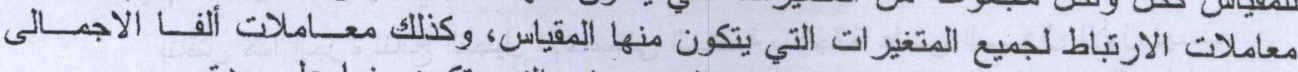

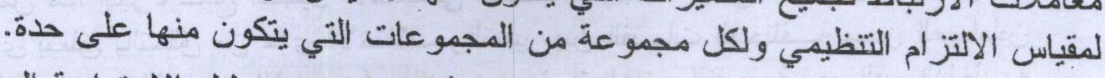

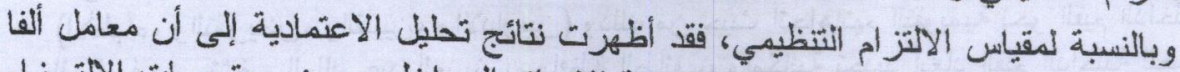

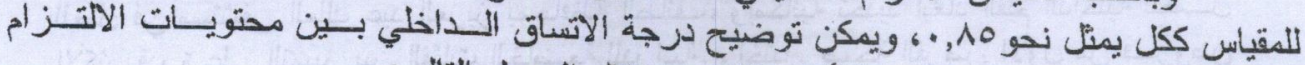

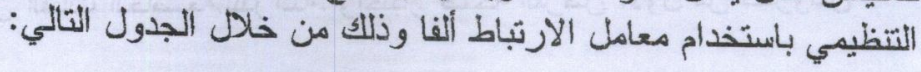

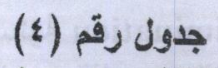

تقيبم درجة التناست الداخلي بين معتويات الألتزام التنظيمي

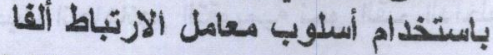

* (Reliability Analysis مخرجات تحليل الاعتمادية)

\begin{tabular}{|c|c|c|c|c|c|}
\hline \multicolumn{2}{|c|}{ 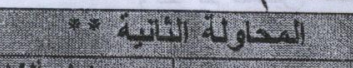 } & \multicolumn{2}{|c|}{ पुरास्या } & & \\
\hline bit Joles & 14 & Lit diles & $=$ & & \\
\hline Alpha & 4 Lueli & Alpha & t) thet & & \\
\hline$\cdot, \wedge Y$ & 7 & $\cdot, \wedge Y$ & 7 & الالتز لم العاطفي & - \\
\hline$\cdot, 74$ & 0 & $\cdot, 7 \varepsilon$ & 7 & الالتزز ام الاستمر اري & - \\
\hline$\cdot, \sqrt{9}$ & - & $\cdot, \mathrm{VV}$ & 1 & الالتز ام الأخلاقي & $\cdot$ \\
\hline 2,14 & 114 & 1,10 & $\sqrt{11}$ & 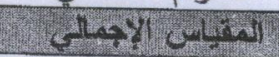 & \\
\hline
\end{tabular}

* تم تطبيق هذا الأسلوب على كل بعد من أبعاب المقياس الخاضع للاختبار على حده، بالإضافة إلى المقياس الاجمـالى ولى

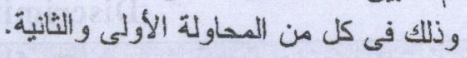

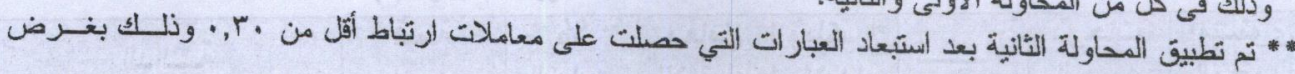
تدسين درجة الاعتمادية للمقياس.

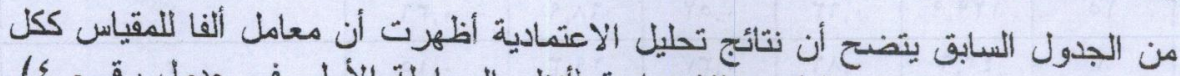

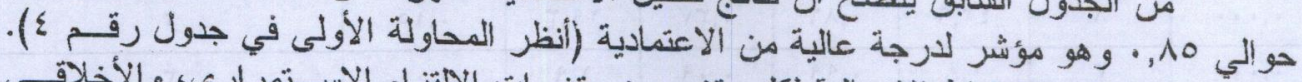

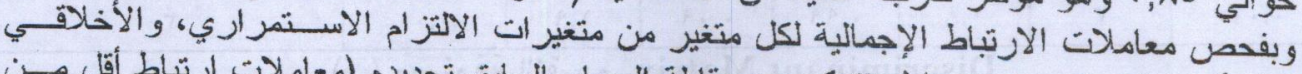

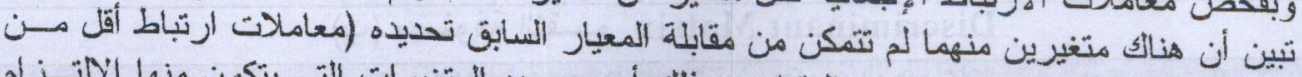

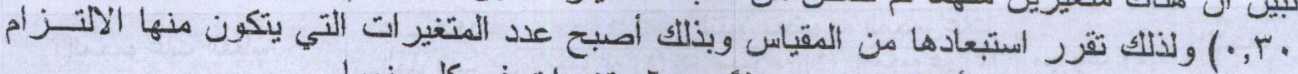

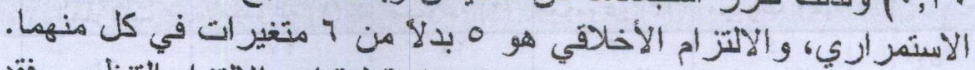

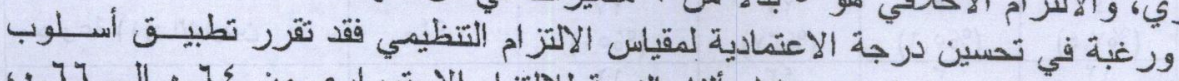

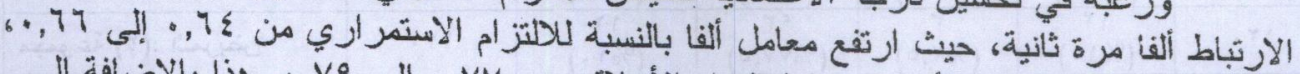

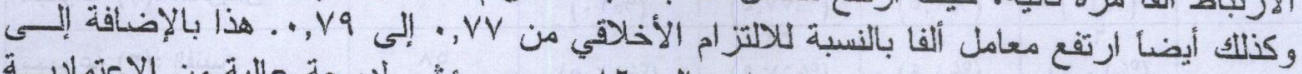

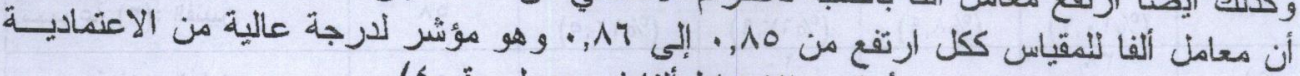

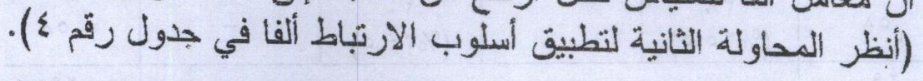

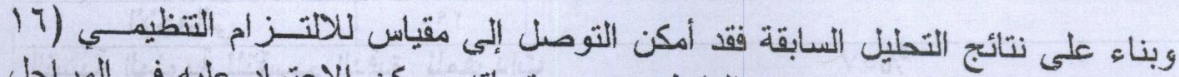

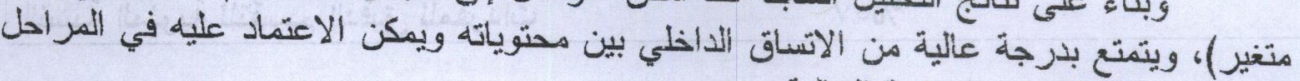
اللاحقة من التحليل في الدرابة والية الحالية. 


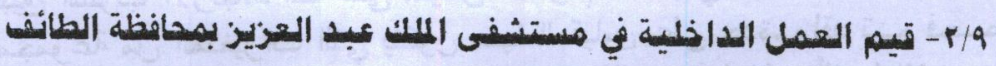

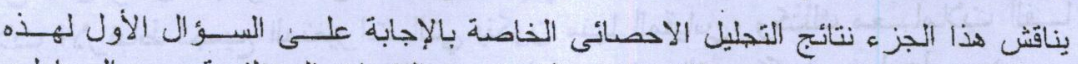

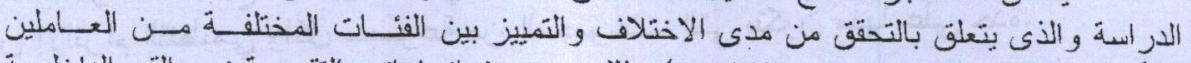

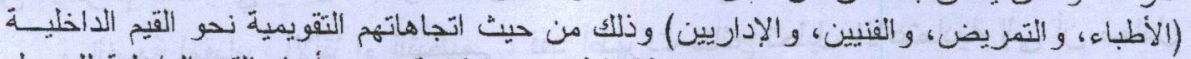

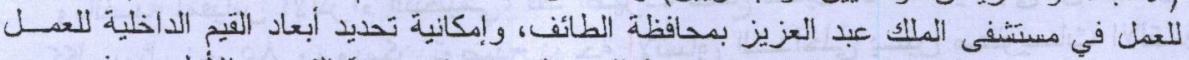

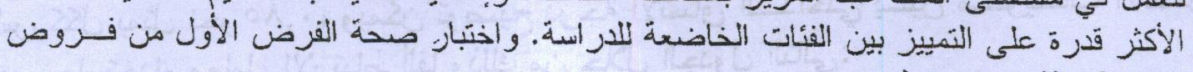

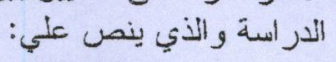

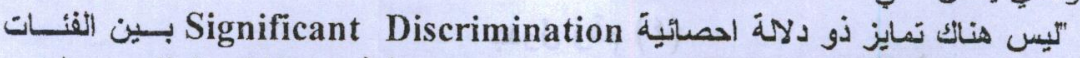

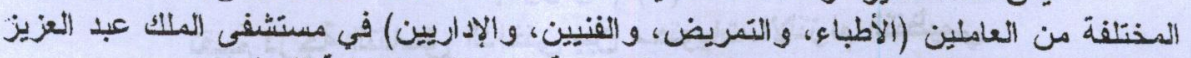

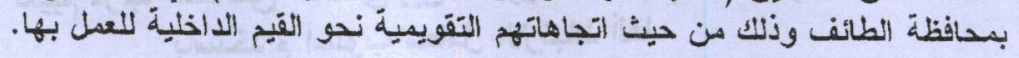

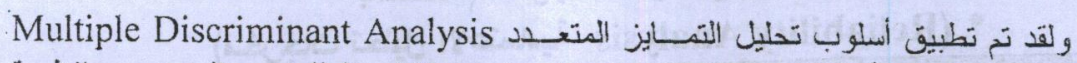

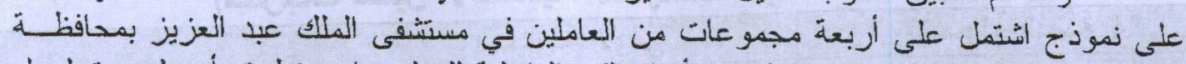

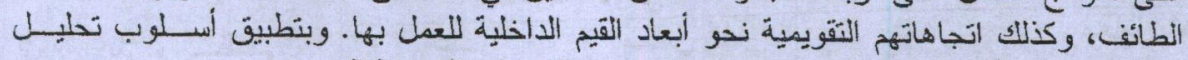

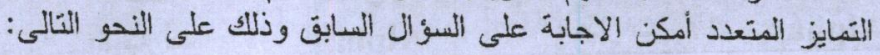

أ- دوال تحليل التصايز المتعدد ومصفوفة التقسيم على أساس القيم الأخلية للعنل

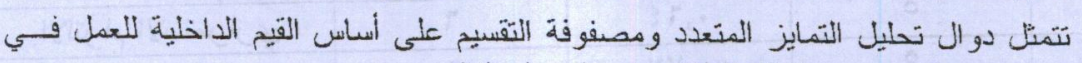

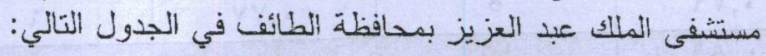

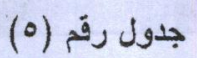

دوال تحليل التمايز المتعدد ومصفوفة التقسيم بين العاملين على أساس القيم الداخلية للعهل

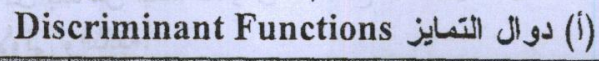

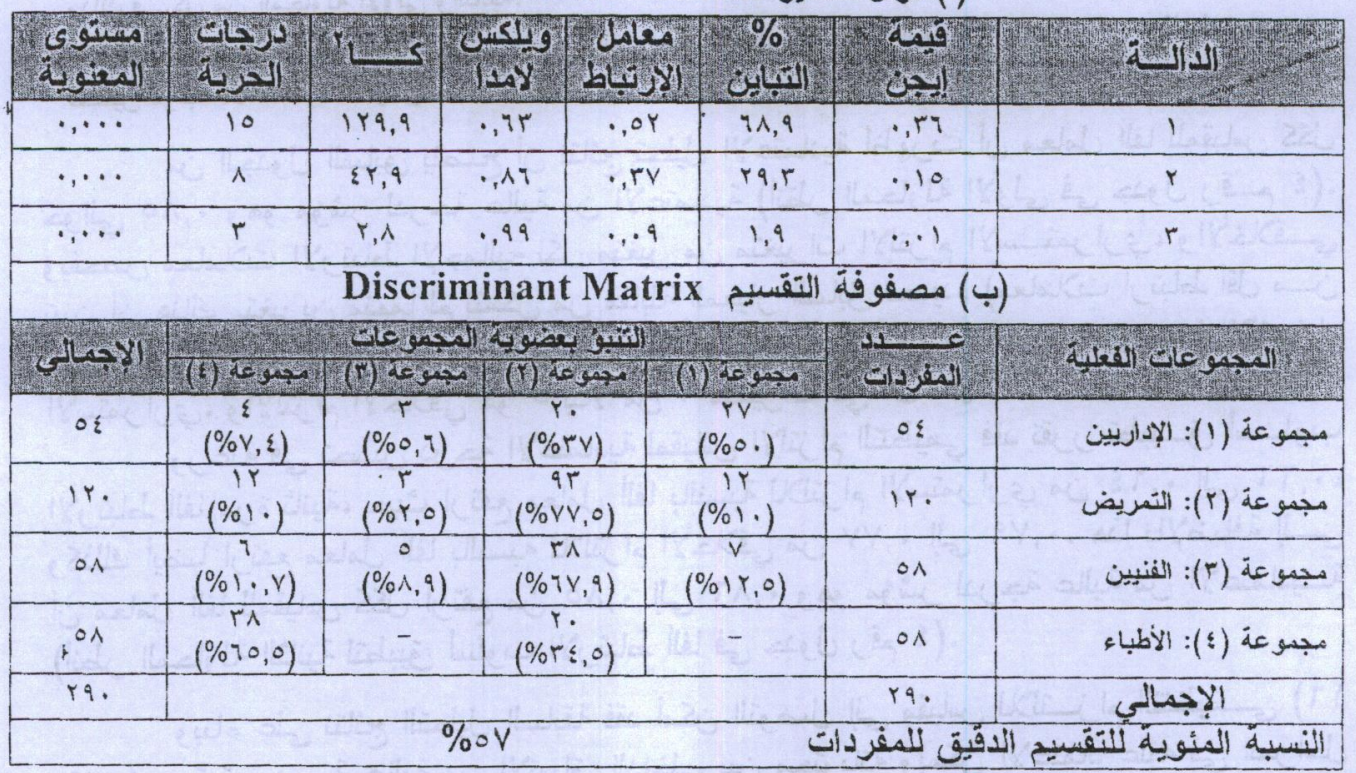




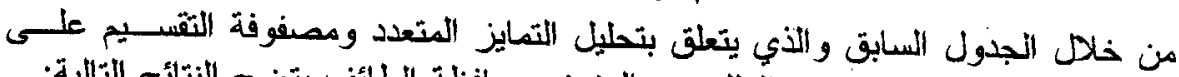

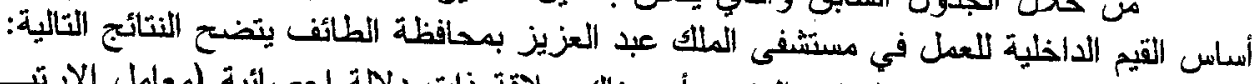

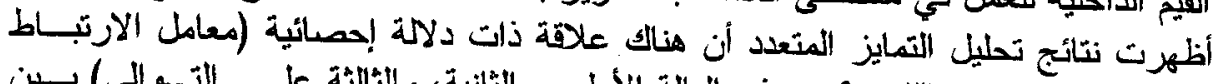

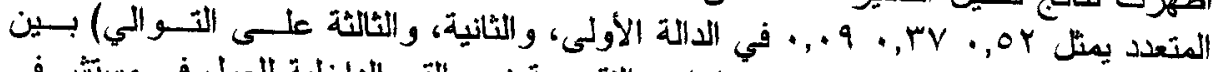

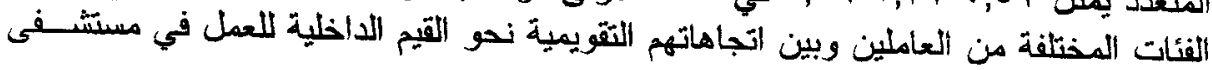
الملك عبد العزيز بمحافظة الطائف. أن هناك تفاوت بين اتجاهات العاملين في مستشفى الملاك عبد العزيز نحو القيـيم الإخليـة

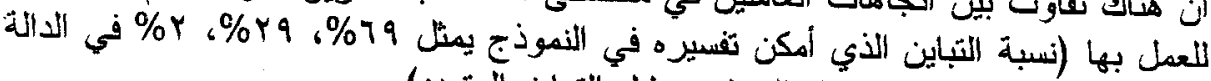

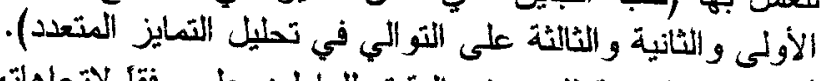

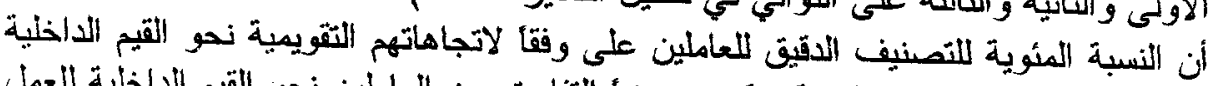

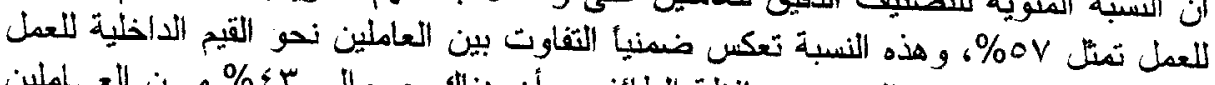

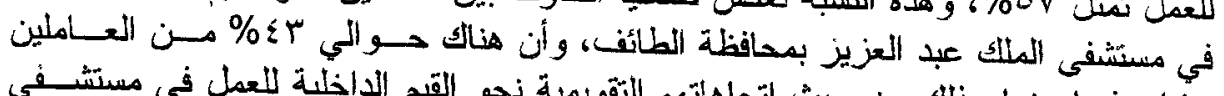

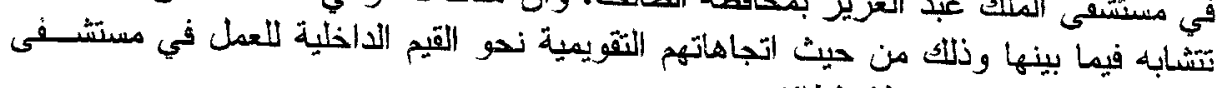

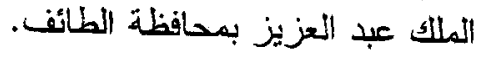

\section{ب- الأهمية النسبة للقيم الداخلية للعمل}

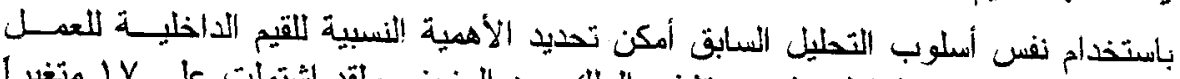

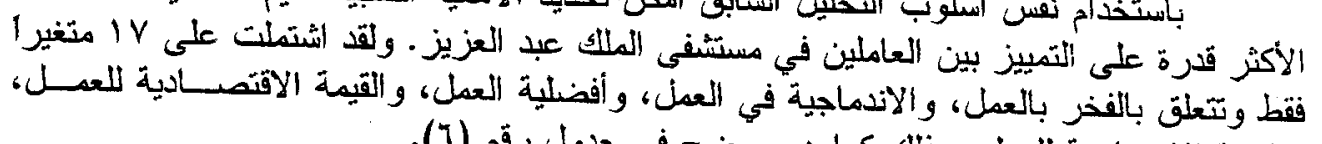

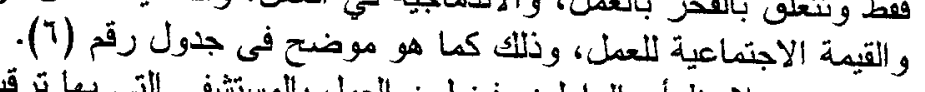

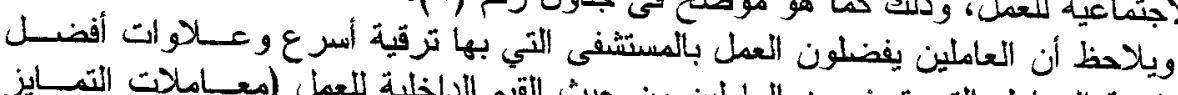

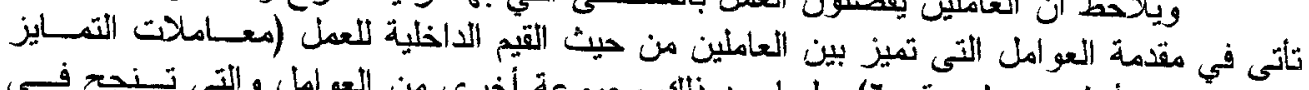

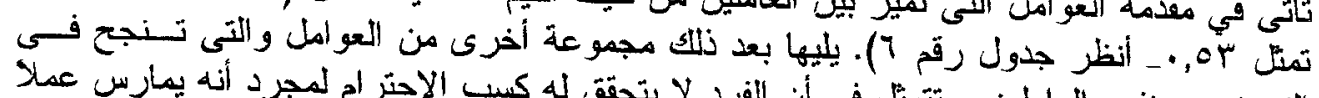

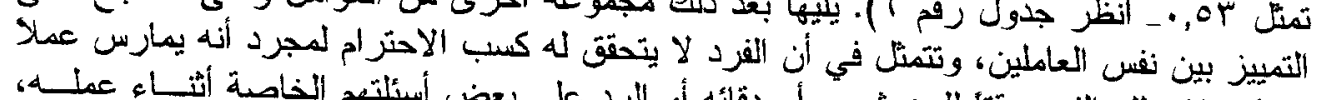

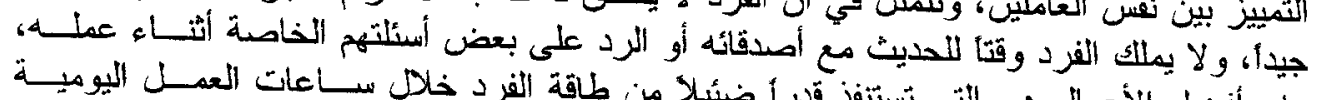

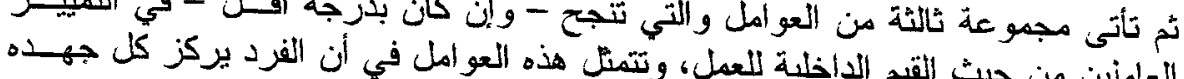

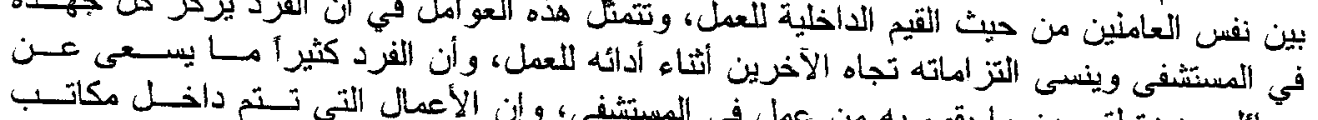

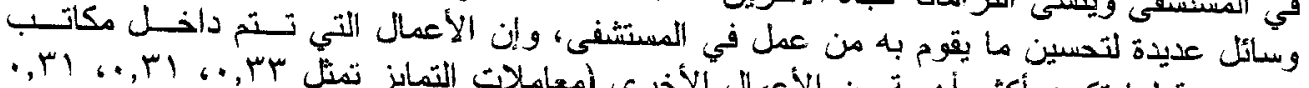

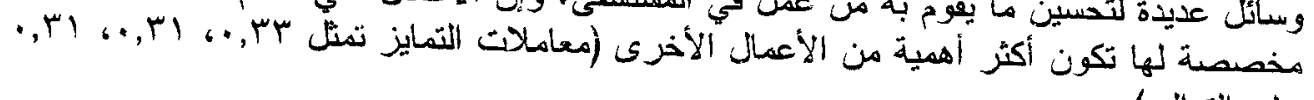
على التواليّ). تأتي محمو عة رابعة من العو امل و التي تتجح - وان كان بدرجة أقل - في التمبيز بين

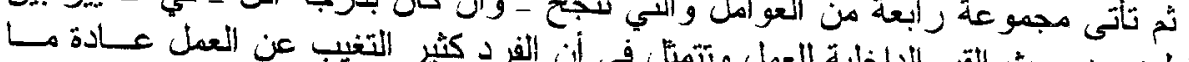

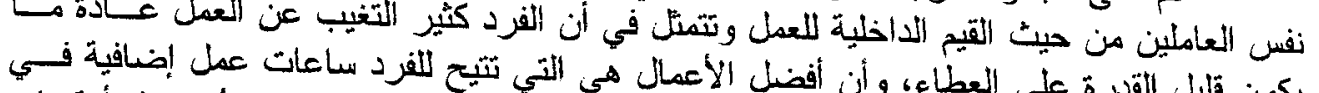

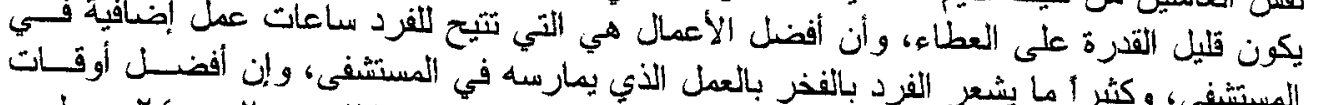

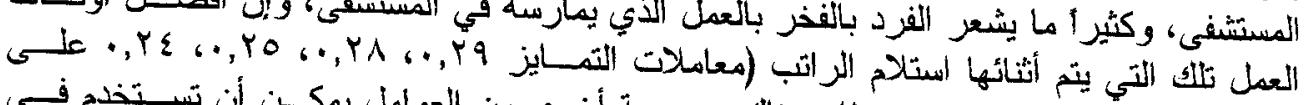

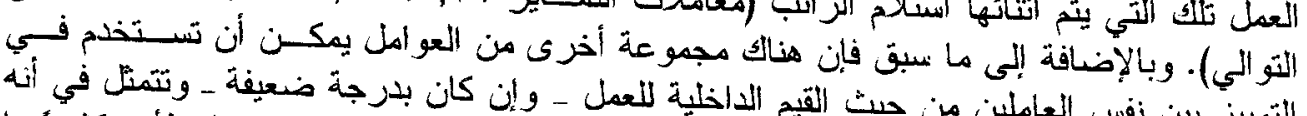

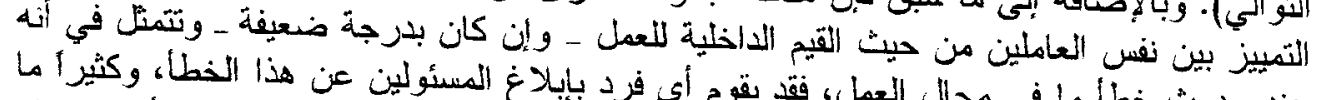

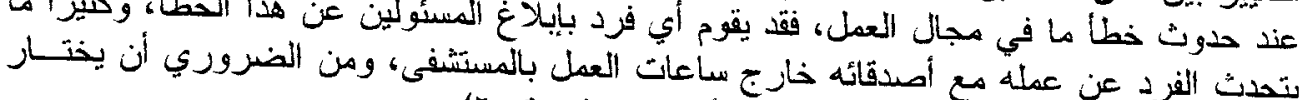

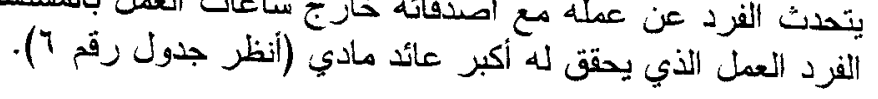




\section{$-\varepsilon+\varepsilon-$}

ج- توصيف مقارن للعاملين على أساس القيم الأخلية للعهل

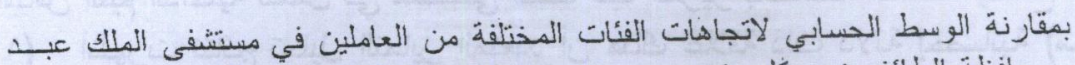

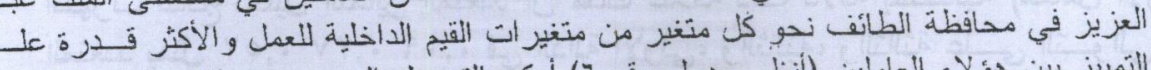

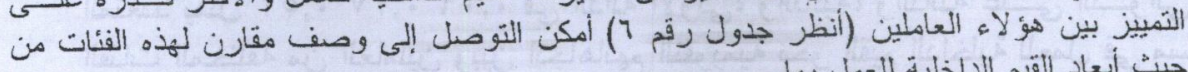

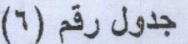

عوامل ومعاملات التهايز بين العاملين على أساس القيم الأخلية للعمل

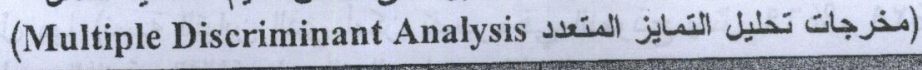

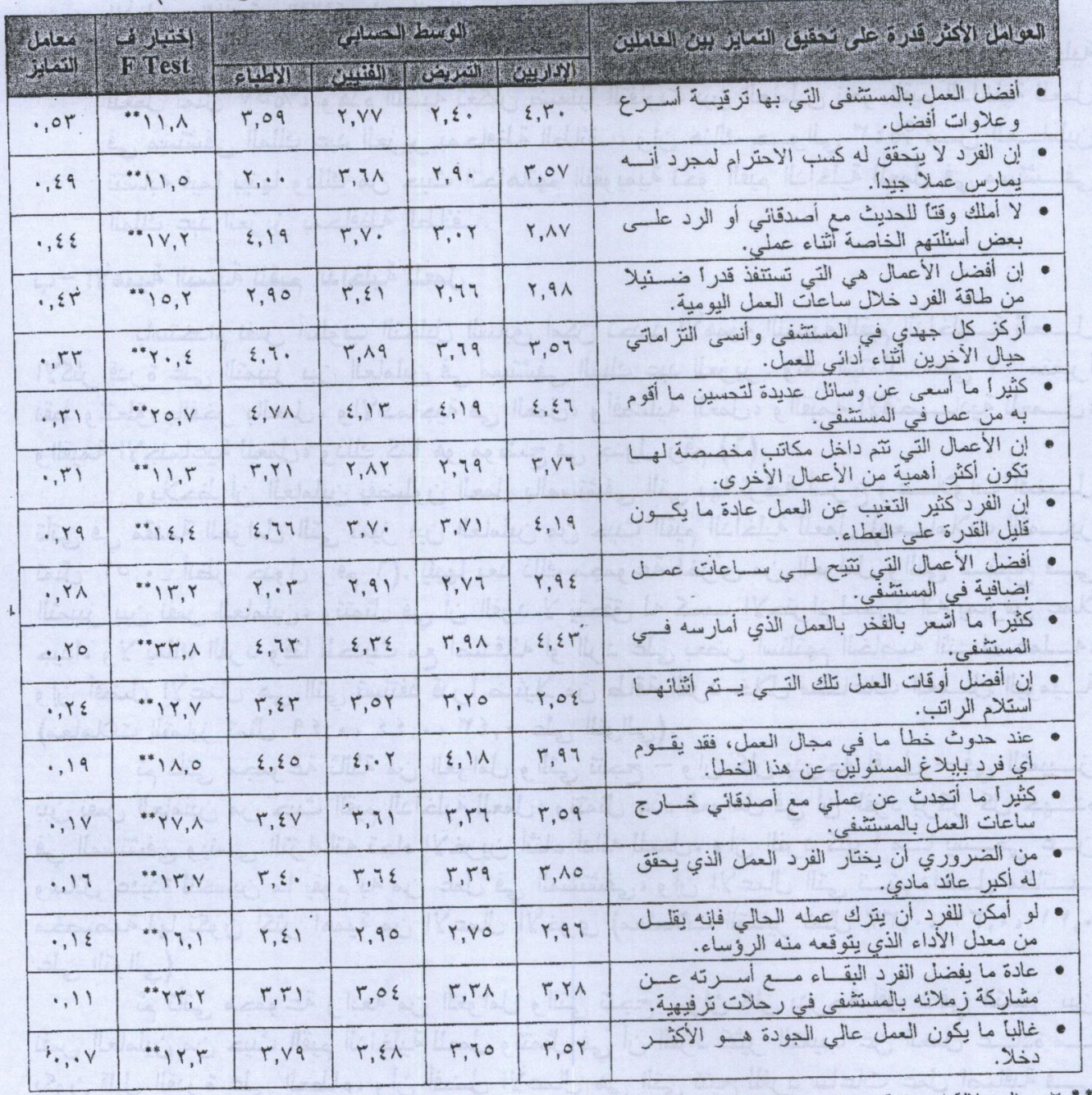

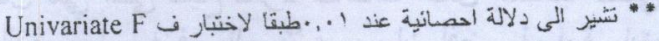

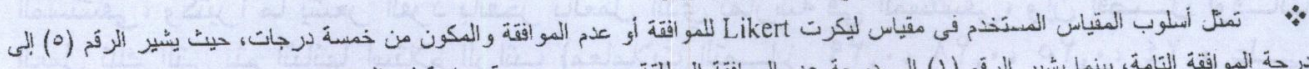

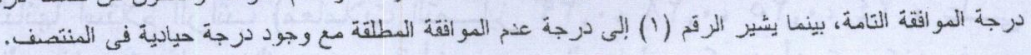




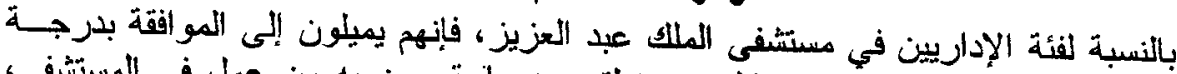

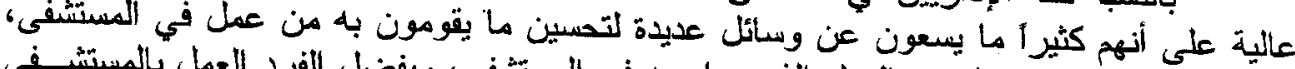

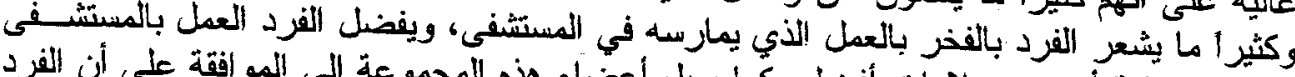

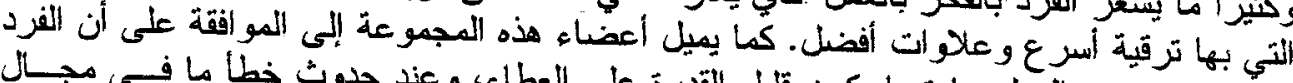

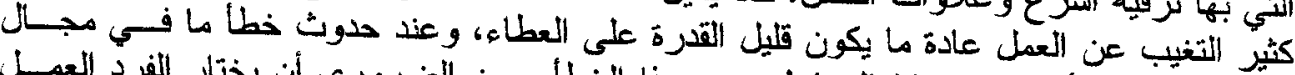

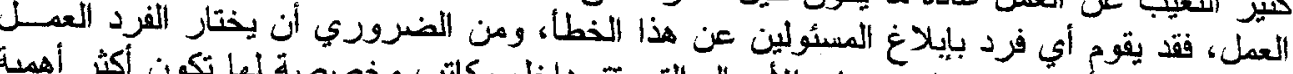

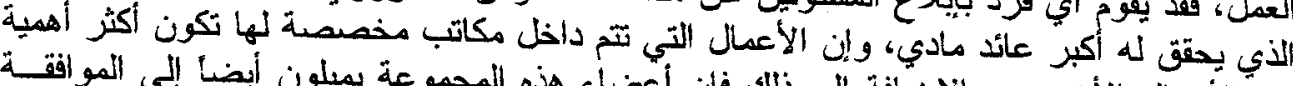

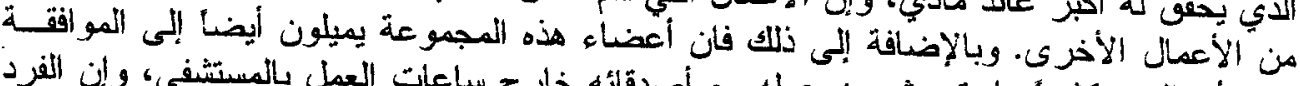

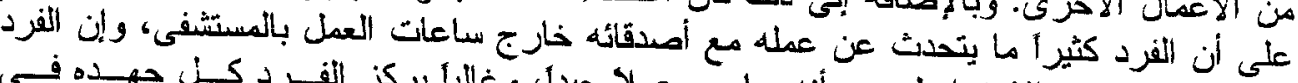

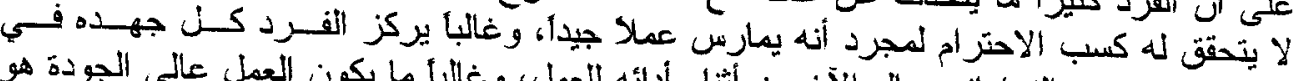

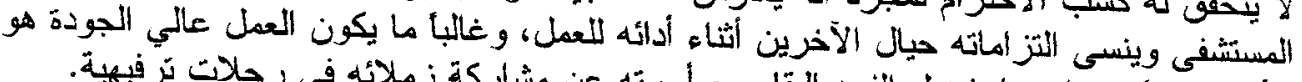

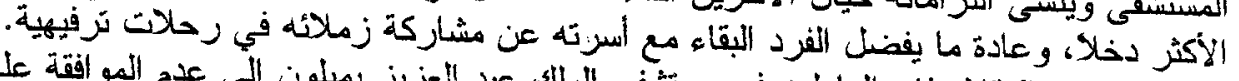

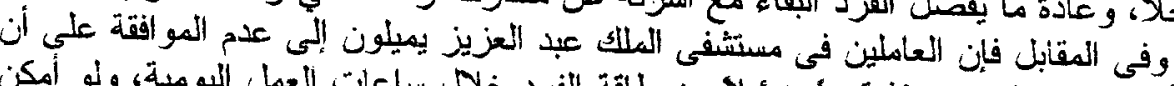

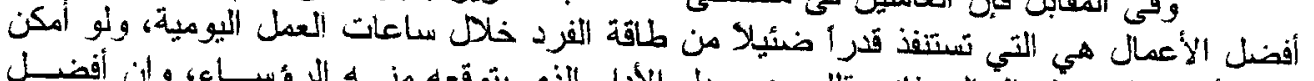

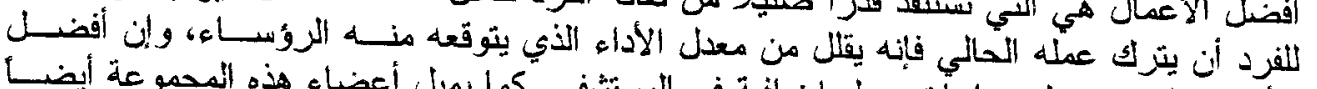

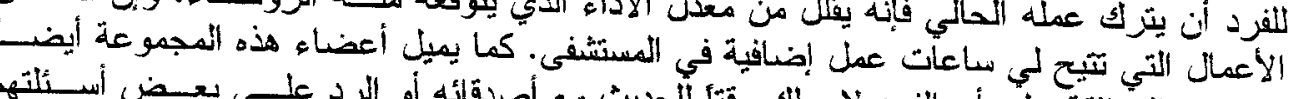

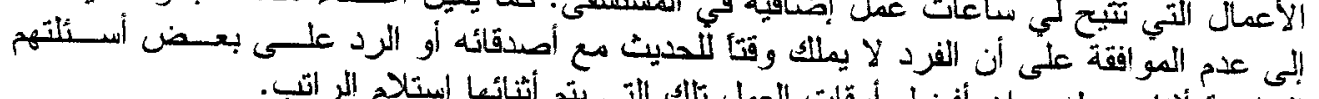

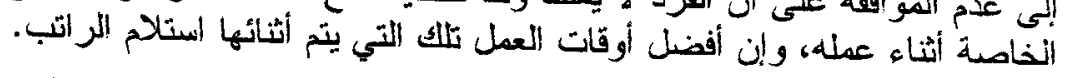

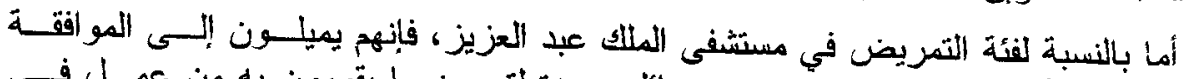

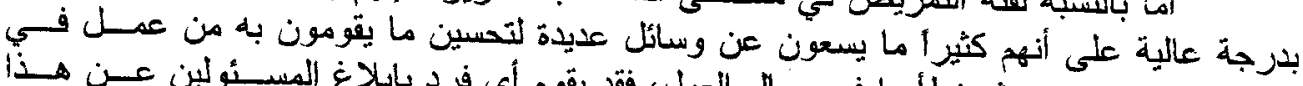

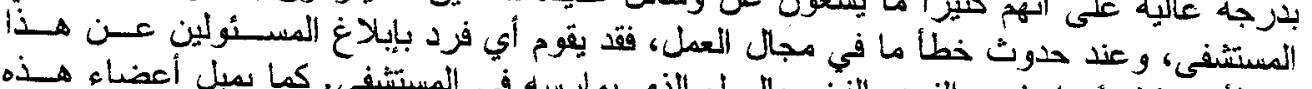

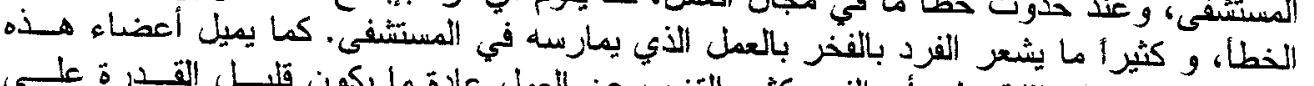

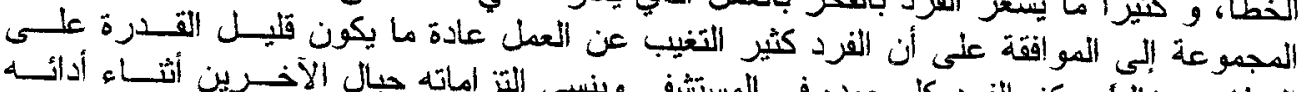

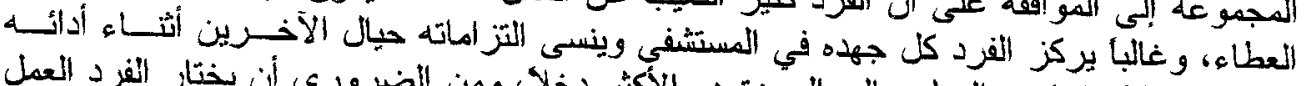

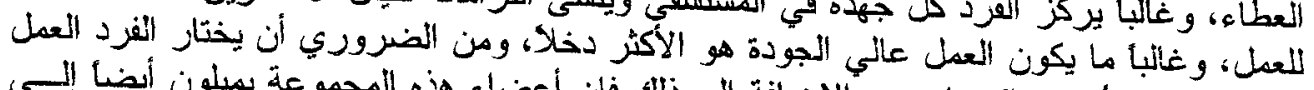

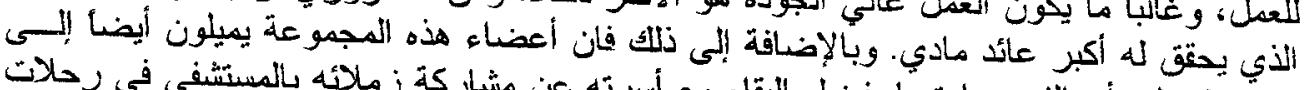

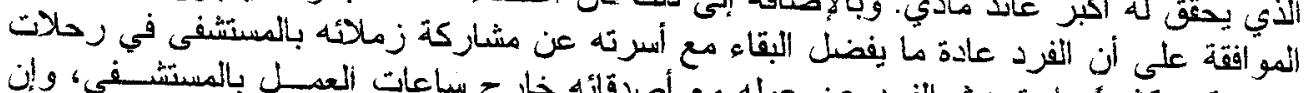

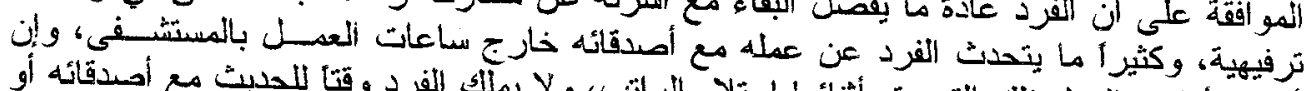

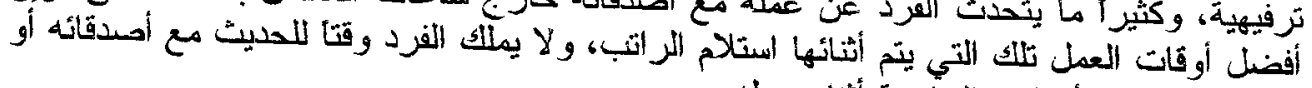

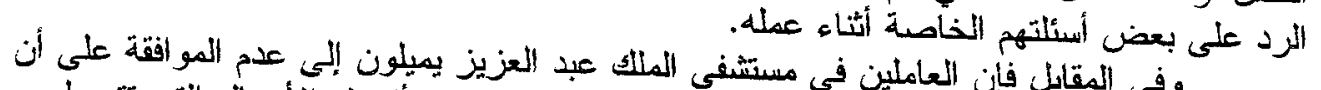

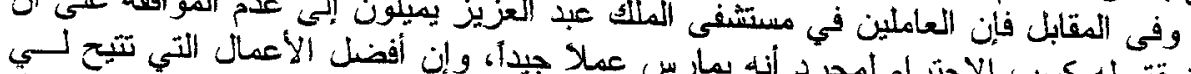

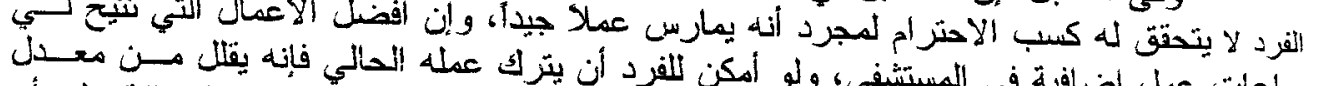

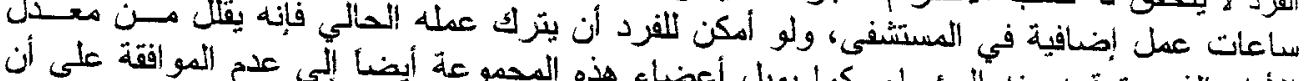

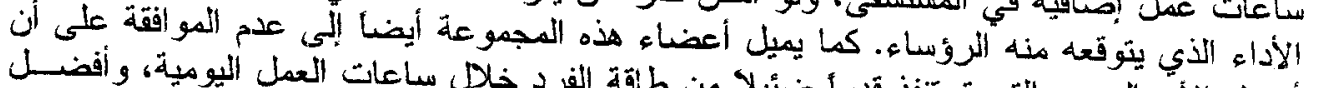

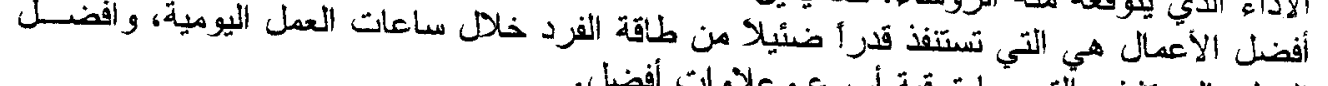

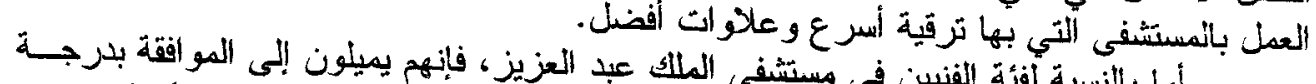

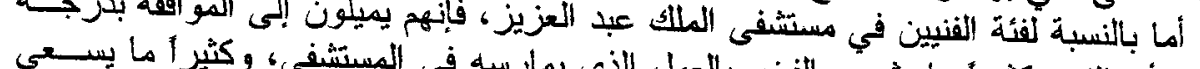

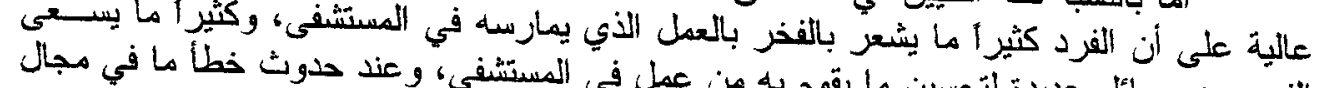

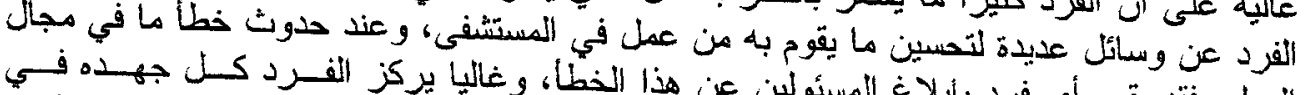

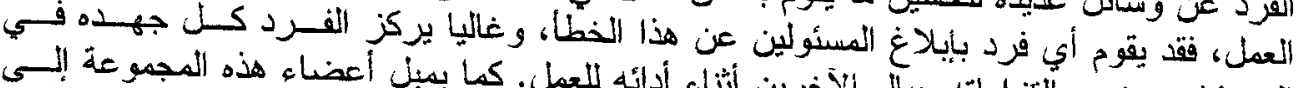

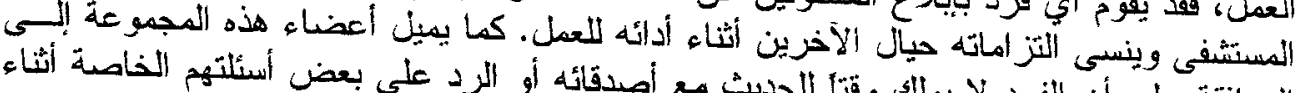

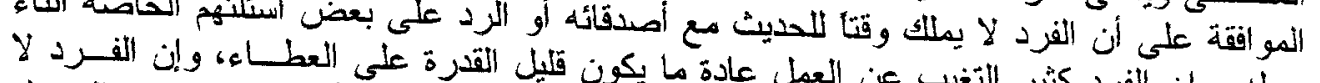

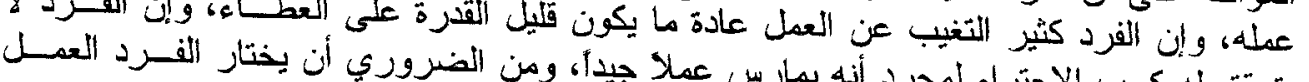




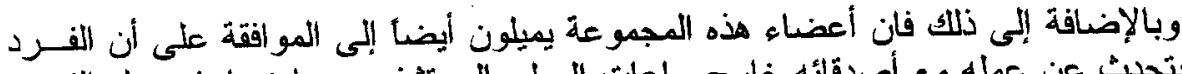

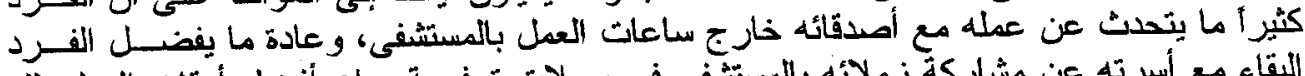

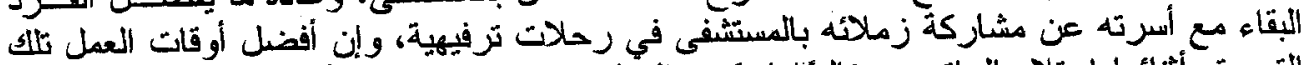

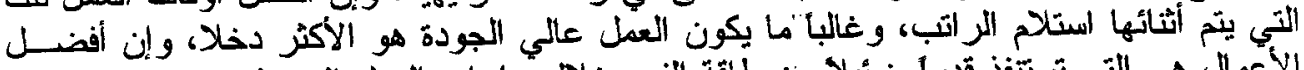

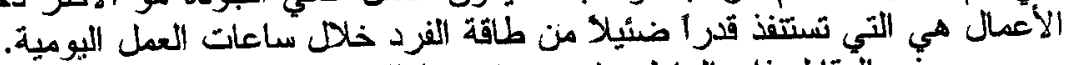

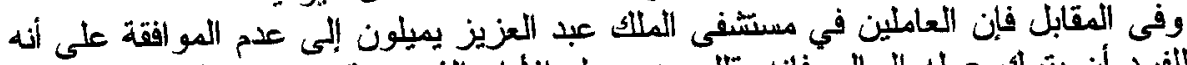

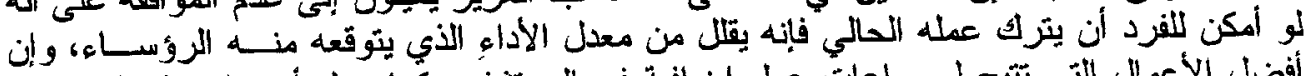

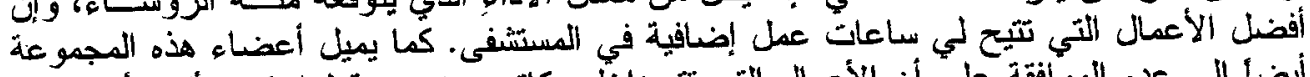

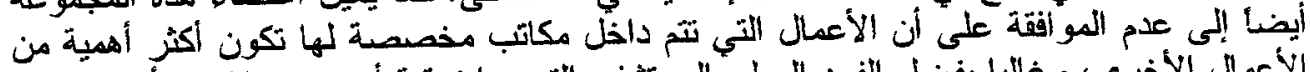

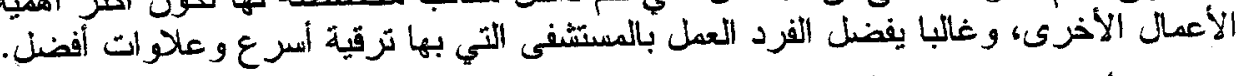

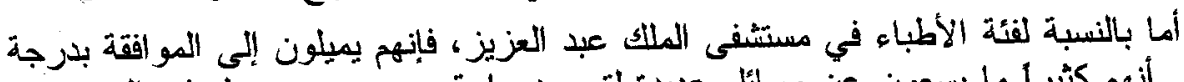

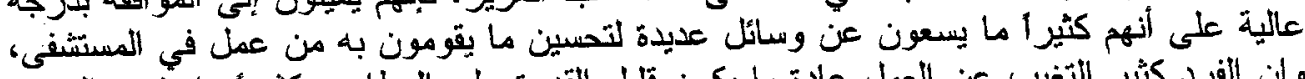

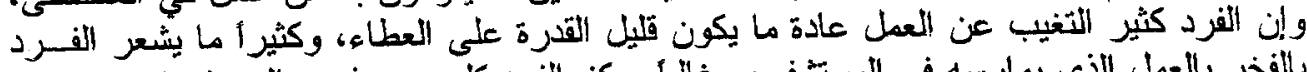

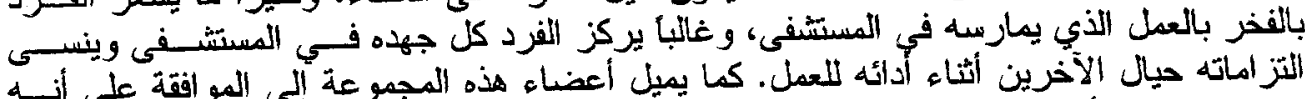

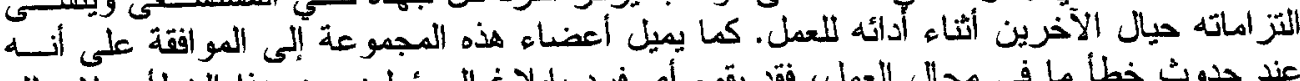

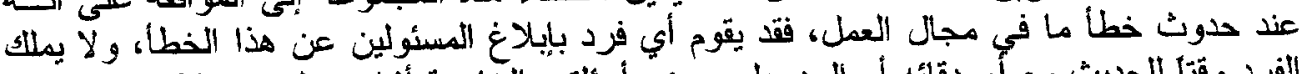

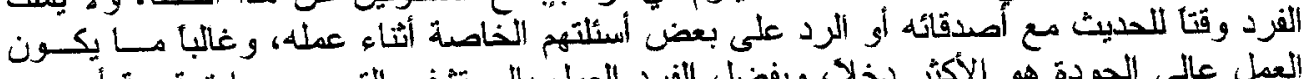

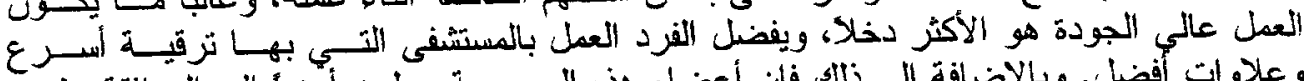

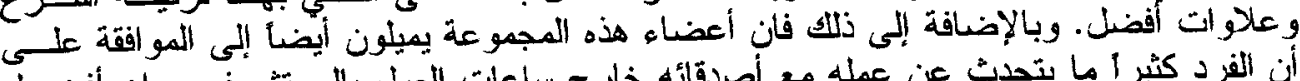

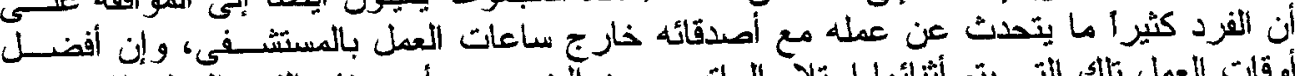

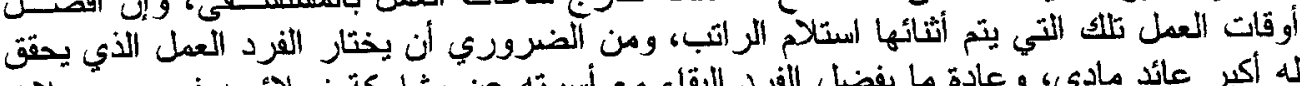

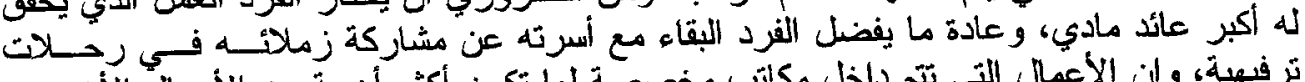

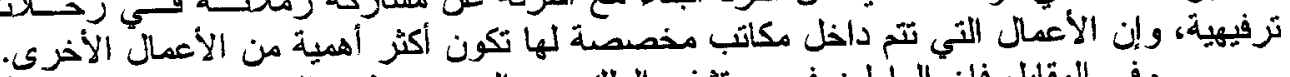

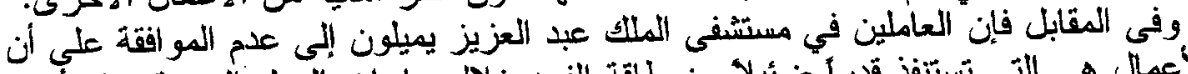

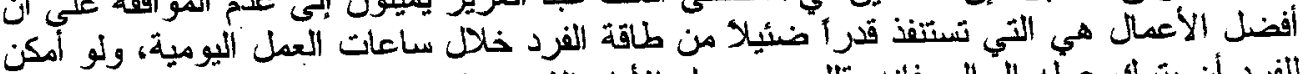

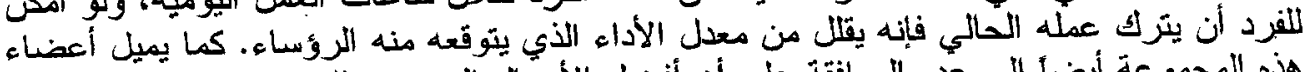

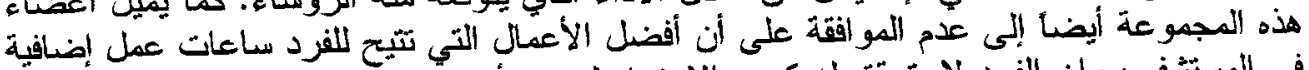

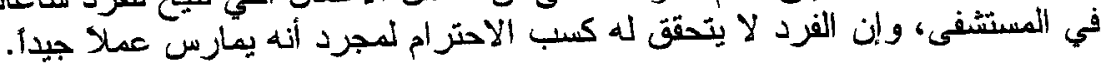

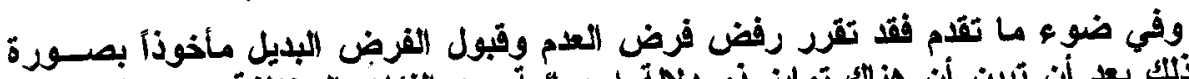

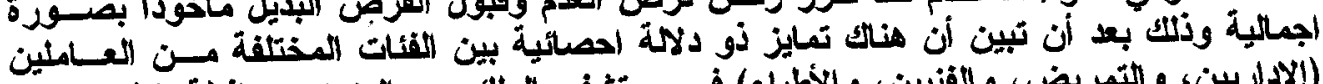

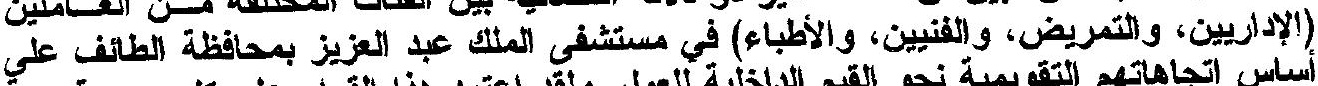

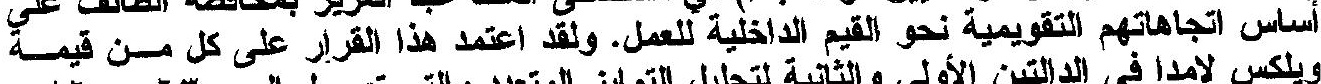

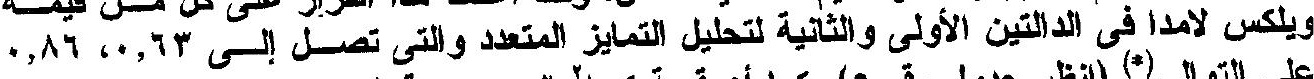

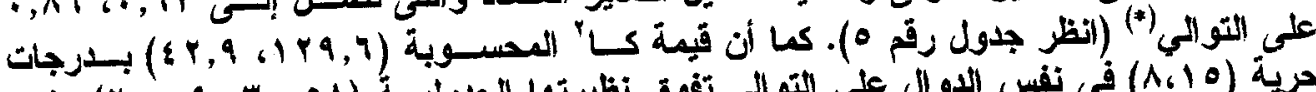

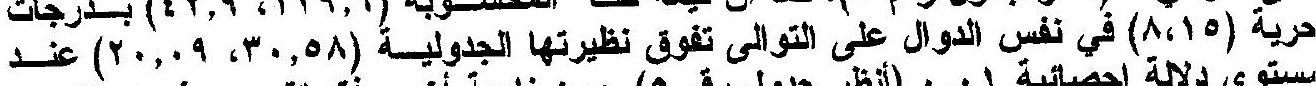

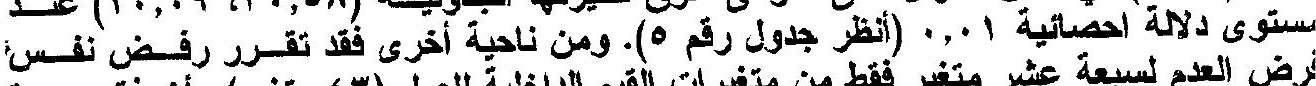

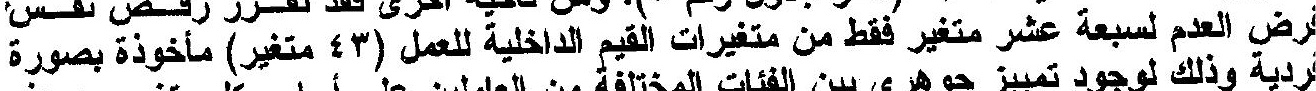

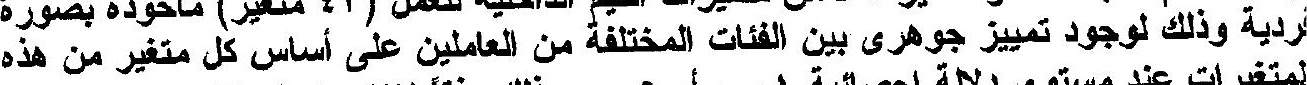

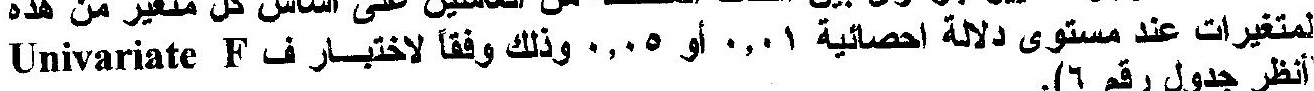

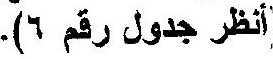

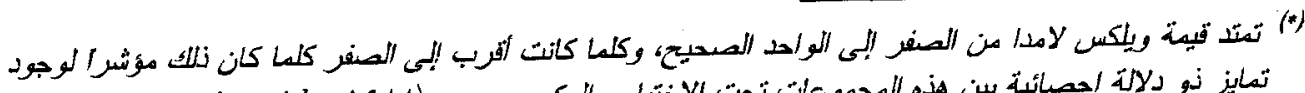

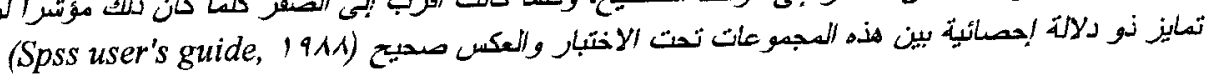




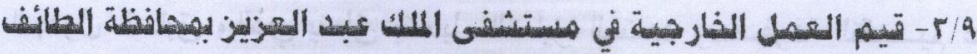

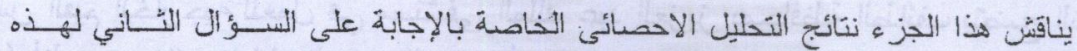

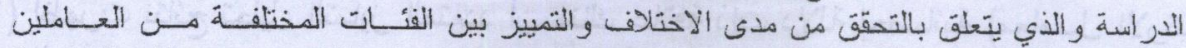

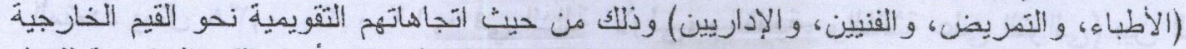

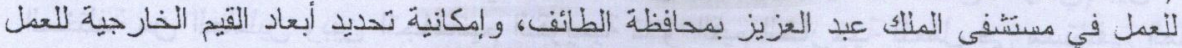

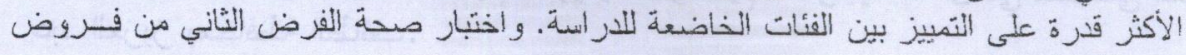

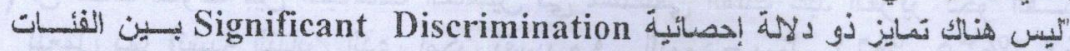

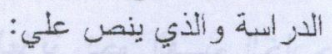

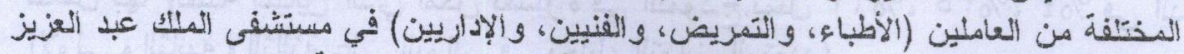

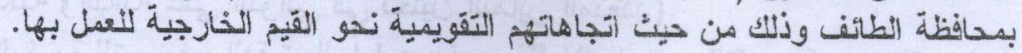

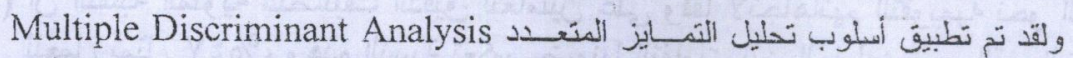

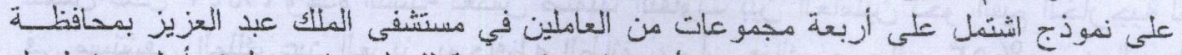

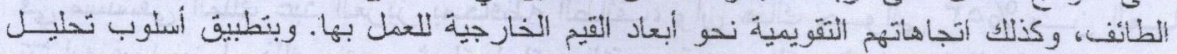

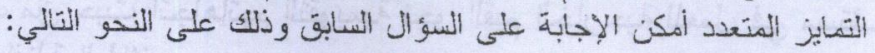

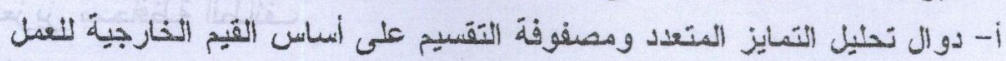

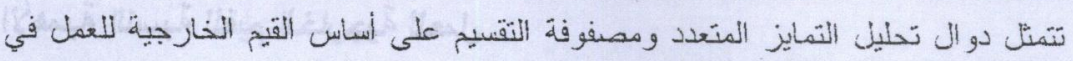

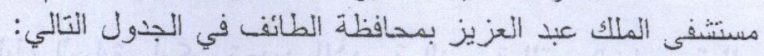

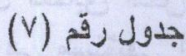

دوال تحليل التمايز المتعدد ووصفوفة التقبيم ببين العاملين على أساس الثقيم الخارجية للعهل Discriminant Functions التهايز (i)

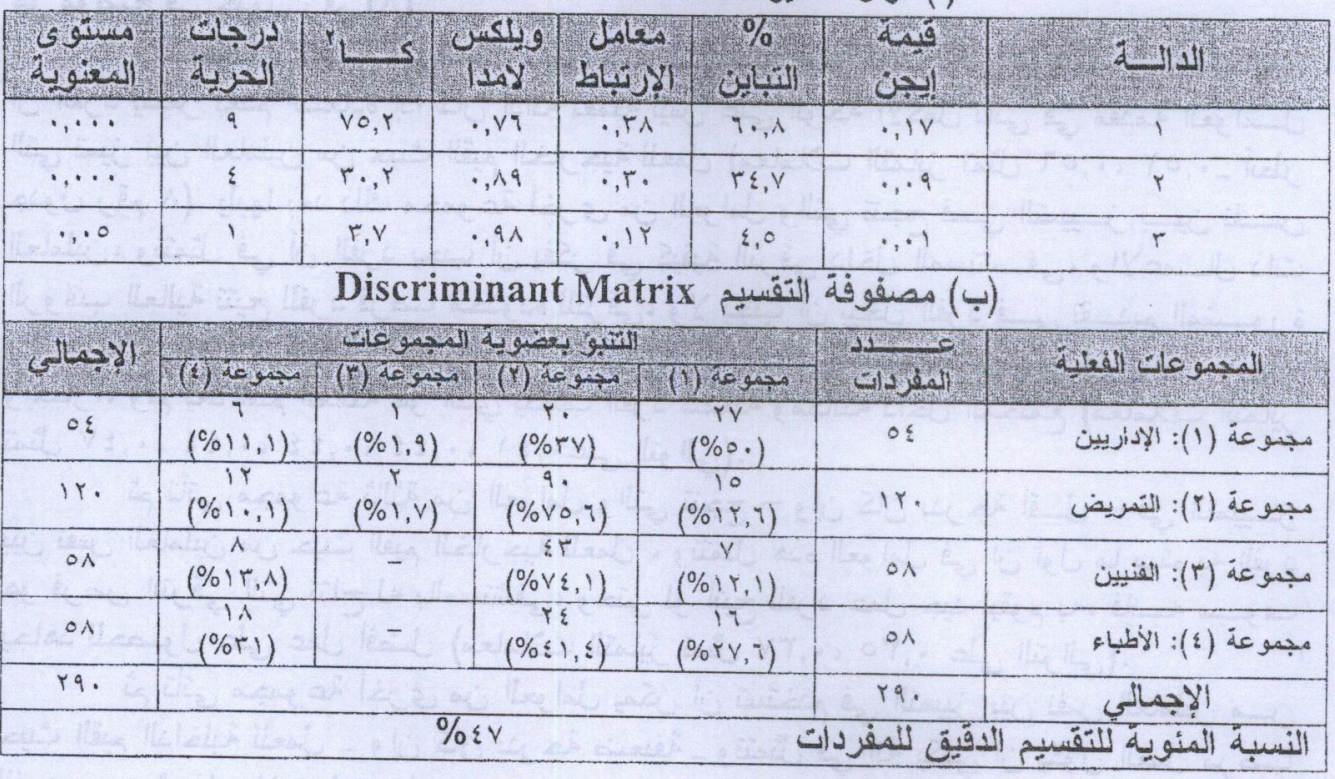




\section{$-2 \cdot 1-$}

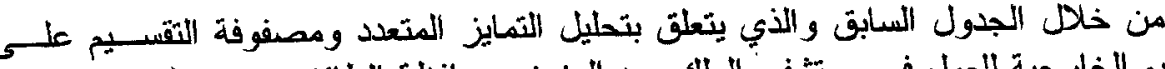

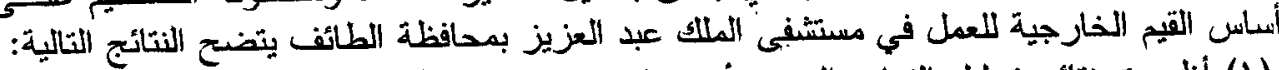

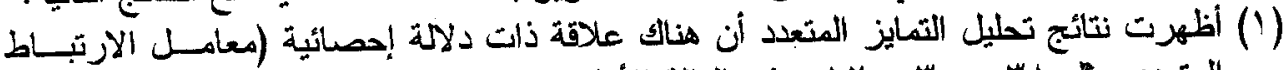

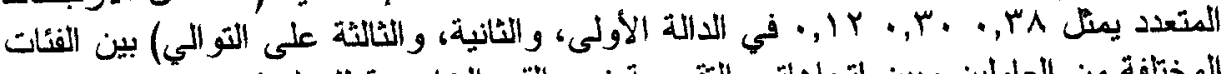

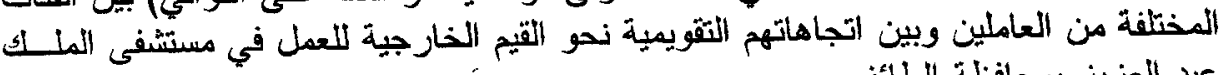
عبد العزيز بمحافظة الطائف.

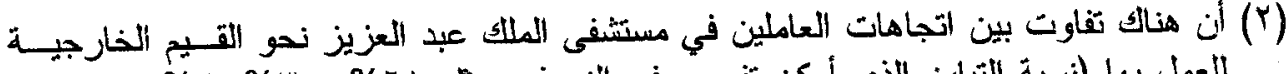

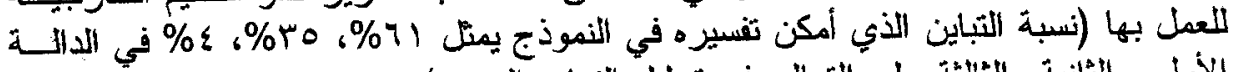

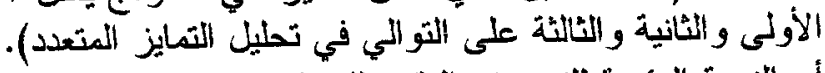

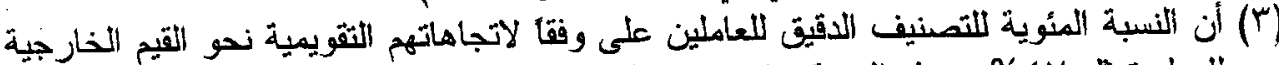

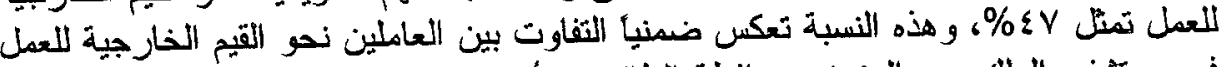

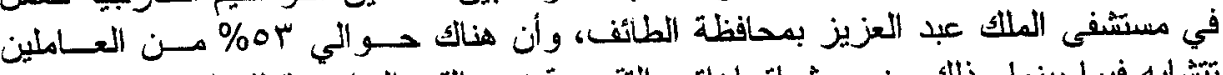

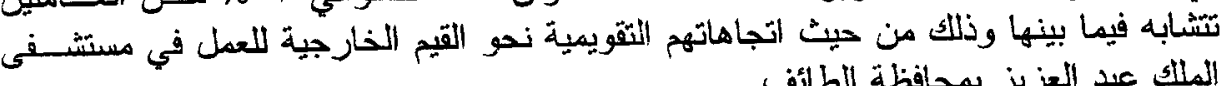
الملك عبد العزيز بمحافظة الطائف.

\section{ب- الأهمية النسبة للقيم الخارجية للعمل}

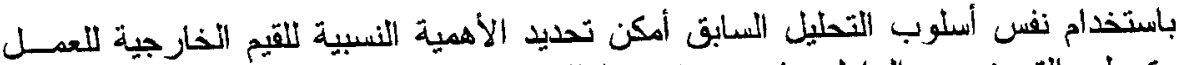

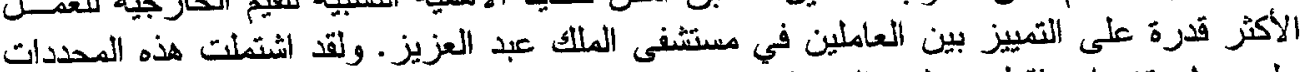

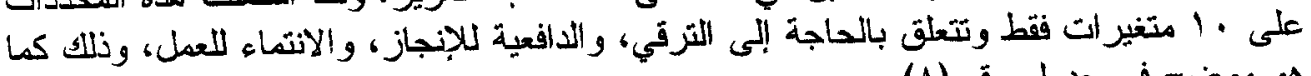

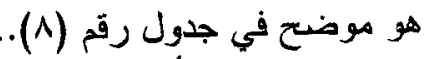

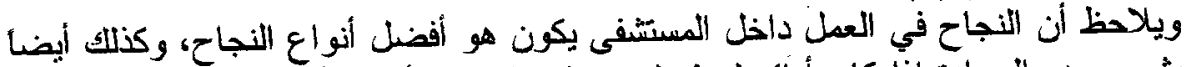

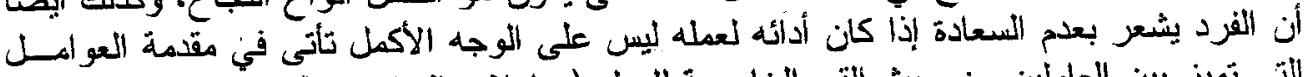

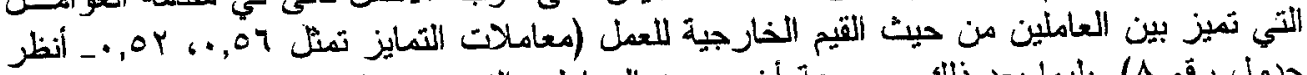

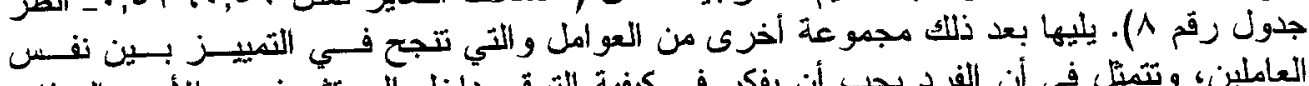

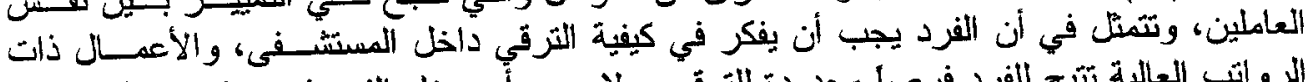

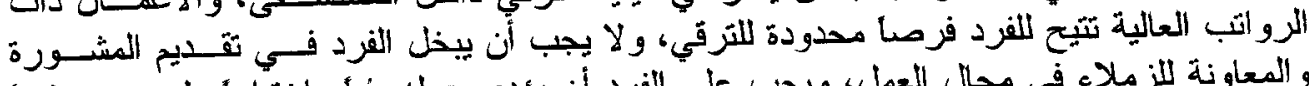

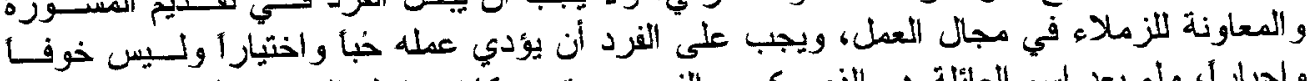

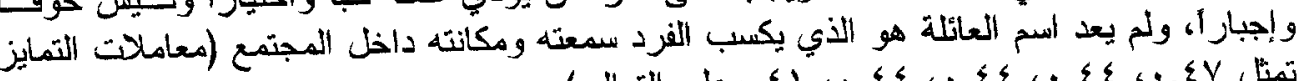

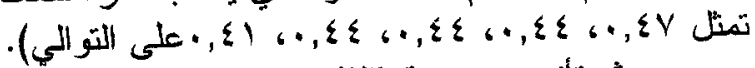

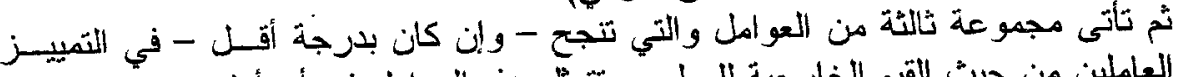

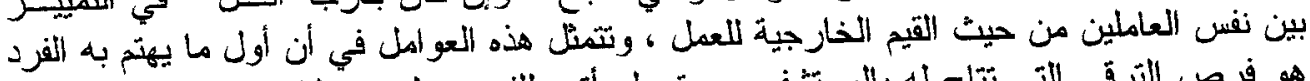

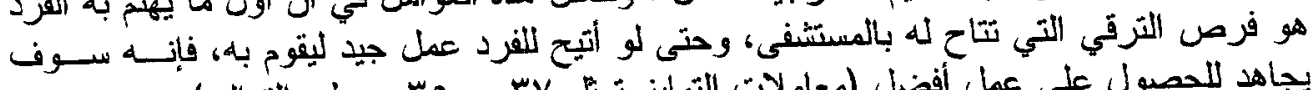

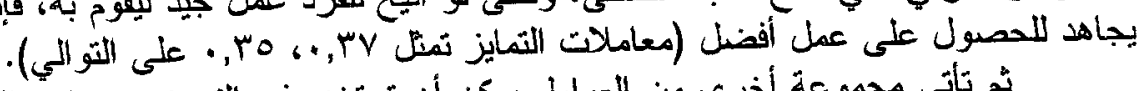

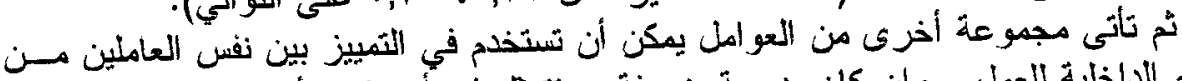

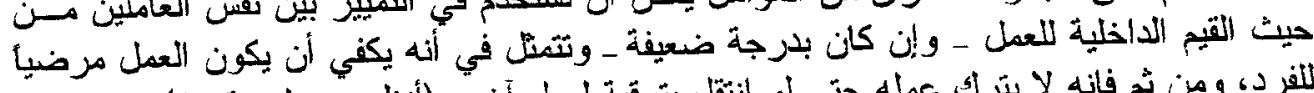

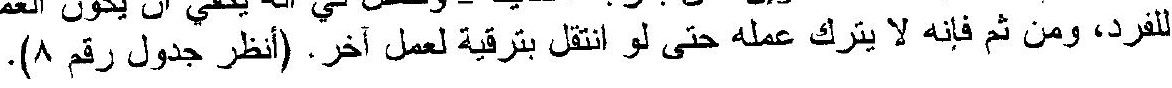

\section{ج- توصيف مقارن للعالملين على أسساس القبم الإخلية للعمل}

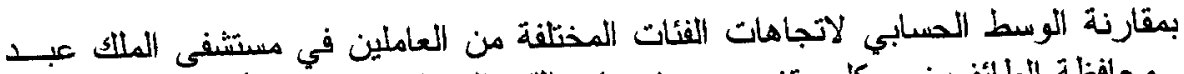

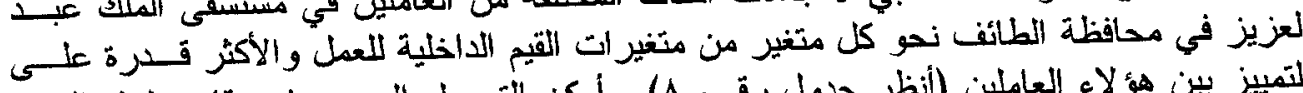

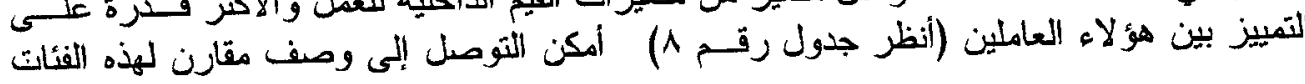




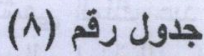

من حيث أبعاد القيم الخارجية للعمل بها.

عوامل ومعاملات الثمايز بين العاملين على أساس القيم الخارجية للعمل

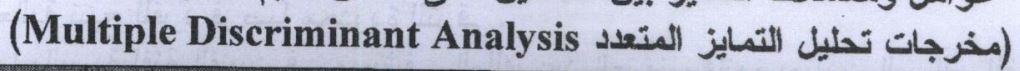

\begin{tabular}{|c|c|c|c|c|c|c|}
\hline Joles & $\begin{array}{l}\text { Tijust } \\
\text { T Test }\end{array}$ & 148 & क्या & 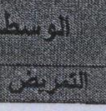 & 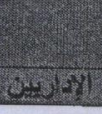 & 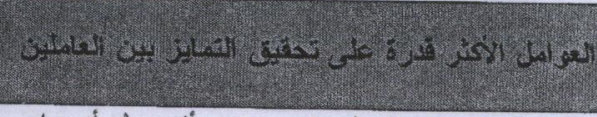 \\
\hline 7,04 & ${ }^{* *}|r, \wedge|$ & $r, \imath v$ & $r, r$. & $\varepsilon, 1$. & r,Ar & 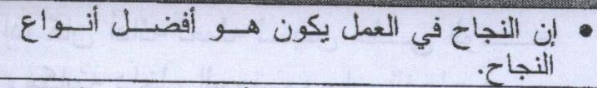 \\
\hline ., Or & ${ }^{* *} \mid 1$, or & $\varepsilon, 9$. & $\varepsilon,+r$ & $\{,+1$ & $\varepsilon, 09$ & 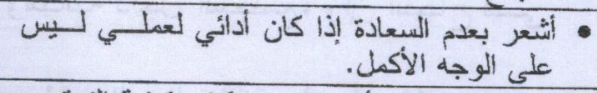 \\
\hline$\cdot, \Sigma V$ & ${ }^{* *} 19, .0$ & $r, v \leqslant$ & r,HA & $r, \lambda$ & $\varepsilon, 0 \leqslant$ & 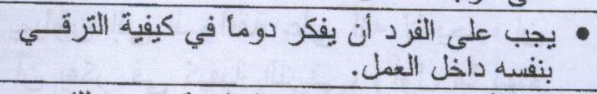 \\
\hline$\cdot, \leq £$ & $\left.{ }^{* *}\right) \vee, 79$ & $Y, Y \wedge$ & r,r & $Y, 01$ & r, ry & 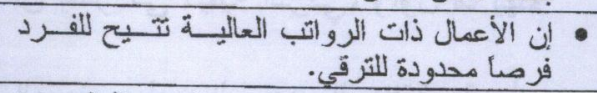 \\
\hline$\cdot, \xi\{$ & $\left.{ }^{* *}\right) \leq, T Y$ & r, & $r, o r$ & Y, $9 \mathrm{~V}$ & $\varepsilon,\}_{0}$ & 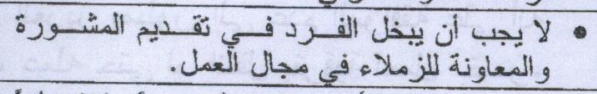 \\
\hline$\cdot, \leqslant \varepsilon$ & $* * 1 r, 1 q$ & $\varepsilon, 7 V$ & $\varepsilon, Y Y$ & $\varepsilon, \cdot r$ & r,v & 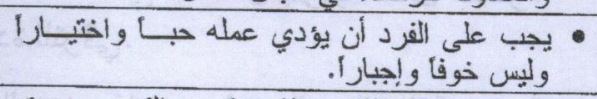 \\
\hline$\cdot, \leqslant 1$ & $* * \mid r$, or & $r, 9 \mathrm{~V}$ & $r, v q$ & r,TE & r & 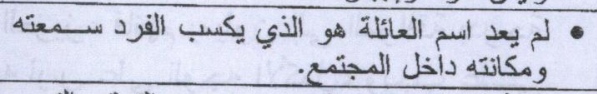 \\
\hline$\cdot, r V$ & $* * Y r, Y 0$ & $r, v q$ & $r, . q$ & $r, \cdot \varepsilon$ & $r, 91$ & 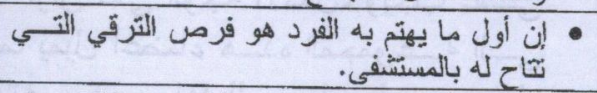 \\
\hline$\therefore$ & $* * Y 0, A$. & $\varepsilon, \ldots$ & $\varepsilon, \cdot q$ & $\varepsilon, M Y$ & $\{$, Or & 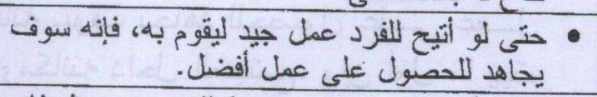 \\
\hline . & ${ }^{* *} \mid 7, .1$ & $r, \Delta V^{\prime}$ & $r, q \wedge$ & $r, r q$ & $r, \cdot v$ & 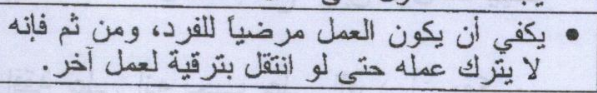 \\
\hline
\end{tabular}

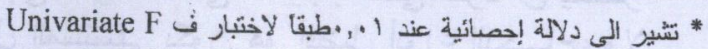

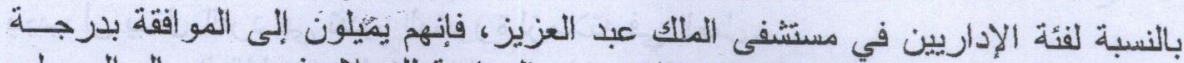

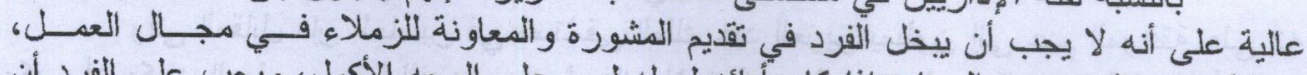

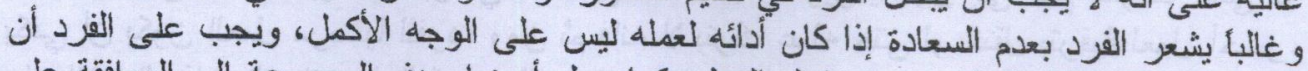

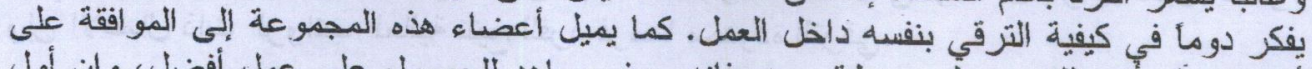

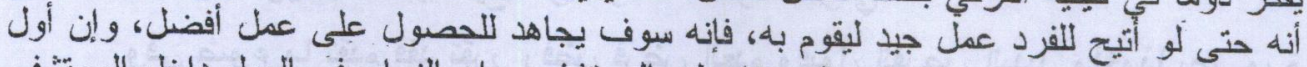

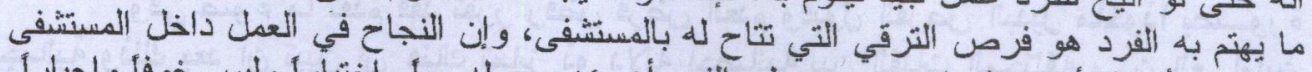

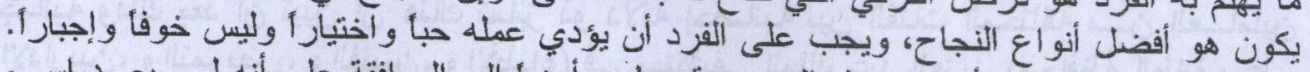

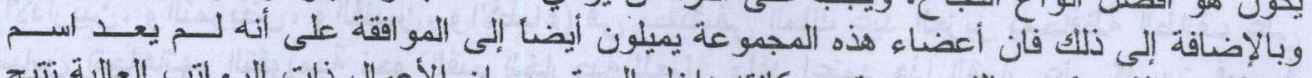

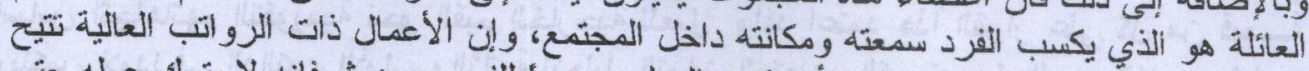

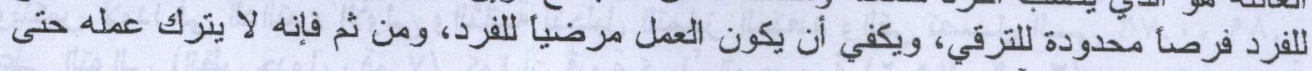

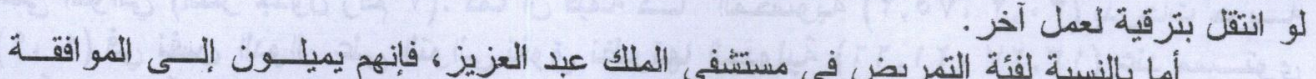

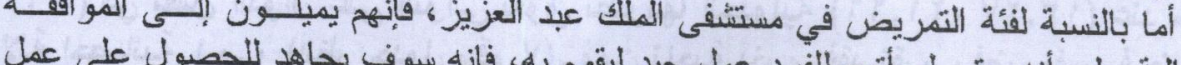

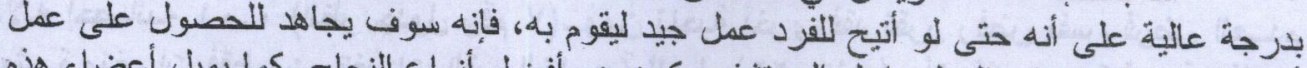

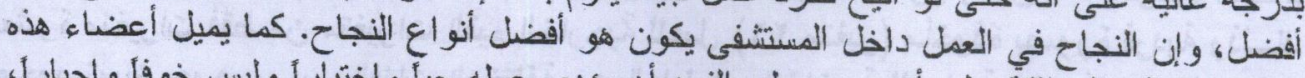

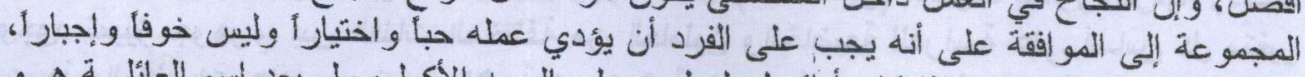

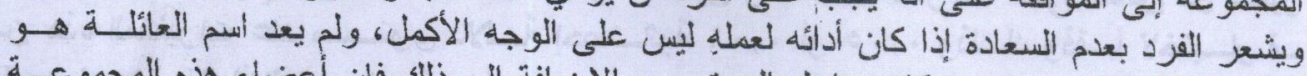

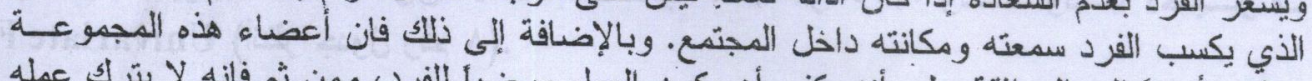

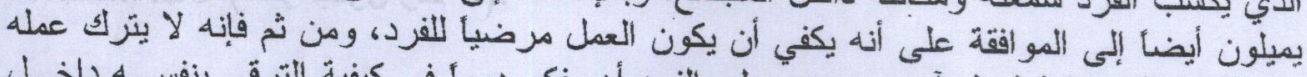

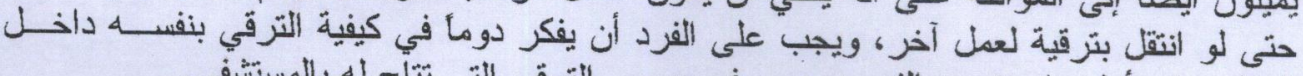

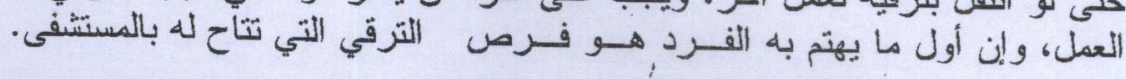




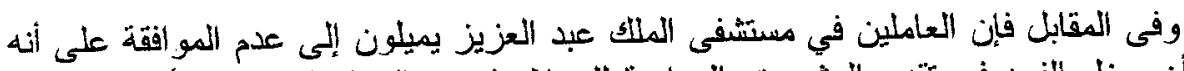

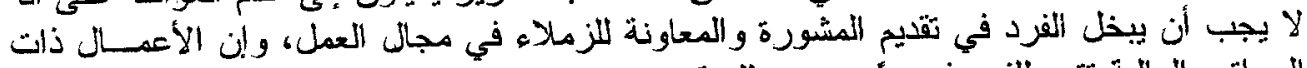

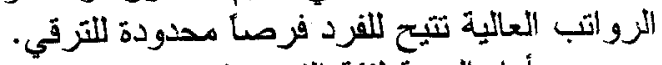

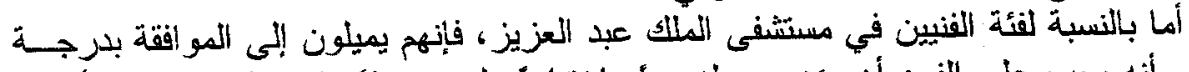

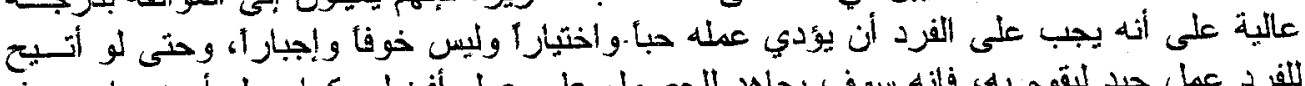

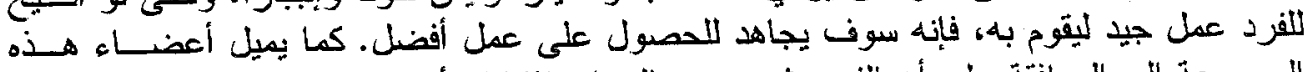

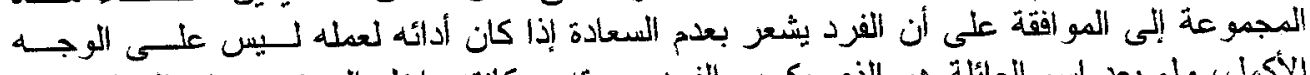

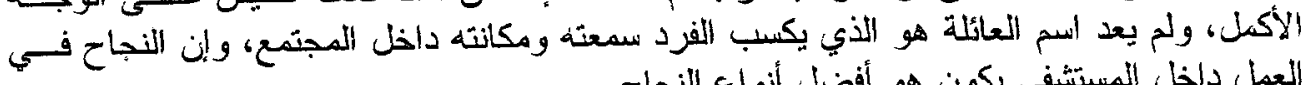

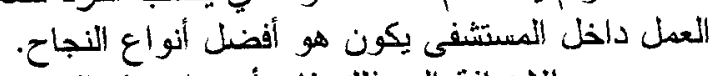

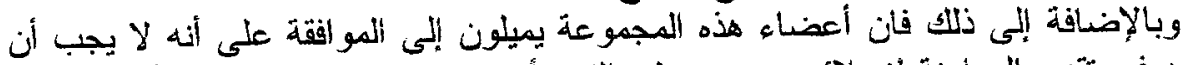

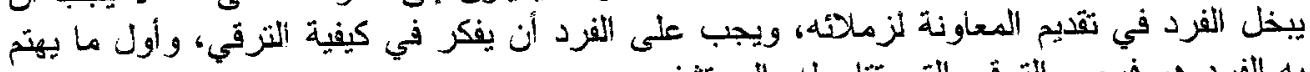

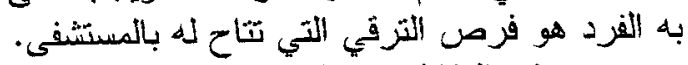

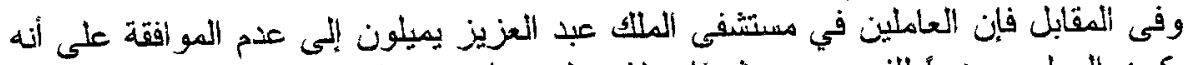

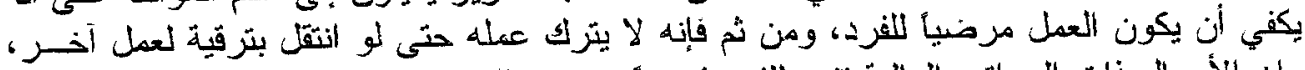

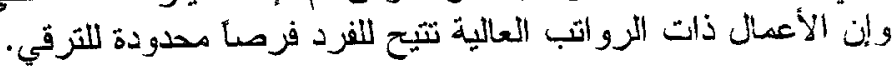

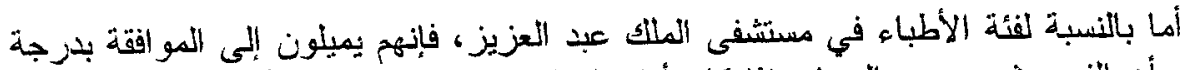

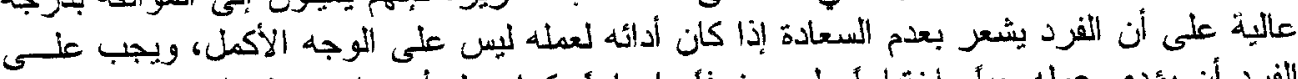

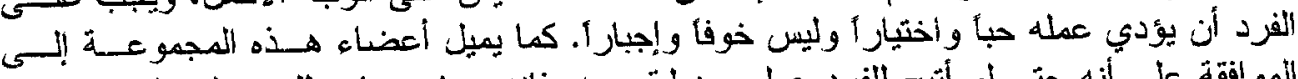

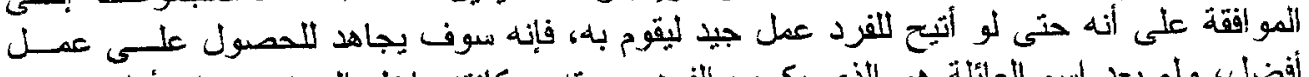

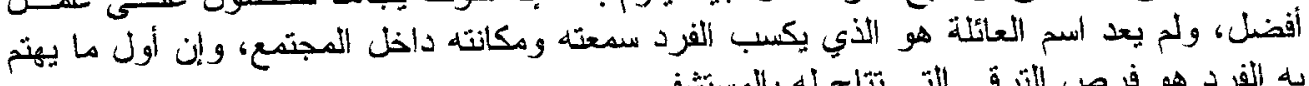

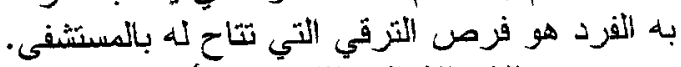

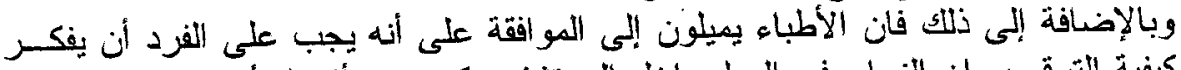

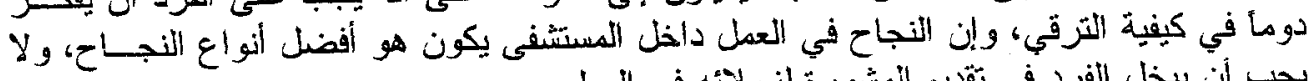

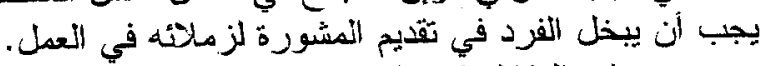

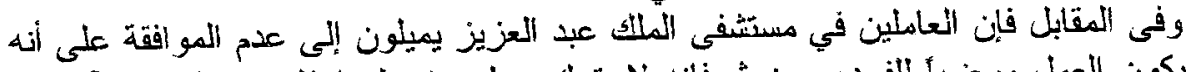

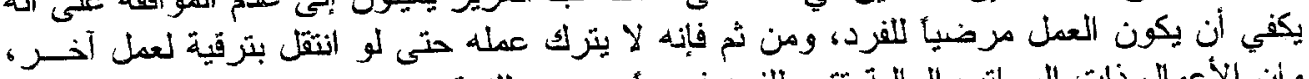

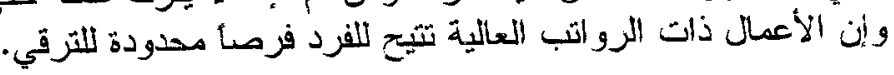

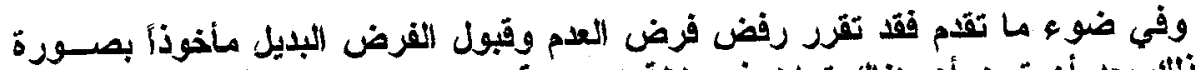

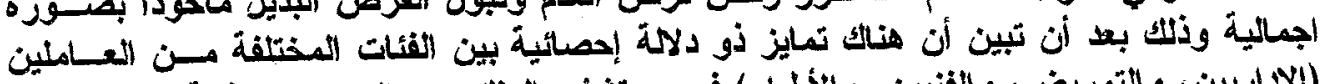

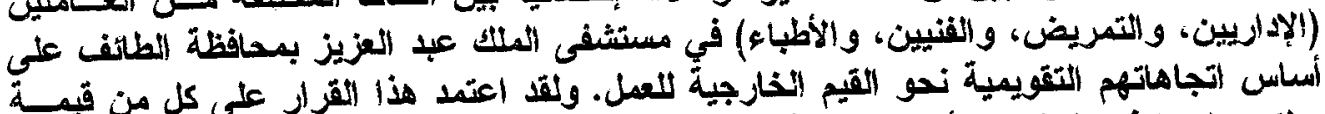

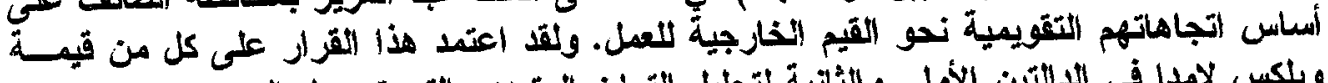

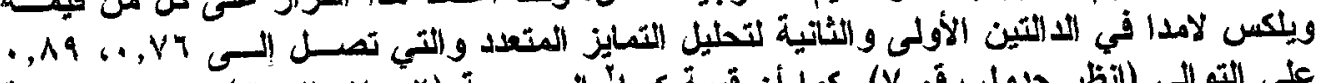

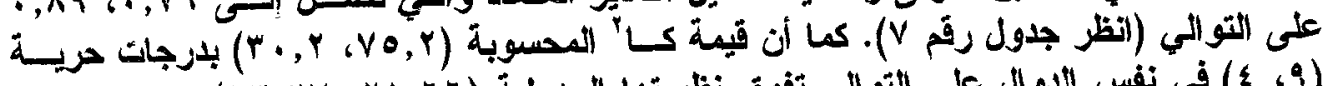

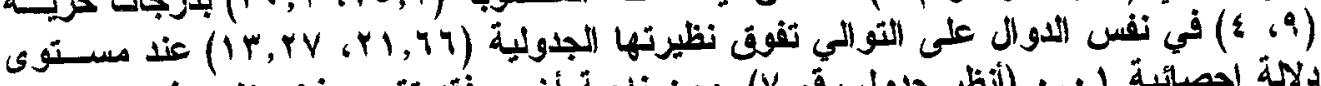

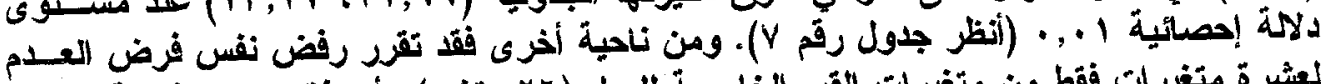

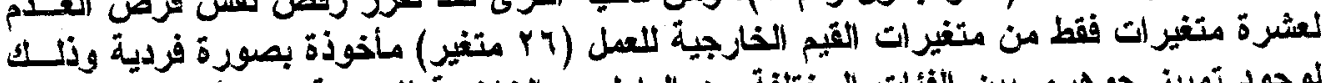

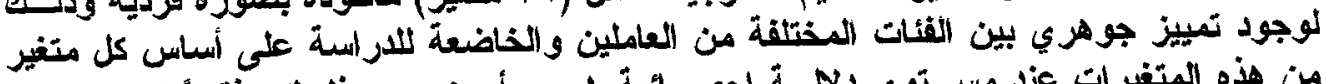

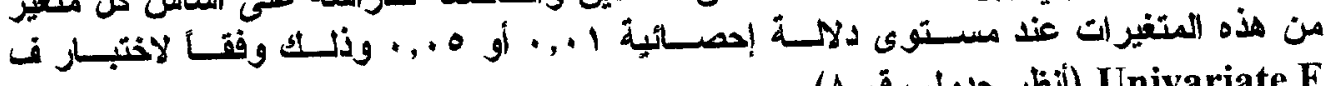
Univariate F 


\section{ع/9- الالتزام التنظيمي في منتشفى اللك عبد العزيز بهمانظة الطائف}

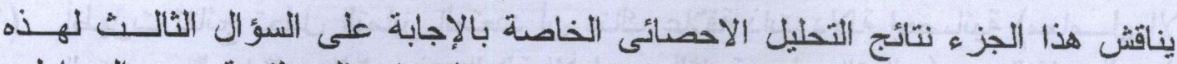

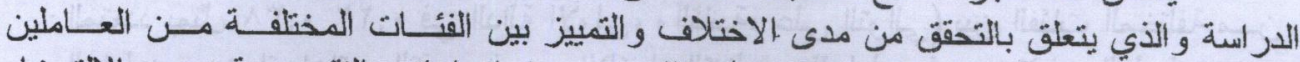

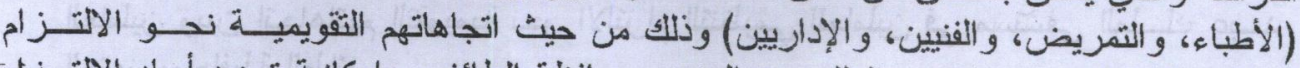

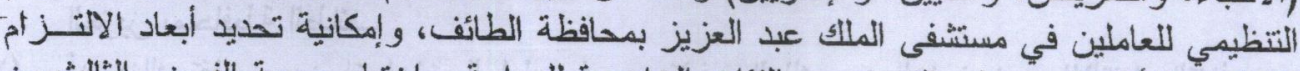
التنظيمي الأكثر قدرة على التمييز بين الفئات الخاضعة للار اسة. واختبار صحة الفرض الثانف الثالث من

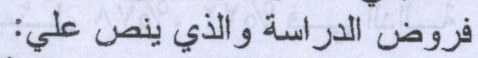

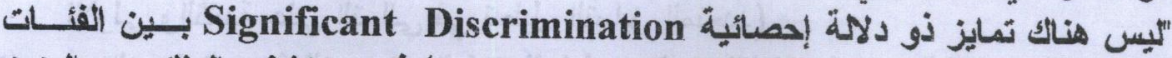

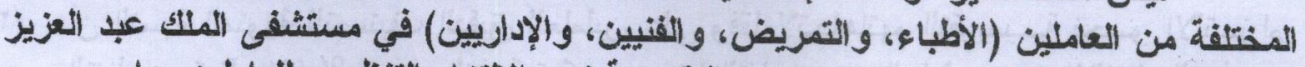

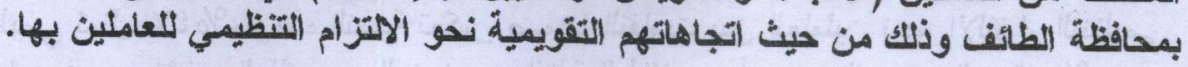

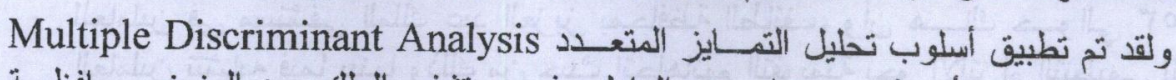

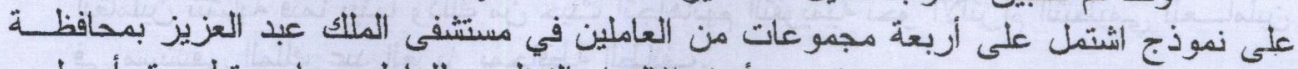

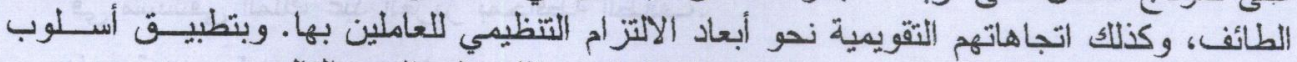

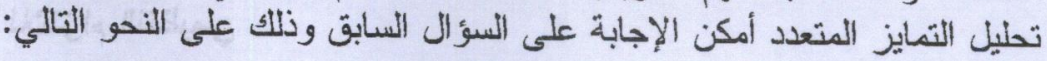

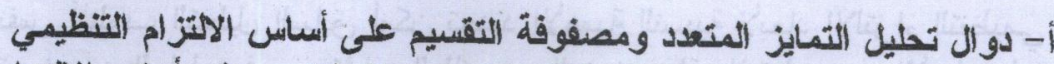

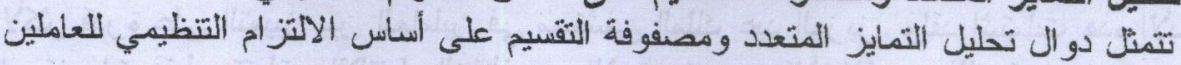
في مستشفى الملاك عبد العزيز بمحافظة الطائف في الجدول التالي:

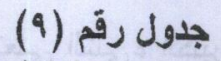

دوال تحليل التمايز المتعدد ومصفوفة التقسيم بين العاملين على أساس الالتزام التنظيمي

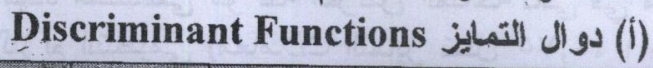

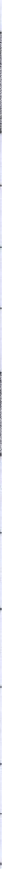




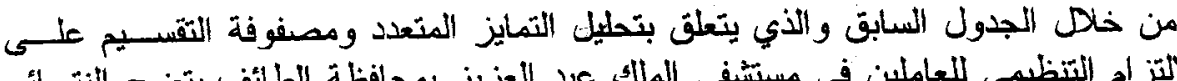

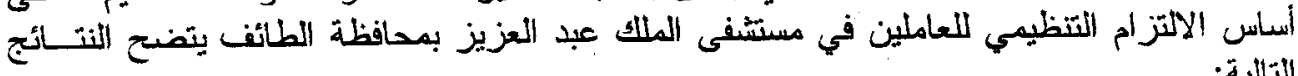

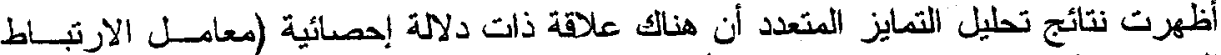

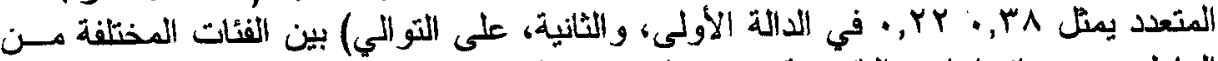

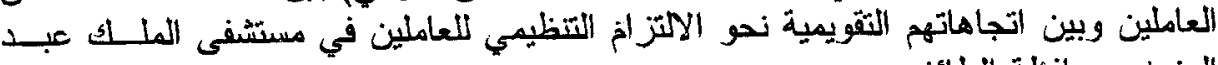
العزيز بمحافظة الطائف

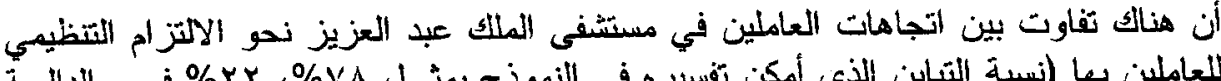

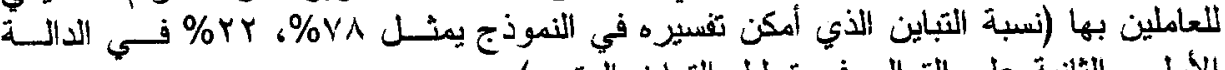

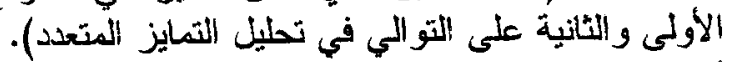

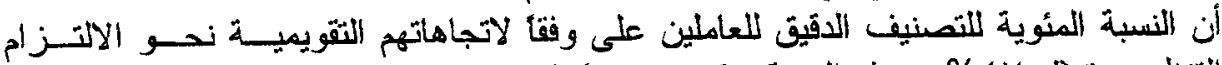

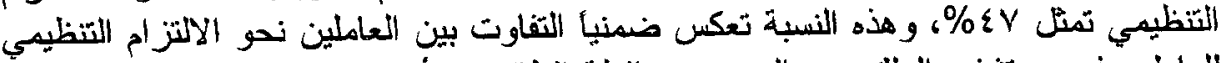

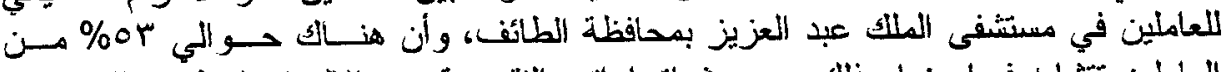

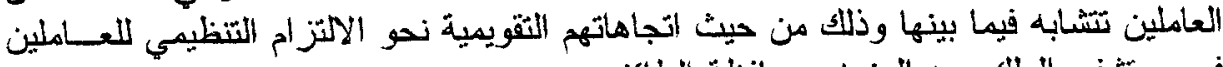
في مستشفى الملك عبد العزيز بمحافظة الطائف. ب- الأهمية النسبة للاتتز ام التنظيمي

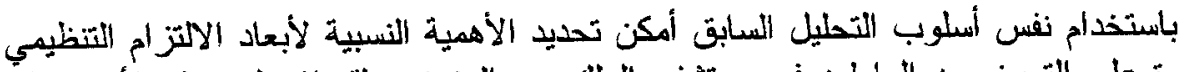

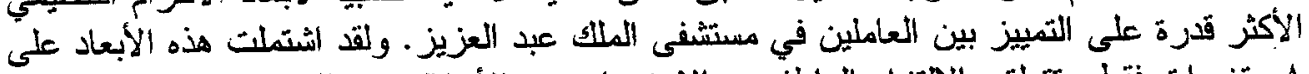

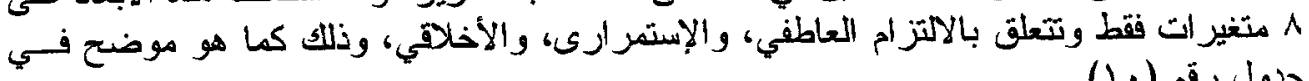

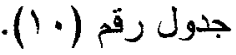

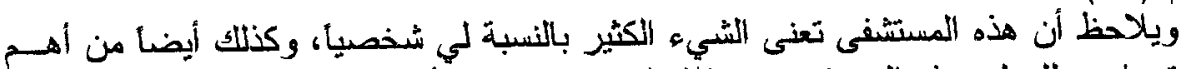

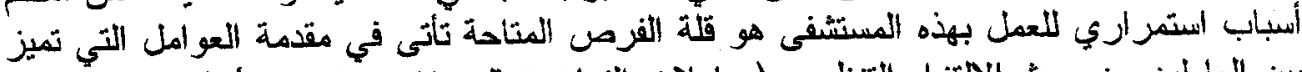

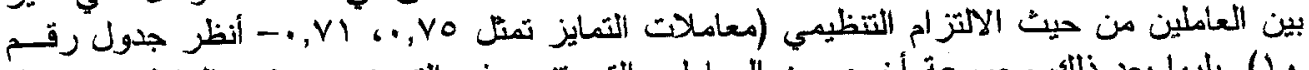

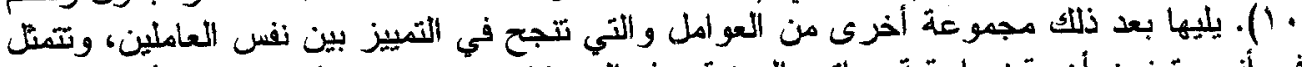

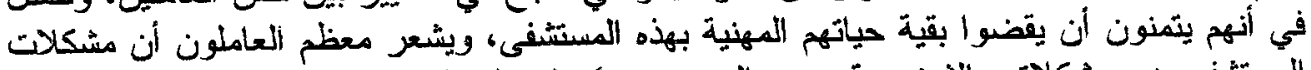

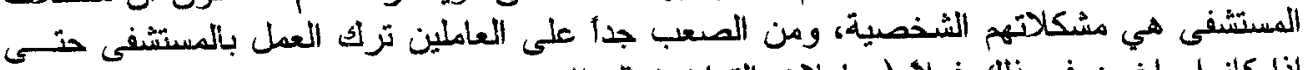

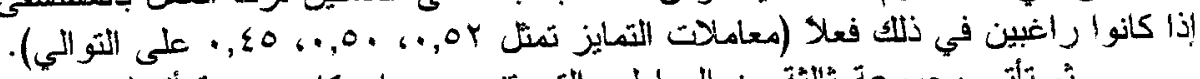

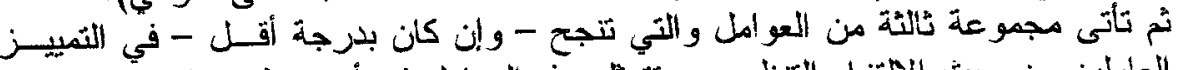

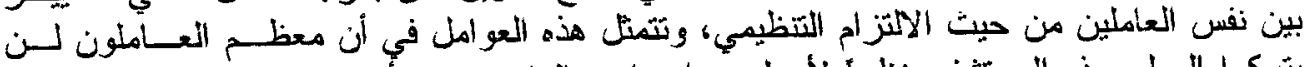

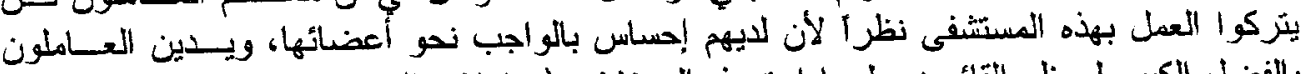

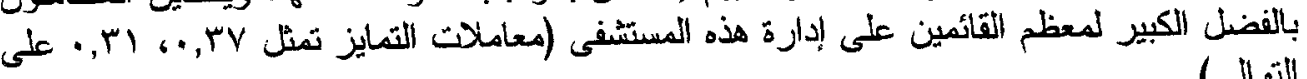
التو اللي).

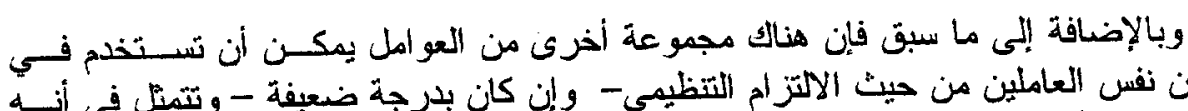

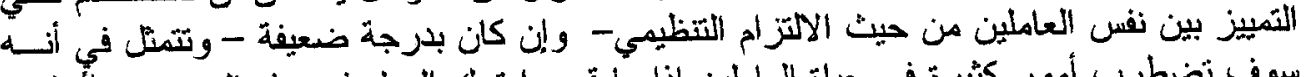

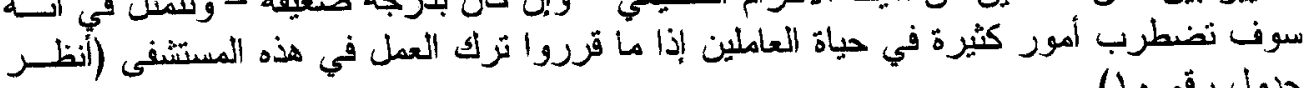

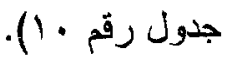


ج- توصيف مقارن للعاملين على أساس الآتزام التنظيمي

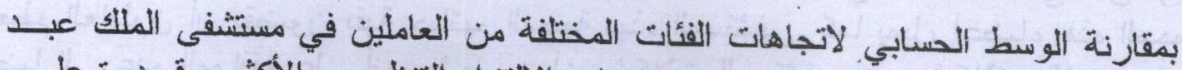

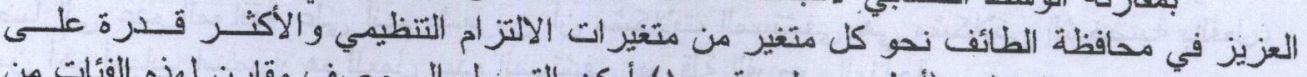
التمييز بين هؤلاء العاملين (أنظر جدول رقم م مالطير من أمكن التوصل إلى وصف مقارن لهذه الفئات من

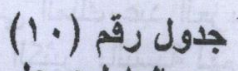

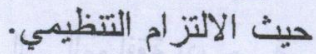

\begin{tabular}{|c|c|c|c|c|c|c|}
\hline Wheo & $\begin{array}{l}\text { Sulusy } \\
\text { f Test }\end{array}$ & fwat & (4xin) & bis, al & (13) & \\
\hline$\cdot$, vo & $* *|\Gamma, \varepsilon|$ & $\varepsilon, \varepsilon$. & $r, 4 q$ & r,or & r,Ar & شخيا. إن هذنشفى تعنى الثيء الكثير بالنسبة لي \\
\hline$\cdot, \times 1$ & ${ }^{* *}, \ldots$ & $1,9 V$ & $Y, Y A$ & $Y, r_{I}$ & $r, 7 r$ & 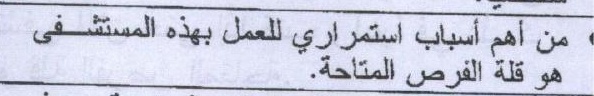 \\
\hline •, OY & $* * Y \leq, 1 Y$ & $r, q \wedge$ & $r, \cdot r$ & $Y, Y \varepsilon$ & $r, 09$ & 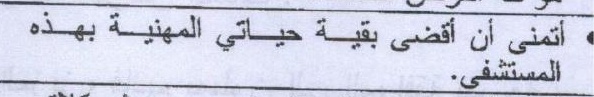 \\
\hline$\cdot, 0$. & $* * 1 \%, \mid r$ & $r, 79$ & $r, 9 \wedge$ & Y, צr & $r, \cdot \varepsilon$ & 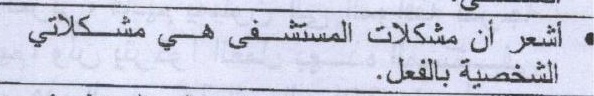 \\
\hline$\therefore, \leqslant 0$ & ${ }^{* *} \|, \wedge V$ & $r, \varepsilon 0$ & $r, \wedge \wedge$ & r,ir & $r, \wedge 1$ & 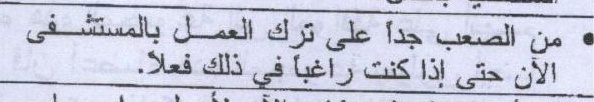 \\
\hline$\cdot, r Y$ & $* * q, \leqslant 0$ & $r, \wedge \Lambda$ & r,ir & r, r & $r, Y r$ & 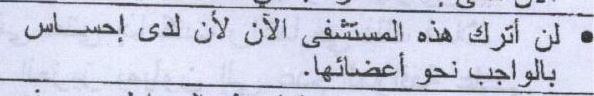 \\
\hline$\cdot, r y$ & ${ }^{* *} \wedge, 90$ & $r, 00$ & r,ru & $r, \varepsilon \varepsilon$ & $\varepsilon, r$. & 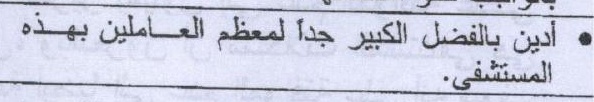 \\
\hline$\cdot, r$ & $\left.{ }^{* *}\right), 1,70$ & $Y, \Sigma \wedge$ & $r, r q$ & $Y, \wedge 9$ & rerr & 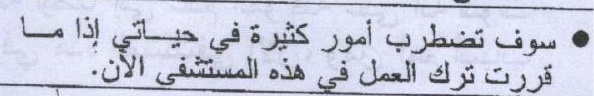 \\
\hline
\end{tabular}

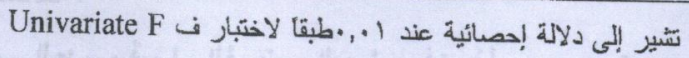

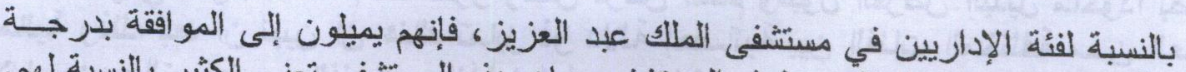

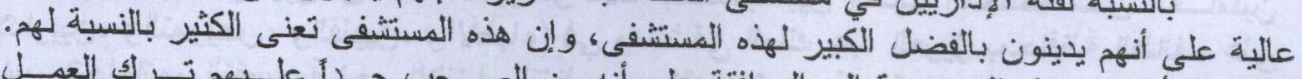

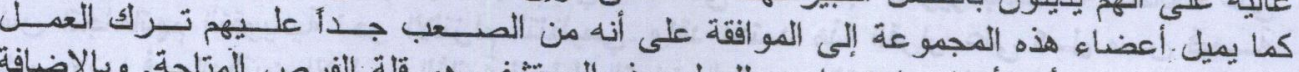

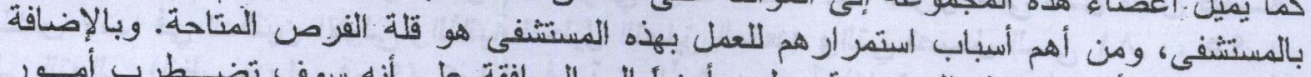

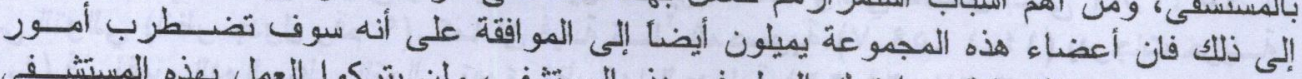

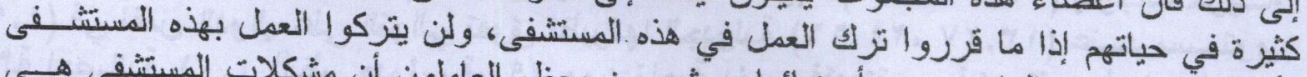

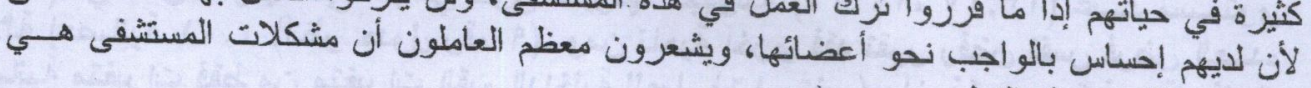

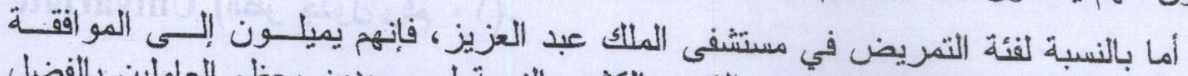

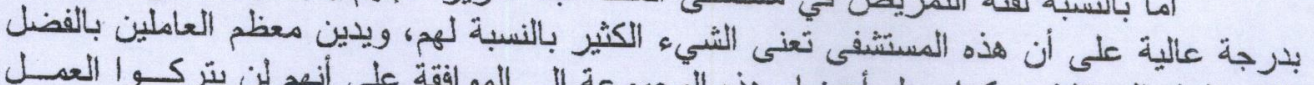

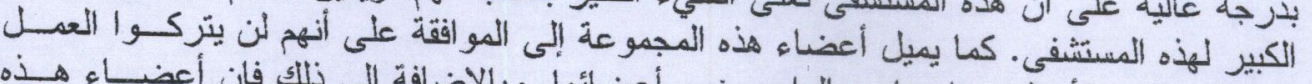

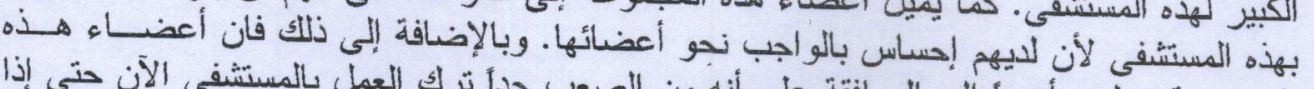

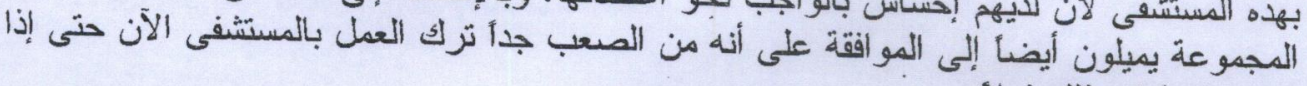
كنت راغباً في ذللك فعلا. 


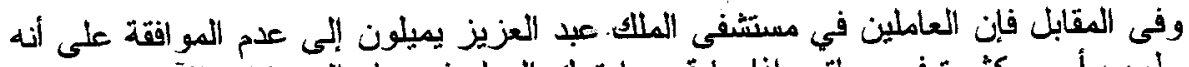

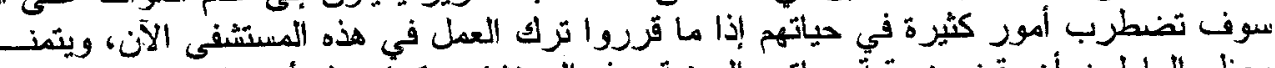

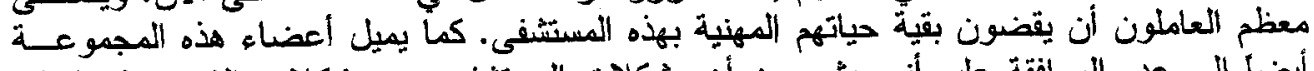

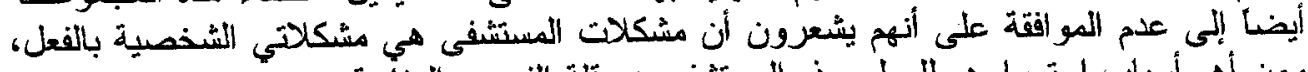

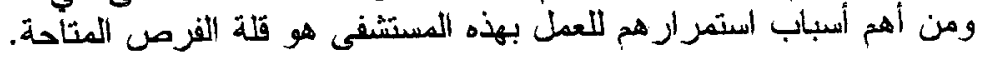

أما بالنسبة لفئة الفنيين في مستشفى الملك عبد العزيز، فإنهم يميلون إلى المو افقة بدرجيسة

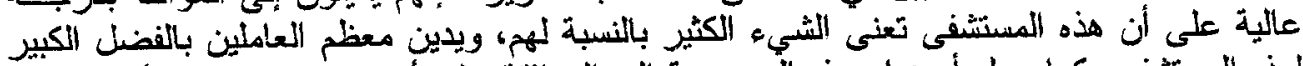

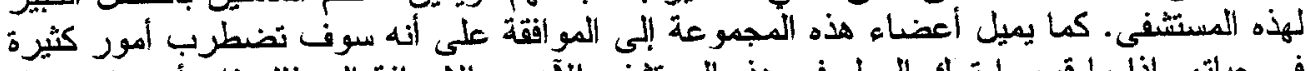

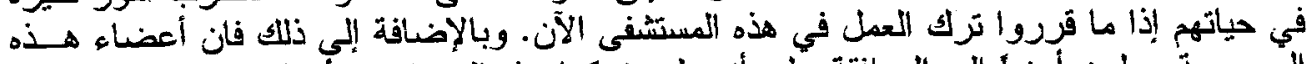

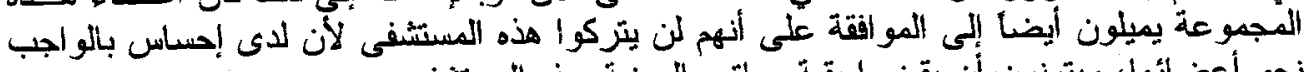

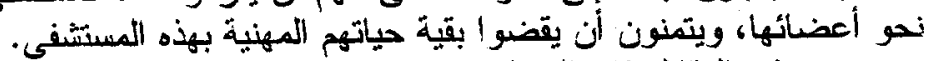

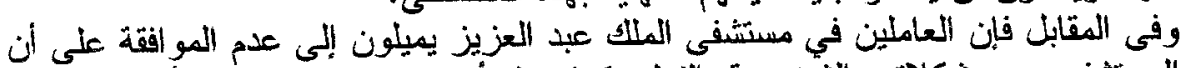

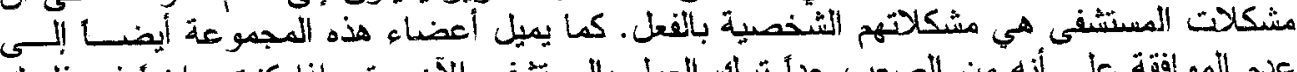

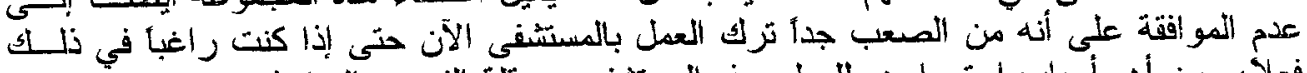

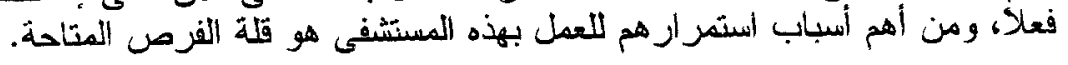

أما بالنسبة لفئة الأطباء في مستشفى الملك عبد العزيز، فإنهم يميلون إلى الموا أفقة بدرجة

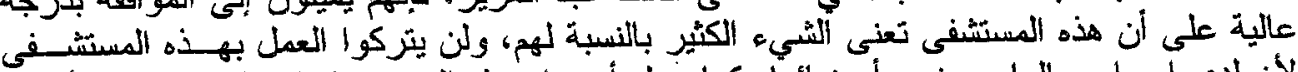

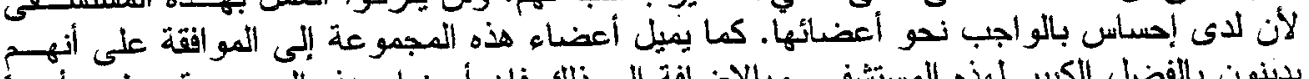

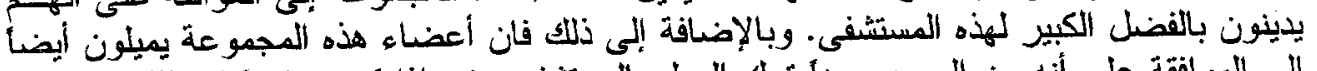

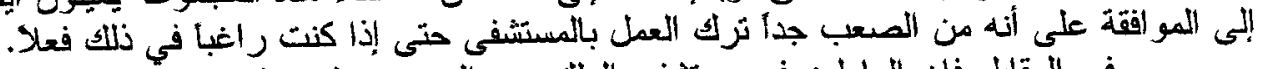

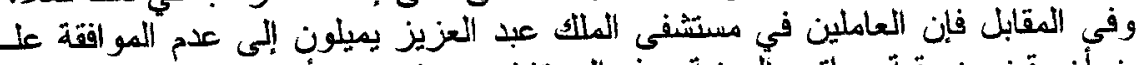

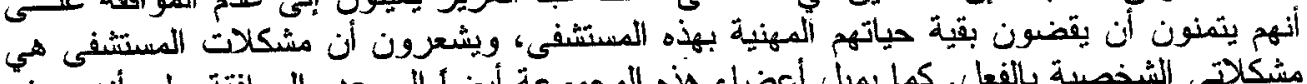

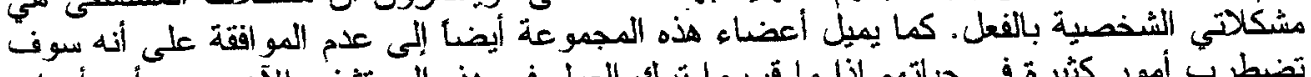

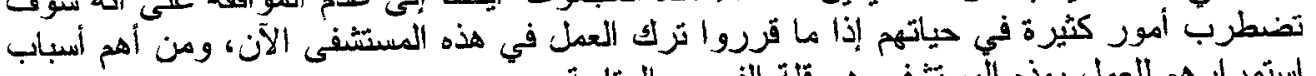

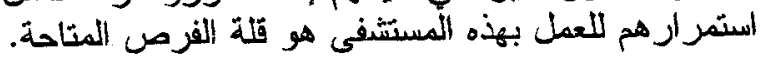

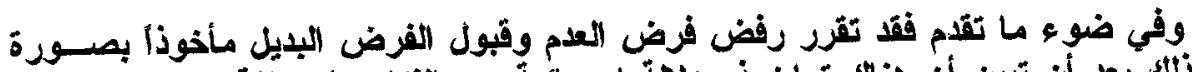

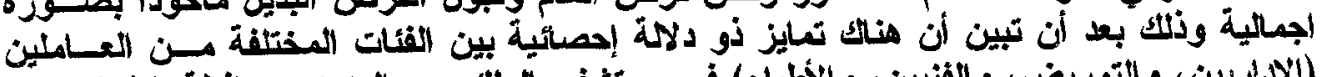

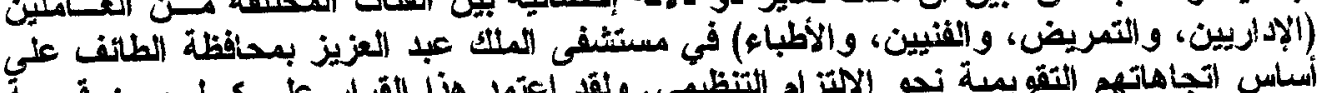

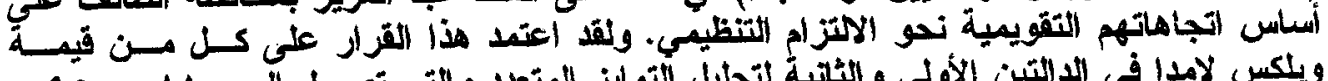

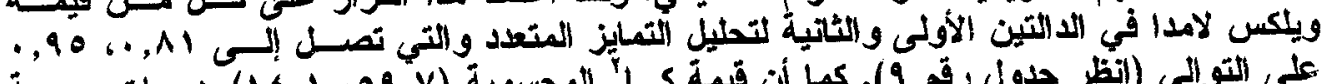

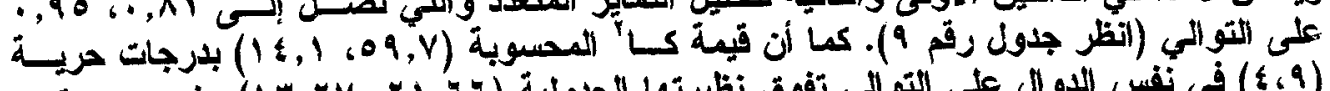

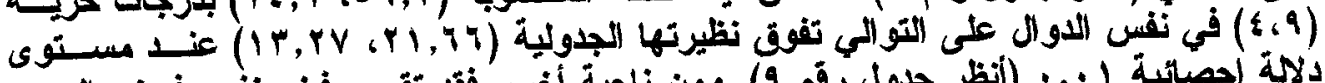

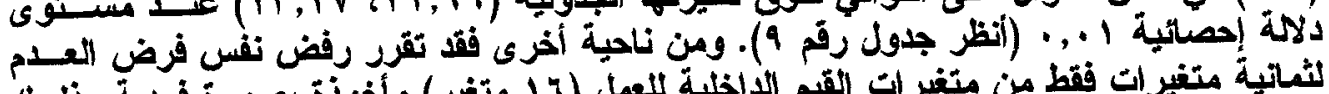

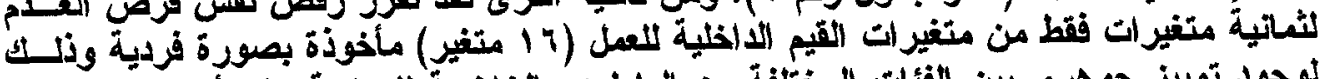

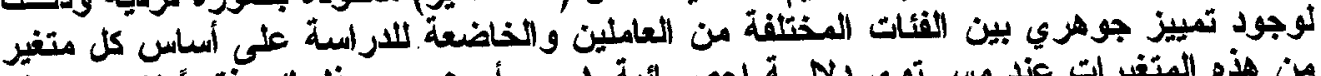

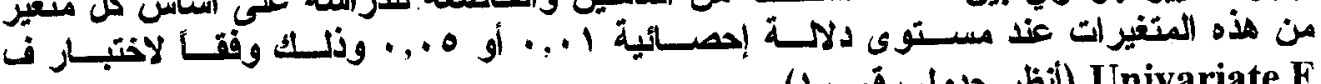
(أنظر جدول رقَم : Univariate F 


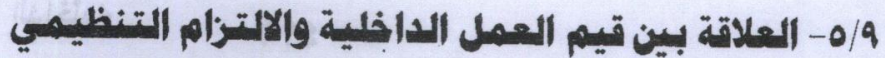

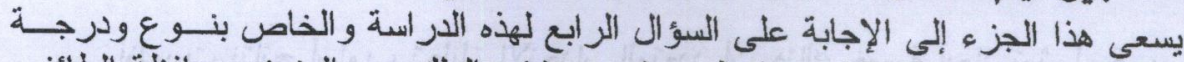

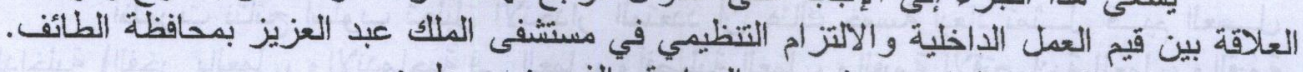

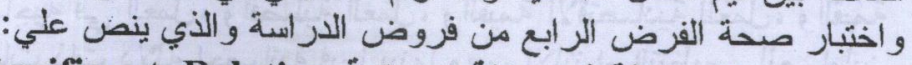

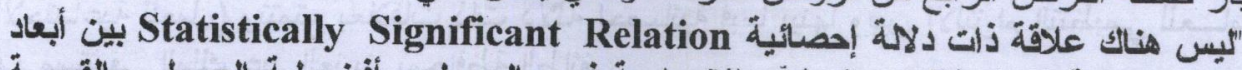

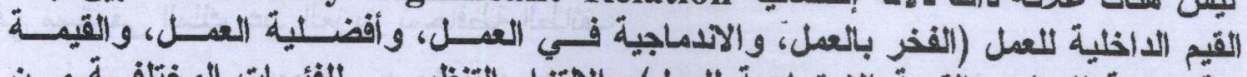

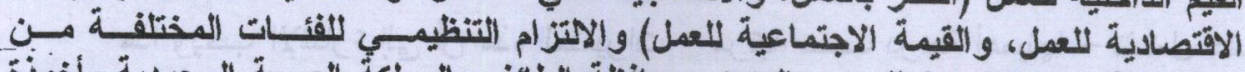

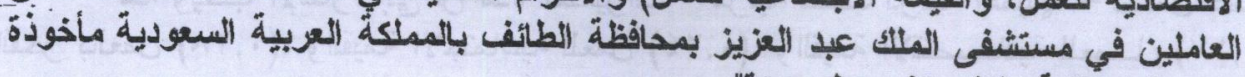

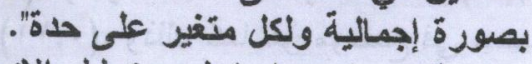

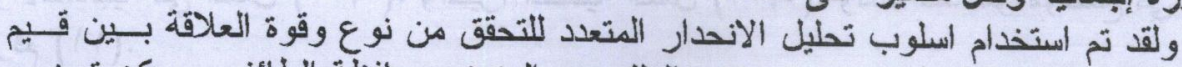

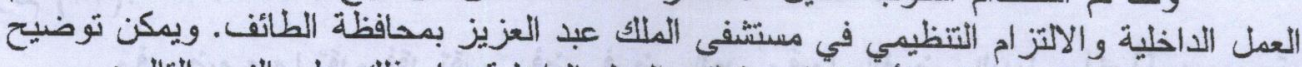
نوع ودرجة العلاقة، وكذلك الأهمية النسبية لقيم العمل الداخلية بها وذلك على على النحو التالي:

(أ) نوع ودرجة العلاقة ودة العة ونة

تتلخص نتائج أسلوب تحليل الانحدار المتعدد في الجدول التالي:

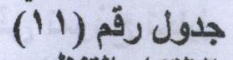

نوع ودرجة العلاقة بين قيم العمل الداخلية والالتزام التنظيمي في مستشفى المثل عبد العزيز بالطائف

(Multiple Regression Analysis مخرجات تحليل الاتحدار المتعة فئندام)

\begin{tabular}{|c|c|c|c|c|}
\hline $\begin{array}{l}\text { Lates } \\
\text { +ukill } \\
\end{array}$ & $\begin{array}{c}\text { bujjli Jates } \\
\mathbf{R}\end{array}$ & $\begin{array}{l}\text { J1 Leta Jen } \\
\text { Beta }\end{array}$ & 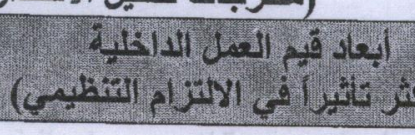 & 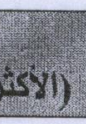 \\
\hline$\cdot, 1 \varepsilon$ & $\cdot, r \wedge$ & $\cdots+, Y A$ & الفذر بالعمل & - \\
\hline., 1 . & •, rY & $\ddot{*} \cdot, \Gamma$ & الاندماجبة في العمل & - \\
\hline$\therefore, .0$ & •, Yr & $\because, 11$ & أفضلية العمل & - \\
\hline$\cdot, \cdot$ & $\rightarrow 1$ & $\cdots \cdot$, IV & القيمة الاقتصادية للعمل & • \\
\hline 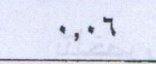 & $\cdot, Y \varepsilon$ & $\cdots \cdot, r \varepsilon$ & القيمة الاجتماعية للعمل & - \\
\hline . & 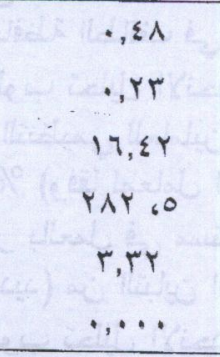 & $x^{2}(6.14$ & 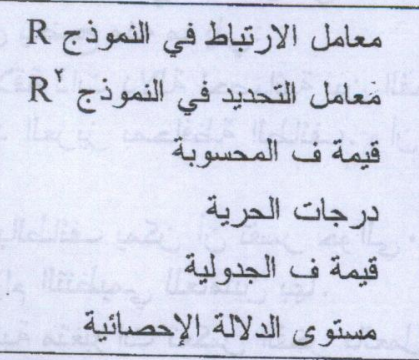 & $\begin{array}{l}\cdot \\
. \\
. \\
. \\
.\end{array}$ \\
\hline
\end{tabular}

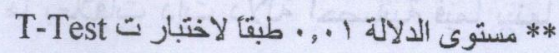
ومن خلال الجدول السابق يتضح النتائج التالية:

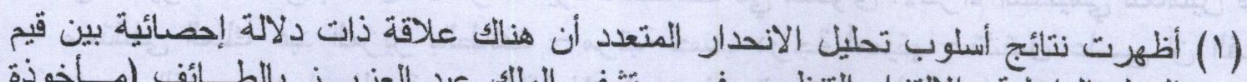

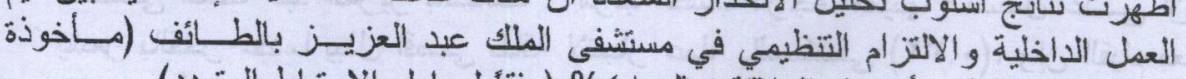

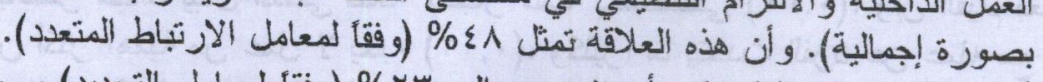

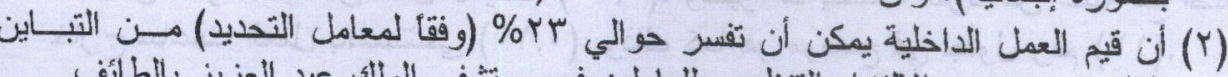

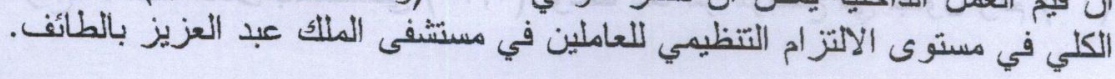




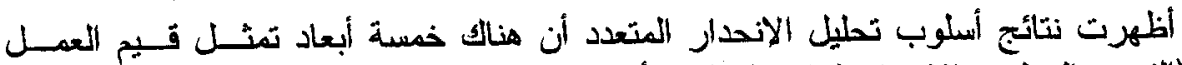

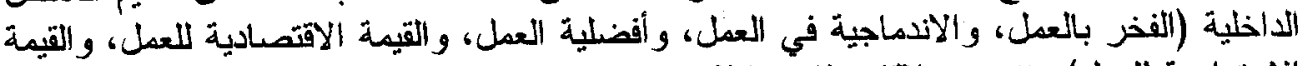

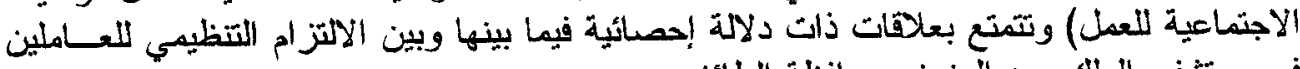

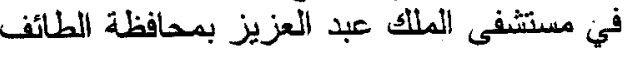

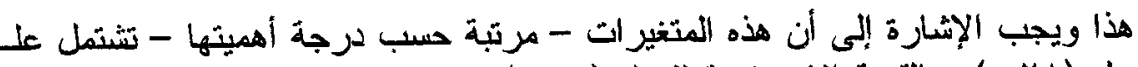

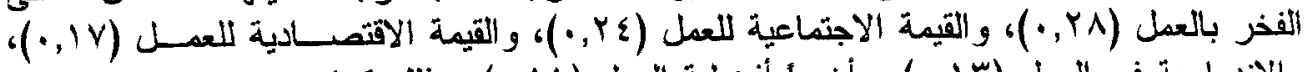

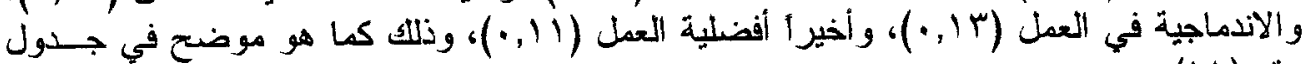
رقم (11) (11)

وفي ضوء ما تقدم فقا تقرد رفض فرض العدم وقبول الفرض البديل مأخوذأ بصــورة

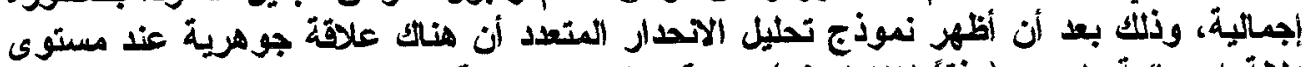

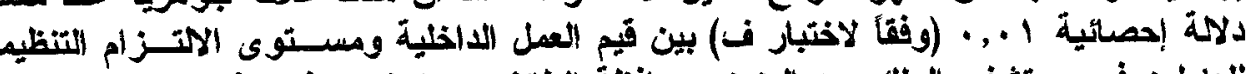

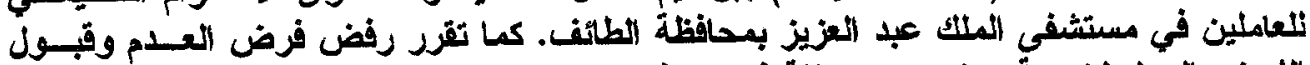

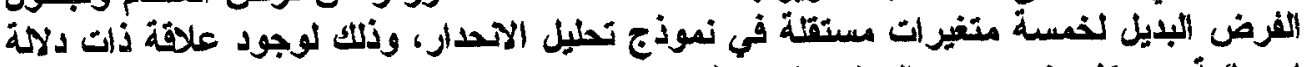

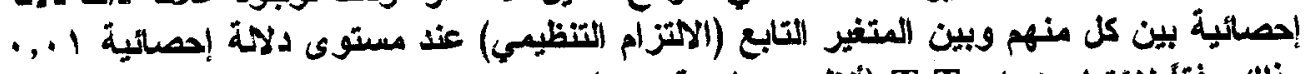

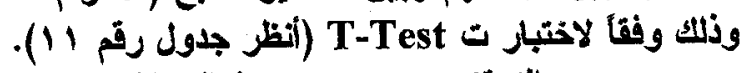

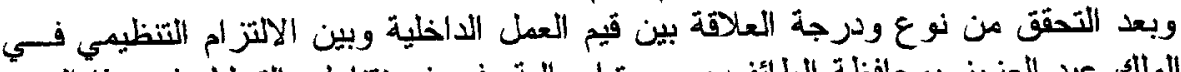

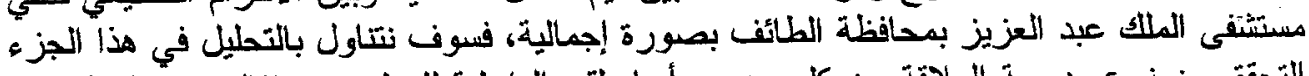

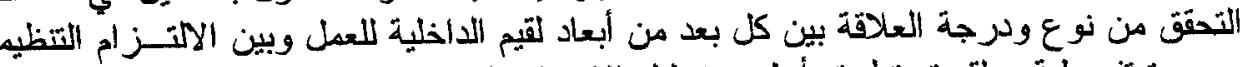

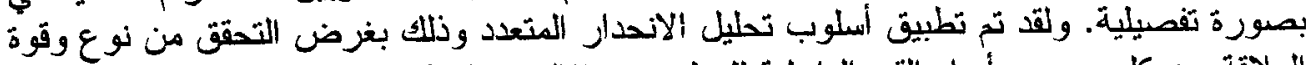

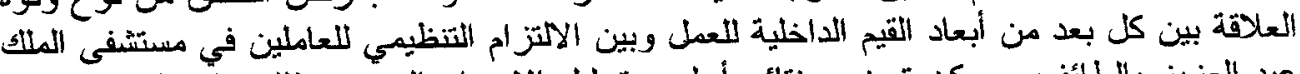

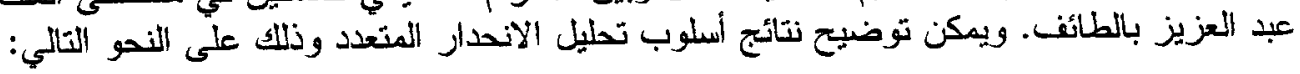

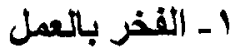

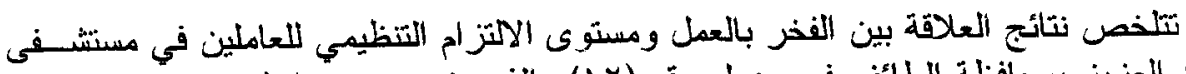

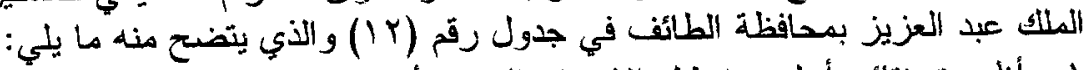

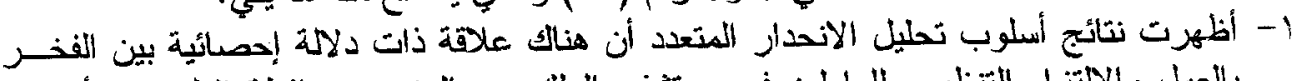

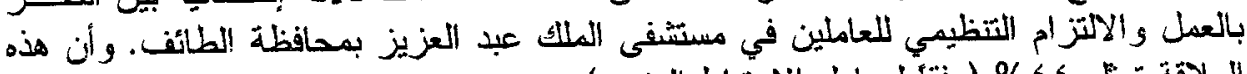

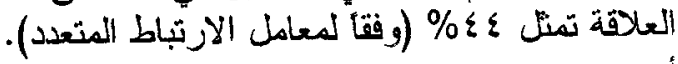

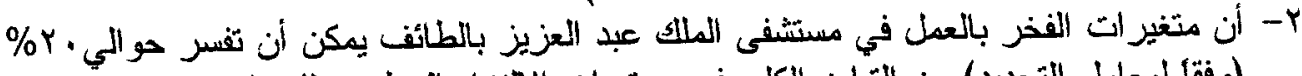

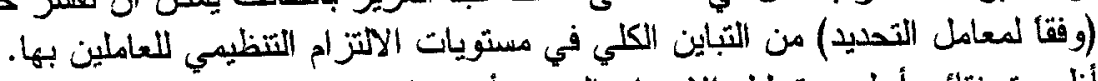

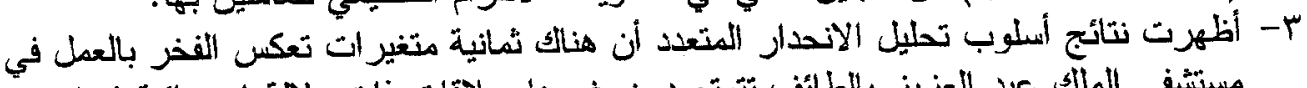

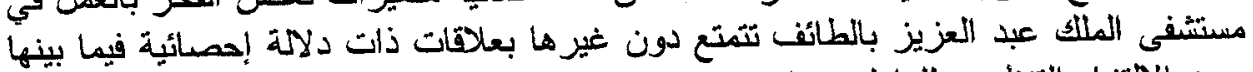

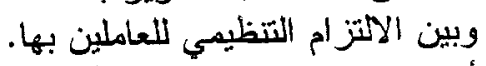

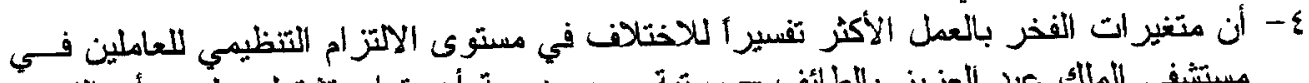

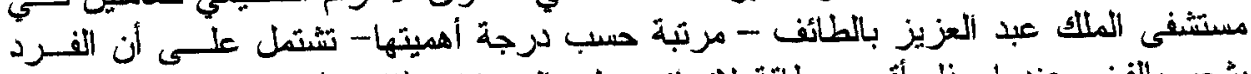

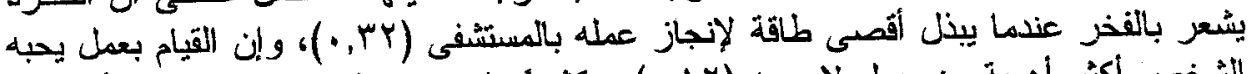

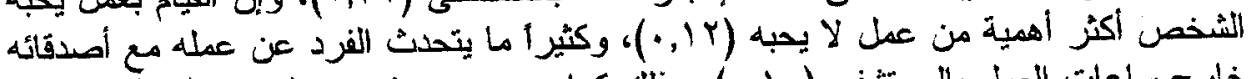

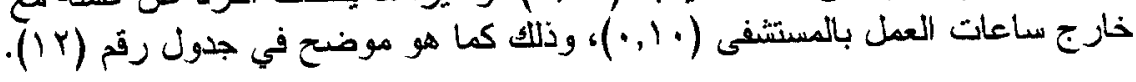




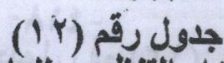

يوع ودرجة العلاقة بين الفخز بالعمل والالتزام النتطيمي للعاملين في مستشفى الملك عبد العزيز بالطائف

\begin{tabular}{|c|c|c|c|}
\hline $\begin{array}{l}\text { Juke } \\
\text { sistill }\end{array}$ & $\frac{6 \operatorname{lig} 81 \text { was }}{\mathrm{R}}$ & 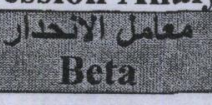 & 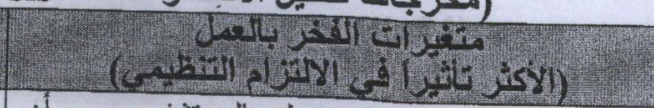 \\
\hline$\cdot, \cdot \circ \varepsilon$ & $\cdot, 19$ & $\cdot,+9$ & 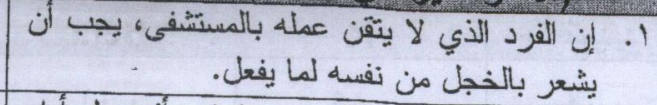 \\
\hline$\because \because r$ &., 17 &,+ .0 & Y. بشعر الفرد بتحقيق ذاته عندما يقدم أفضـلـل أداء \\
\hline$\cdot, \cdot r$ & 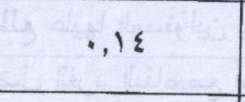 & $\cdot,+1$ & 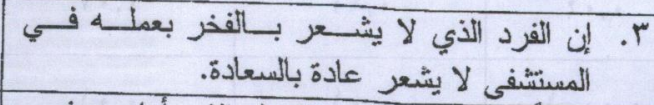 \\
\hline$\cdot, \cdot r$ & $\cdot, 1 V$ & $\cdot, \cdot 1$ & ع. كثيرأ ما أشُعر بالفخر بالحمل الذي أمارسه فـي \\
\hline$\because, \bullet V$ & $\cdot, Y V$ & $\bullet, \wedge$ & 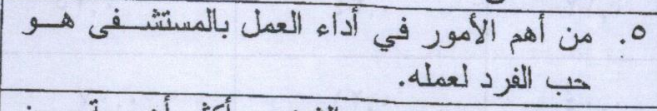 \\
\hline$\cdot, \cdot 7$ & - , Yo & * & 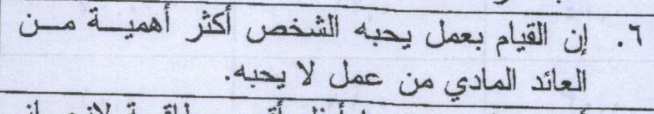 \\
\hline., 10 & - ז & * • & 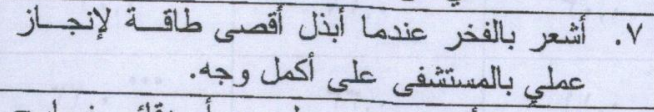 \\
\hline$\cdot, \cdot \varepsilon$ & $\cdot, Y$. & $\cdot 1,1$ & A. كثيرات ها أتعدث عن بالمسشفى. عملي مع أصدقائي خـارج \\
\hline 8 & $\begin{array}{l}\cdot \Sigma \leq \\
,, Y \\
A, Y \\
r \wedge 1, \wedge \\
r, 01 \\
+, \cdots\end{array}$ & & 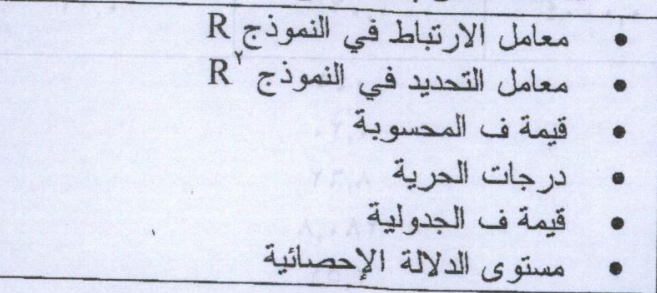 \\
\hline
\end{tabular}

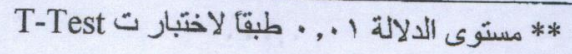

\section{r- الأدماجية في العمل}

تتلخص نتائج العلاقة بين الاندماجية في العمل ومستوى الالتز ام التتظيمي للعاملين في وفي

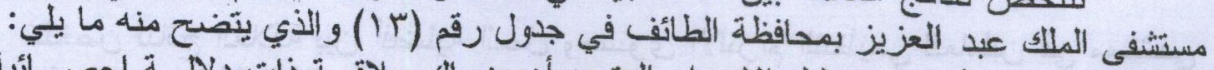

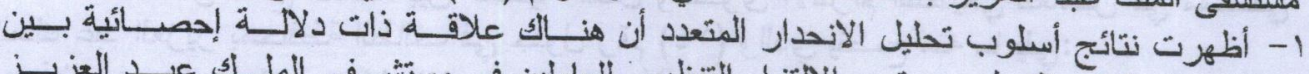

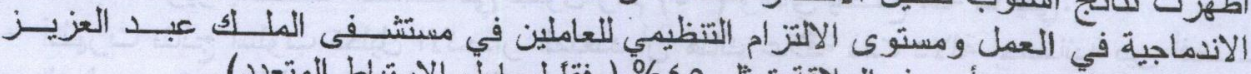

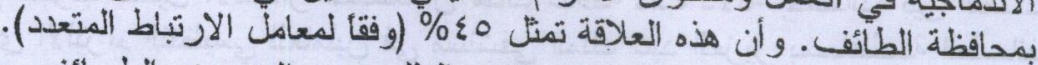

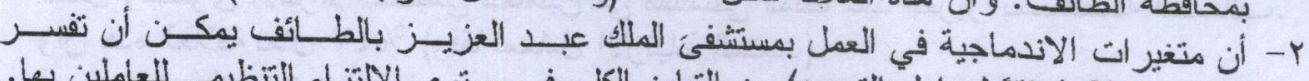

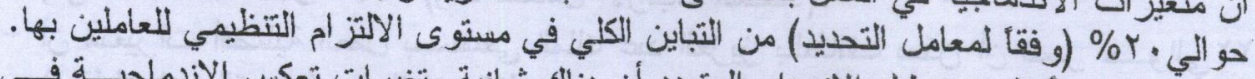

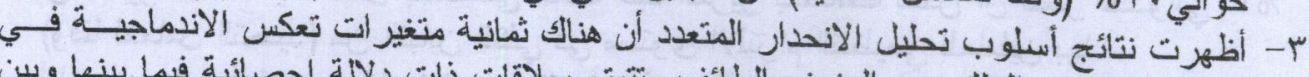

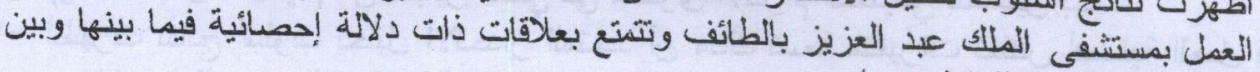
الالتز ام التنظيمي بملي للعاملين بها. ع- أن منغير ات الأندماجية في العمل الأكثر تفسيرا للاختلاف في مسـتوى الالتهز ام التتظيمسي

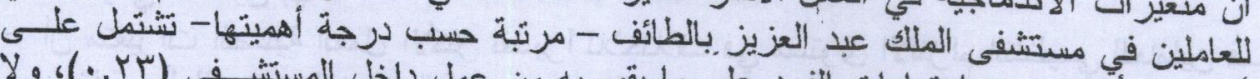

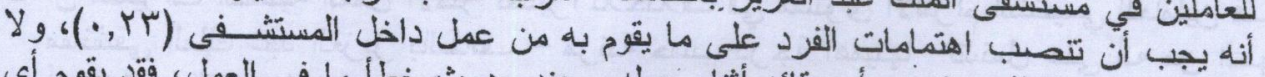

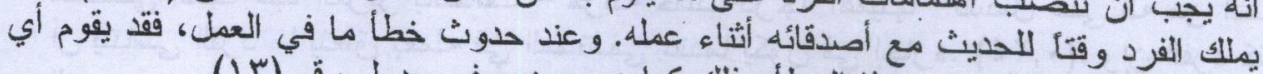

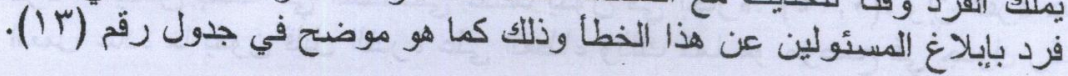




\section{- \\ جدول رقم (ع 1 1)}

ع عدرجة العلاقة بين أفضلية العمل والالتزام التتظيمي للعاملين في مستشفى المبلك عبد العزيز بالطائف

\begin{tabular}{|c|c|c|c|}
\hline $\begin{array}{l}\text { when } \\
\text { twall }\end{array}$ & 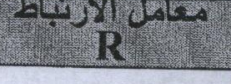 & Beta & 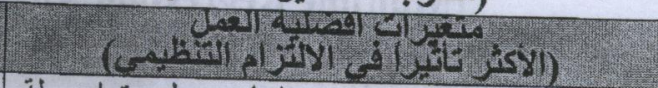 \\
\hline$\ldots, \cdot r$ & , 10 & 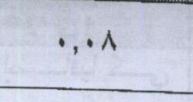 & 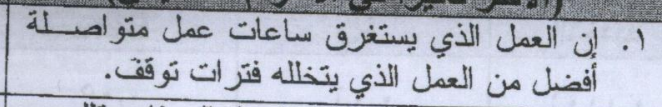 \\
\hline,,,$\ldots \varepsilon$ & P, Y Y & $\cdot,+1$ & 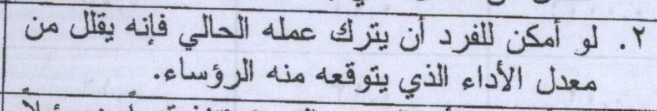 \\
\hline , , . . & $\cdot, \cdot 1$ & .,.r & 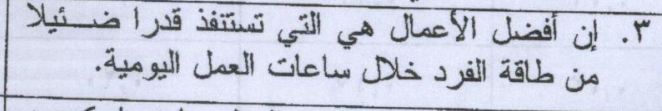 \\
\hline$\therefore, 9$ & $\cdot, r$ & $\cdots \cdot, r$. & 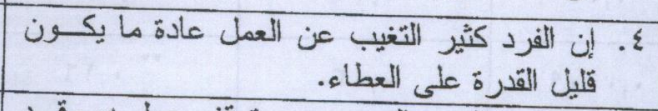 \\
\hline$\therefore . v$ & ז', & ${ }^{*}, 14$ & 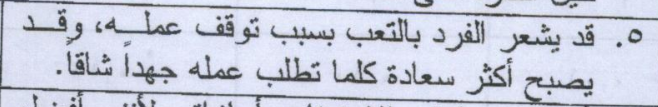 \\
\hline$\cdots$ & $\cdot, 19$ & $\cdots \quad$, , IV & 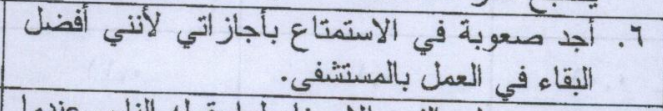 \\
\hline$\cdot, .7$ & - , YO & $\cdots \cdot, 19$ & 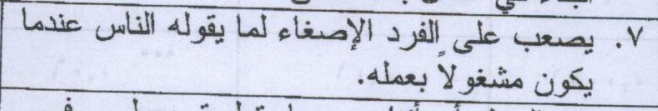 \\
\hline$\because, \cdots \wedge$ & $\therefore, .9$ & $\cdots, r, Y \xi$ & 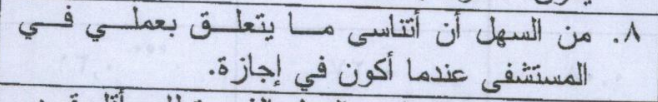 \\
\hline,$\ldots$ & ,. & $\cdot, \cdot 1$ & 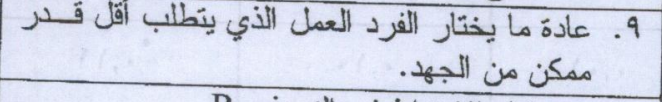 \\
\hline 8 & 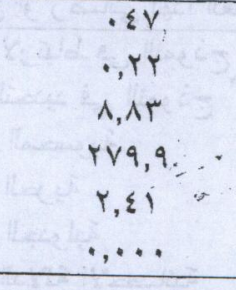 & & 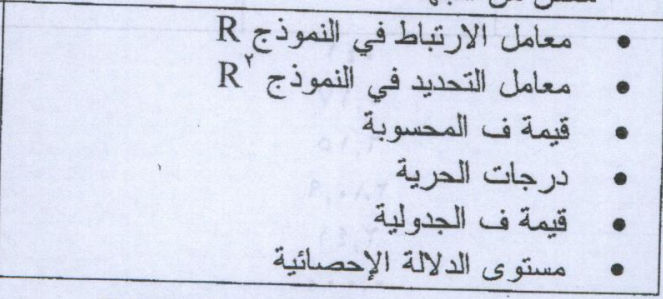 \\
\hline
\end{tabular}

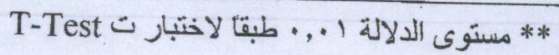

؛ - القيمة الاقتصادية للعمل

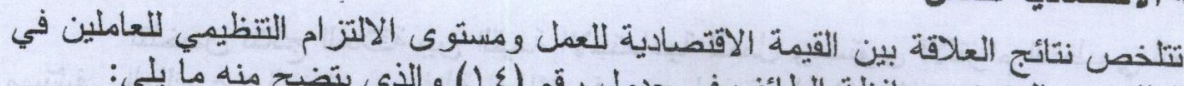

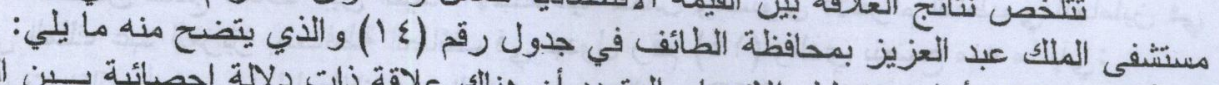

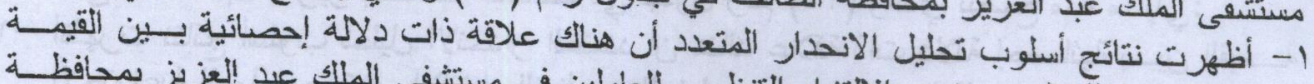

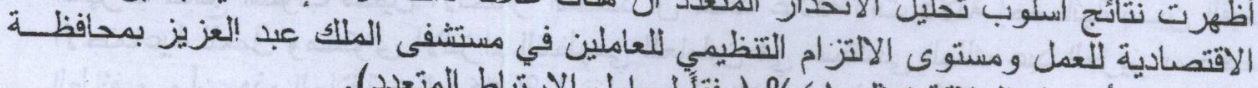

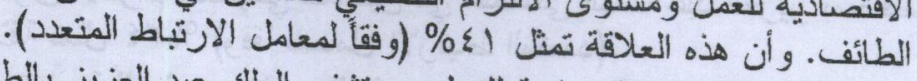

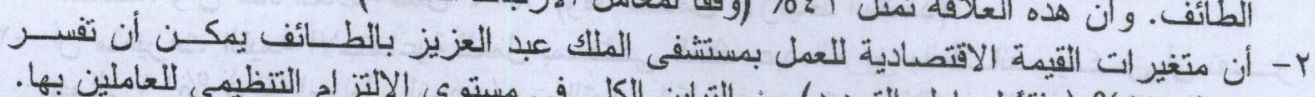

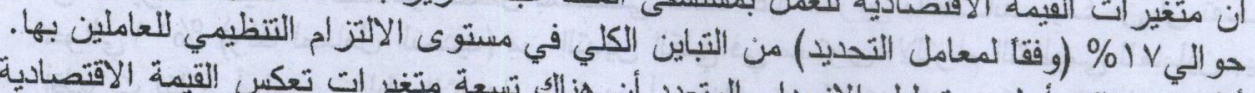

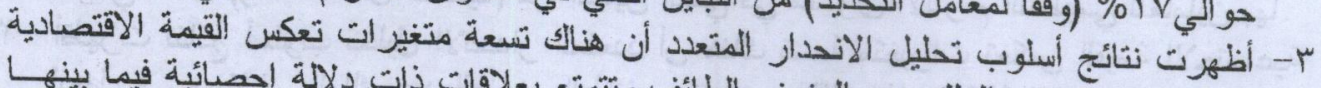

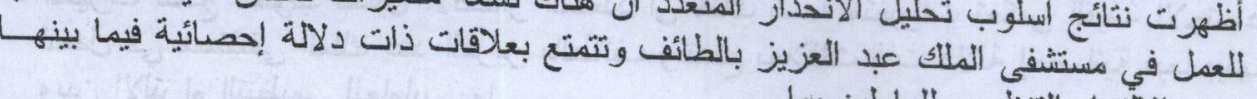
وبين الالتز ام التنظيمي للعاملين بنها.

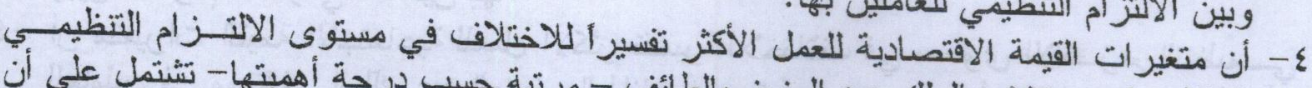

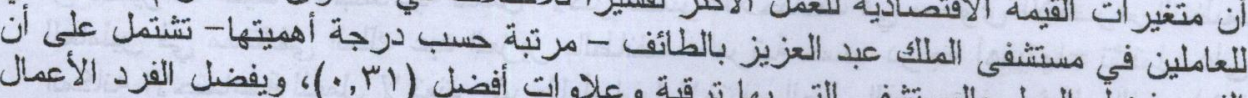

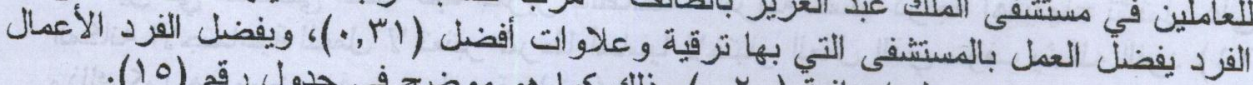

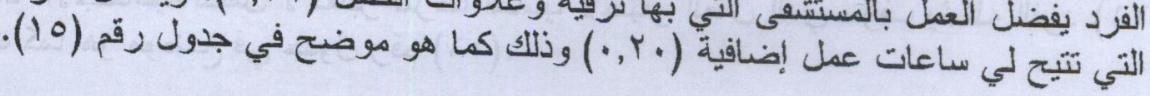




\section{$-\varepsilon r \cdot-$

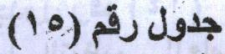

ع ودرجة العلاقة بين القيمة الاقتصادية للعمل والالتزام التظظيمي للعاملين في مستشفى الملك عبد العزيز بالطأ

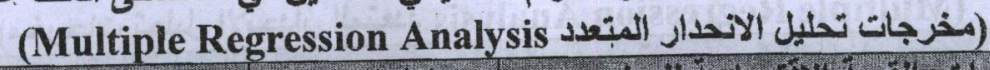

\begin{tabular}{|c|c|c|c|}
\hline $\begin{array}{l}\text { Jules } \\
\text { tunill }\end{array}$ & $\begin{array}{l}\text { blajpl jwa } \\
\text { R }\end{array}$ & $\begin{array}{l}\text { Jiviril Jos } \\
\text { Beta }\end{array}$ & 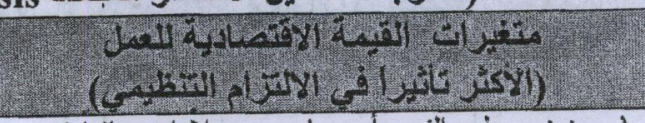 \\
\hline , , , l & $\cdot, \cdot 1$ & $\cdot, .0$ & 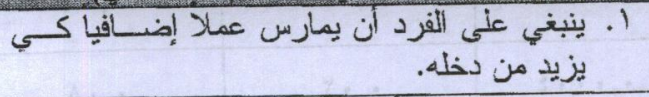 \\
\hline$\ldots Y$ & זו, & $\cdot, 14$ & r. اله أكبر عائد مادي أن يختار الفرد العمل الذي بحقق \\
\hline$\cdot, r$ & , IV & $\cdot, Y \cdot$ & با في المصنش الأعمال التي تشيح لي ساعات عمل إضافية \\
\hline$\cdot, \ldots q$ & $\cdot, \cdot T$ & $*, 17$ & 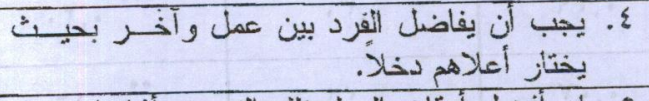 \\
\hline$\cdot, \cdot 1$ & - 1. & $\because, I r$ & 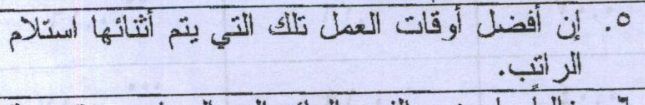 \\
\hline,++1 & $\cdot 1$. & $\cdot, 11$ & 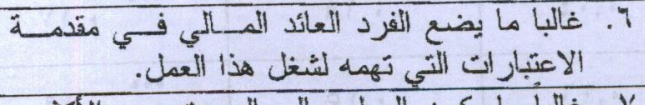 \\
\hline,,$\cdots$, &,,$\cdot 1$ & $\cdots, \cdot, 7$ & 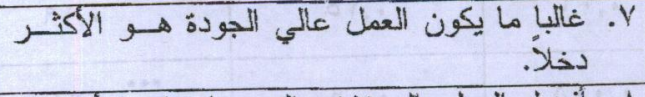 \\
\hline$\because, \cdot A$ & $\cdot, Y V$ & $\cdots, r, r$ & 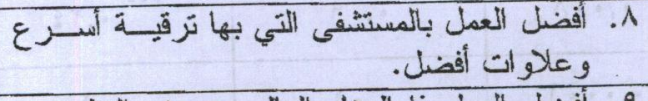 \\
\hline,, .1 & $\cdot, 1$. & $\because, 11$ & 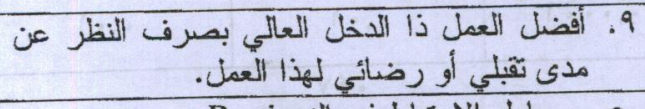 \\
\hline 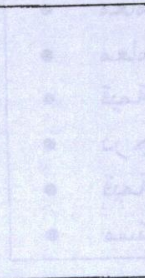 & $\begin{array}{l}. \leqslant 1 \\
\because, 1 v \\
r, 10 \\
r \wedge,, 9 \\
r, \varepsilon 1 \\
r, \cdots\end{array}$ & & 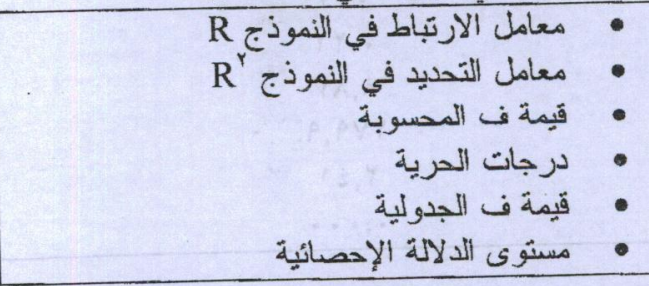 \\
\hline
\end{tabular}

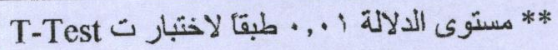

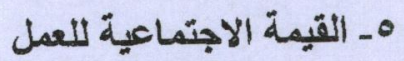

تتلخص نتائج العلاقة بين القيمة الاجتماعية للعمل ومستوى الالثز ام التنظيمي للعاملين في

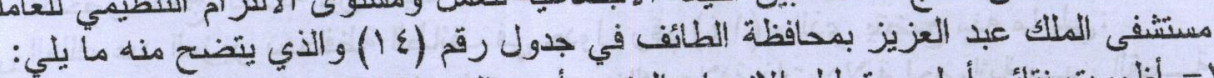

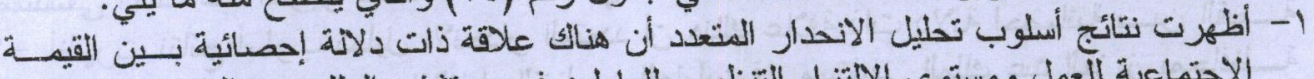

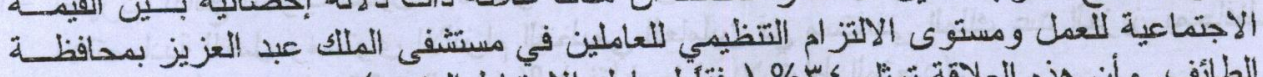

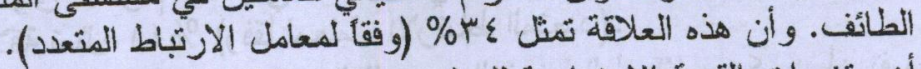

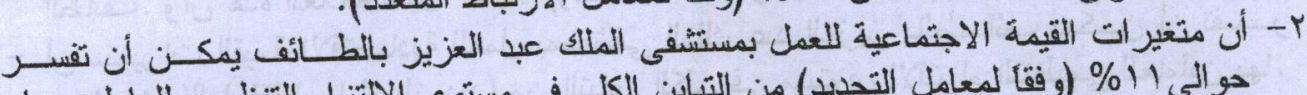

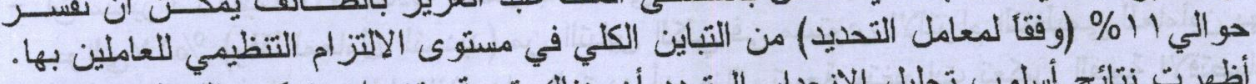

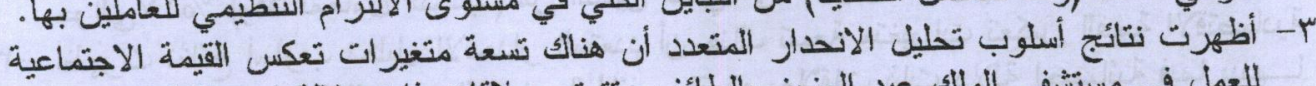

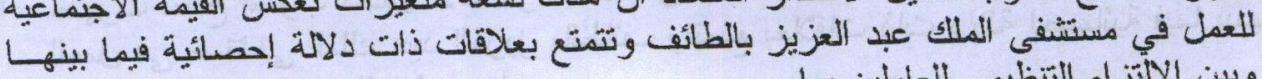

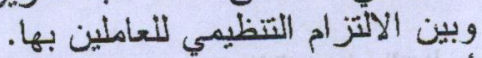

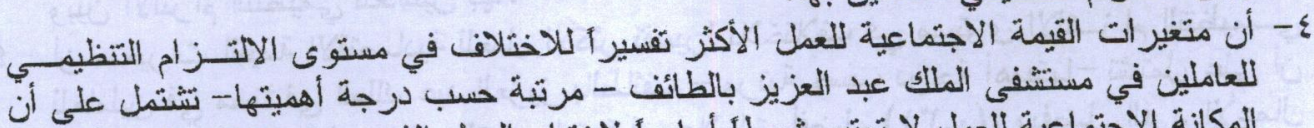

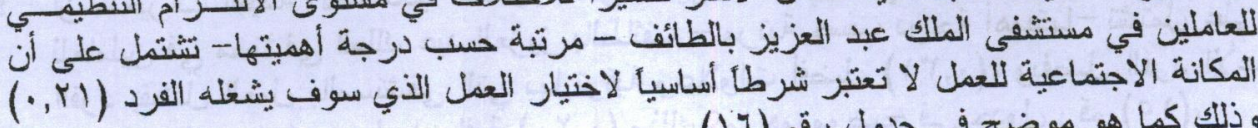

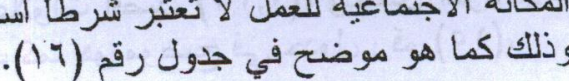


جة العلاقة بين القيمة الاجتماعية للعمل والالتزام التتظيمي للعاملين في مستشفى الملك عبد العزيز بالطائف

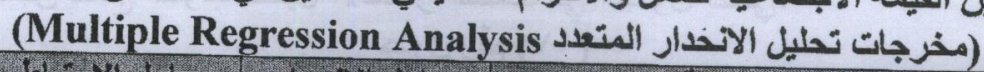

\begin{tabular}{|c|c|c|c|}
\hline $\begin{array}{l}\text { Jules } \\
\text { +utilit } \\
\end{array}$ & $\begin{array}{l}\text { blais } 81 \text { Jules } \\
\mathbf{R}\end{array}$ & $\begin{array}{l}\text { Jis ill Jaka } \\
\text { Beta }\end{array}$ & 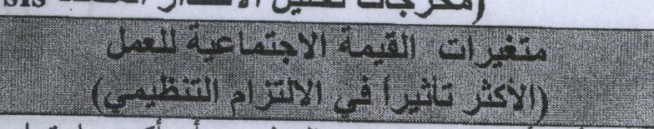 \\
\hline$\cdot, \cdot \varepsilon$ & $\cdot, r$. & $\because, 1 r$ & أس أحد أسباب رغبتي في العمل هو أن أكسب احترام \\
\hline$\because, \cdots q$ & $\cdot, \cdot r$ & $\cdot, \cdot \varepsilon$ & 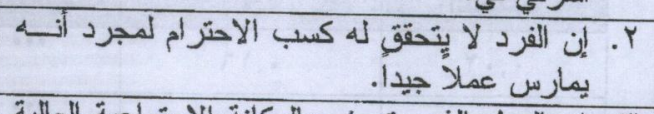 \\
\hline , . ro & $\cdot, .0$ & $\cdot, \cdot r$ & 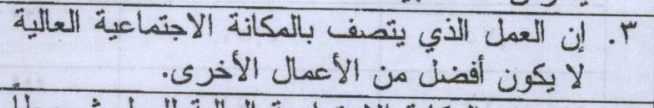 \\
\hline., TVY & $\cdot, Y_{7}$ & $\cdots \cdot r_{1}$ & 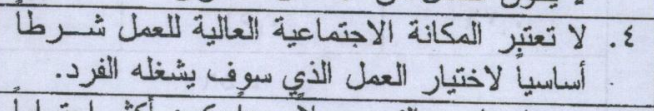 \\
\hline & $\because, \varepsilon$ & $\because, 0$ & •. بين الآخرين. بمارس الفرد عملا جيدأ بكون أكثر احتر اما \\
\hline., .179 & ., Ir & $\cdot, \cdot r$ & 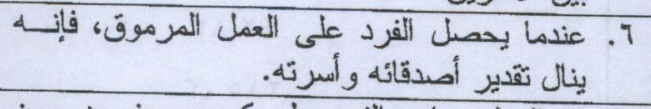 \\
\hline., .0 & $\cdot, Y_{1}$ & $\cdot, i r$ & 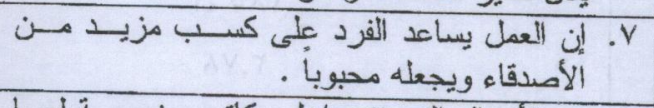 \\
\hline,$\ldots \varepsilon \varepsilon$ & $\bullet, \cdot r$ & $\cdots,, \cdot r$ & 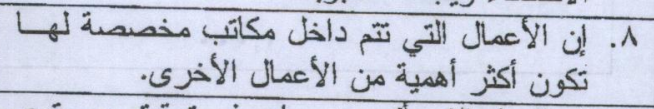 \\
\hline., 0194 & $\cdot, 1 \leq$ & $\cdot, \cdot \varepsilon$ & 9 9. إنتماعي أفضل الذي أقوم به يساهم في تحقيق مسـتوى \\
\hline & $\begin{array}{l}. r \xi \\
., 11 \\
r, 9 \vee \\
r \wedge, q- \\
r, \Sigma 1 \\
., \ldots\end{array}$ & & 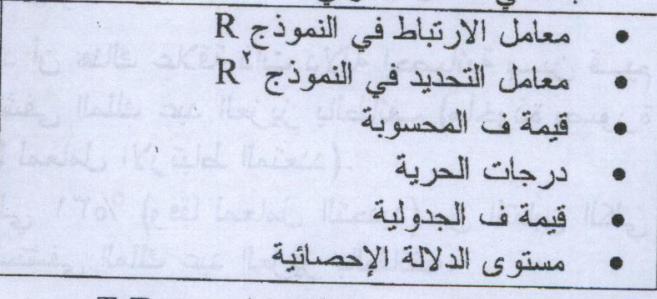 \\
\hline
\end{tabular}

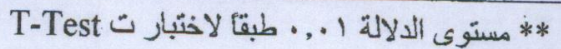

\section{1/9 - العلاقة بين قيم العمل الخارجية والالتزام التنظيمي}

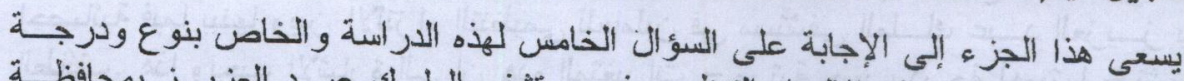

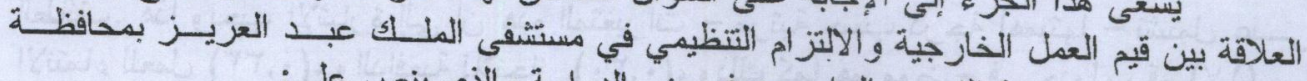

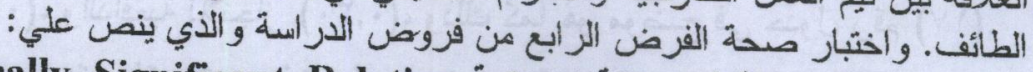

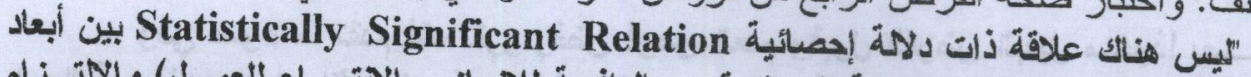

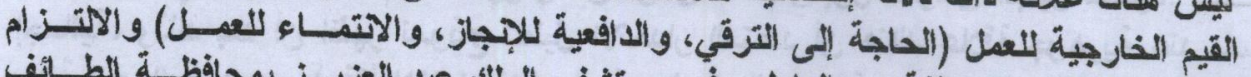

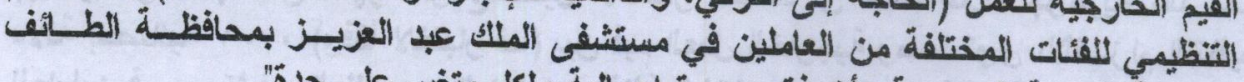

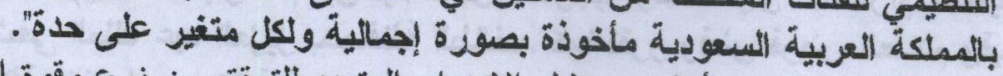

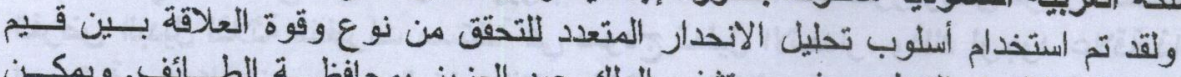

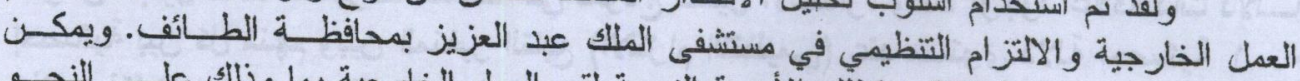

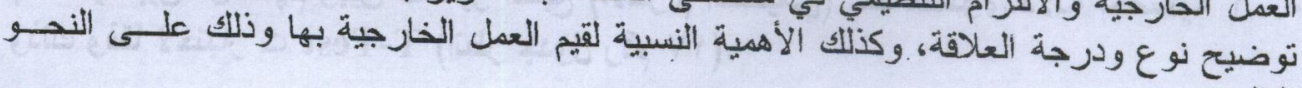




\section{تثلخص نتائج أسلوب تخليل الانحدار المنعدد في الجدول التالي:}

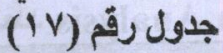

نوع ودرجة العلاقة بين قيم العمل الخارجية والالتزام التنظيمي في مستشفى المبلك عبد العزيز بالطائف

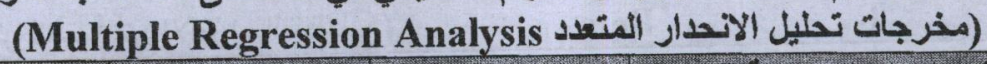

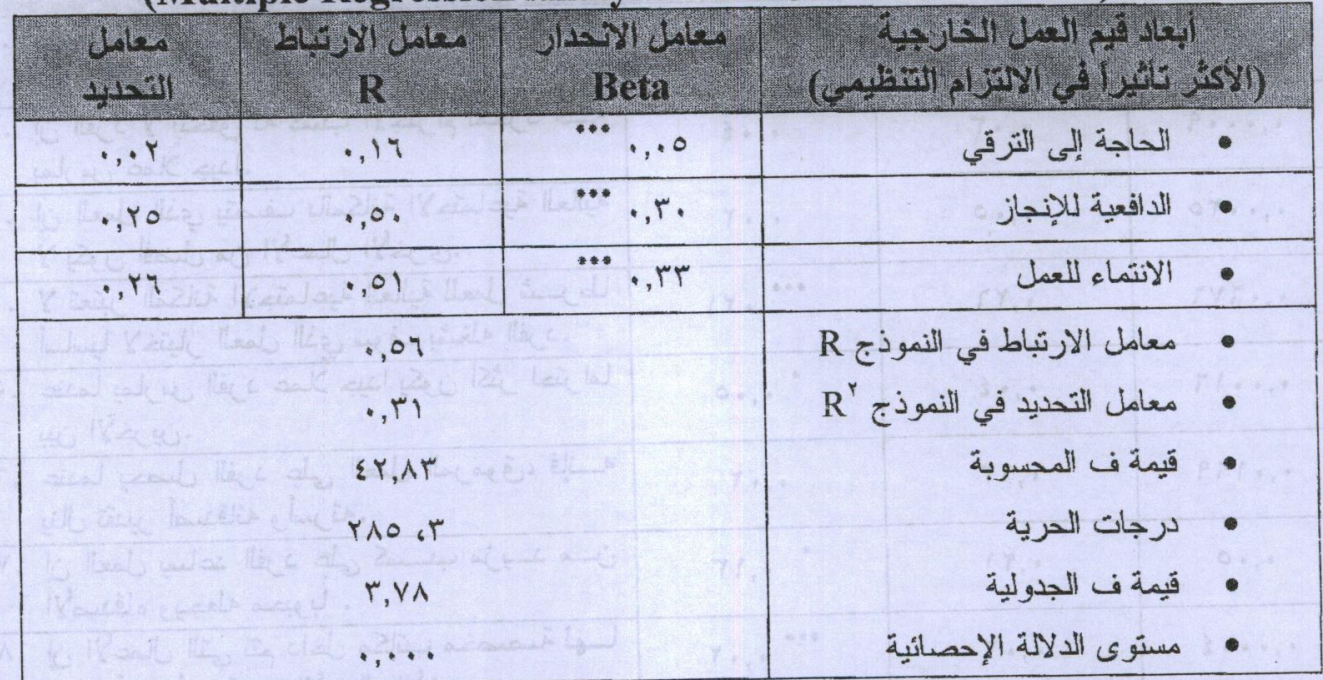

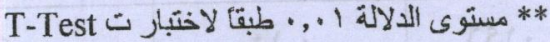

ومن خلال الجدول السابق يتضح النتائج التالية:

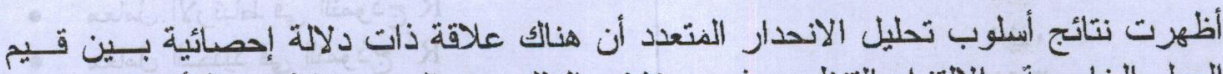

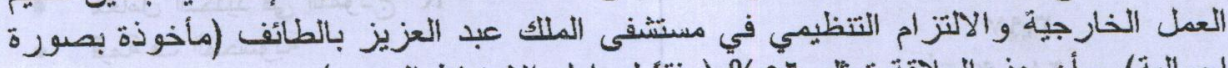

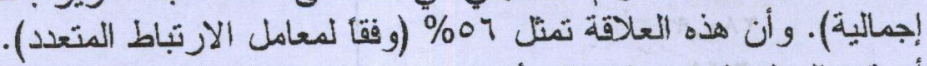

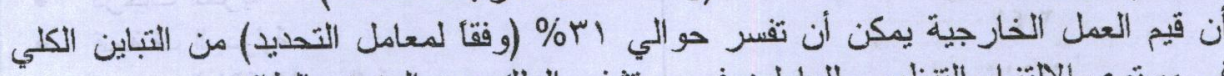

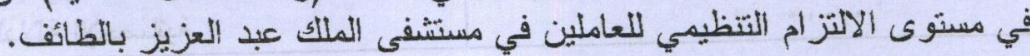

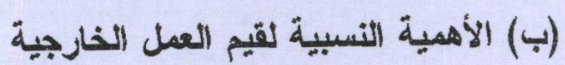

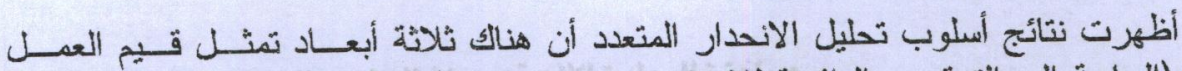

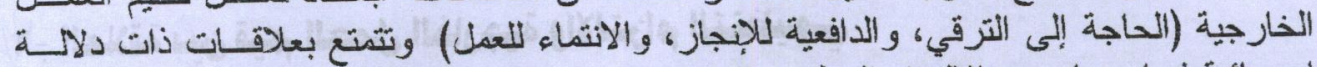

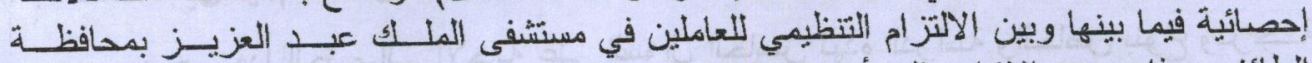

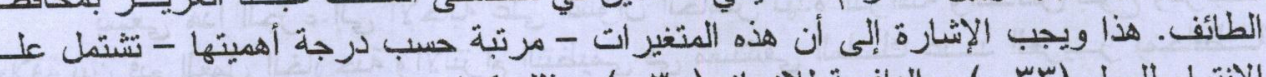

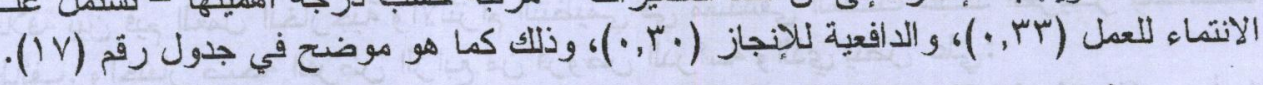

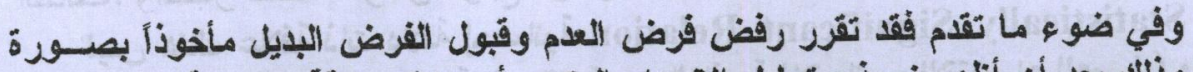

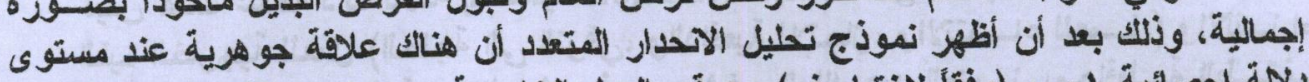

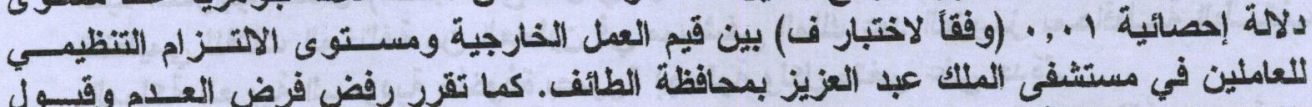

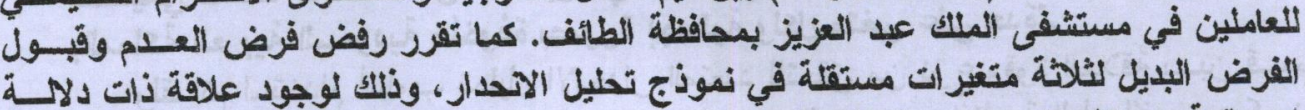

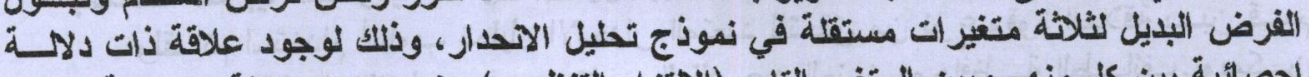

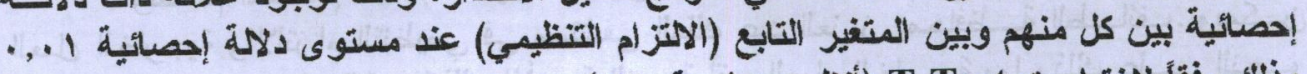

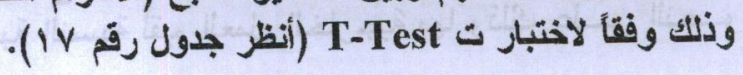




\section{- EYT-}

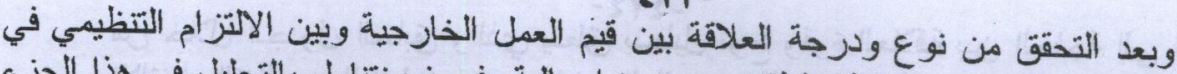

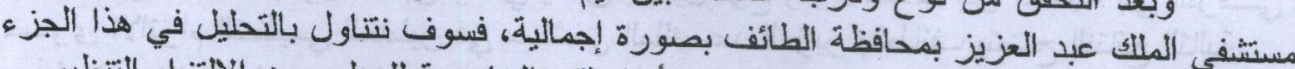
التحقق من نو ع ودرجة العلاقة بين كل بعد من أبعاد لقيم الخارجية للعمل وبين الالتز ام التتظيمسي التيلي

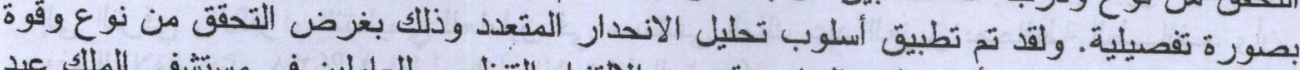

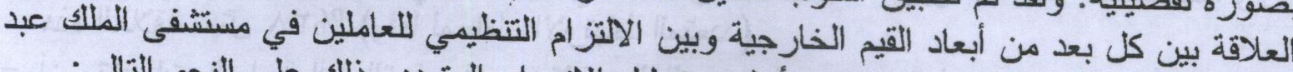
العزيز بالطائف. ويمكن ثوضيح نتائج أسلوب تحليل الانحدار المتعدد وذلك على النحو التالي: 1ـ الحاجة إلى الترقي

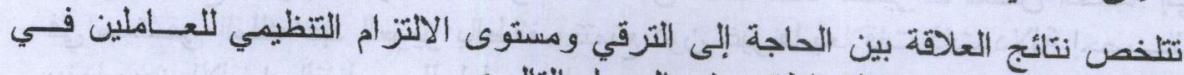
مستشفى الملاك عبد العزيز بمحافظة الطائف في الجدول التالي:

$$
\text { جدول رقم (11) }
$$

ع ودرجة العلاقة بين الحاجة إلى الترقي والالثزام التتطيمي للعاملين في مستشفى الملاد عبد العزيز بالطائف

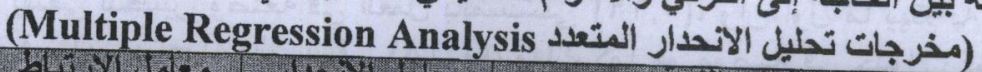

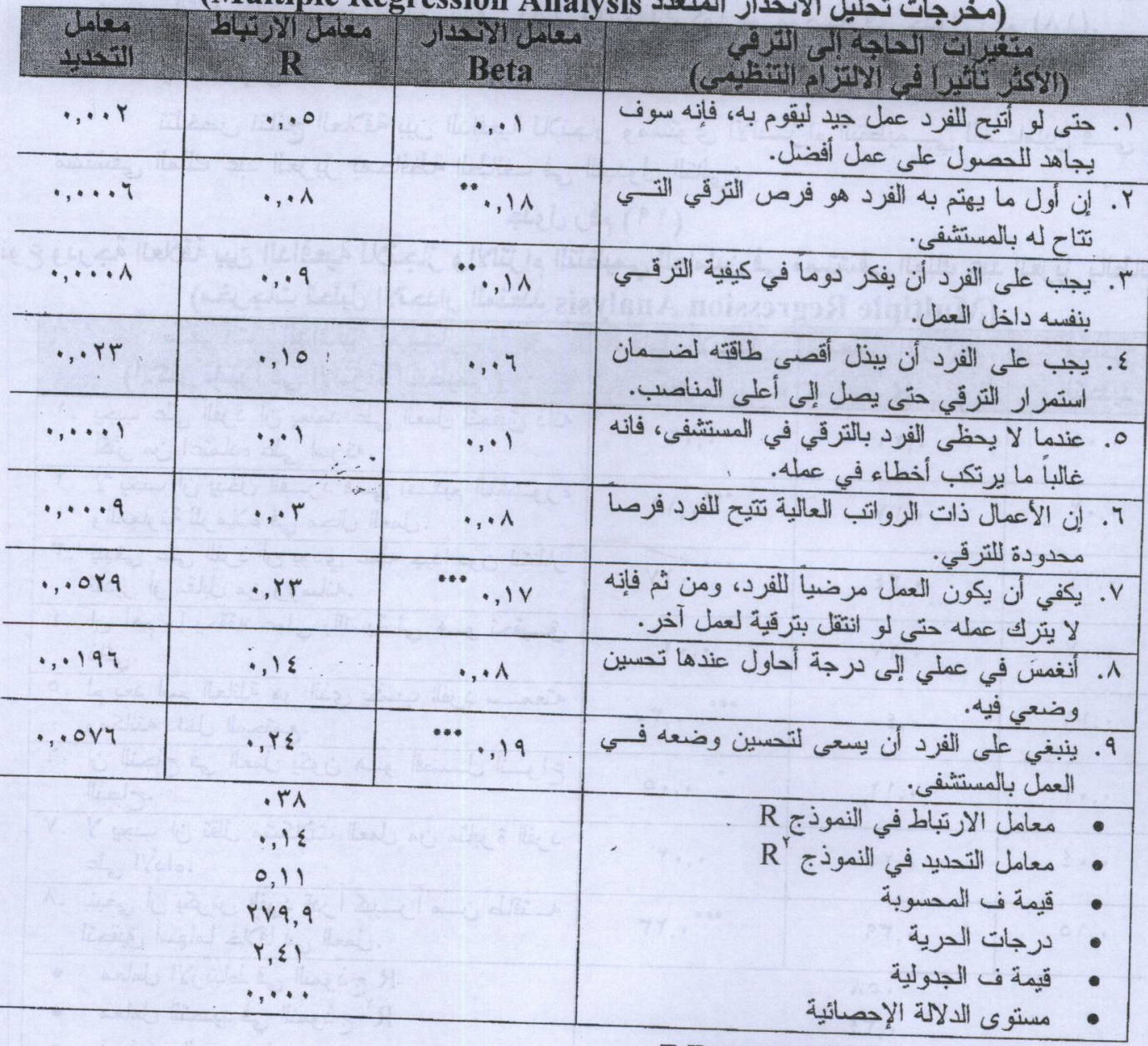

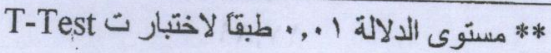




\section{- ЕY乏 -}

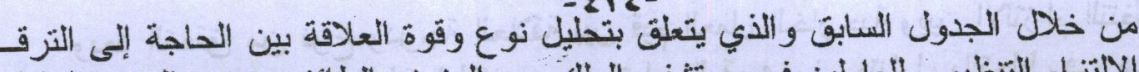

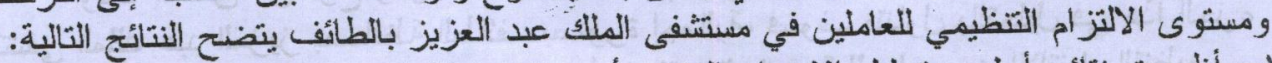

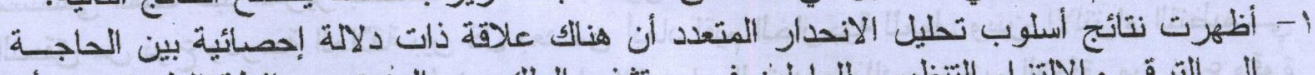

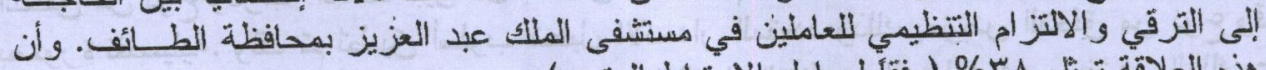

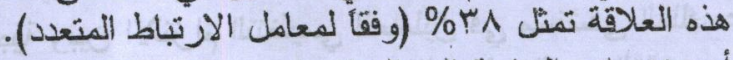

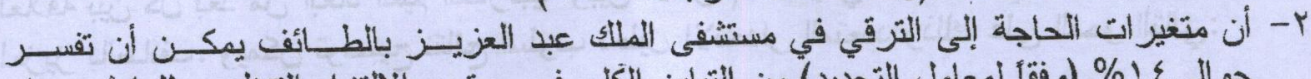

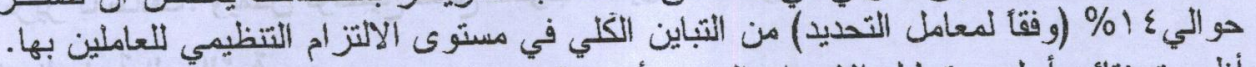

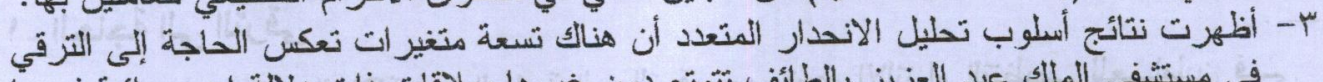

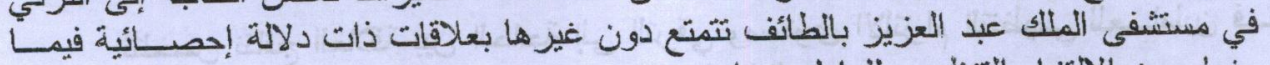
بينها وبين الالثز ام التنظيمي للتعاملين بها.

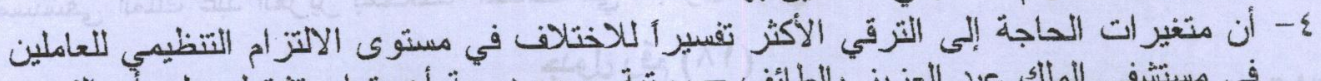

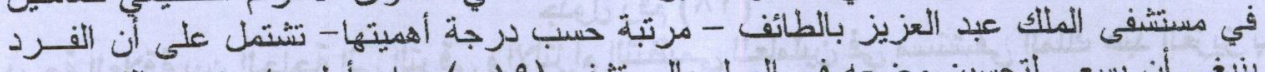

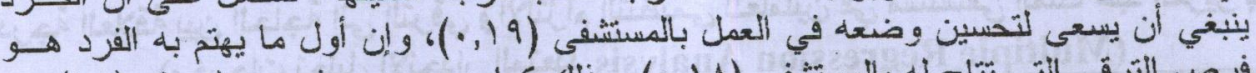

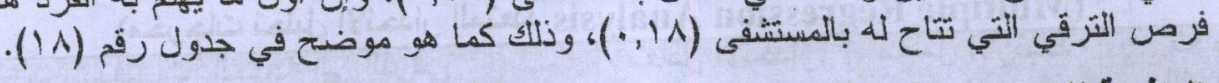

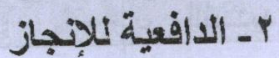

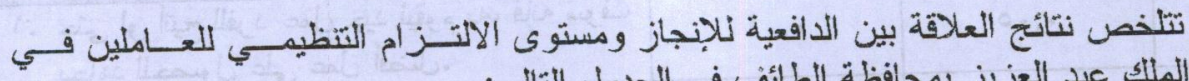

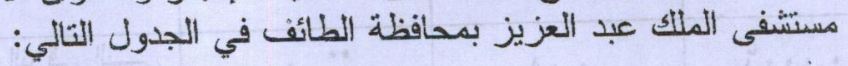

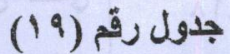

نوع ودرجة العلاقة بين الدافعية للإنجاز والالتز ام التظظيمي للعاملين في مستشفى الملك عبد العزيز بالطائف

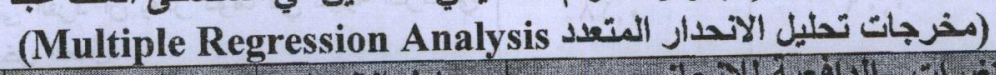

\begin{tabular}{|c|c|c|c|}
\hline $\begin{array}{l}\text { Jubes } \\
\text { yotifl }\end{array}$ & $\begin{array}{l}b+4, y 1 \text { tak } \\
\mathbf{R}\end{array}$ & $\begin{array}{l}\text { jingyl Jolus } \\
\text { Beta }\end{array}$ & 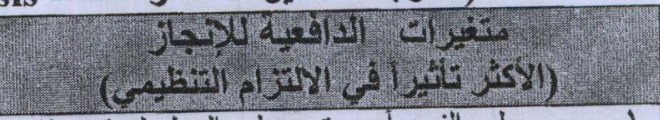 \\
\hline$\cdot, \cdot \varepsilon$ & $\cdot, Y_{1}$ &.,+7 & 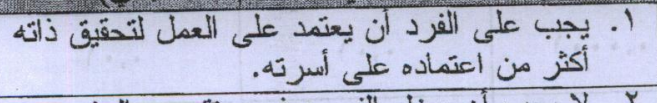 \\
\hline$\cdot, \cdot r$ & $\cdot, r v$ & $\cdots \cdot, 19$ & 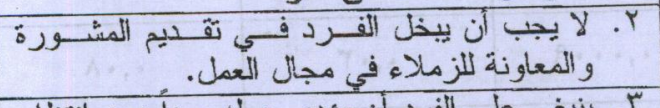 \\
\hline . ir & .,$\pi \varepsilon$ & $* *+1 \mathrm{~V}$ & 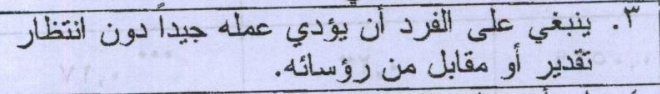 \\
\hline$\because \cdot V$ & $\cdot, r V$ & $\cdot, \cdot r$ & أ. إن أهم ما يحققه عملي با \\
\hline$\cdot, 19$ & $\cdot, \varepsilon$. & $\cdots \cdot, r$ & 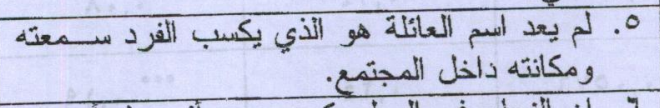 \\
\hline$\cdot, \cdot Y$ &,$+ I Y$ & $\cdot, . .0$ & 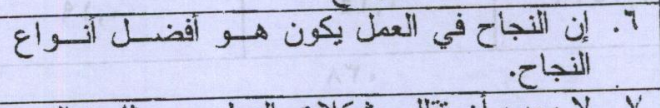 \\
\hline,,$\cdot \leqslant$ & $\cdot, Y_{\bullet}$ & $\cdot, \cdot r$ & 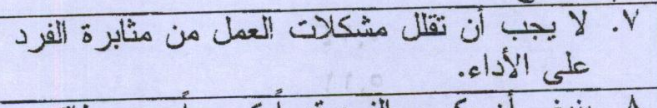 \\
\hline$\cdot, 10$ & $\cdot, r q$ & "*, & 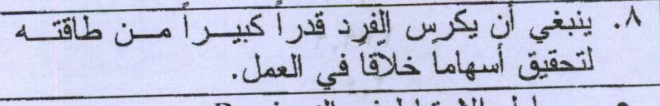 \\
\hline & $\begin{array}{l}.01 \\
., \Gamma \varepsilon\end{array}$ & & 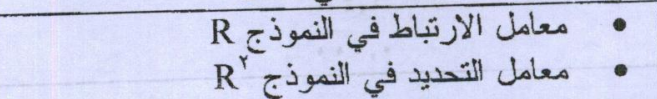 \\
\hline$\sqrt{4}-2$ & $1 \mathrm{~V}, \wedge 9$ & & 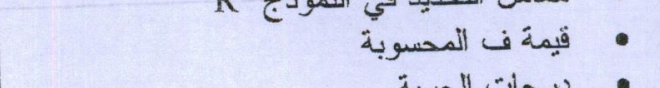 \\
\hline & $\begin{array}{l}r A 1, A \\
r, 01\end{array}$ & & قيمة فات الجدولية \\
\hline & & & • مستوى الاللالة الإحصائية \\
\hline
\end{tabular}


من خلال الجدول السابق والذي يتعلق بتحليل نوع وقوة العلاقة بين الدافعيــة للإنجبـاز

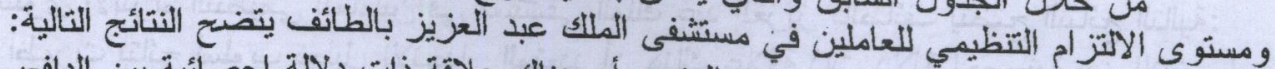
1- أظهرت نتائج أسلوب تحليل الانحدار المنعدد أن هنالك علاقة ذات دلالة إحصائية بين الدافعيسة

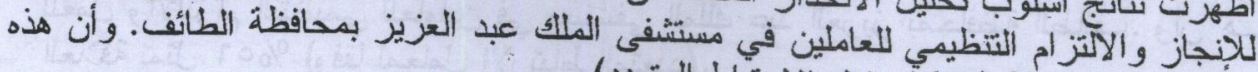

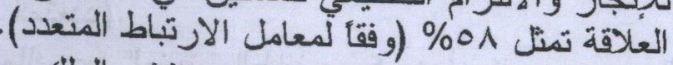

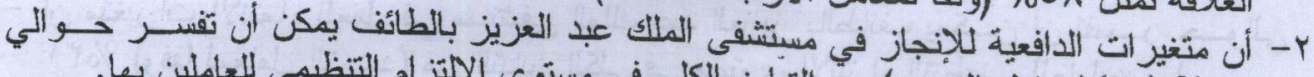

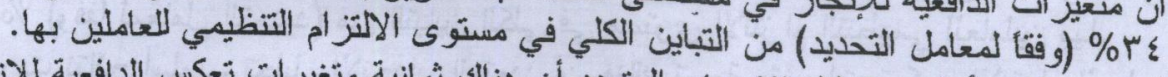

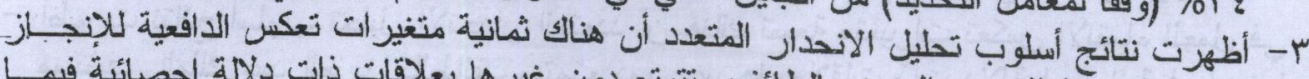

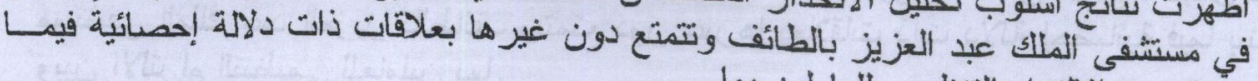

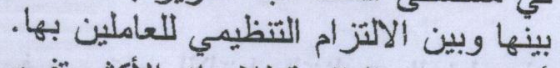

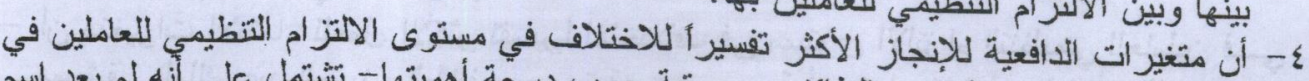

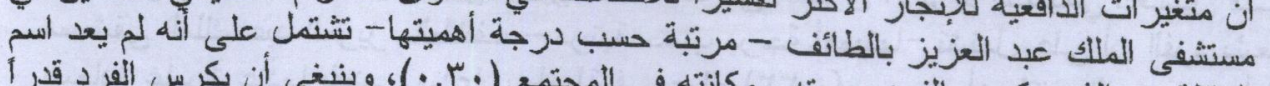

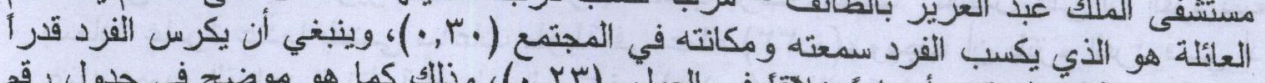

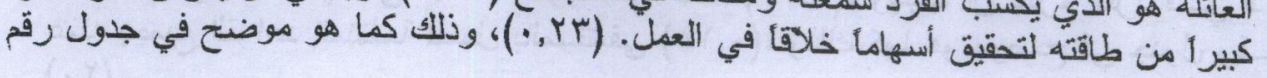

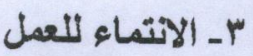

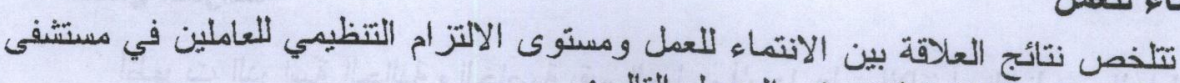

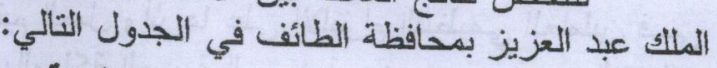

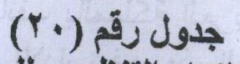

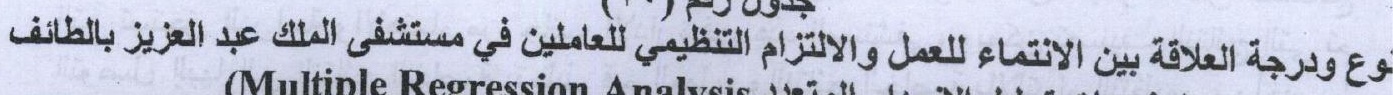

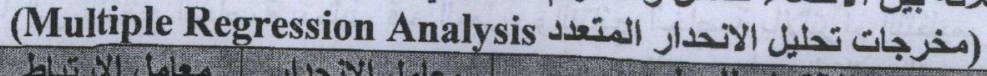

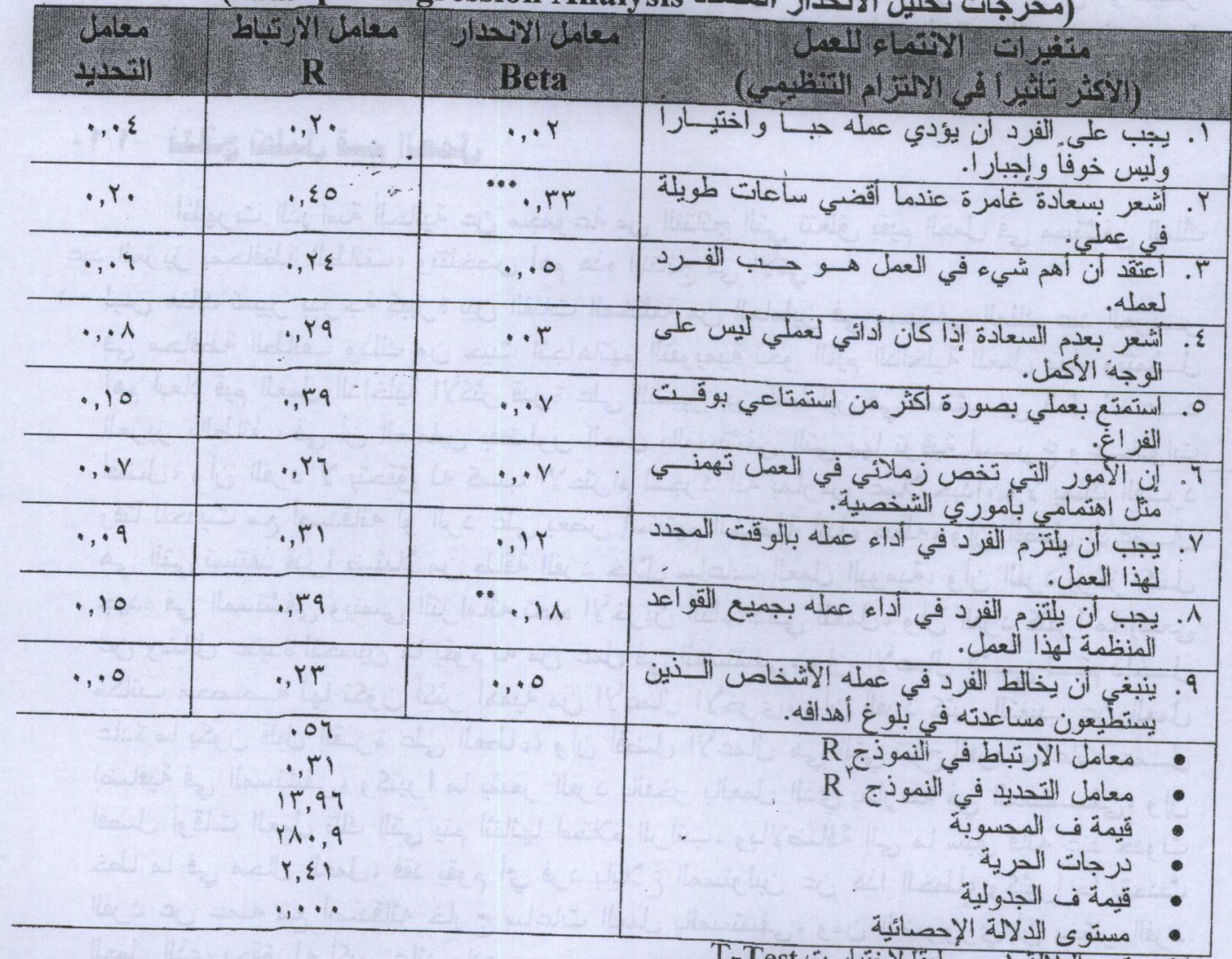




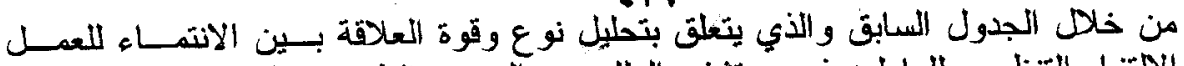

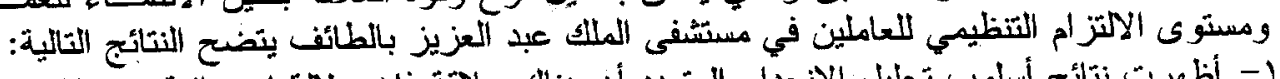

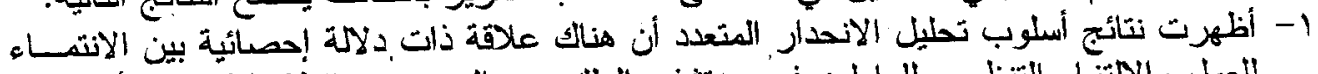

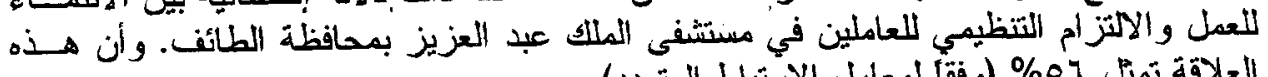

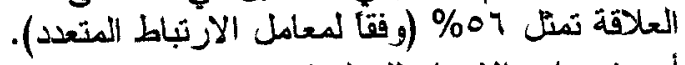

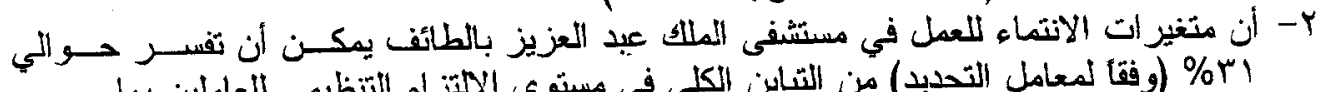

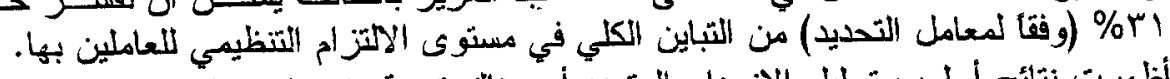

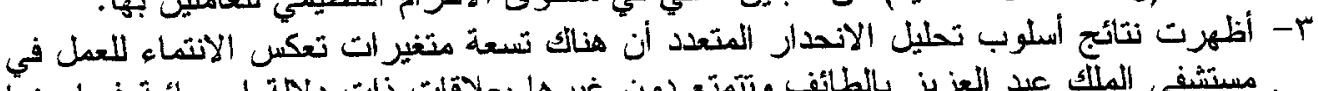

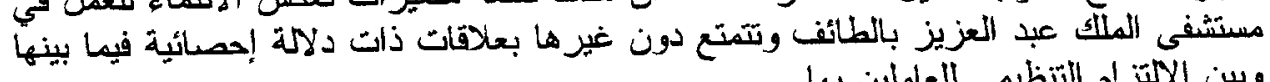

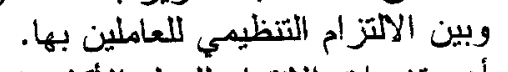

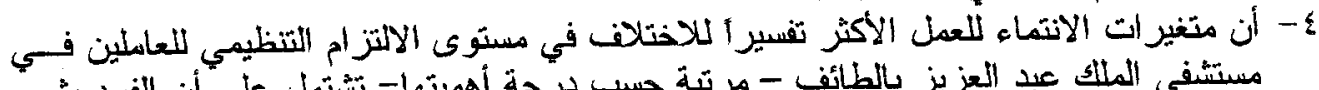

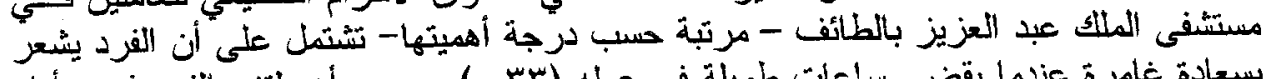

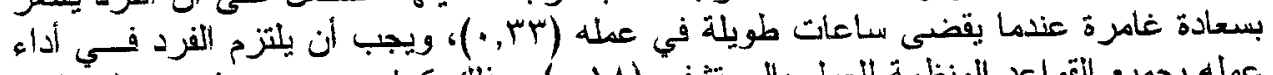

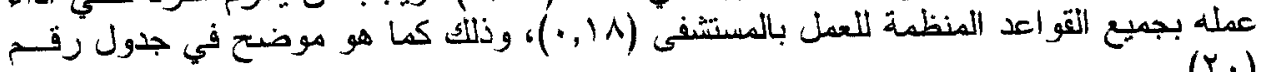

\section{1.}

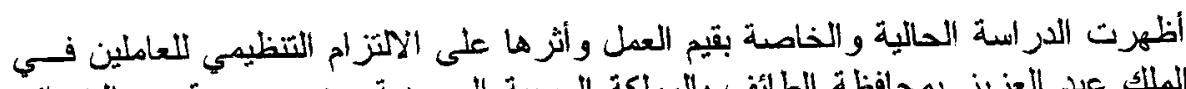

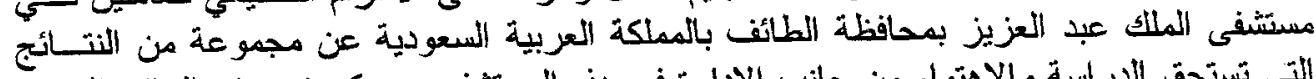

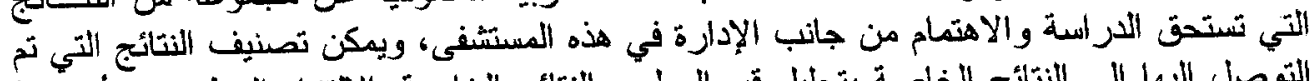

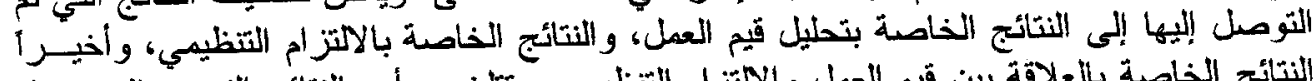

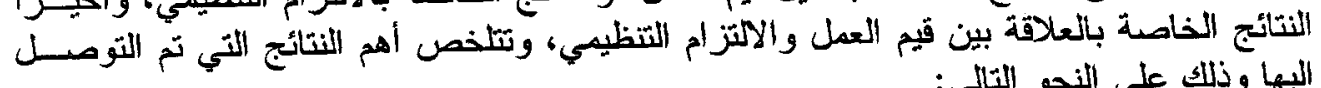
إليها وذذلك على النحو التالتي:

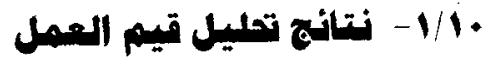

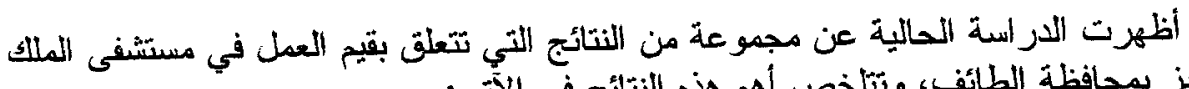
عبد العزيز بمحافظة الطائف، وتتلخص الهر أهم هذه النتائج في الآتئي:

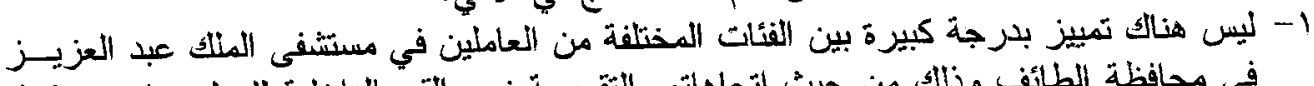

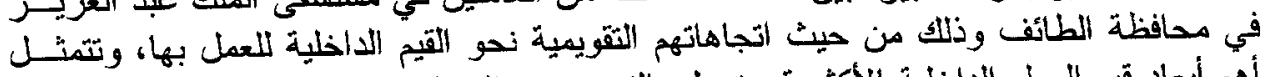

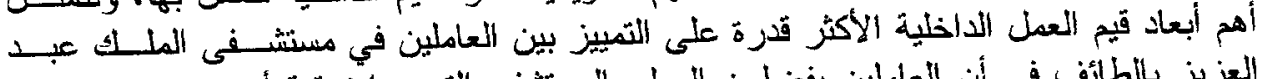

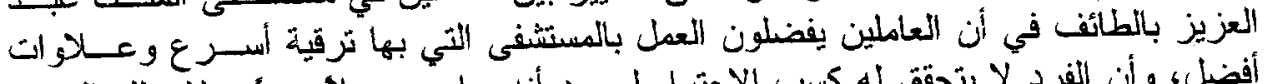

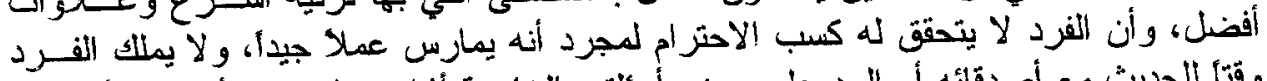

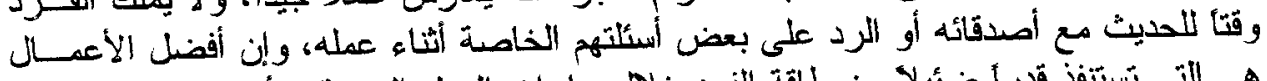

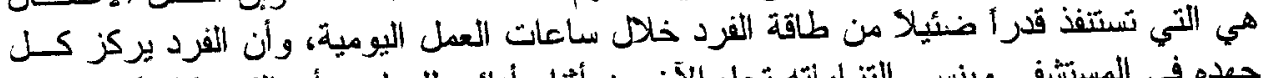

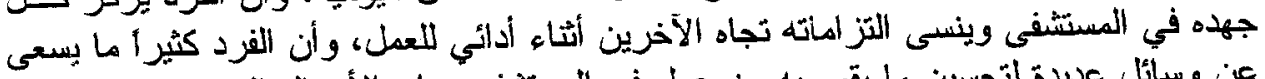

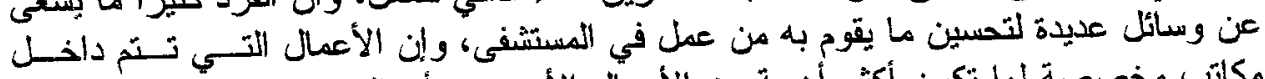

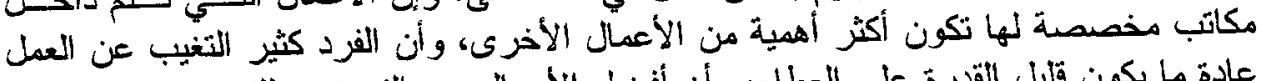

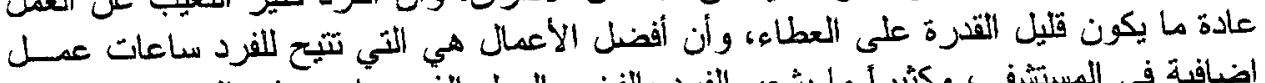

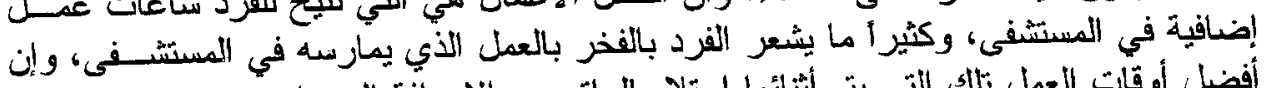

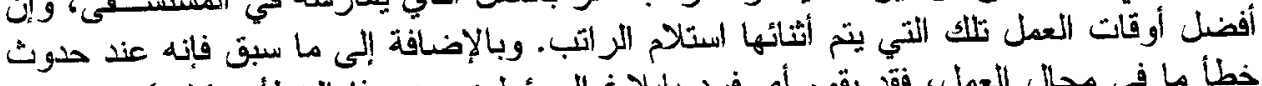

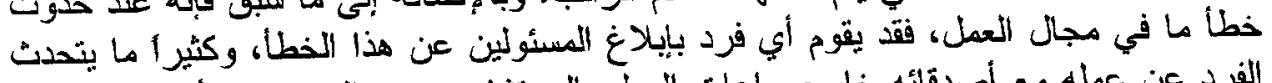

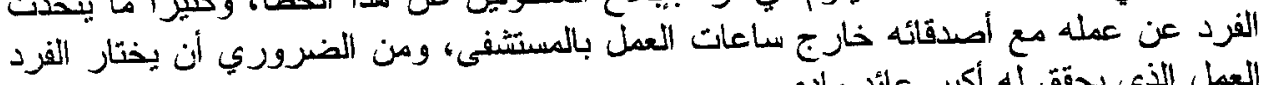
العمل الذي يحقّ لَه أكبر عائد مادي. خارجي. 


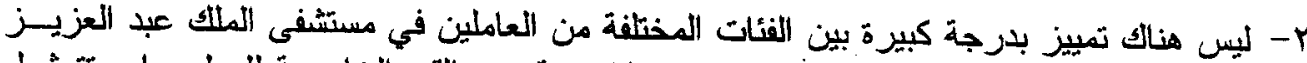

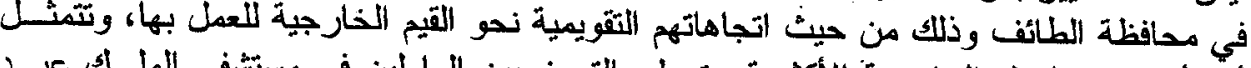

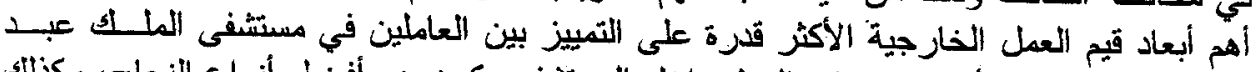

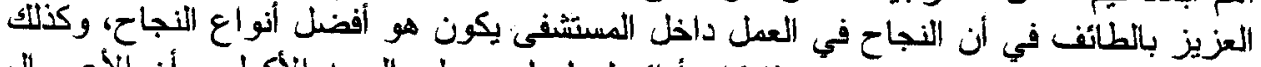

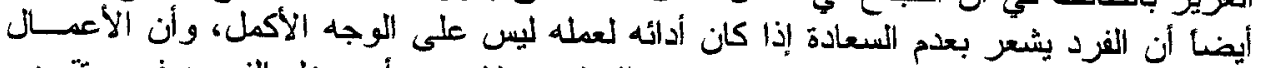

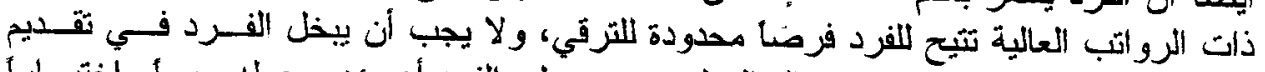

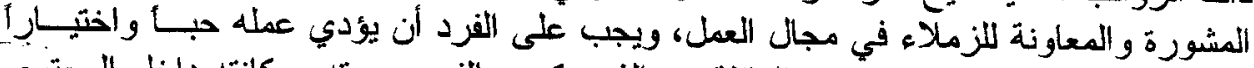

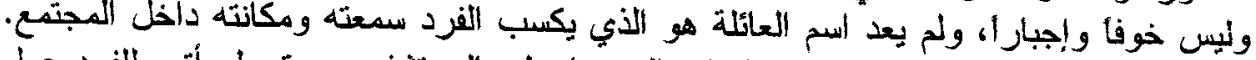

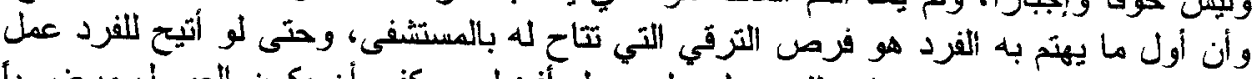

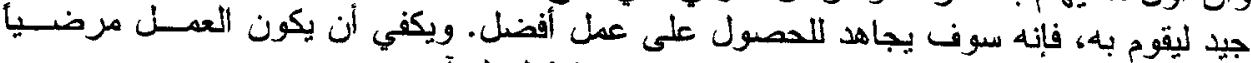

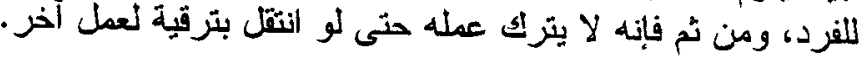

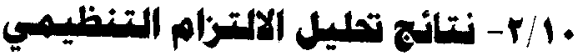

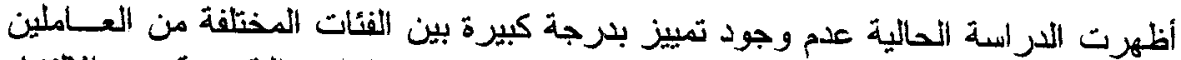

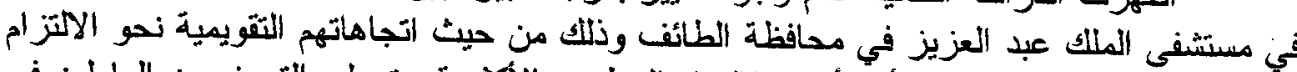

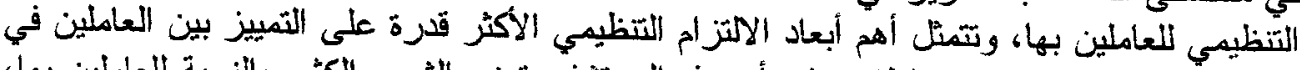

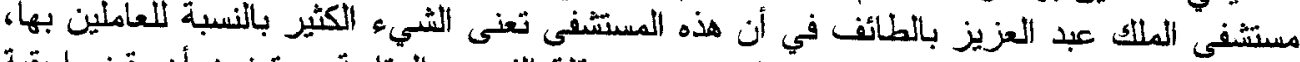

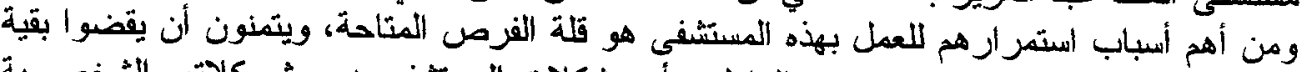

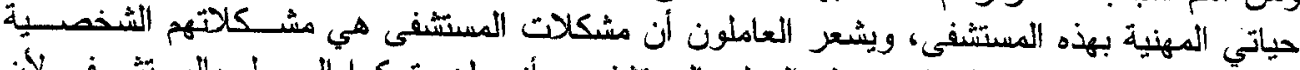

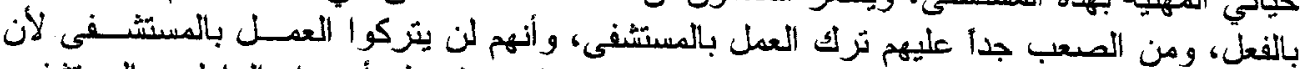

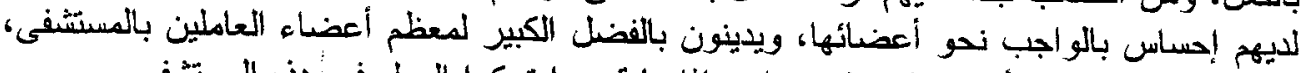

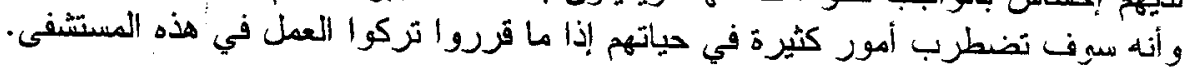

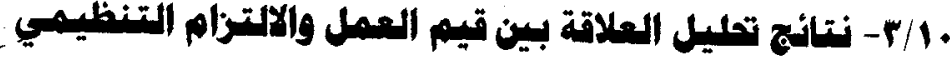

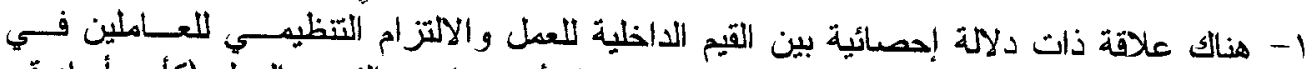

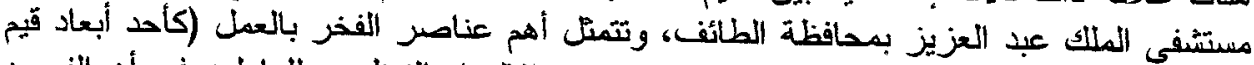

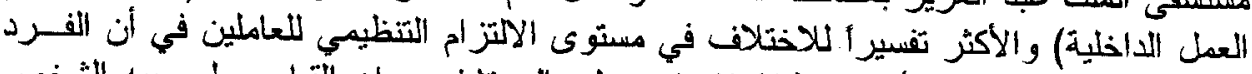

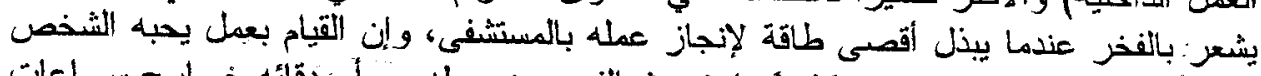

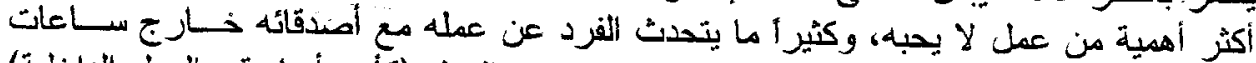

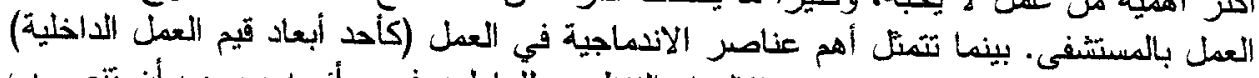

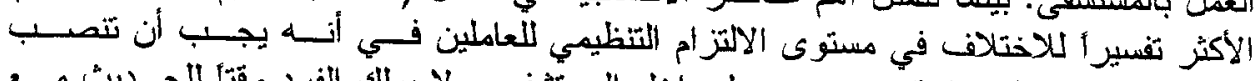

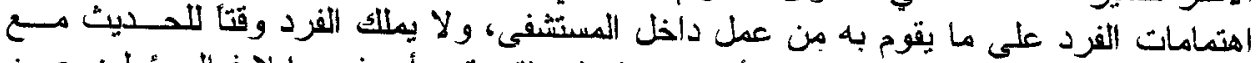

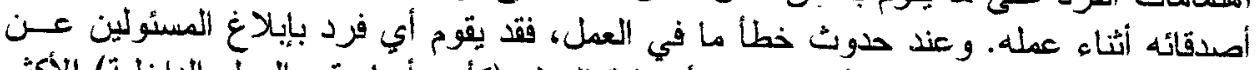

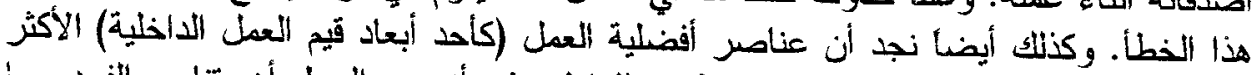

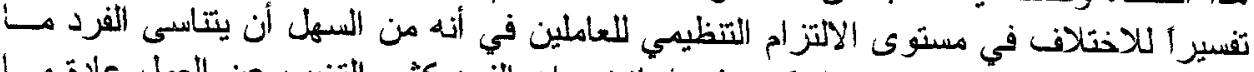

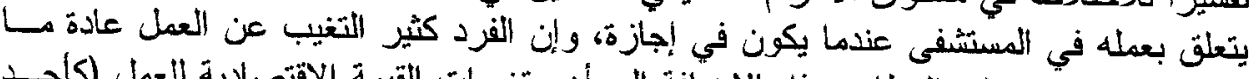

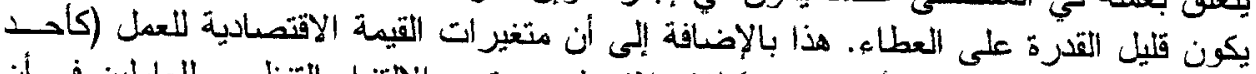

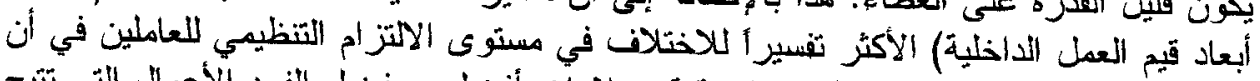

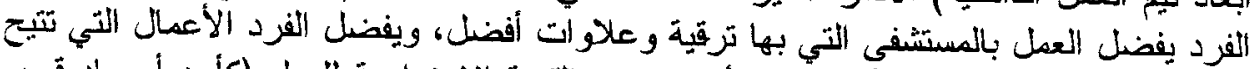

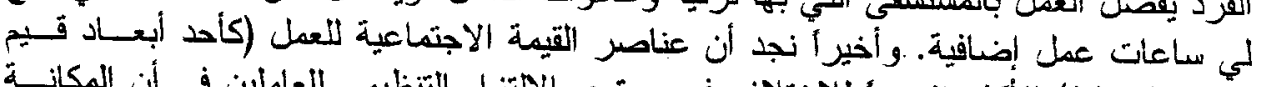

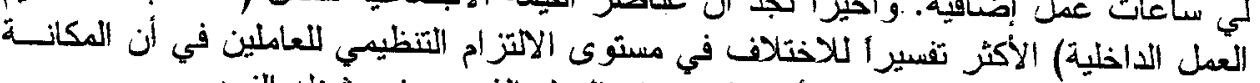
الاجتماعية للعمل لا تعتبر شرطا أساسيا لاختيار العمل الذي سوف يشّفله الفرد. 


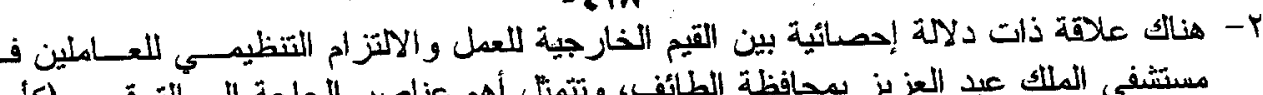

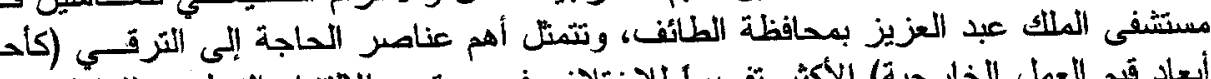

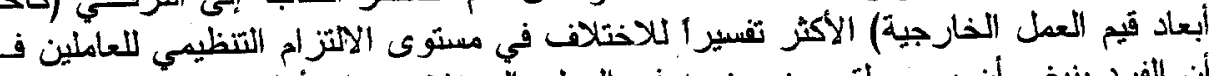

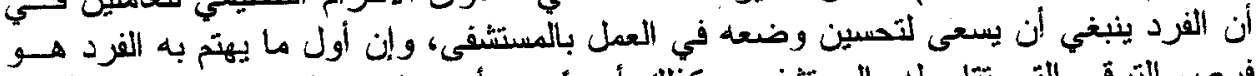

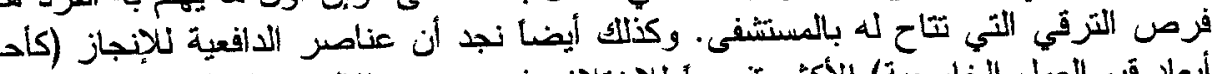

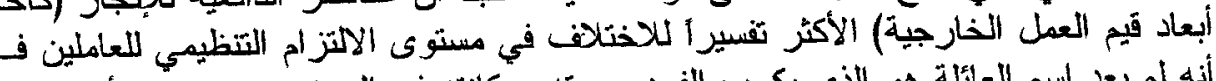

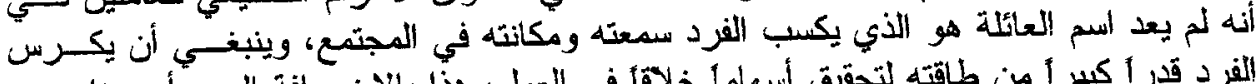

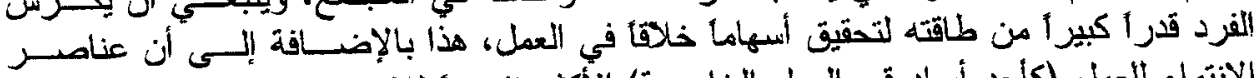

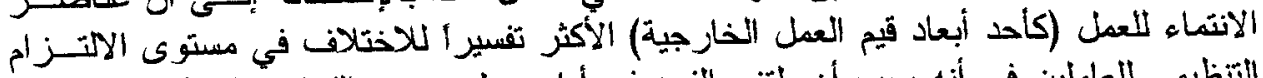

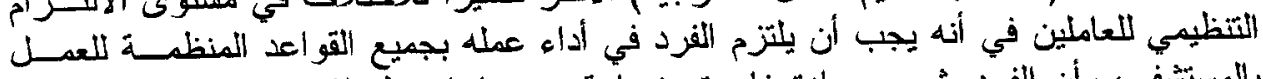
بالمستشفى، وأن الفرد يشعر بسعادة غامرة عندما يقضى ساعات طويلة لألة في عمله بالمستشفى.

-11

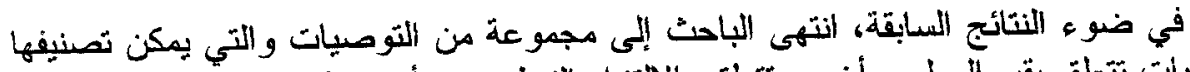

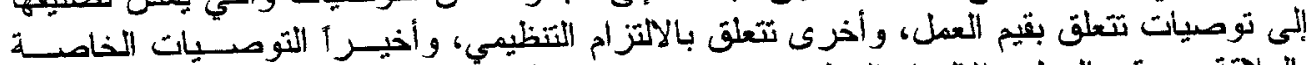

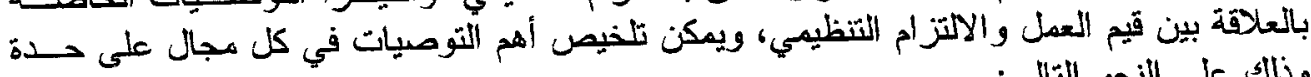

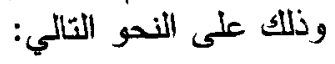

\section{1/11 - التوصيات الفاصة بقيم العمل}

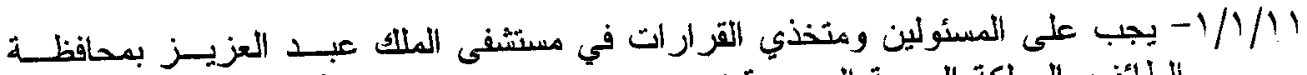

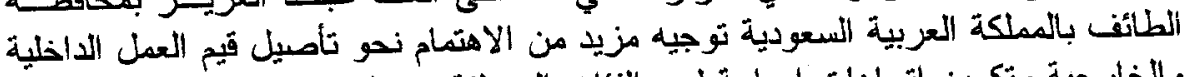

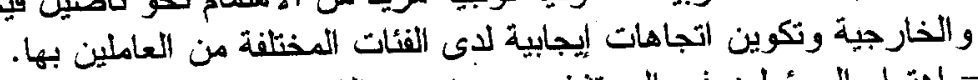

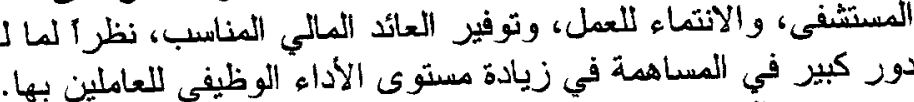

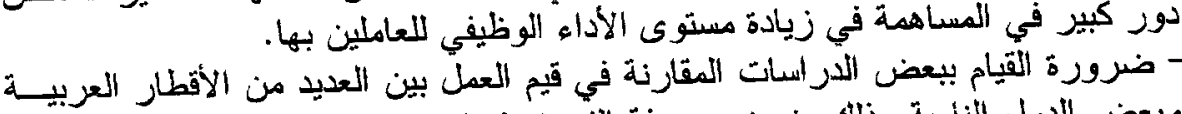

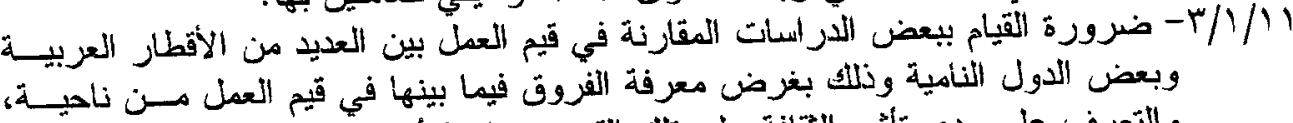

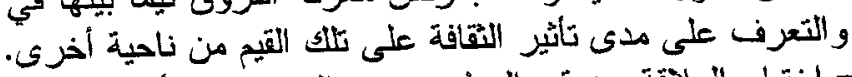

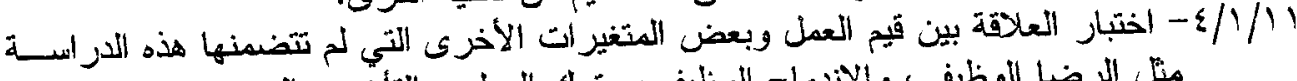

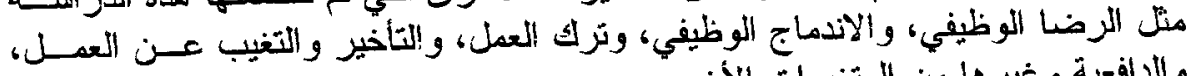
والدافعية وغير ها من المتنير التيات الأخرى.

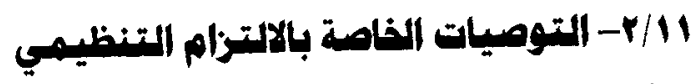

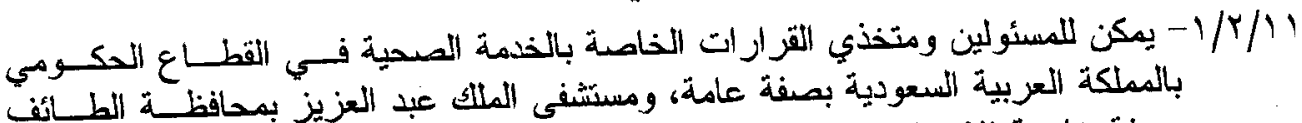

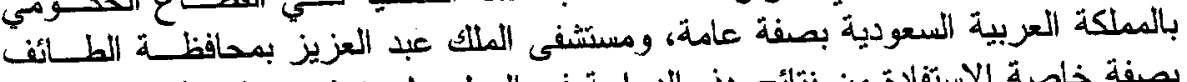

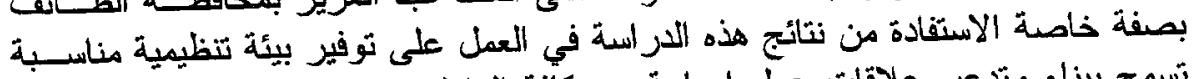

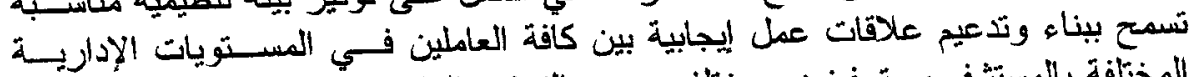

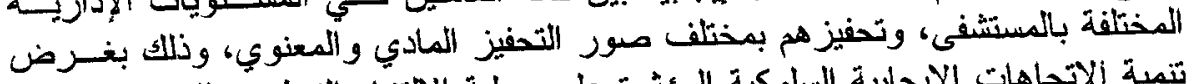

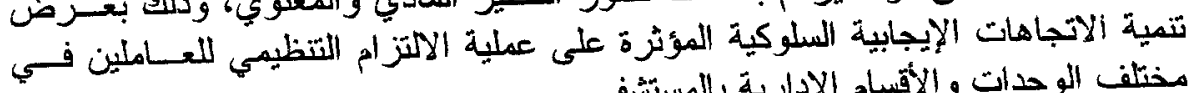

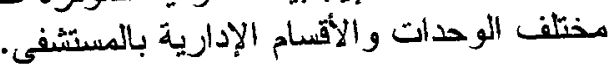


1/Y/M

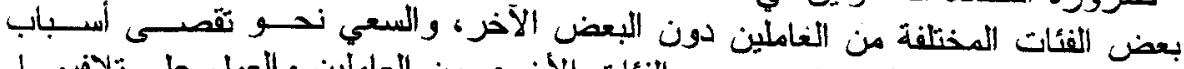

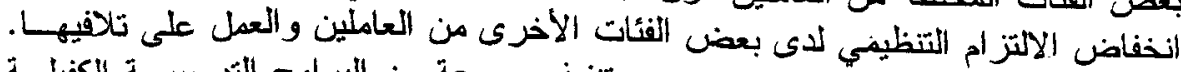

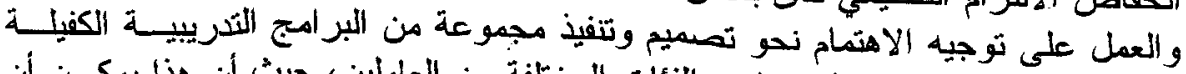

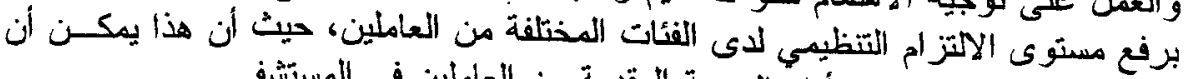

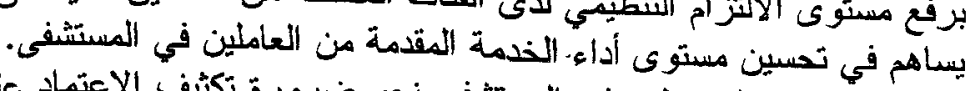

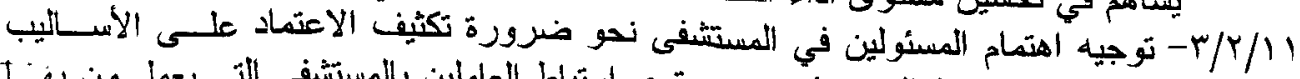

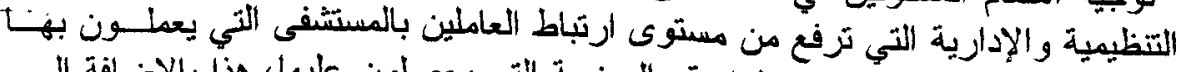

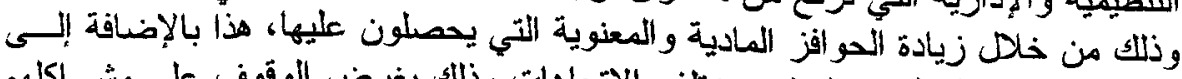

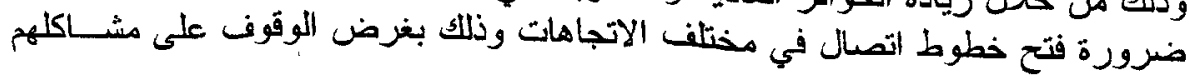

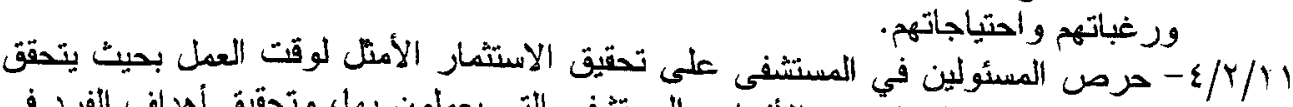

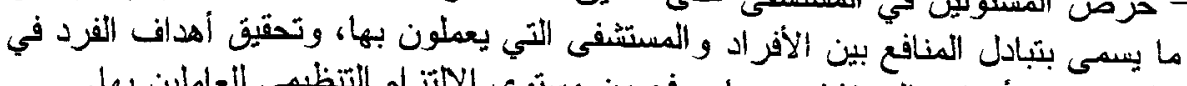

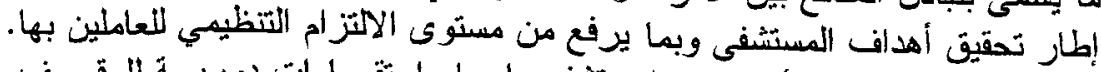

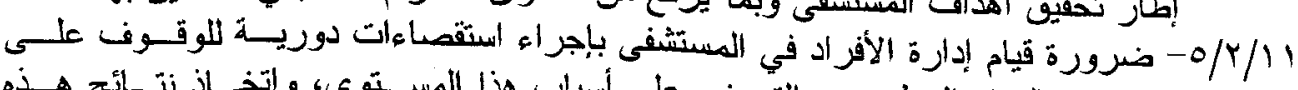

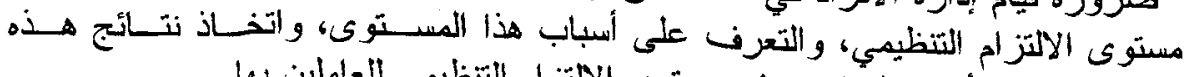

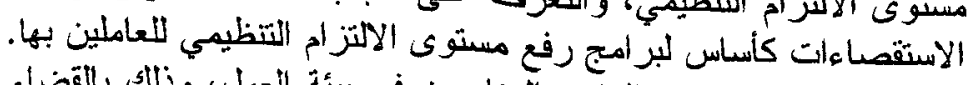

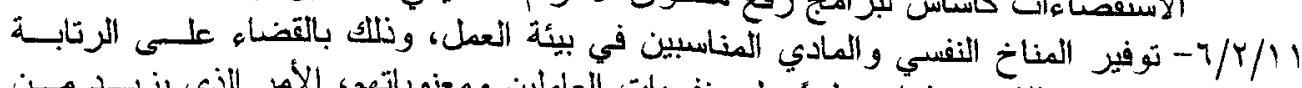

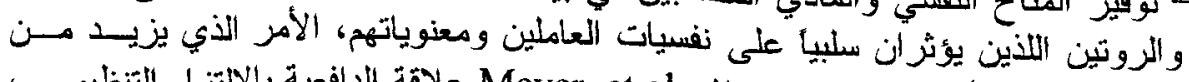

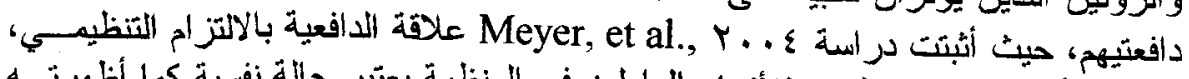

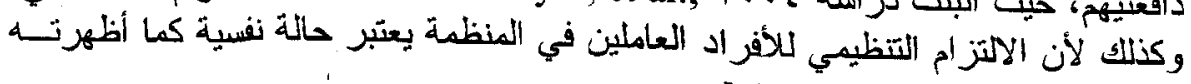

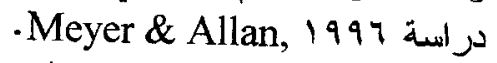
V-r/T/1

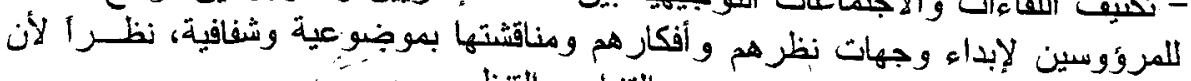

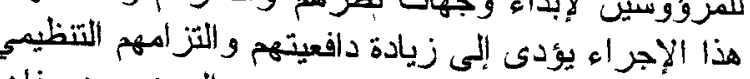

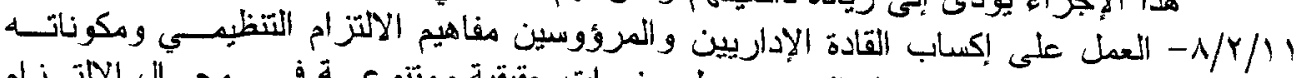

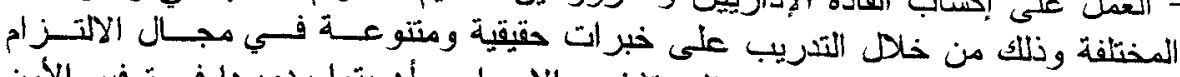

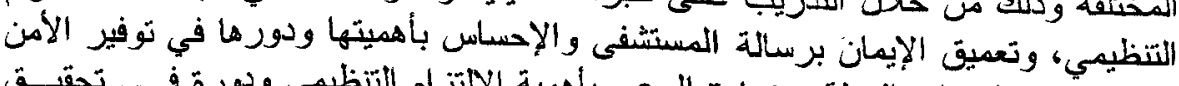

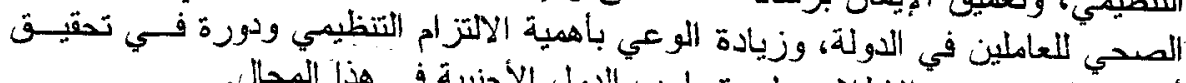

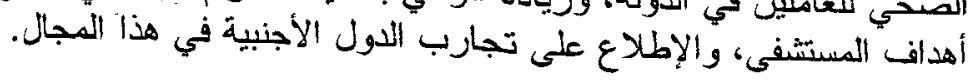

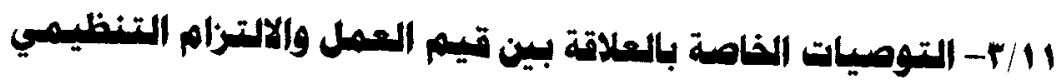

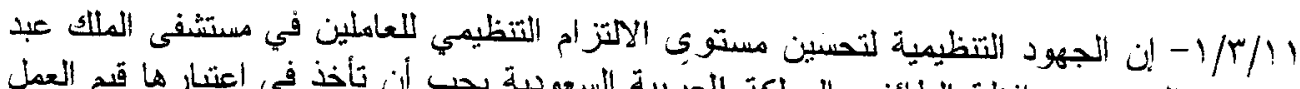

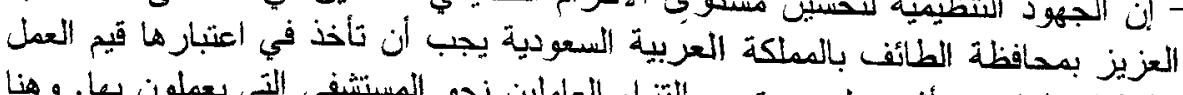

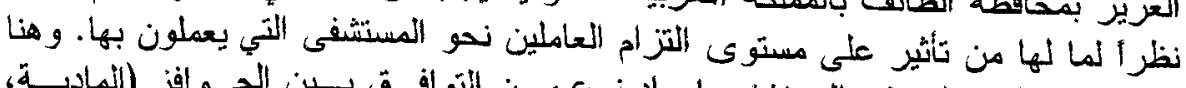

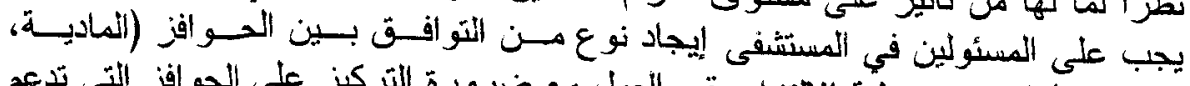

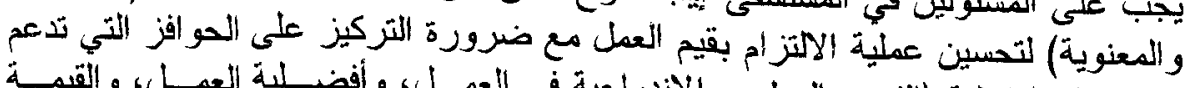

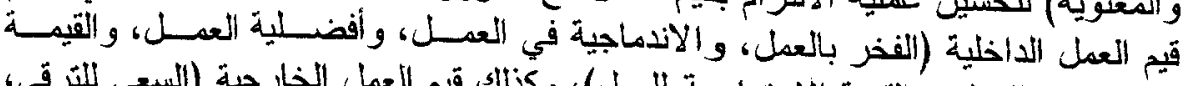

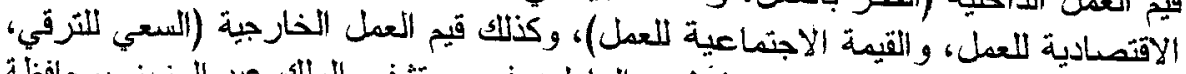

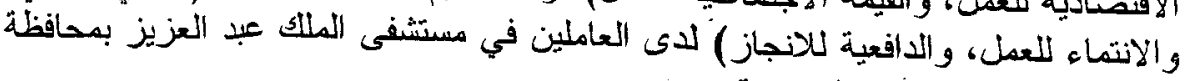
الطائف بالمملكة العزبية السعودية. 


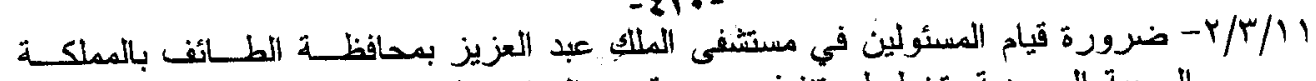

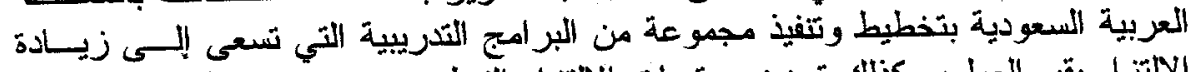

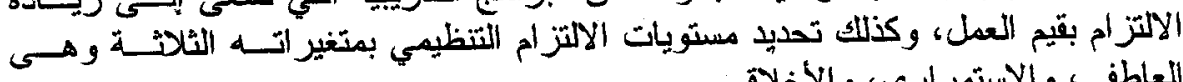

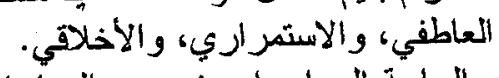

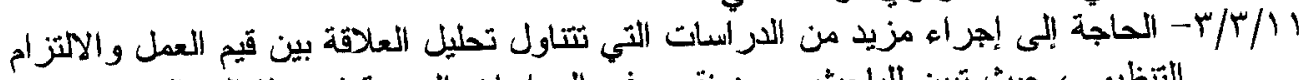

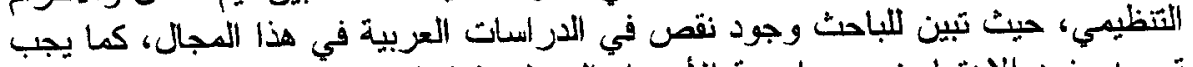

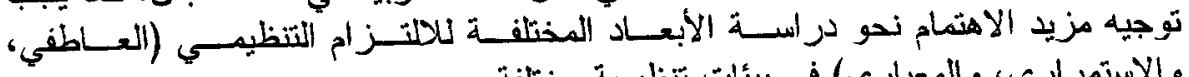

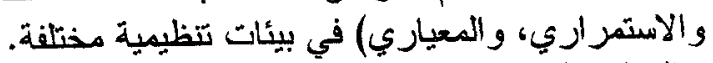

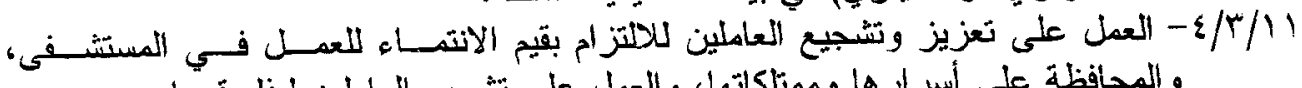

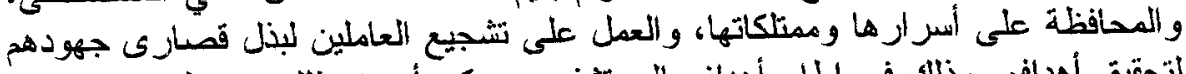

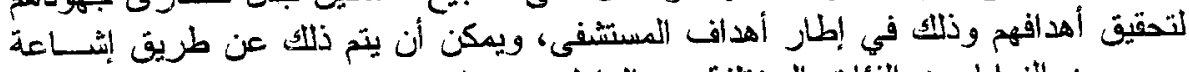

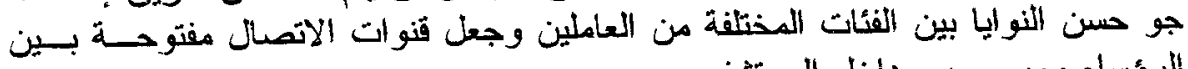
اللرؤساء ومر عوسيهم داخل المستشفى.

\section{r ا البحوث المستقبلية المتترحة}

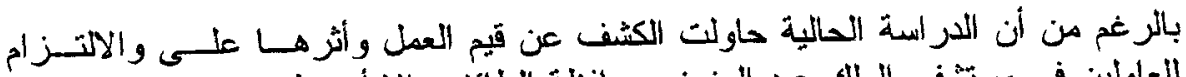

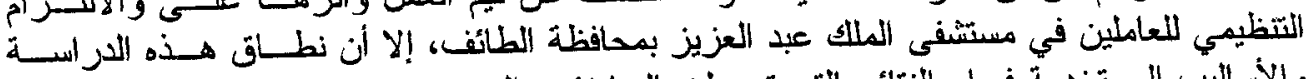

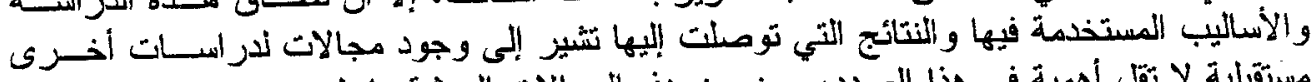

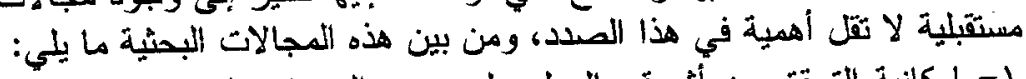

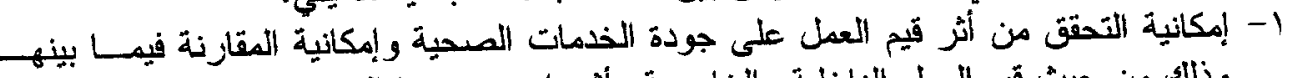

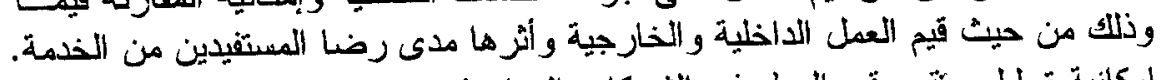

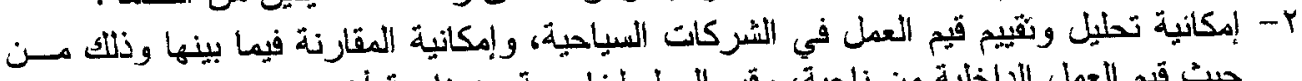

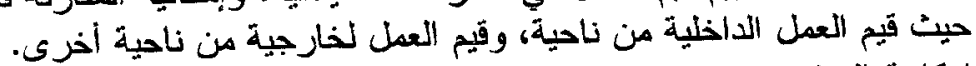

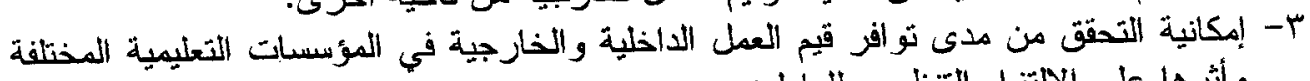

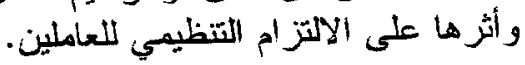

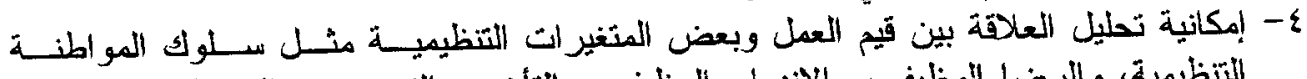

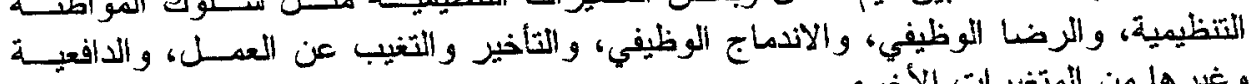

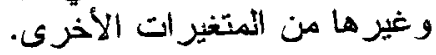




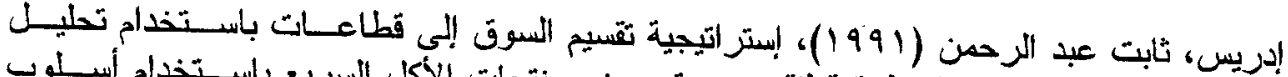

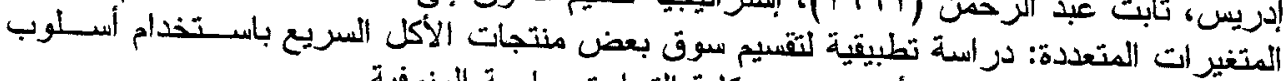

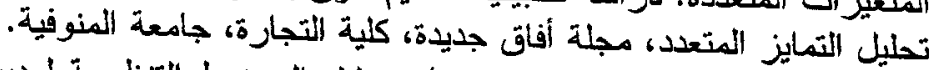

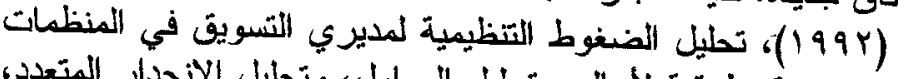

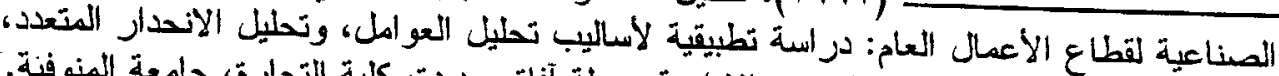

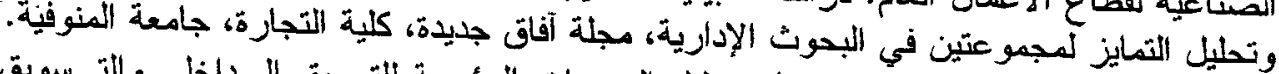

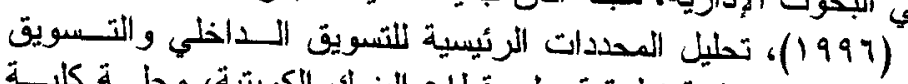

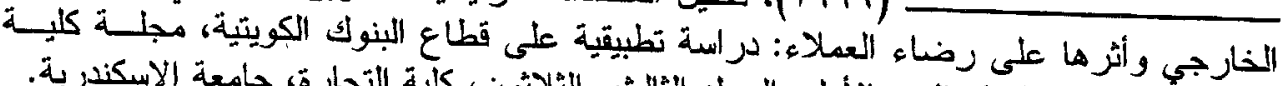

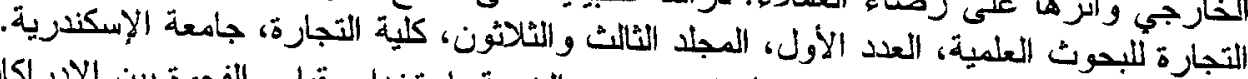

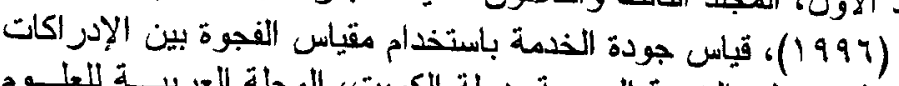

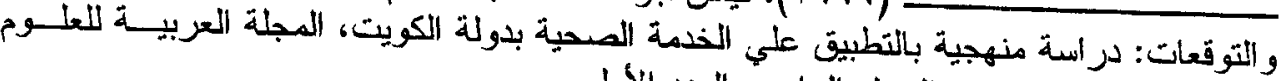

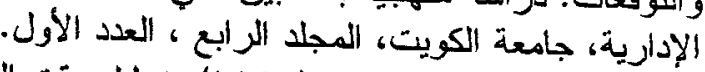

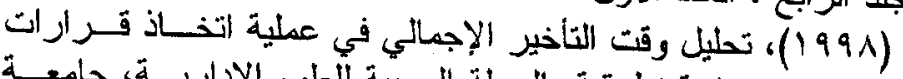

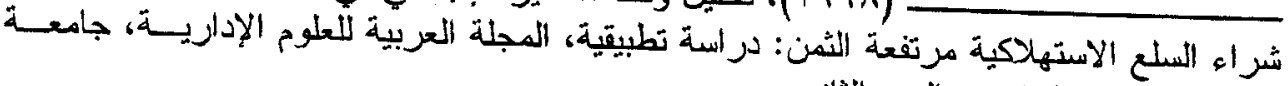

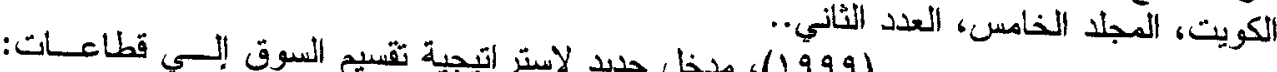

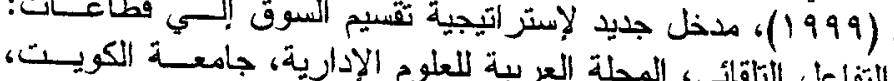

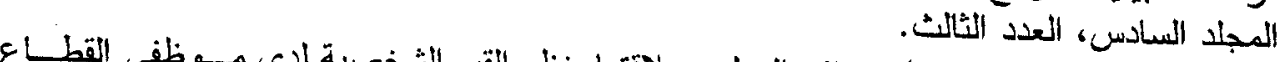

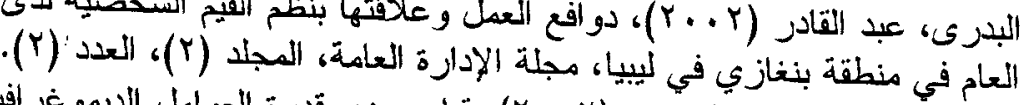

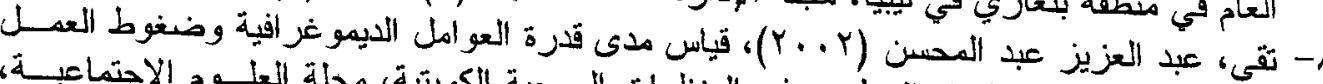

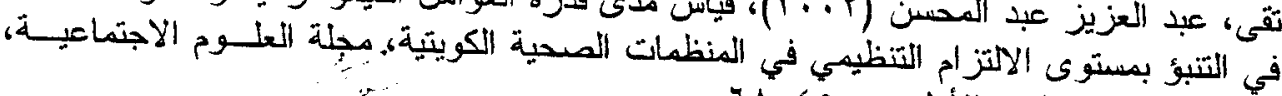

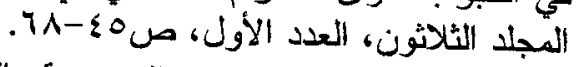

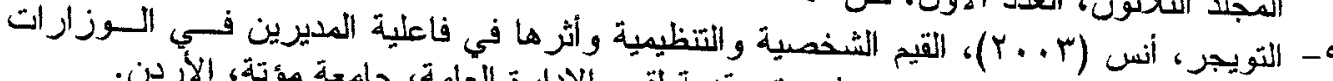

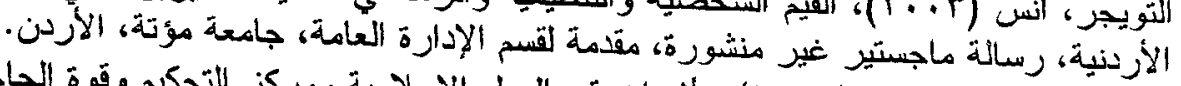

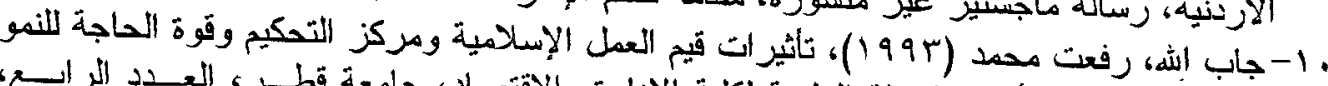

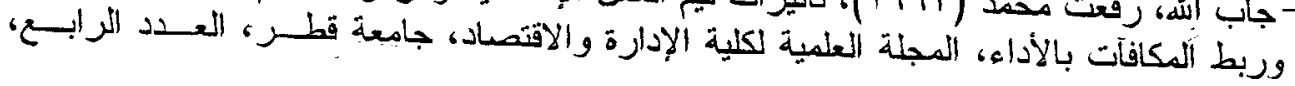

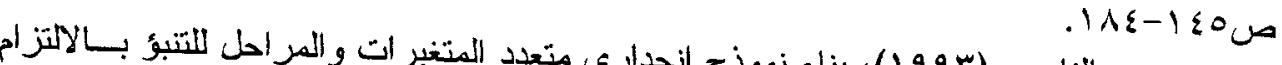

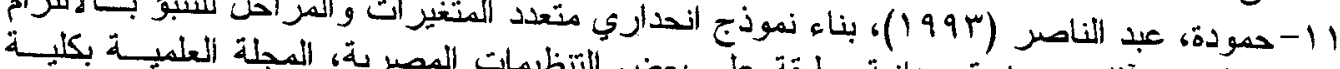

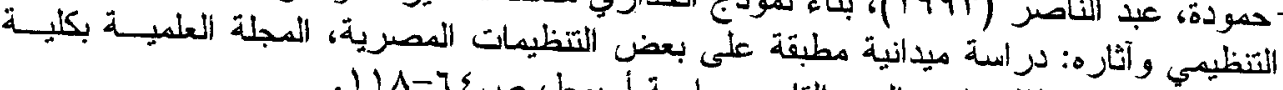

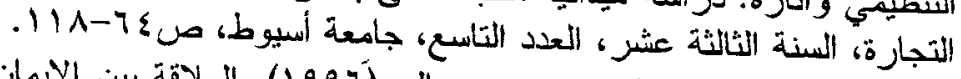

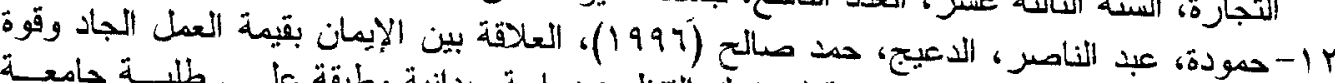

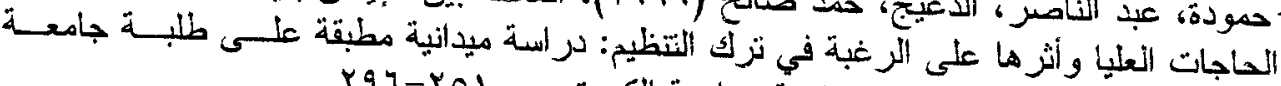

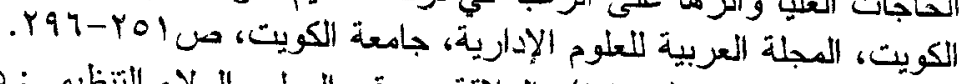

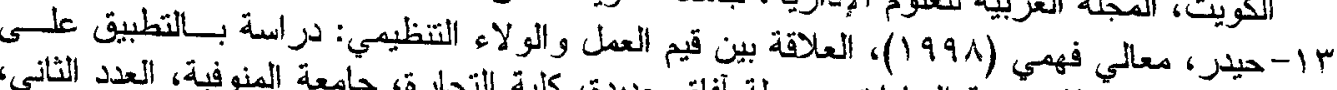

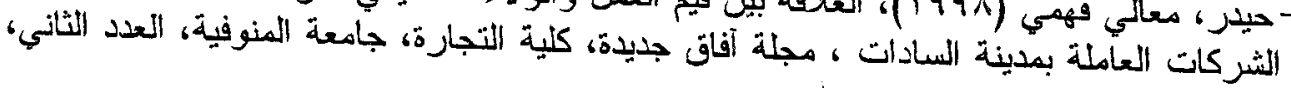

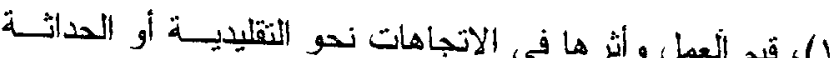

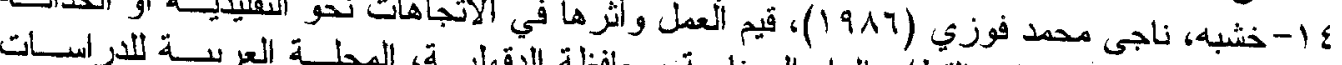

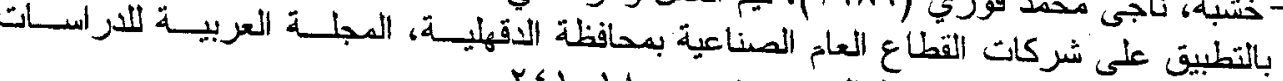

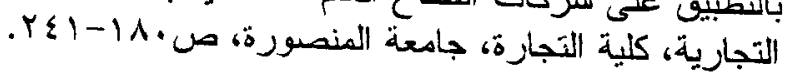




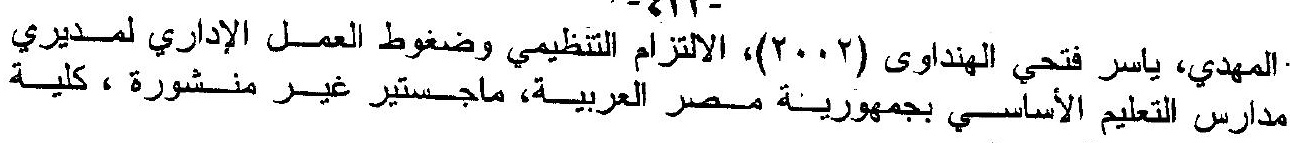

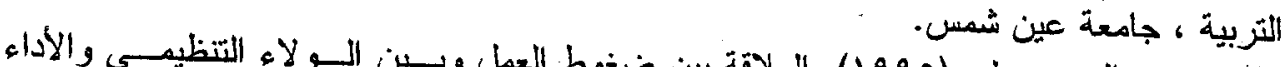

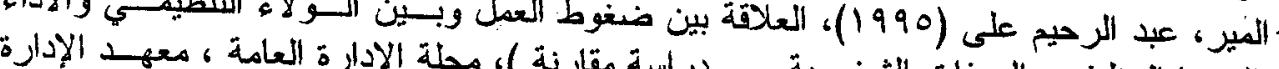

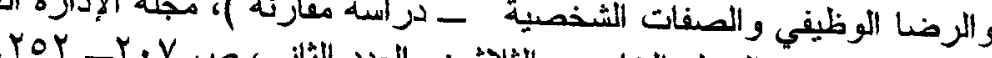

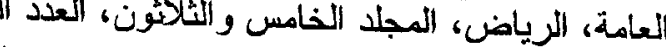

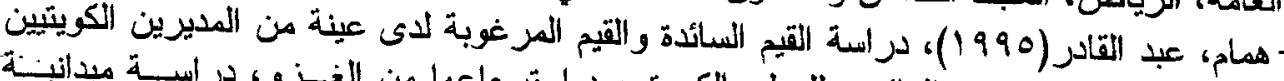

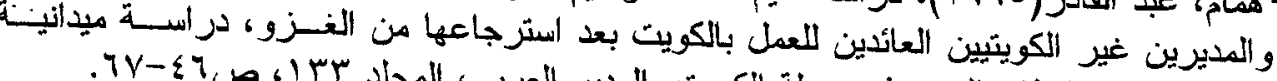

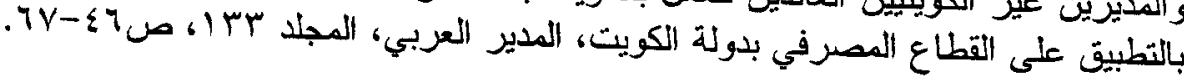

1- Al-Ammaj, F., 2000, An Investigation of Leadership Style and Organizational Commitment among Saudi Public Employee, Diss. Abs. Int., Vol. 61, No. (4-A), October, P. 1605.

2- Allen, N., and Meyer, J., 1984, Testing the Side - Bet Theory of Organizational Commitment: Some Methodological Considerations, Journal of Applied Psychology, Vol. 69, No. 3, PP.327-378.

3- Allen, N., and Meyer, J., 1990, The Measurement and Antecedents of Affective, Continuance and Normative Commitment to the Organization, Journal of Occupational Psychology, Vol. 63, No. 1, PP.1-18.

4- Bello, T., 1994, Work Values of Males and Females: A Developing Country's Example, International Journal of Management, Vol. 11, No.2, PP.940-945.

5- Bhagat, R. S., et al., 1985, Total Life Stress: A Multimethod Validation of the Construct and its Effects on Organizationally Valued Outcomes and Withdrawal Behaviors, Journal of Applied Psychology, Vol. 70, No.1, PP.202-214.

6- Borg, M., and Riding, R., 1991, Occupational Stress and Satisfaction in Teacher in Teaching, British Educational Journal, Vol. 17, No3, P. P. 263- 281.

7- Dubin, R., Champoux, J., and Porter, L., 1975, Centeral Life and Organizational Commitment of blue Collar and Clerical Workers, Administrative Science Quarterly, Vol.20, PP.411-421.

8- Dunham, D., et al, 1994, Organizational Commitment: The Utility of An Integrative Definition, Journal of Applied Psychology, Vol. 79, No. 3, PP.370-380.

9- Eby, L., et al., 1999, Motivational Bases of Affective Organizational Commitment: A Partial Test of An Integrative Theoretical Model, Journal of Occupational and Organizational Psychology, No.72, PP. 463-483.

10-Elangovan, A., 2001, Causal Ordering of Stress, Satisfaction and Commitment and intention to Quit: A structural Equations Analysis, Leadership and Organizational Developmental Journal, Vol. 22, No. 4, 
11 -Elizur, D., 1997, Work Values and Commitment International, Journal of Manpower, Vol.i 'Y, No.r, PP. Yo_r.

ir-Engle, J., 199^, Work Values of Japanese and American Men, Journal of Social Behavior and Personality, Vol. $r$, No.r, PP.191-r...

$1 \%$-Farrell D., and Rusbult, C., 1911, Exchange Variables as Predictors of Job Satisfaction, Job Commitment and Turnover: The Impact of Rewards Cost, Alternatives and Investments, Organizational Behavior and Human Performance, Vol. $Y \wedge$, PP. $Y \Lambda_{-} 90$.

1 \&-Geartner, K., Nollen, S., 1919, Career Experiences, Perceptions of Employment Practice and Psychological Commitment to the Organization, Human Relations, Vol. \{r, No. 11 , PP. 9vo-991.

10-Hackett, R., Bycio, P., and Hausdrof, P., 199r, Further Assessment of A Three Component Model of Organizational Commitment, Academy of Management, Best Paper Prceedings.

17-Hart, D., and Willower, D., 199\&, Principal's Organizational commitment and school Environmental Robustness, The Journal of Educational Research, Vol. Av, No. $r$, PPIV $-1 \vee q$.

iv-Hofstade, G. et al., 199., Measuring Organizational Culture: A Qualitative and Quantitative Study across Twenty Cases, Administrative Science Quarterly, Vol. ro, PP.YAT_MIT.

१^-Huang, L., Y..., The Perceived Leadership Behavior and Organizational Commitment CPA Firms, Diss., Abs., Int., Vol. ${ }^{\top}$, No.( ${ }^{r}-$ - A) June, P. ะะ9१.

19-Hult, C., Y.. , International Commitment and Conflicting Values: Impact of Systems of Norms in Six Countries, International Journal of Comparative Sociology, Vol. $\varepsilon \varepsilon, N_{0}^{\circ}$, PP. $\leqslant \cdot \Lambda_{-} \leqslant \varepsilon r$.

r.-Jamal, M., 199., Relationship of Job Stress and Type A Behavior to Employees Job Satisfaction, Organizational Commitment, Psychosomatic health Problems and Turnover Motivation, Human Relation, Vol. $\Sigma r$, No. A, PP.YYV_rYh.

r -Jaros, S., 1990, An Assessment of Meyer and Allen's (1991) Three Component Model of Organizational Commitment and Turnover intention, Academy of Management Journal, Vol. $r \wedge$, No. $r$, PPrI $\vee$ _r $r$ I.

rr-Jones, M., 199^, The Relationship of Organizational Commitment to the Organizational Culture of high School, Diss., Abs., Int., Vol.॰9, No. ( $\varepsilon-$ A), October, P. 1.Y7.

r r-Kabonoff, B. and Daly, J. Y..., Values Espoused by Australian and U.S Organization, Applied Psychology, Vol. ¿9, No. ${ }^{\prime}$, PP. Y $\{\wedge-r 10$.

r६-Keller, L., et al., 199r, Work Values: Genetic and Environmental

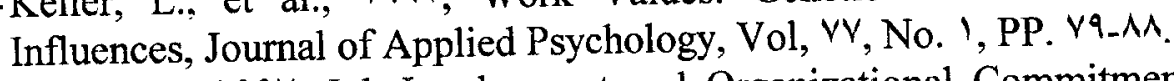
ro-Keller, R., 199v, Job Involvement and Organizational Commitment as Longitudinal Predictors of Performance: A Study of Scientists and Engineers, Journal of Applied Psychology, Vol.^r, No. , PP. or १_०६०. 
r7-Khaleque, A., 199r, Work Value, Attitude and Performance of Industrial Workers in Ben Gladesh, Social Indicators Research, Vol. YV, PP. IAV. 190

rv-Kidrom, A., 19v^, Work Value and Organizational Commitment, Academy of Management Journal, Vol. $r$, PP. Yrq- $r \varepsilon \wedge$.

Y^-Knoop, R., 19१०, Influence of Participative Decision Making on Job Satisfaction and Organizational Commitment of school Principals, Psychological Reports, Vol. V7, No. r, PPrYq_rAr.

Y१-Kushman, J., 19१r, The Organizational Dynamics of Teacher Workplace Commitment: A study of Urban Elementary and middle Schools",

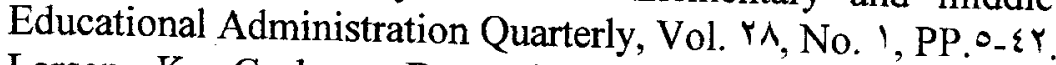

r.-Larsen, K., Groberg, D., and Simmons, D., 199r, Authoritarianism Perspectives on the Environment and Work Values among Social Science Students in Former Socialist and Western Societies, Social Behavior and Personality, Vol. Y', No.r, PP. Y0)_ry

r)-Larson, E., \& Fukami, C., 19^乏, Relationship between Worker Behavior and Commitment to the Organization and Union, Proceedings of the Academy of Management, PP.YYY_YYY

rr-Leslo, R., et al., 1990, Work Value Similarities among Students from Six Countries, Career Development Quarterly, June, PP. INY_/9Y.

$r r$-Lious, K., 1990, Understanding Employee Commitment in Public Organization, International Journal of Public Administration, Vol.11, PP. 1 Y $79.1 Y 90$.

$r$ \&-Locke, E., 199\&, The Nature and Causes of Job Satisfaction, 19v7 in: Mason, E. Sharon. Work Values: A Gender Comparison and Implications for Practice, Psychological Reports, Vol.V₹, PP. $\left\{10_{-}\{1 \wedge\right.$.

ro-Mannheim, B., 199ץ, Gender and the Effects of Demographics and Work Values on Work Centrality, Work and Occupations, Vol. ${ }^{\text {. }}$, No. I, PP.r. rr.

ry-McCaul, H., \& Hinsz, S., 1990, Assessing Organizational Commitment: An Employee's Global Attitude Toward the Organization, Journal of Applied Behavioral Science, Vol., PP. $\wedge .-q$.

r $\vee$-Meglino, B., Ravlin, E., and Adkins, C., 19^9, A Work Values Approach to Corporate Culture: A Field Test of the Value Congruence Process and its Relationship to Individual Outcomes, Journal of Applied Psychology,

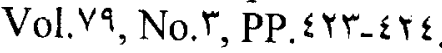

rA-Merrens, M., and Garrwtt, J., 19vo, The Protesant Ethic Scale as a Predictor of Repetivie Work Performance, Journal of Applied Psychology, Vol.'., PP. IYo_IrV.

rq-Meyer, J., \& Allen, N., 19^^, Links between Work Experiences and Organizational Commitment during the First Year of Employment: A Longitudinal Analysis, Journal of Occupational Psychology, Vol. 7), 
\& --Meyer, J., Allen, N., \& Smith, C., 19१५, Commitment to Organizations and Occupations: Extension and test of three Component Conceptualization, Journal of Applied Psychology, Vol. VA, No. \&, PP.0Yᄉ_.001.

§)-Meyer, J., et al., Y..l, Affective Continuance and Normative Commitment to the Organization: A Meta Analysis of Antecedents, Correlates and Consequences, Unpublished Article: Personal Submitted, PP. I- $\{0$.

¿Y-Moideekatty, U., Blau, G., Kumar, R., and Nalakath, A., 199^, Perceived Organizational Support as Amodiator of the Relationship of Perceived Situational Factor to Affective Organizational Commitment, Paper Presented at Eastern Academy of Management Annual Meeting Philadelphia.

$\leqslant r-M o t t a z, C$., 19^^, Determinants of Organizational Commitment, Human Relation, Vol. «1, NO. ?, PP. $\{$ TV- $\{\lambda Y$.

\&\&-Mowday, R. Porter, L., 19^r, Steers, R., Employee-Organizations Linkages: The Psychology of Commitment, Absenteeism and Turnover, Academic Press, New York.

\&0-Mowday, R., Porter, L., \& Dubin, R., 19^Y, Unit Performance, Situational Factor, and Employee Attitudes in Specially Separated Work Units, Organizational Behavior and human Performance, Vol. Ir, PP. YYI. Y $\leqslant$.

₹7-Onne, J., Y.. , The Barrier Effect of Conflict with Superior in the Relationship between Employee Empowerment and Organizational Commitment, Work and Strees, Vol. 1 A, No. 1A, PP. 07_to

¿V-Orpen, C., 1914, Work Values As A Moderator of the Effect of Participation in Budget-Setting on Employee Satisfaction and Performance, Psychological Studies, Vol. $M$ ', No. ', PP. \&Y_\{Y.

\&^-Perry, R., Y..\&, The Relationship of Affective Organizational Commitment with Supervisory Trust, Review of Public Personnel Administration, Vol. $Y \varepsilon$, No. $r$, PP. $1 \varepsilon-1 r r$.

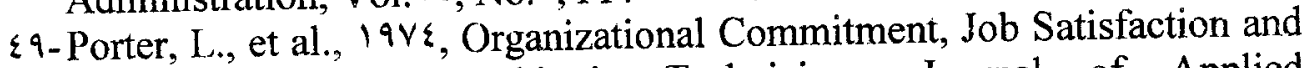
Turnover Among Psychiatric Technicians, Journal of Applied Psychology, Vol. ${ }^{\circ}$, No. ${ }^{\circ}$.

๑.-Puttie, J., Aryee, S., Liang, T., 19^9, Work Values and Organizational Commitment: A Study in the Asian Context, Human Relation, Vol. $\{r$, No.r, PP.r-10.

0)-Rahim, M., Magner, N., and Shapiro, D., Y..', Do Justic Perceptions Influence Style of Handling Conflict with Supervisors? What Justic Perceptions, Precisely? International Journal of Conflict Management, Vol. 11, PP.0.Y7.

or-Ralvin, E., et al., 19^V, Effects of Values on Perception and DecisionMaking: A Study of Alternative Work Values Measures, Journal of Applied Psychology, Vol. VY, No. \&, PP. 747_TVY. 
०r-Shapira, Z., and Griffith, 199., T., Comparing the Work Values Engineers with Managers, Production and Clerical Workers: Multivariate Analysis, Journal of Organizational Behavior, Vol.) PP.YAI-YqY.

० \&-Shore, L., and Wayne, S., 1994, Commitment and Employee Behavio Comparison of Affective Commitment and Continuance Commitmer with Perceived Organizational Support, Journal of Applied Psychology Vol. YA, No. ${ }^{\circ}$, PP. VY _. YA.

०0-Singh, S., 199\&, Gender Differences in Work Values and Personalit Characteristics among Indian Executive, The Journal of Socia Psychology, Vol. $11 \leqslant$, No. ${ }^{\circ}$, PP. $799 . V .$.

07-Somers, M., 1990, Organizational Commitment Turnover anc

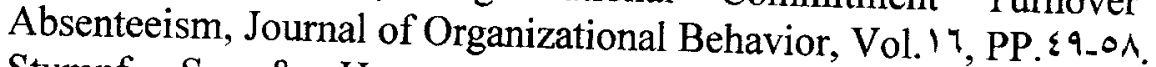

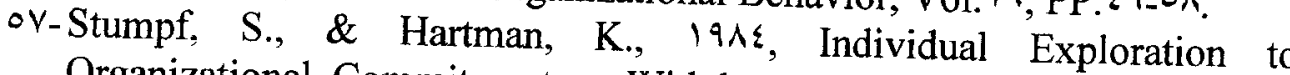
Organizational Commitment or Withdrawal, Academy of Managemen Journal, Vol.rY, PP.r.A_rrY.

$\triangle \wedge$-Vandenberghe, C. and Pelro, M., 1999, Organizational and Individual Values, Journal of Work and Organizational Psychology, Vol. ^, No. $\varepsilon$ PP.079_oxr.

०9-Veitenheimer, J., 1994, Employee - Organizational linkages: Teacher and Principal Organizational Commitment in High - performing and low performing Elementary, Diss, Abs., Int. Vol. ${ }^{\circ}\{$, No. $(\{-A)$, October, P. IrTs.

7.- Vondracek, F., Shimizu, K., Schulenberg, J., Hostetler, M., \& Saka, Y., A 199., Comparison between American and Japanese Students, Work Values, Journal of Vocational Behavior, Vol.r7, No.r, PP. YV _ YA .

7)-Wallace, J., Hant, J. and Richard, C., 1999, The Relationship between Organizational Value, Journal of Public Sector Management, Vol. Ir, No. $\vee$, PP. $7 \leqslant$ _- 07 .

$7 r$-Wallace, J., 1990, Organizational and Non-Professional Commitment in Professional and Non-Professional Organizations, Administrative Science Quarterly, Vol. \&., PP. rYA-Yro.

7 r-Werkmeister, W., 197V, Man and his Values, University of Nebraska Press, Lincoln, NE.

$7 \varepsilon-W i e n e r, Y ., 19 \wedge \mathrm{r}$, Commitment in Organization a Normative View, Academy of Management Review, Vol. $\vee$, No.r, PP. $\left\{\right.$ i $\Lambda_{-}\{Y \wedge$.

10-Wilson, P., 1990, The Effects of Politics and Power on the Organizational Commitment of Federal Executives, Journal of Management, Vol. ${ }^{1}$, PP.1.1.111.

77-Wollack, S., et al., 19V1, Development of the Survey of Work Values, Journal of Applied Psychology, Vol.00, No. \&., PP.Tri_rTA. 


